\title{
Nondestructive and Supplemental Measurements of the University of New Mexico AGN-201M
}

\section{Approved for public release.} Distribution is unlimited.
Larry Wetzel

Robert Busch Ken Carpenter Douglas Bowen December 2019 


\title{
DOCUMENT AVAILABILITY
}

Reports produced after January 1, 1996, are generally available free via US Department of Energy (DOE) SciTech Connect.

Website www.osti.gov

Reports produced before January 1, 1996, may be purchased by members of the public from the following source:

\author{
National Technical Information Service \\ 5285 Port Royal Road \\ Springfield, VA 22161 \\ Telephone 703-605-6000 (1-800-553-6847) \\ TDD 703-487-4639 \\ Fax 703-605-6900 \\ E-mail info@ntis.gov \\ Website http://classic.ntis.gov/
}

Reports are available to DOE employees, DOE contractors, Energy Technology Data Exchange representatives, and International Nuclear Information System representatives from the following source:

Office of Scientific and Technical Information

PO Box 62

Oak Ridge, TN 37831

Telephone 865-576-8401

Fax 865-576-5728

E-mail reports@osti.gov

Website http://www.osti.gov/contact.html

This report was prepared as an account of work sponsored by an agency of the United States Government. Neither the United States Government nor any agency thereof, nor any of their employees, makes any warranty, express or implied, or assumes any legal liability or responsibility for the accuracy, completeness, or usefulness of any information, apparatus, product, or process disclosed, or represents that its use would not infringe privately owned rights. Reference herein to any specific commercial product, process, or service by trade name, trademark, manufacturer, or otherwise, does not necessarily constitute or imply its endorsement, recommendation, or favoring by the United States Government or any agency thereof. The views and opinions of authors expressed herein do not necessarily state or reflect those of the United States Government or any agency thereof. 
Reactor and Nuclear Systems Division

\title{
NONDESTRUCTIVE AND SUPPLEMENTAL MEASUREMENTS OF THE UNIVERSITY OF NEW MEXICO AGN-201M
}

\author{
Larry Wetzel \\ Robert Busch \\ Ken Carpenter \\ Douglas Bowen
}

Date Published:

December 2019

\author{
Prepared by \\ OAK RIDGE NATIONAL LABORATORY \\ Oak Ridge, TN 37831-6283 \\ managed by \\ UT-BATTELLE, LLC \\ for the \\ US DEPARTMENT OF ENERGY \\ under contract DE-AC05-00OR22725
}





\section{CONTENTS}

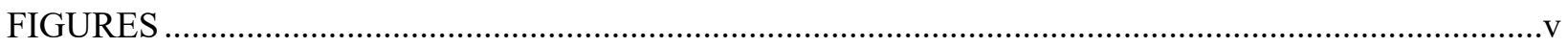

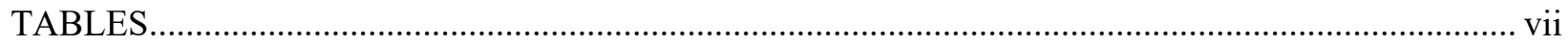

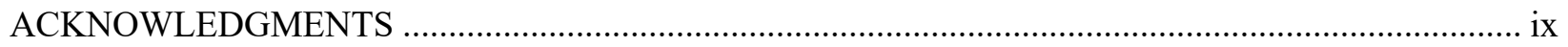

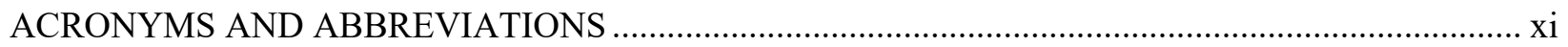

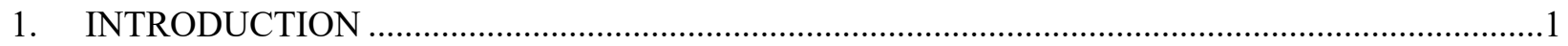

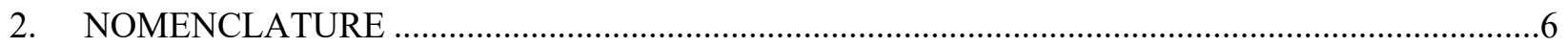

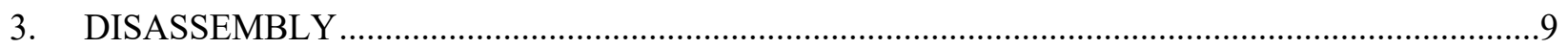

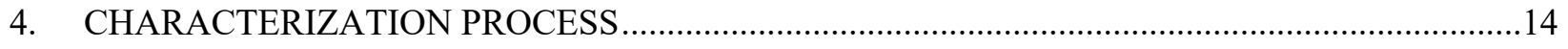

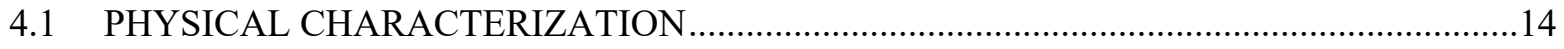

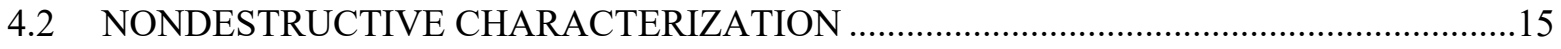

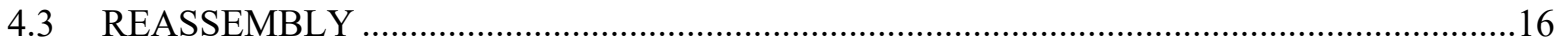

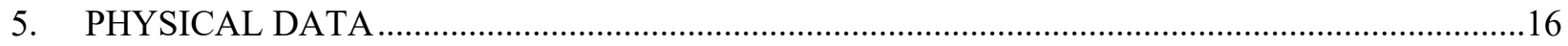

5.1 SUMMARY OF PHYSICAL MEASUREMENTS ............................................................17

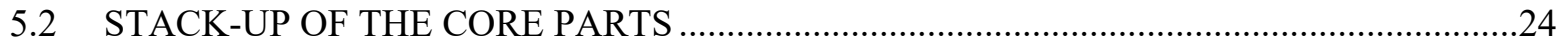

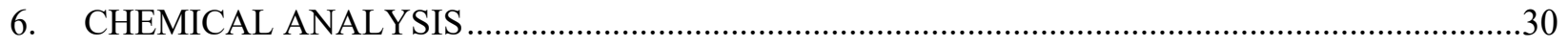

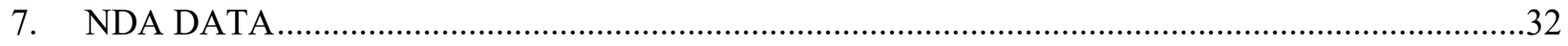

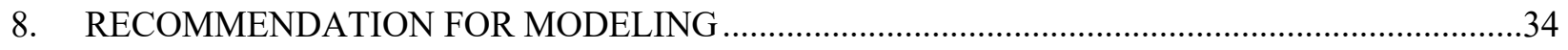

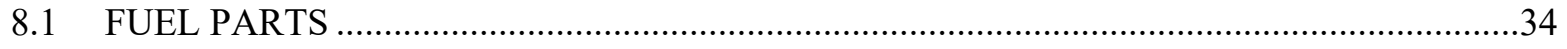

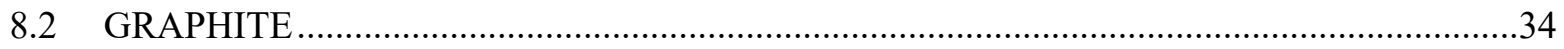

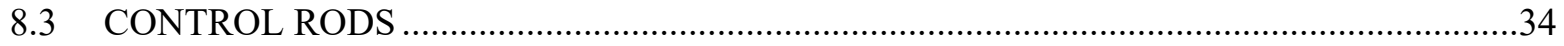

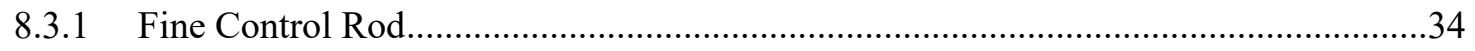

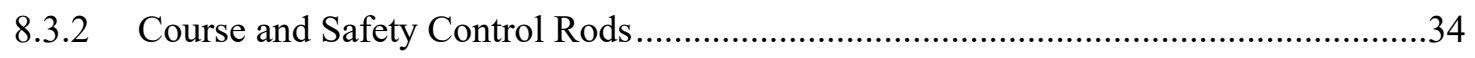

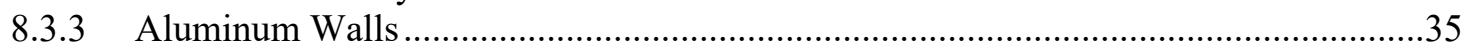

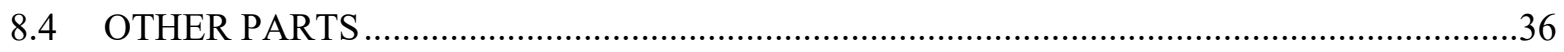

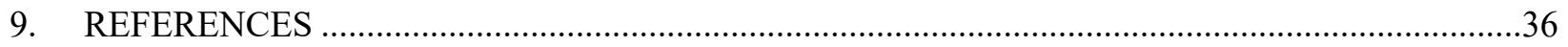

APPENDIX A. ATTRIBUTE MEASUREMENTS ….............................................................. A-1

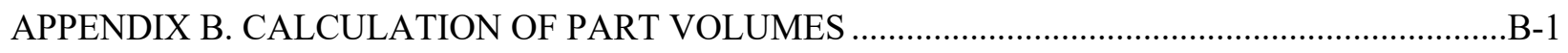

APPENDIX C. UNIVERSITY OF NEW MEXICO PROCEDURES …................................................ -1

APPENDIX D. LAB RESULTS OF UNIVERSITY OF UTAH LEAD AND GRAPHITE AND

IDAHO STATE UNIVERSITY FUEL SAMPLES .................................................................. D-1

APPENDIX E. SANDIA NATIONAL LABORATORIES NDA RESULTS ......................................... E-1 



\section{FIGURES}

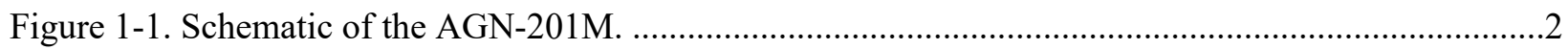

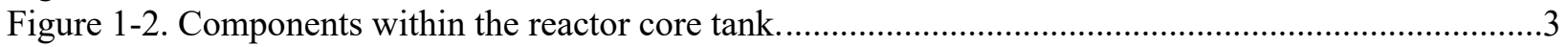

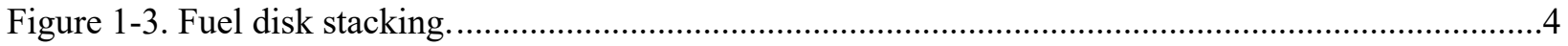

Figure 2-1. Standard access port loading. ....................................................................................

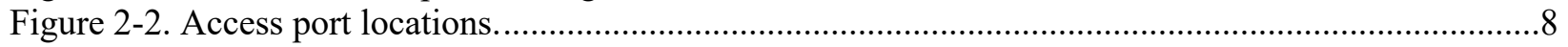

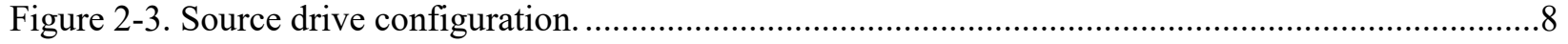

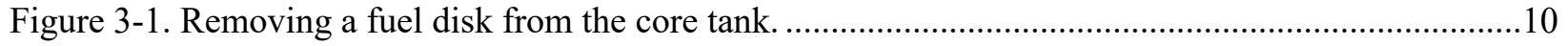

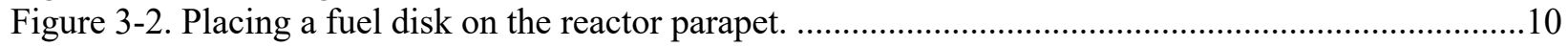

Figure 3-3. Lifting the core tank being and resting it on the reactor's top platform.................................11

Figure 3-4. Removing the control rod cans and fuel disk 204100 from the core tank..........................11

Figure 3-5. Top graphite shells after removal (left); baffle plates being removed (right).........................12

Figure 3-6. Bottom graphite reflector and bottom three fuel disks.........................................................13

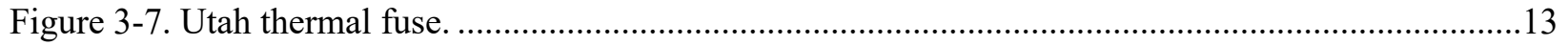

Figure 4-1. Measuring physical attributes of components. ..................................................................14

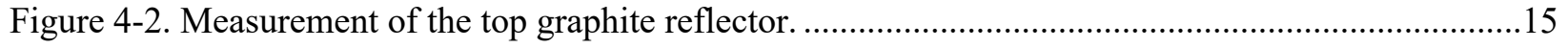

Figure 4-3. Setup of NDA measurement for a fuel disk. .....................................................................15

Figure 4-4. Detection equipment with a small aperture collimator. ........................................................16

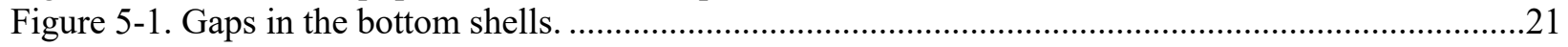

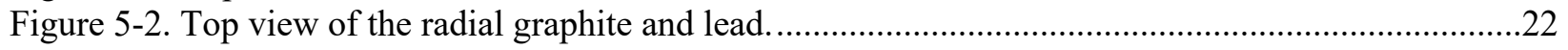

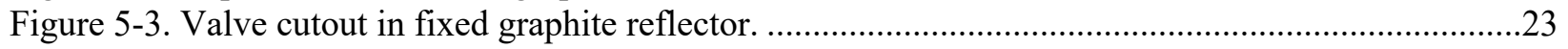

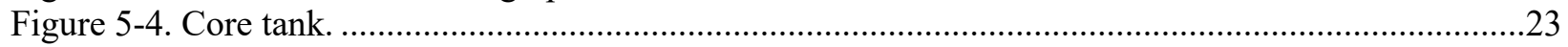

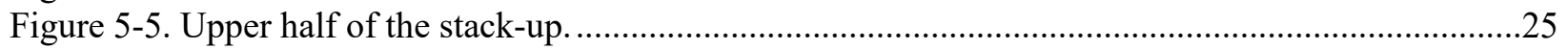

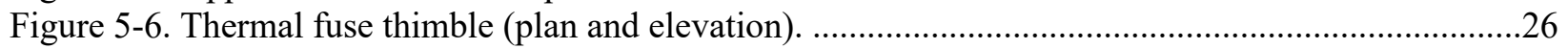

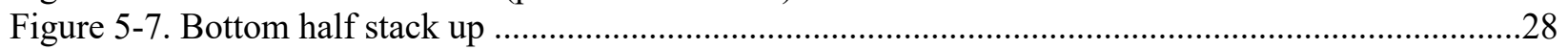

Figure 5-8. Bottom graphite reflector (plan and elevation views) ......................................................29

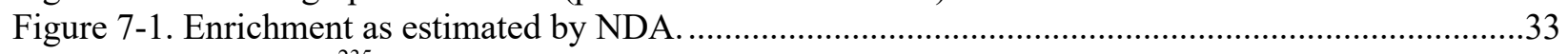

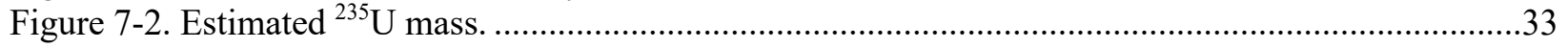





\section{TABLES}

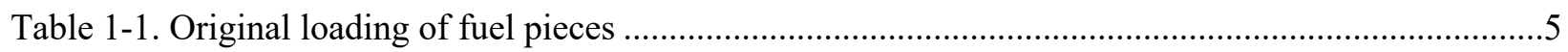

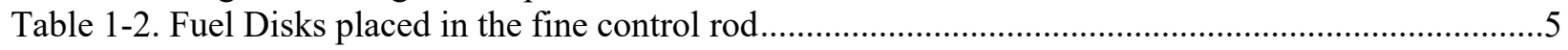

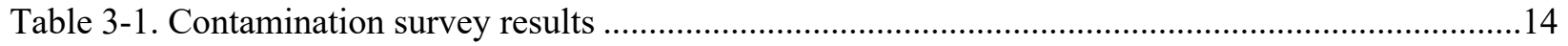

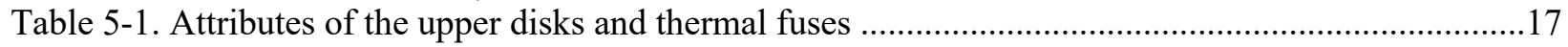

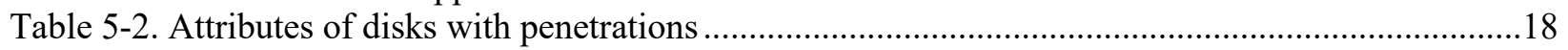

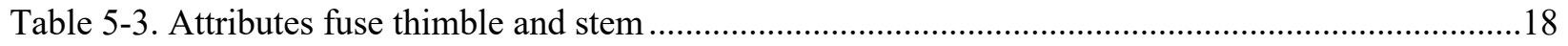

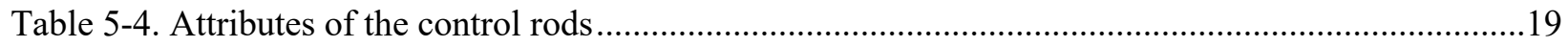

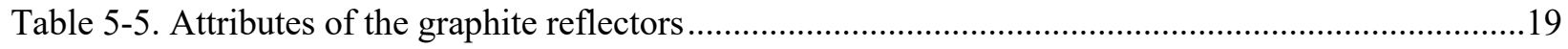

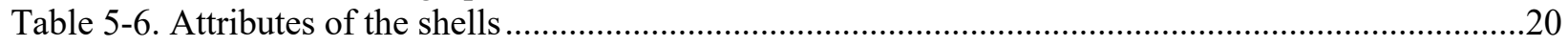

Table 5-7. Measurement of gaps between bottom reflector shells ...................................................20

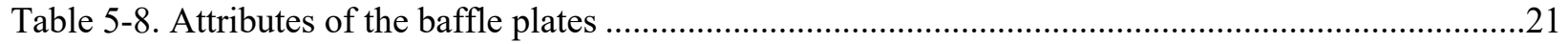

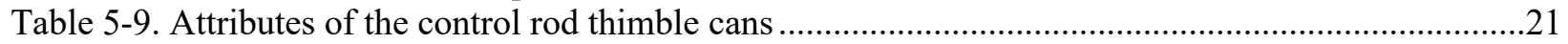

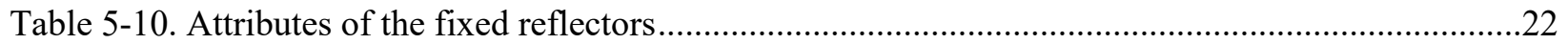

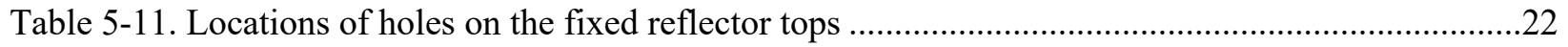

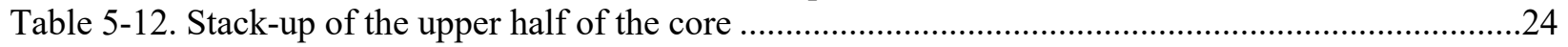

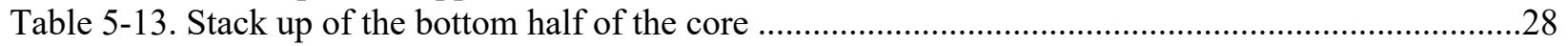

Table 6-1. Chemical analysis from the University of Utah parts..............................................................30

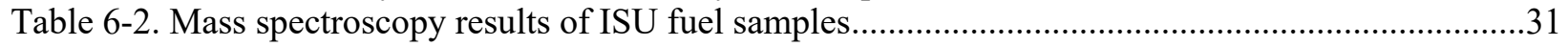

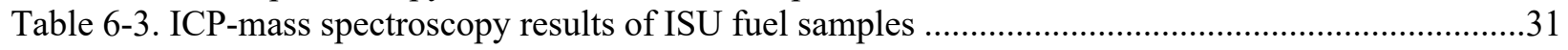

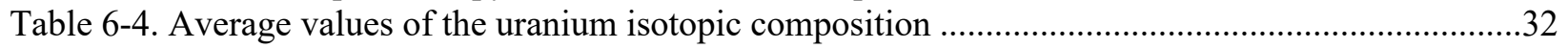

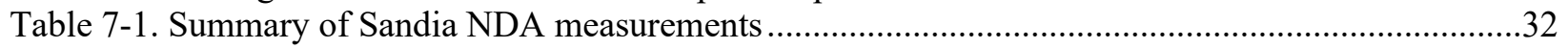

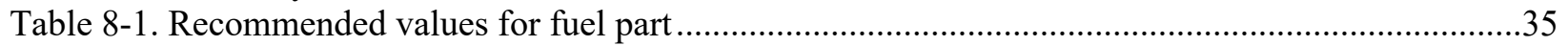

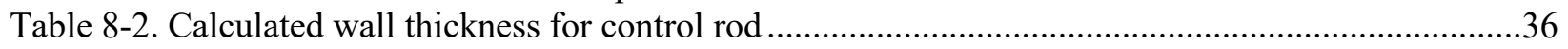

Table 8-3. Calculated wall thickness for control rod guide tubes..............................................................36 



\section{ACKNOWLEDGMENTS}

The authors would like to acknowledge the following people who helped in making these measurements and preparing this report.

- US Department of Energy (DOE) Nuclear Criticality Safety Program (NCSP): Dr. Angela Chambers and Dr. Doug Bowen

- Sandia Radiation Protection Sample Diagnostics Program (RPSD), especially Elliot Leonard, Sean Fournier, Robert Reese, and Mark Allen

- Sandia NCSP: John Miller, William (Mac) Cook, Shawn Henderson, and Kyle Warns

- Sandia Environmental, Safety and Health Coordinator: Michael D. Starr 



\section{ACRONYMS AND ABBREVIATIONS}

$\begin{array}{ll}\text { AGN } & \text { Aerojet General Nucleonics Model } \\ \text { CCR } & \text { coarse control rod } \\ \text { DOE } & \text { US Department of Energy } \\ \text { FCR } & \text { fine control rod } \\ \text { FP } & \text { fission plate } \\ \text { ICP-MS } & \text { inductively coupled plasma mass spectroscopy } \\ \text { ID } & \text { Inside Diameter } \\ \text { ISU } & \text { Idaho State University } \\ \text { NCSP } & \text { Nuclear Criticality Safety Program } \\ \text { NDA } & \text { nondestructive analysis } \\ \text { NRC } & \text { US Nuclear Regulatory Commission } \\ \text { OD } & \text { Outside Diameter } \\ \text { ORNL } & \text { Oak Ridge National Laboratory } \\ \text { SR } & \text { safety rod } \\ \text { UNM } & \text { University of New Mexico }\end{array}$





\section{INTRODUCTION}

The Aerojet General Nucleonics Model 201-M (AGN-201M) research reactor at the University of New Mexico (UNM) has been in operation for over 50 years. The AGN reactor core is a mixture of lowenriched $\mathrm{UO}_{2}\left(19.5 \mathrm{wt} \%{ }^{235} \mathrm{U}\right)$ powder and polyethylene reflected with $20 \mathrm{~cm}$ of reactor-grade graphite. It has a critical mass of $665 \mathrm{~g}{ }^{235} \mathrm{U}$ and a licensed maximum power of $5 \mathrm{~W}$ thermal. The AGN reactor is controlled using four fueled control rods which are driven into the core from the bottom of the reactor. The AGN core and reflector configuration allows the reactor to operate with a minimal quantity of fissile material but with enough excess reactivity to allow for significant research flexibility.

The AGN reactor unit shown in Figure 1-1 was installed in the Nuclear Engineering Laboratory at UNM in 1969. The US Nuclear Regulatory Commission (NRC) approved shielding upgrades for operations at a greater reactor power (5 W thermal) in October of 1969. Figure 1-2 shows the configuration of the fuel disks, the control elements, and the graphite reflector in the reactor core tank. Figure 1-3 provides the fuel disk numbers. The AGN fuel disk thicknesses vary as a function of height to allow for smaller reactivity worths as fuel is added to the core region during approach-to-critical experiments. The core is designed with an aluminum baffle that separates the top half of the core from the bottom half. The core fuse or thermal fuse, which contains a higher fuel loading than the fuel disks in the core, is designed to melt during adverse transient conditions: that is, when the fuse temperature increases above $100^{\circ} \mathrm{C}$. If the core fuse melts, then the bottom half of the core (below the baffle) drops approximately $5 \mathrm{~cm}$ ( $2 \mathrm{in}$.), which is sufficient to terminate the transient.

As shown in Figure 1-3, components within the reactor core tank fuel disks 20497-204100 are $\sim 4 \mathrm{~cm}$ thick, disks 204101-204103 are $\sim 2 \mathrm{~cm}$ thick, and disks 204104 and 204105 are $\sim 1 \mathrm{~cm}$ thick. There is a void region above fuel disk 204105 that is approximately $1 \mathrm{~cm}$ thick. There is a thermal fuse in the center of the core. A spare fuse was obtained from the decommissioned University of Utah AGN reactor. The AGN also includes a thermal column that is used for experimental work. The glory hole, which is used for experimental access to the core, passes completely through the uranium-polyethylene core, the graphite reflector, and the lead and water shields. The AGN also has four 4-inch ports that provide irradiation and detector locations in the graphite reflector. The access ports are filled with a combination of graphite, lead, and wood when they are not filled with experiments. A $2 \mathrm{Ci}^{239} \mathrm{Pu}-\mathrm{Be}$ source and source drive are mounted in the north end of access port 2 to provide a source of neutrons during reactor startup. A boronlined ionization chamber for data acquisition is mounted in the south end of access port 4. 


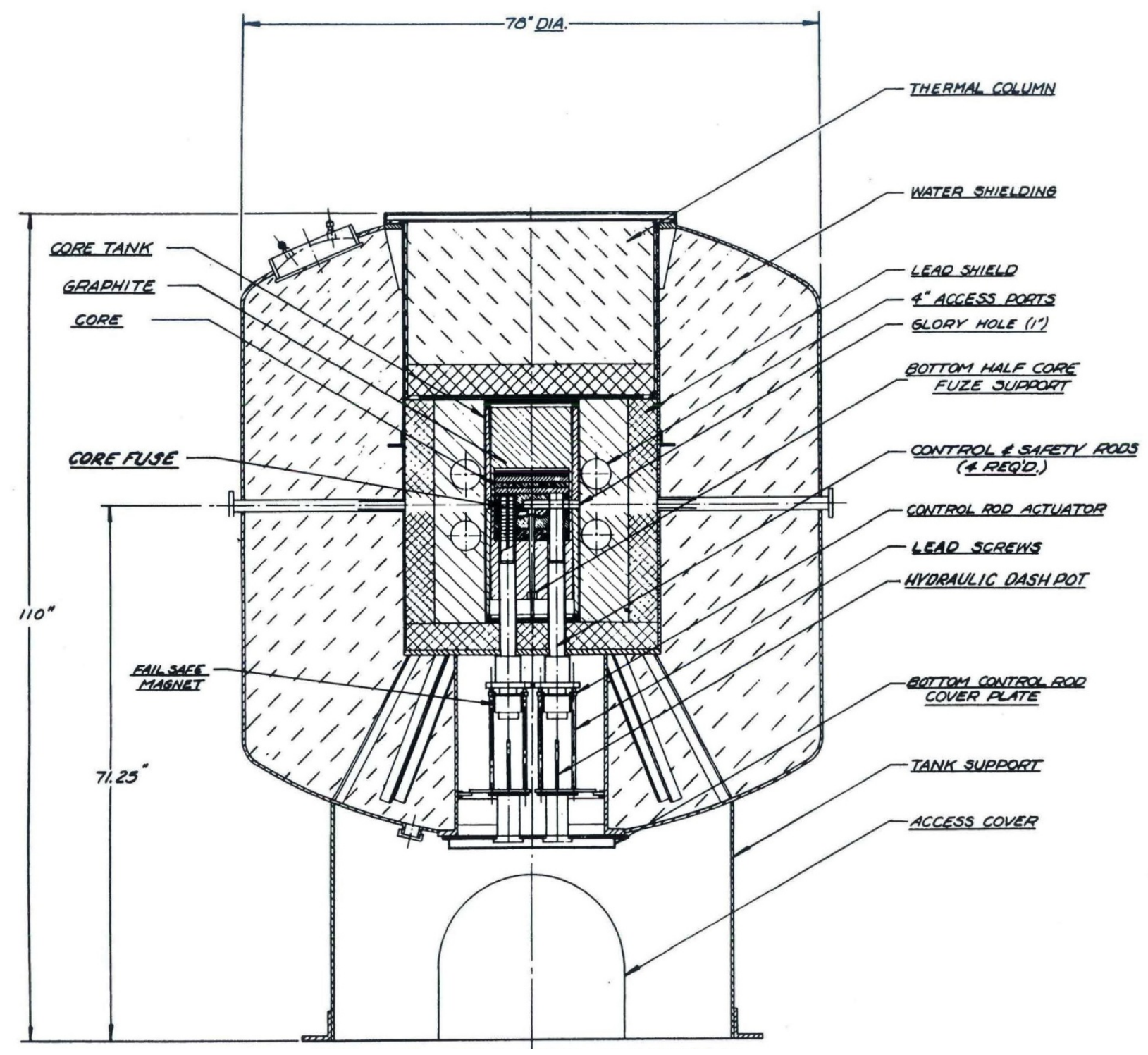

Figure 1-1. Schematic of the AGN-201M. 


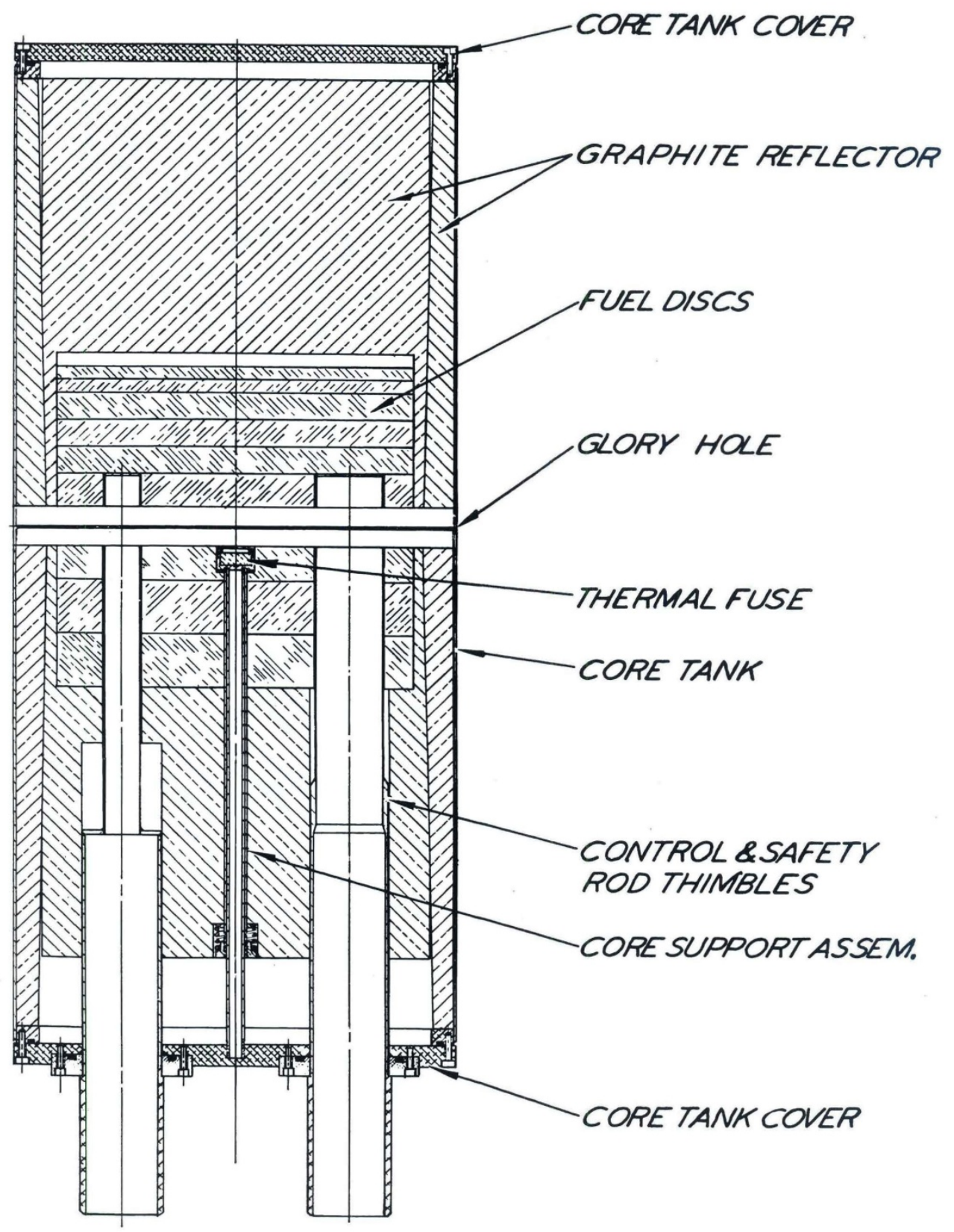

Figure 1-2. Components within the reactor core tank. 


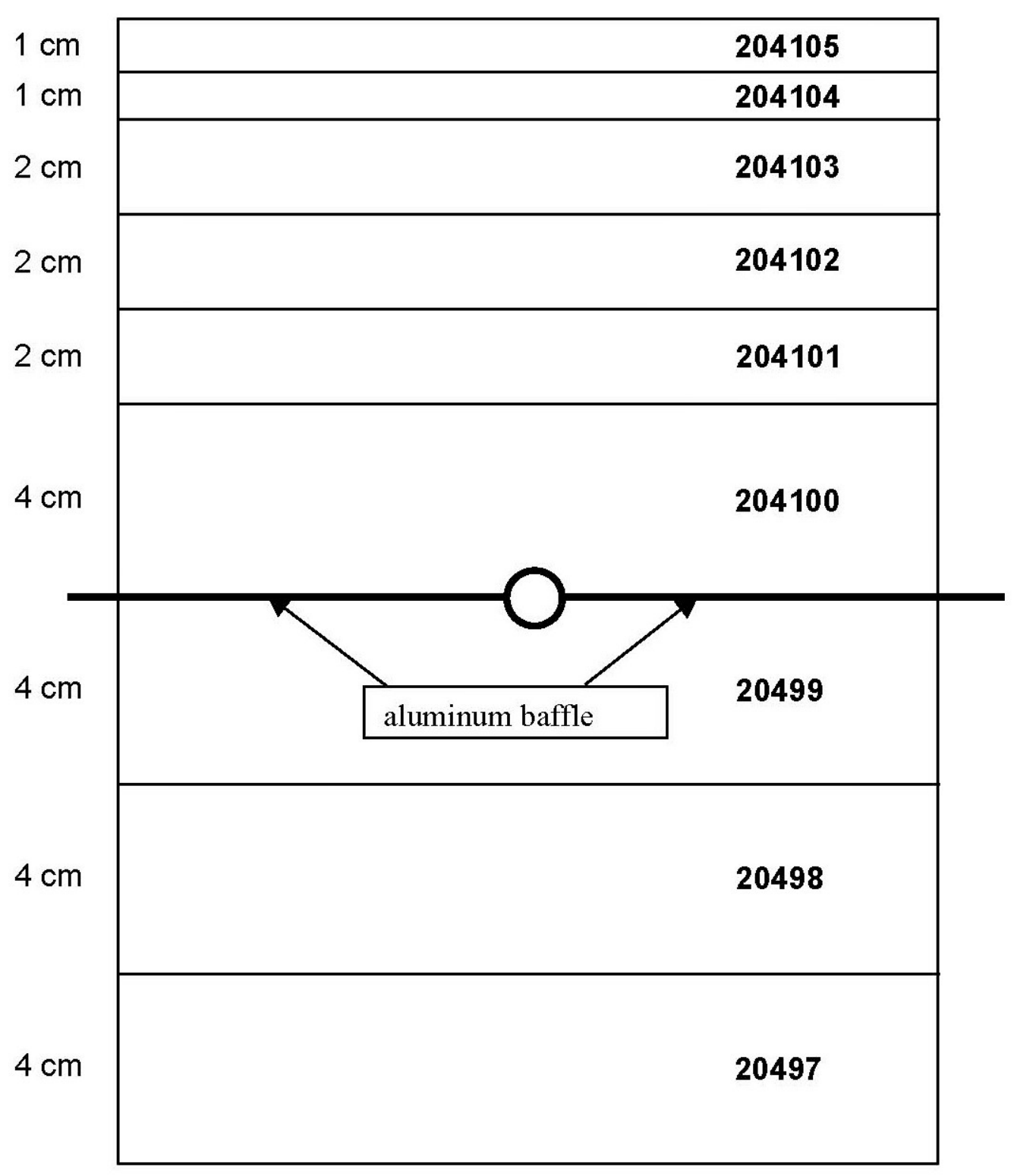

Figure 1-3. Fuel disk stacking.

The original mass values for the disks, which were obtained from the Reactor Operation and Training Manual [1], are provided in Table 1-1. 
Table 1-1. Original loading of fuel pieces

\begin{tabular}{|c|c|c|c|c|}
\hline Piece & Height (cm) & Diameter, cm & Total mass, $\mathbf{g}$ & ${ }^{235} \mathrm{U}$ mass, g \\
\hline \multicolumn{5}{|c|}{ Fixed fuel pieces } \\
\hline 20497 & 4 & 25.6 & $2,150.00$ & 98.89 \\
\hline 20498 & 4 & 25.6 & $2,158.50$ & 99.12 \\
\hline 20499 & 4 & 25.6 & $2,026.50$ & 93.17 \\
\hline 204100 & 4 & 25.6 & $2,052.00$ & 94.39 \\
\hline 204101 & 2 & 25.6 & $1,262.50$ & 58.01 \\
\hline 204102 & 2 & 25.6 & $1,263.50$ & 58.07 \\
\hline 204103 & 2 & 25.6 & $1,263.00$ & 58.05 \\
\hline 204104 & 1 & 25.6 & 670.00 & 30.80 \\
\hline 204105 & 1 & 25.6 & 648.50 & 29.79 \\
\hline \multirow[t]{2}{*}{ Fuse } & 0.9 & 2.2 & 5.86 & 0.41 \\
\hline & & Total mass, $\mathbf{g}$ & $13,500.36$ & 620.7 \\
\hline \multicolumn{5}{|c|}{ Movable fuel pieces } \\
\hline $\mathrm{SR}^{a}$ & 1 & 16 & 4.5 & 315.77 \\
\hline SR & 2 & 16 & 4.5 & 315.53 \\
\hline $\mathrm{CCR}^{b}$ & 16 & 4.5 & 315.58 & 14.51 \\
\hline \multirow[t]{3}{*}{$\mathrm{FCR}^{c}$} & 16 & 2.0 & 58.95 & 2.71 \\
\hline & & Total mass, $\mathbf{g}$ & 383.53 & 648.52 \\
\hline & & Total fuel mass, $\mathrm{g}$ & $13,883.89$ & $1,269.22$ \\
\hline
\end{tabular}

${ }^{a} \mathrm{SR}=$ safety rod

${ }^{b} \mathrm{CCR}=$ coarse control rod

${ }^{c} \mathrm{FCR}=$ fine control rod

A second fuse was obtained from the decommissioned University of Utah AGN-201. The uranium mass is $5.92 \mathrm{~g}$, and the ${ }^{235} \mathrm{U}$ mass is 0.438 grams.

As originally installed, the reactor had only polyethylene disks in the fine control rod (FCR). In 1966, UNM received a notice that excess fuel was available to the facilities, so they received three $4 \mathrm{~cm}$ fuel disks, which are listed in Table 1-2. These disks were used in two experiments, as they fit in the glory hole. The disk dimensions are 0.912 inches $(2.316 \mathrm{~cm})$ diameter $\times 1.578$ inches $(4.008 \mathrm{~cm})$ high.

Table 1-2. Fuel Disks placed in the fine control rod

\begin{tabular}{ccc}
\hline Disk ID & Uranium mass, $\mathbf{g} \mathbf{~}$ & ${ }^{235} \mathbf{U}$ mass, $\mathbf{g}$ \\
\hline 20230 & 4.57 & 0.91 \\
20233 & 4.62 & 0.91 \\
$20231^{*}$ & 4.53 & 0.89 \\
\hline
\end{tabular}

* Disk ID is in question, but mass values are known

A note in the logbook from October 28, 1968 states that the three fuel disks were put into the fine rod, replacing the top three polyethylene disks. This was done for a transfer function/oscillator experiment to add some additional reactivity. There is no indication in the logbook that the three fuel disks were ever 
removed from the FCR. Two of the original polyethylene disks were found in the lab. They measured $2.311 \mathrm{~cm}$ in diameter $\times 4.013 \mathrm{~cm}$ in length.

\section{NOMENCLATURE}

Bottom graphite reflector: a solid graphite tapered cylinder that includes holes for the control guide tubes, fuse stem, and core support rod. The top of the reflector is recessed to accommodate the three bottom fuel disks. There are semicircular cutouts on the top edge to mate with the glory hole.

Bottom half of the core: the lower half of the core that is composed of fuel disks 20497, 20498, and 20499 , along with the thermal fuse, fuse stem, and fuse stem bottom nut.

Bottom removable graphite shells: four radially tapered pieces of graphite that form a tapered annulus when assembled. These are located between the inside of the core tank and the bottom half of the core. Two of the shells have semicircular cutouts at the top to mate with the glory hole.

Control rod guide tubes: four thin 6061 aluminum tubes sized to receive the control rods. The tubes enter through the bottom core tank cover, pass through the bottom graphite reflector, the bottom three fuel disks, the baffle plate, and the bottom disk (204100) in the upper half of the core. They stop at the top of fuel disk 204100. The tubes include a flange that is used to secure the tube to the bottom core tank cover.

Control rod: an aluminum can that holds fuel disks. Safety rod (SR) 1, SR2 and the coarse control rod (CCR) have four nominal disks, each of which is $4 \mathrm{~cm}$ tall. The fine control rod (FCR) has three nominal $4 \mathrm{~cm}$ fuel disks and a $4 \mathrm{~cm}$ nominal polyethylene disk. All of the control rods have $8 \mathrm{~cm}$ of graphite below the fuel, or in the case of the FCR, the graphite is located below the polyethylene. The control rods are driven in from the bottom with a screw mechanism. The three large rods - SR1, SR2, and CCR — are coupled to the screw drive mechanism with an electromagnet. As these rods are driven in, they compress a spring. If the current is lost to the magnet, then the spring drives the control rod out of the core, and a snuffer absorbs the energy from the control rod and stops it. The FCR is mechanically coupled to the screw drive, and it drives out on a scram signal. For startup, SR1 must be fully inserted before SR2 can be inserted. After the two SRs are inserted, the CCR can then be inserted to achieve criticality. The FCR can be moved any time that current is applied to the magnets of the large rods.

Core cover plates: two 6061 aluminum disks with recesses for O-rings. Both the top and bottom covers attach with screws onto the flanges on the core tank. The bottom core tank cover has a 0.5 inch $(1.27 \mathrm{~cm})$ threaded hole on the inside to receive the core support rod.

Core support rod: a 0.5 inch $(1.27 \mathrm{~cm}) 6061$ aluminum rod threaded into the bottom core support plate, extending through the bottom graphite reflector and the bottom three fuel disks, into the fuse stem and against the fuse.

Core tank: a 6061 aluminum cylinder with a welded guide tube for the glory hole liner. The top and bottom of the tank have flanges which mate with the top and bottom core cover plates. A valve is located on the upper side of the core tank to allow for collection of air samples to measure for fission gasses. 
Fuse stem: a stem that has a recess in the upper potion where the fuse is placed and is held in with a snap ring. The narrower, bottom section of the stem passes down through the bottom half of the core and is threaded on the end. A nut is threaded on to pull the lower three fuel disks and bottom graphite reflector together. The core support rod touches the core fuse and then passes through the lower portion of the stem.

Glory hole liner: a thin aluminum tube that passes through the fixed shielding and the guide tube in the core tank.

Maximum excess reactivity: without an experiment, the highest excess reactivity is $0.25 \% \Delta \mathrm{k} / \mathrm{kd}$. Since the beta effective of the reactor is 0.0074 , the maximum excess reactivity without an experiment is $\$ 0.338$. The maximum $\mathrm{k}_{\mathrm{eff}}$ of the reactor without an experiment is 1.0025 .

Nondestructive analysis (NDA): measurement of the characteristics of a gamma-ray emitter using a high-purity germanium detector.

Reflector access ports: four access holes that are $10 \mathrm{~cm}$ (4 inches) in diameter that pass through the graphite and can be used for experiments. When they are not filled with experiments, the standard loading of the access port is a combination of graphite, lead, and wood, as shown in Figure 2-1. The access ports are numbered 1 through 4 and are located as shown in Figure 2-2. Spacing between ports 1 and 2 is $20 \mathrm{~cm}$ from center to center horizontally and is the same between ports 3 and 4 . The vertical separations between the ports are $44 \mathrm{~cm}$. In the present configuration, two of the access ports have equipment loadings. The $2 \mathrm{Ci}^{239} \mathrm{Pu}$-Be source and source drive (shown in Figure 2-3) are mounted in access port \#2 on the north end, while an auxiliary ionization chamber is located in access port \#4 on the south end.

Wood, $70.4 \mathrm{~cm} \quad$ Graphite, $48.4 \mathrm{~cm} \quad$ Wood, $70.4 \mathrm{~cm}$

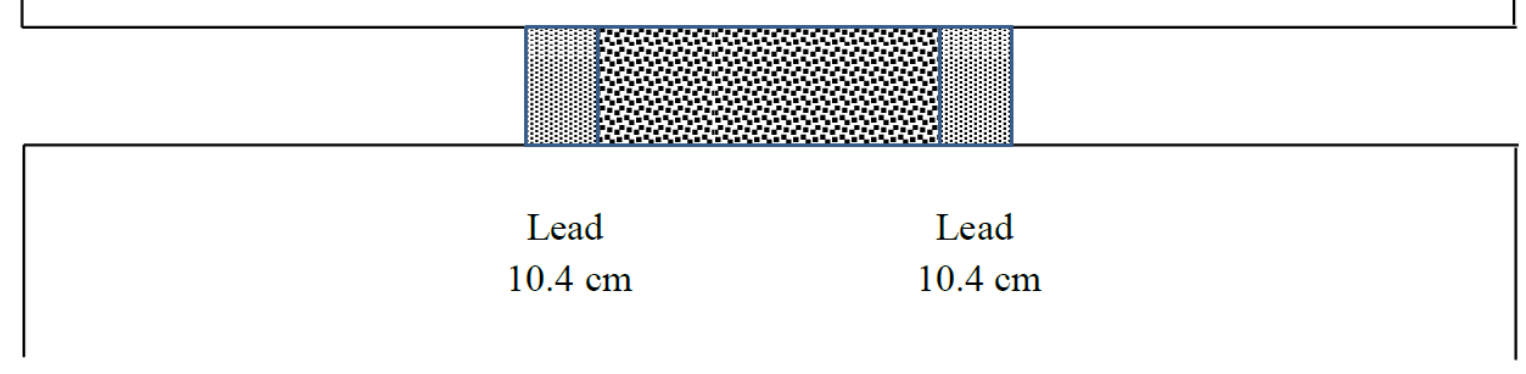

Figure 2-1. Standard access port loading. 


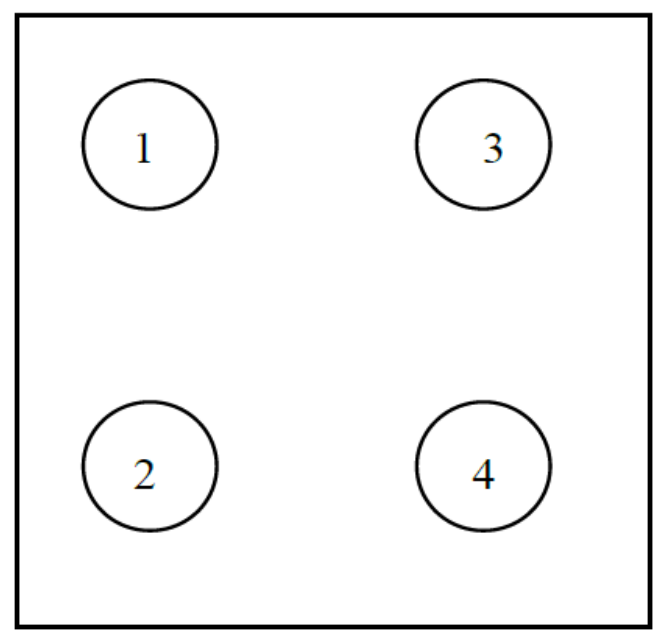

FACING NORTH

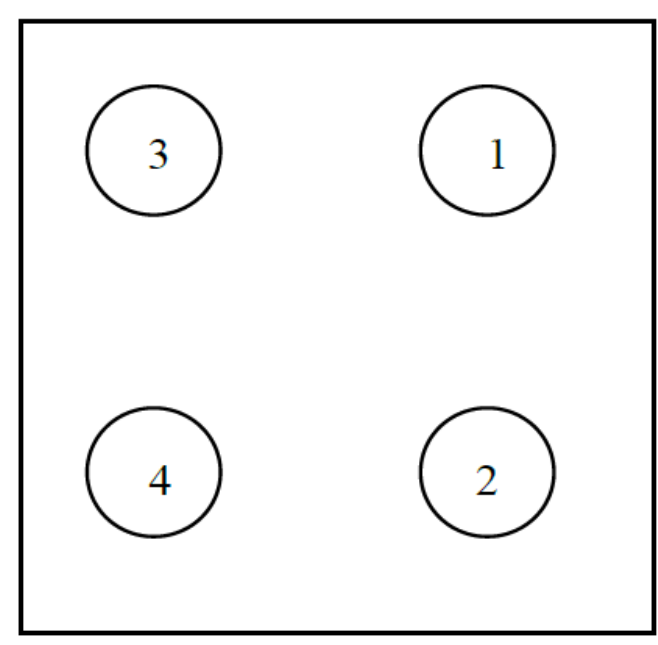

FACING SOUTH

Figure 2-2. Access port locations.

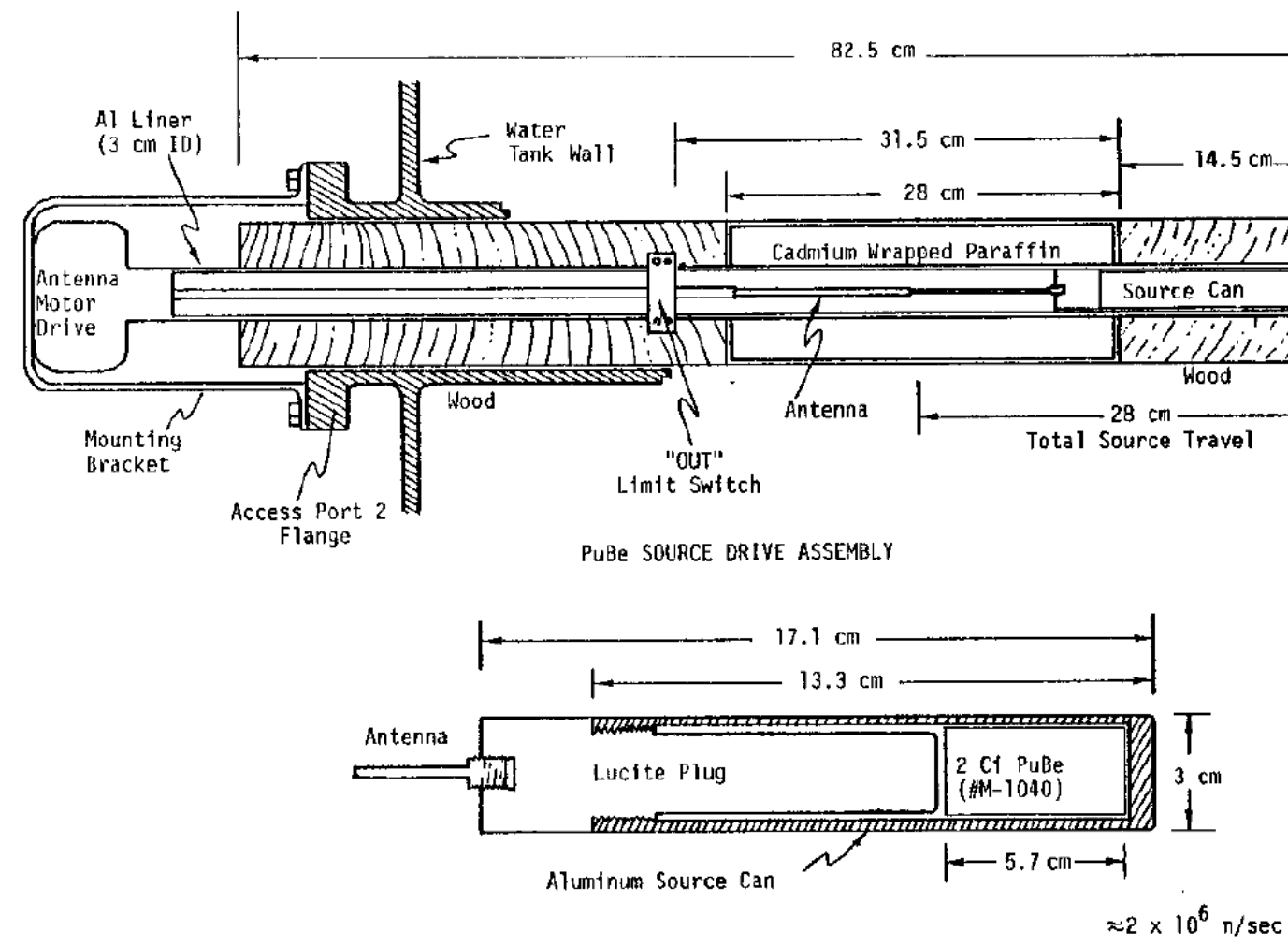

Figure 2-3. Source drive configuration.

Thermal column: a large reflector placed on top of the core. The thermal column currently installed is a large tank of water placed on top of the core tank. In normal use, the thermal column contains 10 $\mathrm{cm}$ of lead shielding and then is filled with water. 
Top graphite reflector: a solid graphite tapered cylinder that is recessed on the bottom to accommodate the top six fuel disks, with a small void between the top of the recess and the top surface of the upper fuel disk. Semicircular cutouts on the bottom edge mate with the glory hole. On the top of the reflector, a threaded adapter is installed into which a T-handle can be threaded to use when lifting the reflector out during disassembly.

Top half of the core: the top half is composed of the baffle plate, fuel disks 204100-204105 and the top graphite reflector.

Upper removable graphite shells: four radially tapered pieces of graphite that form a tapered annulus when assembled. These are located between inside of the core tank and the top half of the core. The bottom of each shell includes a lip on which the top graphite reflector rests. Two of the shells have semicircular cutouts in the lip to mate with the glory hole.

\section{DISASSEMBLY}

On May 13, 2019, UNM staff members removed the control rod drives and control rods from the reactor. They also lifted the thermal column and placed it on the reactor shielding parapet. The glory hole extensions were removed. A gas sample was taken from inside the core tank. With the thermal column removed, the dose rate at the top of the reactor was $3.5 \mathrm{mR} / \mathrm{hr}$. Sandia NDA personnel set up HPGe detectors in the reactor room.

Fuel disk unloading began on May 14, 2019. Two jack bolts were installed on the top core tank cover, and was manually lifted off. It was placed on the reactor top platform, as seen to the left of center in Figure 3-1. The T-handle was threaded into the top graphite reflector, and was manually lifted and placed on the reactor's top platform, as shown in the center of Figure 3-1. At this point, the dose rate at $30 \mathrm{~cm}$ above the top fuel disk was $21 \mathrm{mR} / \mathrm{hr}$.

The process of removing the first five fuel plates (105-101) follows the same sequence of steps, as listed shown below:

1. Measure the radiation level at $30 \mathrm{~cm}$ above the fuel disk.

2. Manually lift the fuel disk out and place it in the appropriate location on the parapet.

3. Smear the disk for loose contamination.

See Table 3-1 for smear test results. 


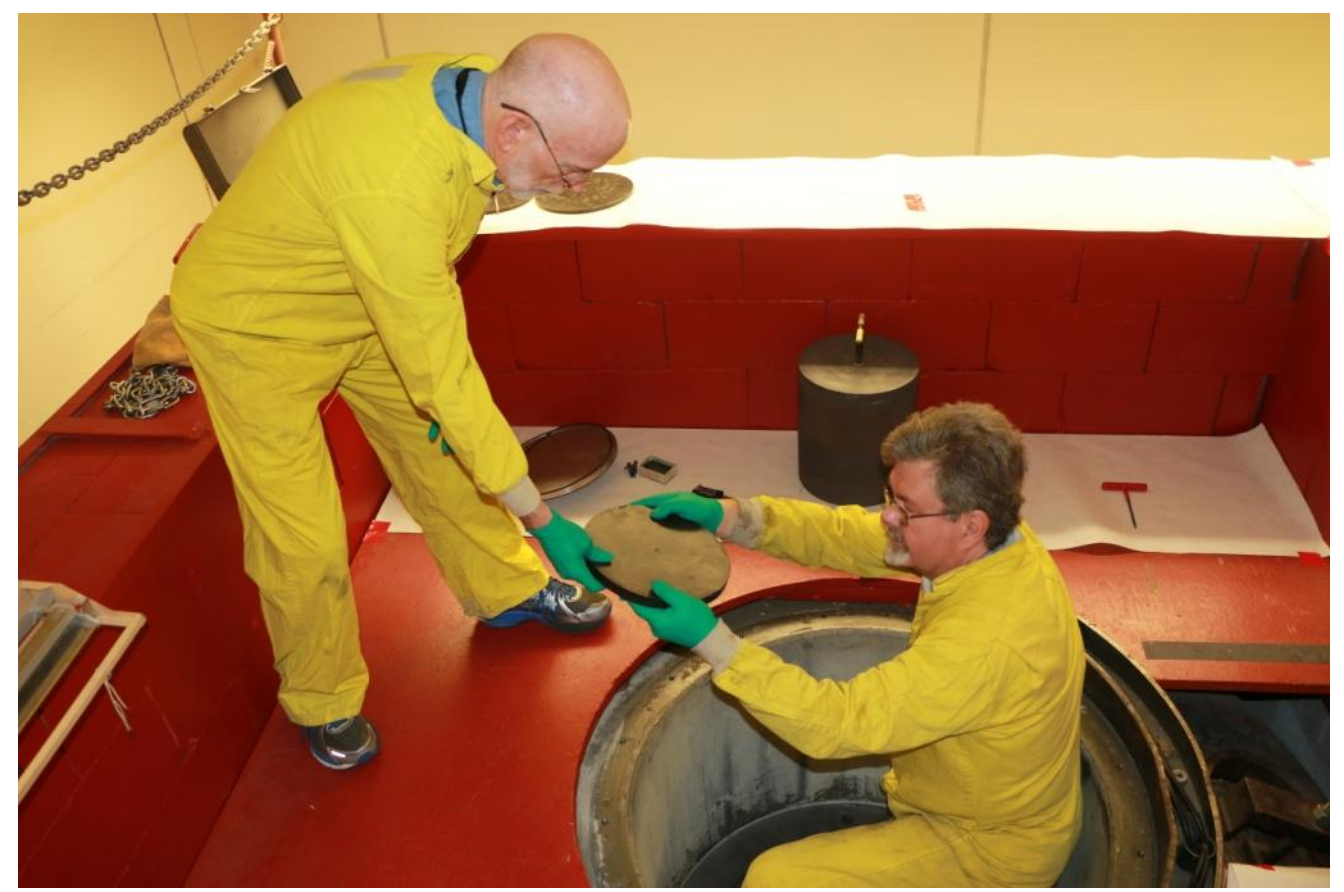

Figure 3-1. Removing a fuel disk from the core tank.

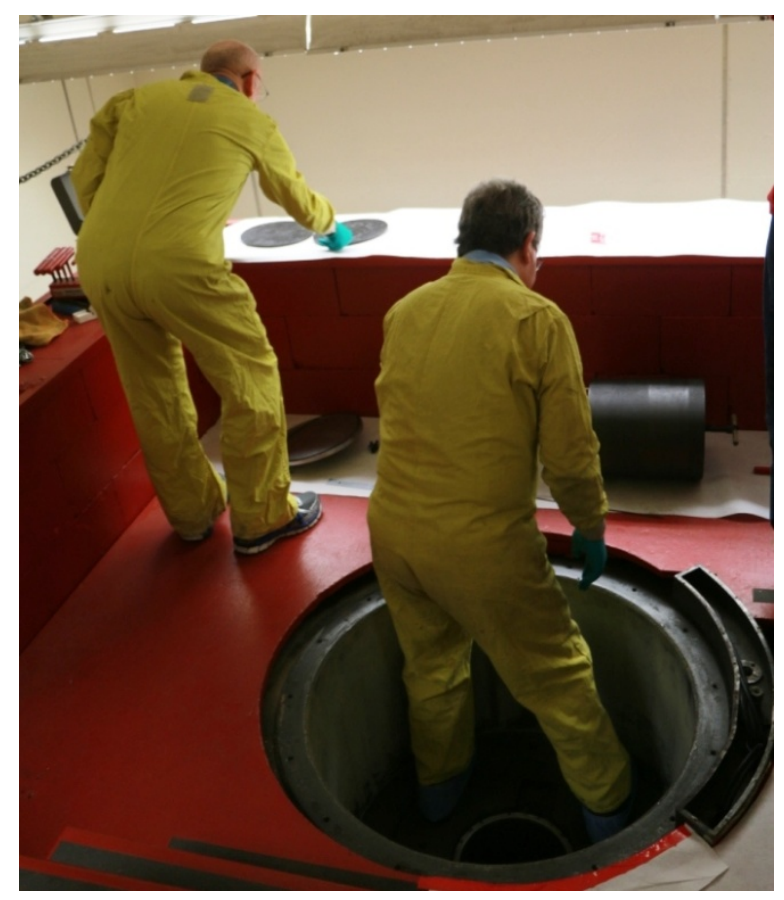

Figure 3-2. Placing a fuel disk on the reactor parapet.

After the top five fuel disks were removed, a different procedure sequence was followed for the four remaining fuel disks, as required. To access these disks, the reactor core tank required removal. The top 
core tank lid was placed on the core tank and bolted in place, and two additional jack bolts were installed to provide for four lifting points. The lifting chain was attached to the crane hook. The core tank was slowly lifted and moved onto the reactor's top platform. The crane was used to lower the core tank onto its side, and then was unrigged.
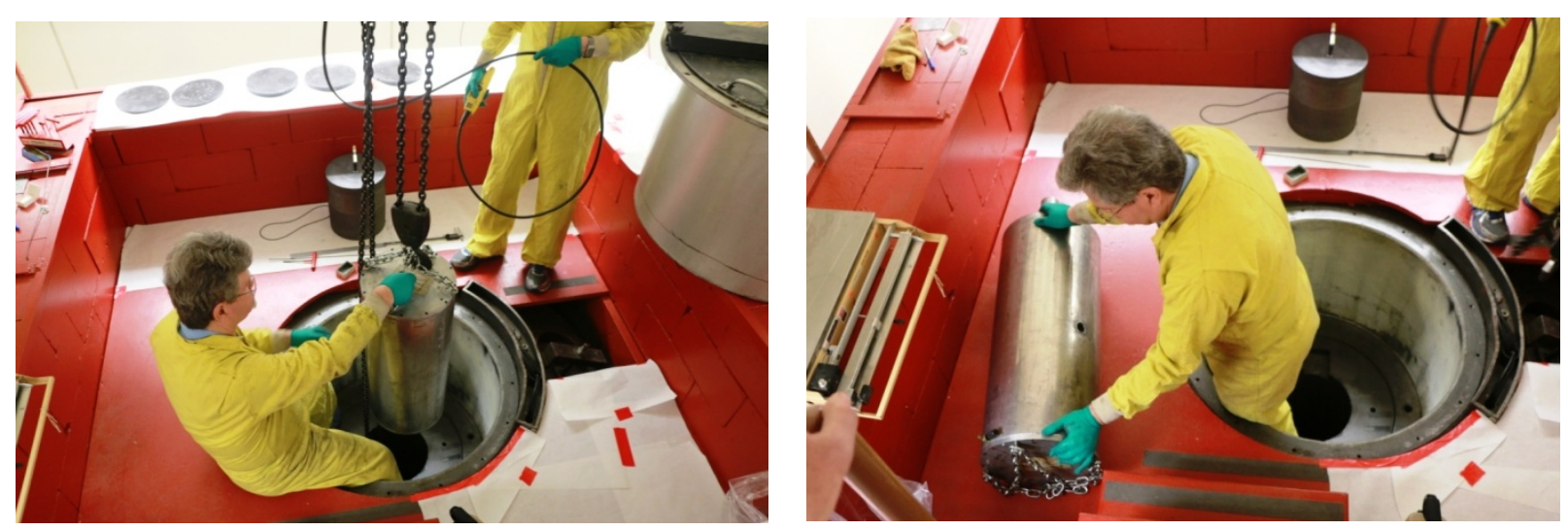

Figure 3-3. Lifting the core tank being and resting it on the reactor's top platform.

Four bolts were removed from each control rod thimble, and the cans were then removed and placed on the reactor's top platform. The core can's top was removed. The dose rate at $30 \mathrm{~cm}$ above the sixth fuel disk was $14.4 \mathrm{mR} / \mathrm{hr}$. The sixth fuel disk (204100) was removed, placed on the parapet, and smeared.

The reflector shells were removed and then the baffle plates were removed. They all were placed on the reactor's top platform.
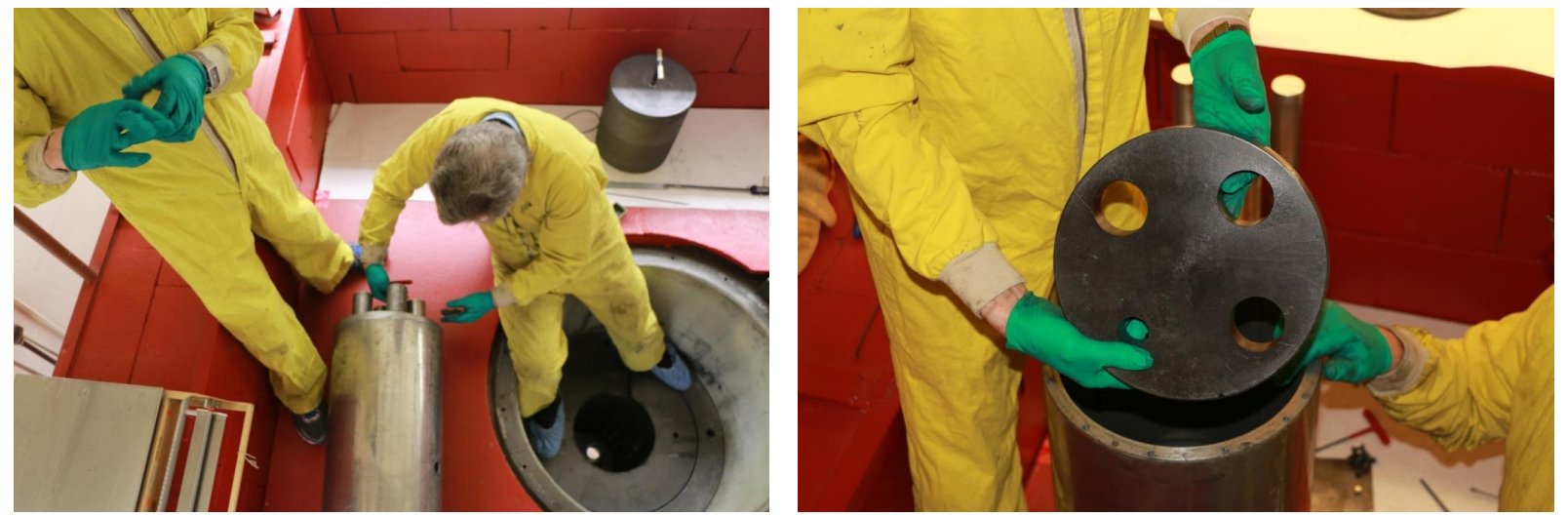

Figure 3-4. Removing the control rod cans and fuel disk 204100 from the core tank. 

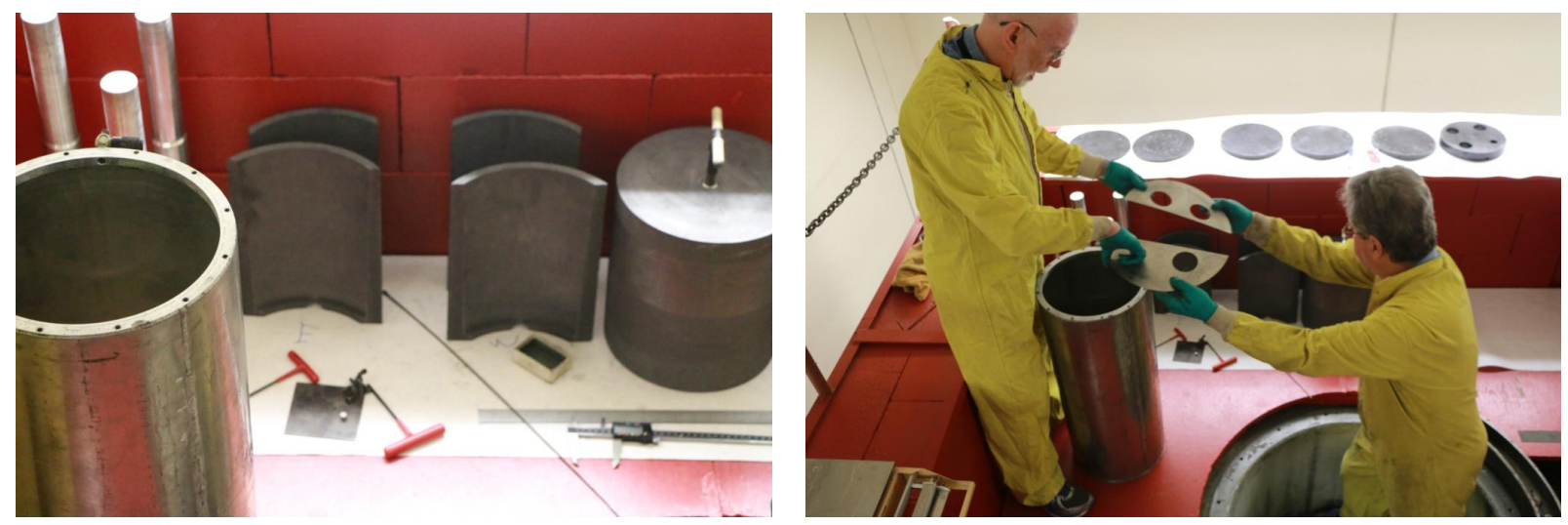

Figure 3-5. Top graphite shells after removal (left); baffle plates being removed (right).

After the aluminum baffle plates were removed, the core tank bottom was unbolted. The can with bottom fuel disks and bottom graphite reflector was then moved into an upright position. An attempt to lift the core tank off the fuel and graphite failed when the tank caught on something when being lifted. Therefore, the tank was placed on its side so that the bottom support plate and attached fuel could be slid out horizontally from the tank. When this occurred, the bottom support plate dropped to a horizontal position that bent and cracked the bottom support rod that was screwed into the core bottom support plate. This did not affect the disassembly of the fuel, but a replacement rod had to be created before the reactor could be reassembled.

After the tank was in a horizontal position, the bottom cover and damaged rod were removed. The assembly with the lower three fuel disks and the bottom graphite reflector were then slid out of the core tank and placed on its side as shown in Figure 3-6.

NOTE: Because of the damage to the support rod, a new rod was fabricated as a replacement. Upon examination, it was found that the original rod was annular instead of solid, with a closed top and a threaded bottom. The original rod measured one half inch in diameter and had a one-inch threaded portion at 20 threads per inch. The damaged rod was replaced with a solid rod which to provide additional mechanical strength. It was threaded for one inch at 20 threads per inch. As a lesson learned from the disassembly, the procedure was modified to keep the bottom core support plate bolted to the tank until the tank was in a horizontal position. This should minimize the stress on the support rod. 


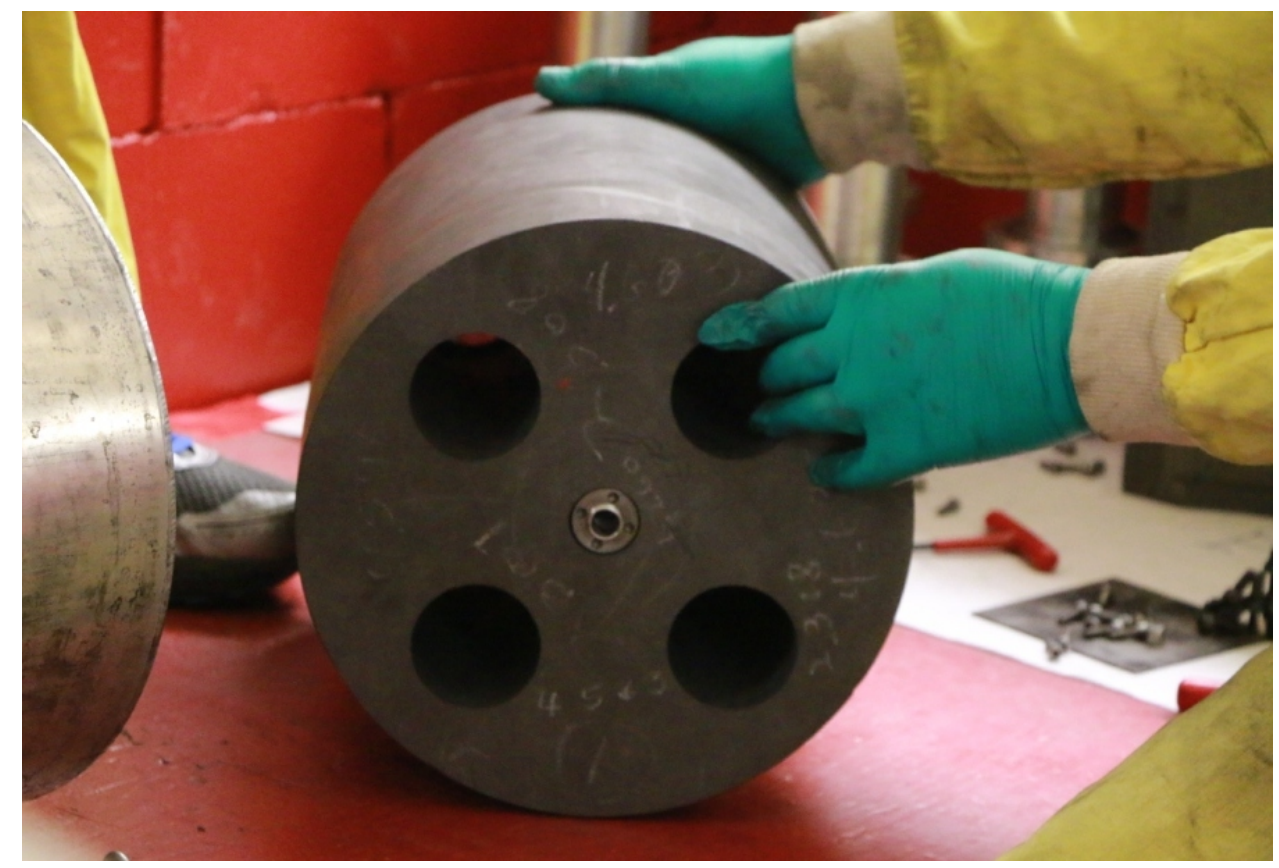

Figure 3-6. Bottom graphite reflector and bottom three fuel disks.

The nut on the bottom of the fuse rod was removed by holding the top of the fuse thimble with pliers while turning the nut. After the nut was removed, the graphite reflector and the lower three fuel disks (99, $98,97)$ were separated and placed on the reactor's shielding parapet. Each disk was swiped for loose contamination; the results are shown in Table 3-1. The thermal fuse was removed from the holder by removing the retaining ring. Cracking in the fuse was noted, as seen in Figure 3-7. The cracks did not go through the fuse height and were judged to have minimal impact on the mechanical integrity of the fuse. The presence of cracks is not a safety issue, as total failure of the fuse would shut the reactor down by separating the top and bottom halves of the core. The fuse was placed on the parapet and swiped which completed the disassembly.

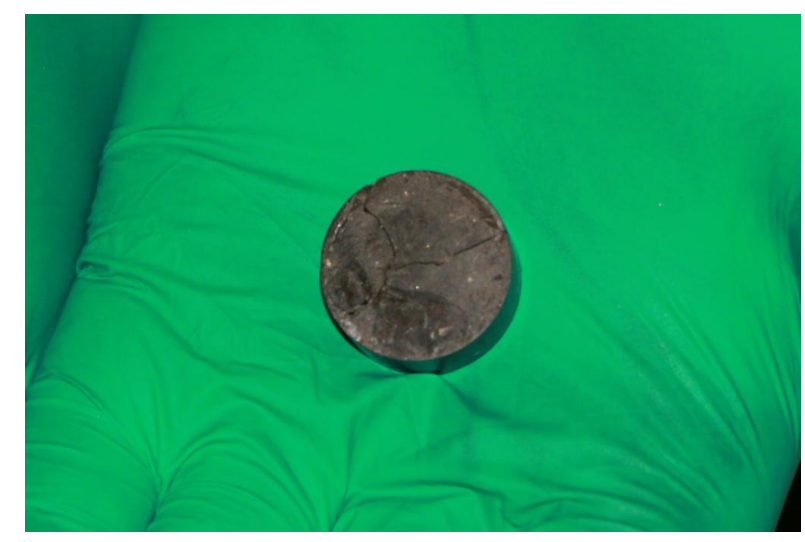

Figure 3-7. Utah thermal fuse. 
Contamination smears were taken on all of the fuel disks. To reduce the loose contamination, the disks were sprayed with clear coat Krylon ${ }^{\circledR}$. The results of the initial smears and the smears taken after coating the fuel disks with Krylon ${ }^{\circledR}$ are shown in Table 3-1.

Table 3-1. Contamination survey results

\begin{tabular}{|c|c|c|c|c|c|c|}
\hline \multirow[b]{2}{*}{ Unit } & \multicolumn{3}{|c|}{$\begin{array}{l}\text { Fuel disk contamination - initial } \\
\left(\mathrm{dpm} / 100 \mathrm{~cm}^{2}\right)\end{array}$} & \multicolumn{3}{|c|}{$\begin{array}{l}\text { Fuel disk contamination - coated } \\
\left(\mathrm{dpm} / 100 \mathrm{~cm}^{2}\right)\end{array}$} \\
\hline & $\alpha$ & $\boldsymbol{\beta}$ & $\gamma$ & $\alpha$ & $\beta$ & $\gamma$ \\
\hline 20497 & 86 & 362 & 100 & 8 & 41 & 0 \\
\hline 20498 & 63 & 598 & 400 & 15 & 40 & 2 \\
\hline 20499 & 48 & 547 & 500 & 44 & 51 & 11 \\
\hline 204100 & 74 & 731 & 367 & 20 & 28 & 57 \\
\hline 204101 & 20 & 449 & 0 & 0 & 6 & 0 \\
\hline 204102 & 6 & 576 & 233 & 9 & 19 & 31 \\
\hline 204103 & 11 & 380 & 0 & 13 & 10 & 0 \\
\hline 204104 & 35 & 277 & 0 & 6 & 38 & 39 \\
\hline 204105 & 5 & 520 & 236 & 4 & 20 & 0 \\
\hline Fuse & 827 & 1,115 & 1,467 & & & \\
\hline
\end{tabular}

\section{CHARACTERIZATION PROCESS}

\subsection{PHYSICAL CHARACTERIZATION}

The physical characterization included weighing the disks and measuring their diameters and thicknesses. Any holes were measured, and the distance from the edge was noted. The process was to transfer a single disk from the reactor's top platform and bring it down the steps to the characterization area, where the dimensional measurement and weight were obtained.
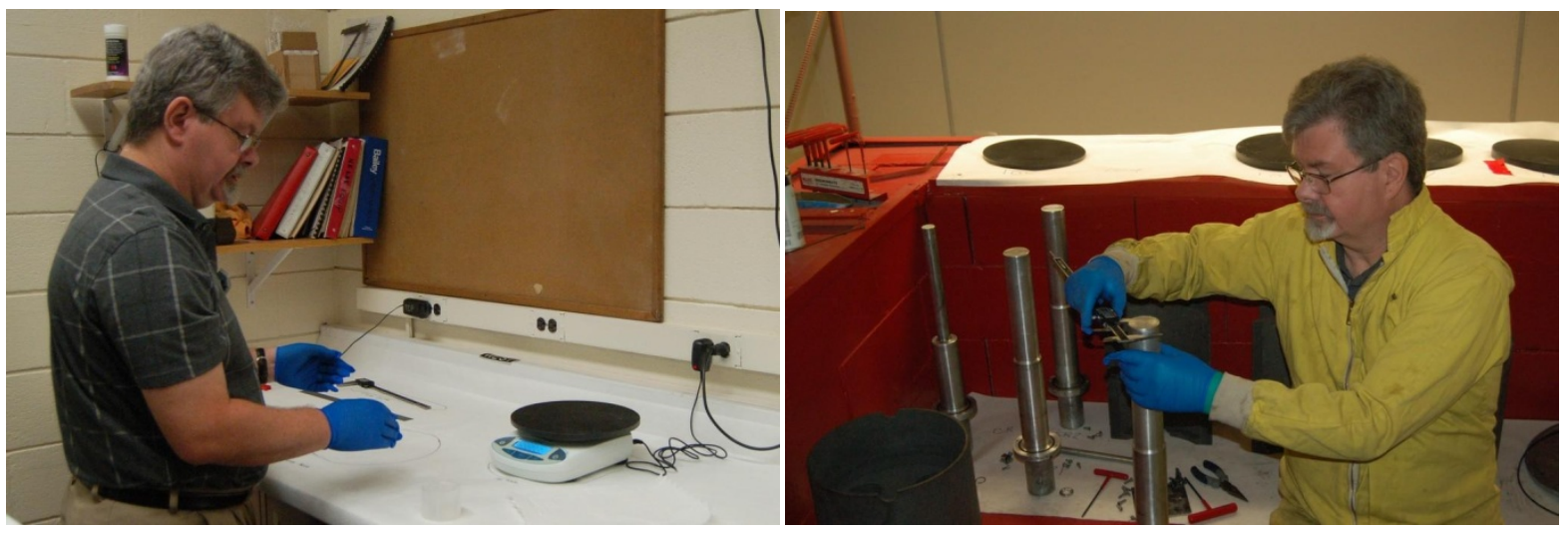

Figure 4-1. Measuring physical attributes of components.

The dimensions of the top and bottom graphite reflectors and core tank graphite shells were taken. The weight of the lower graphite reflector was obtained. The other graphite pieces were not weighed, as they 
had been measured previously. Dimensional measurements of the fixed radial graphite and lead section were taken. The outer dimensions of the control rods and the control rod thimbles along with the baffle plates were obtained.
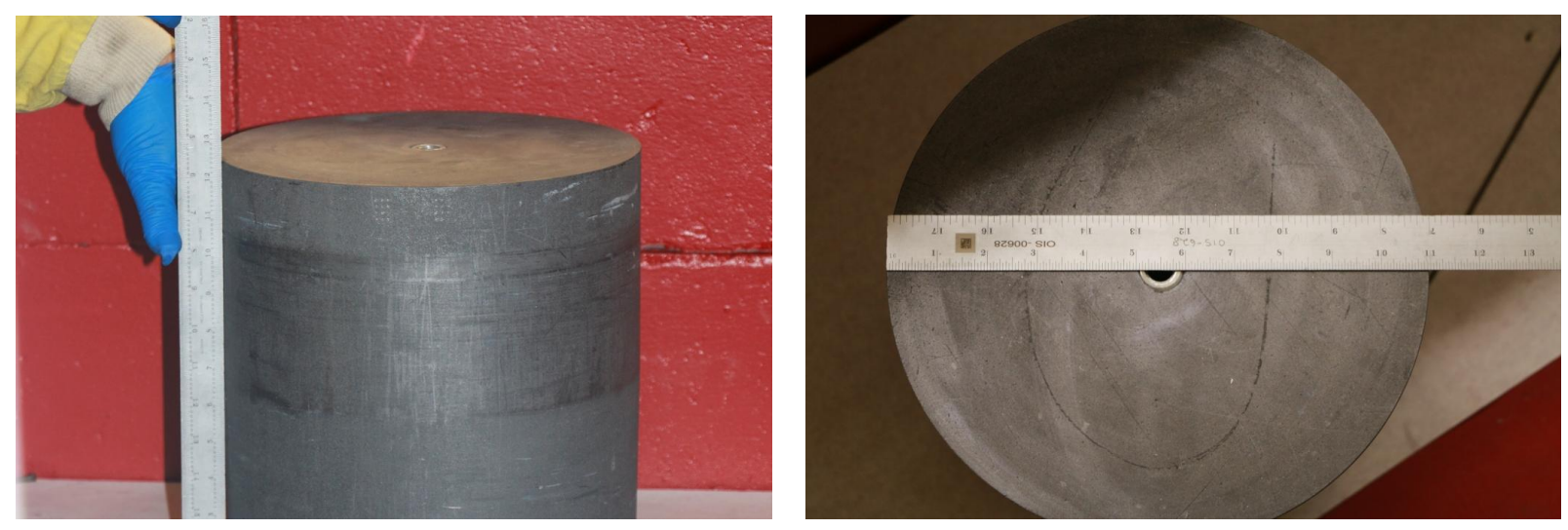

Figure 4-2. Measurement of the top graphite reflector.

\subsection{NONDESTRUCTIVE CHARACTERIZATION}

After each disk had undergone physical and dimensional characterization, it was placed on the easel (see Figure 4-3 for typical setup) and positioned in front of the collimated detector for nondestructive radioisotope analysis. Once the distance between the disk and the detector was adjusted to achieve the desired dead time, the spectrum was captured. Upon completion of characterization, the fuel disk was returned to the reactor parapet. The thermal fuse for the reactor (Utah), the original fuse (UNM), and the fission plate were characterized in the same manner. A portable detector was used to obtain spectra from the four control rods. Supplemental measurements were taken on fuel disk 105. A narrow aperture collimator was used to perform a series of measurements at $1 / 2$ inch steps radially on the disk to determine any radial variation in fuel burn-up.
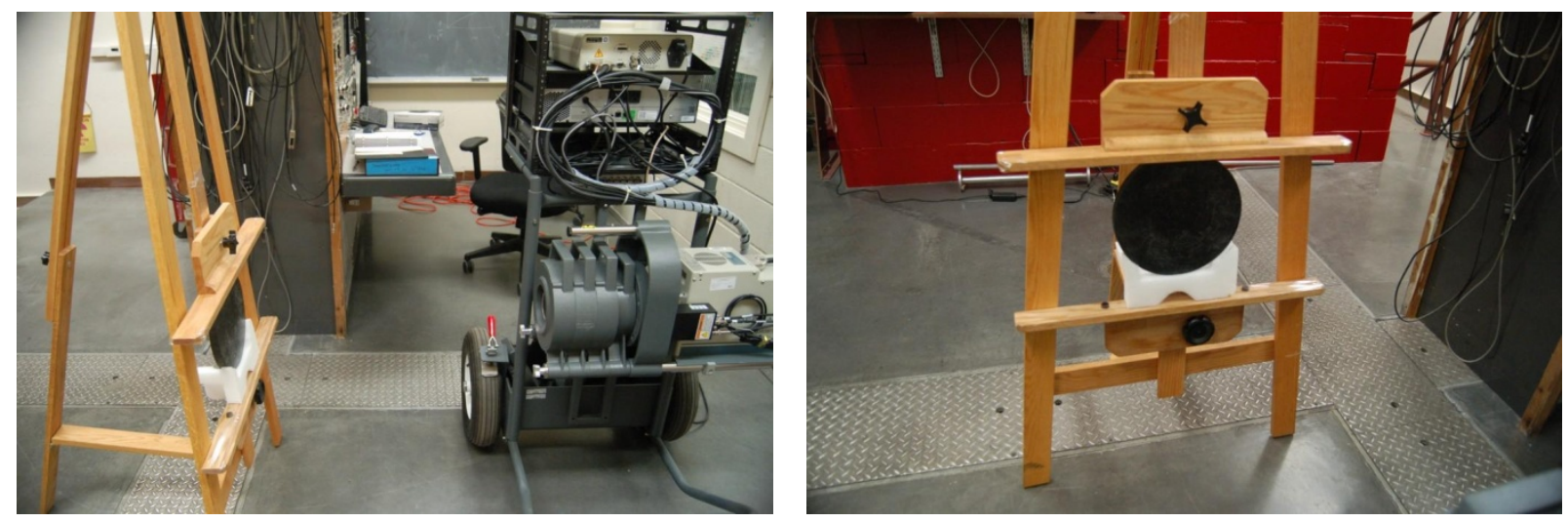

Figure 4-3. Setup of NDA measurement for a fuel disk. 


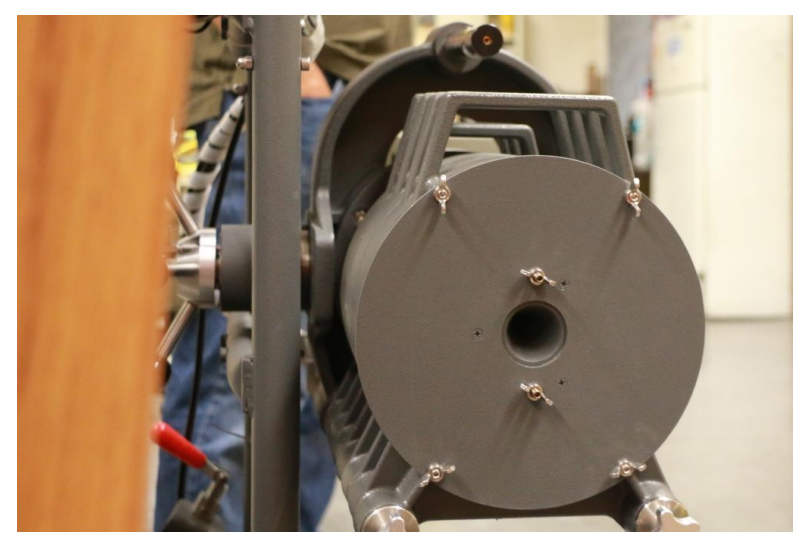

Figure 4-4. Detection equipment with a small aperture collimator.

\subsection{REASSEMBLY}

UNM personnel reassembled the reactor on May 16-20. The reactor then underwent daily and monthly checkouts, followed by an excess reactivity analysis, which indicated that the reactor was performing as expected.

\section{PHYSICAL DATA}

The following pieces of equipment were used for dimensional measurements:

- 12-inch digital calipers

- 6-inch digital calipers

- $\quad 18$-inch scale $(1 / 32$ and $1 / 64$-inch increments)

The 12-inch digital calipers were the preferred tool, but they could not always be used. 
The following equipment was used to measure mass:

- Digital scale (maximum $3 \mathrm{~kg}$ )

- Beam balance scale

\subsection{SUMMARY OF PHYSICAL MEASUREMENTS}

A summary of the measurements is provided in the following tables. The raw data collected are provided in Appendix A.

The best estimates of the physical attributes of the fuel disks and fuses are given in Table 5-1. The uncertainty in the volume and density were calculated as follows (assumes that data are neither independent nor random):

$$
\begin{gathered}
\Delta V=\left(2 \frac{\Delta D}{D}+\frac{\Delta H}{H}\right) V \\
\Delta \rho=\left(\frac{\Delta \mathrm{m}}{\mathrm{m}}+2 \frac{\Delta \mathrm{D}}{\mathrm{D}}+\frac{\Delta \mathrm{H}}{\mathrm{H}}\right) \rho
\end{gathered}
$$

Table 5-1. Attributes of the upper disks and thermal fuses

\begin{tabular}{lcccc}
\hline Disk & $\mathbf{2 0 4 1 0 5}$ & $\mathbf{2 0 4 1 0 4}$ & $\mathbf{2 0 4 1 0 3}$ & $\mathbf{2 0 4 1 0 2}$ \\
\hline Disk diameter $(\mathrm{cm})$ & $25.603 \pm 0.058$ & $25.590 \pm 0.003$ & $25.633 \pm 0.002$ & $25.628 \pm 0.006$ \\
Disk height $(\mathrm{cm})$ & $1.039 \pm 0.013$ & $1.076 \pm 0.009$ & $2.004 \pm 0.013$ & $2.005 \pm 0.015$ \\
Mass $(\mathrm{g})$ & $653.730 \pm 0.030$ & $675.767 \pm 0.030$ & $1268.197 \pm 0.030$ & $1269.150 \pm 0.030$ \\
\hline Calculated volume $\left(\mathrm{cm}^{3}\right)$ & $535.1 \pm 9.105$ & $553.4 \pm 4.892$ & $1034.4 \pm 6.895$ & $1034.4 \pm 8.315$ \\
Calculated density $\left(\mathrm{g} / \mathrm{cm}^{3}\right)$ & $1.222 \pm 0.021$ & $1.221 \pm 0.011$ & $1.226 \pm 0.008$ & $1.227 \pm 0.010$ \\
\hline Disk & $\mathbf{2 0 4 1 0 1}$ & UNM fuse & Utah fuse & \\
\hline Disk diameter $(\mathrm{cm})$ & $25.633 \pm 0.003$ & $2.234 \pm 0.001$ & $2.229 \pm 0.001$ & \\
Disk height $(\mathrm{cm})$ & $2.022 \pm 0.020$ & $0.932 \pm 0.000$ & $0.939 \pm 0.004$ & \\
Mass $(\mathrm{g})$ & $1270.437 \pm 0.030$ & $5.883 \pm 0.030$ & $5.920 \pm 0.030$ & \\
\hline Calculated volume $\left(\mathrm{cm}^{3}\right)$ & $1043.6 \pm 10.677$ & $3.653 \pm 0.005$ & $3.663 \pm 0.020$ & \\
Calculated density $\left(\mathrm{g} / \mathrm{cm}^{3}\right)$ & $1.217 \pm 0.013$ & $1.610 \pm 0.004$ & $1.616 \pm 0.012$ & \\
\hline
\end{tabular}

The best estimate of the physical attributes of the fuel disks that contained voids due to rods, fuse holders, and the glory hole are listed in Table 5-2. The uncertainty in the individual regions is calculated as shown in Eq. (1), but the uncertainty is calculated as:

$$
\Delta V=\sqrt{\sum \Delta V_{i}^{2}}
$$

With the volume uncertainty already calculated, the uncertainty on the density is:

$$
\Delta \rho=\left(\frac{\Delta m}{m}+\frac{\Delta V}{V}\right) \rho
$$


Table 5-2. Attributes of disks with penetrations

\begin{tabular}{lcccc}
\hline Disk & $\mathbf{2 0 4 1 0 0}$ & $\mathbf{2 0 4 9 9}$ & $\mathbf{2 0 4 9 8}$ & $\mathbf{2 0 4 9 7}$ \\
\hline Disk diameter $(\mathrm{cm})$ & $25.559 \pm 0.030$ & $25.611 \pm 0.060$ & $25.659 \pm 0.143$ & $25.692 \pm 0.200$ \\
Disk height $(\mathrm{cm})$ & $3.968 \pm 0.014$ & $3.994 \pm 0.034$ & $4.005 \pm 0.034$ & $3.982 \pm 0.026$ \\
SR 1 hole diameter $(\mathrm{cm})$ & $5.076 \pm 0.007$ & $5.074 \pm 0.049$ & $5.163 \pm 0.068$ & $5.121 \pm 0.009$ \\
SR 2 hole diameter $(\mathrm{cm})$ & $5.078 \pm 0.030$ & $5.114 \pm 0.004$ & $5.109 \pm 0.009$ & $5.102 \pm 0.032$ \\
CCR hole diameter $(\mathrm{cm})$ & $5.046 \pm 0.024$ & $5.096 \pm 0.021$ & $5.113 \pm 0.006$ & $5.105 \pm 0.003$ \\
FCR hole diameter $(\mathrm{cm})$ & $2.844 \pm 0.054$ & $2.951 \pm 0.000$ & $2.948 \pm 0.002$ & $2.937 \pm 0.012$ \\
Thermal fuse holder diameter $(\mathrm{cm})$ & - & $2.725 \pm 0.008$ & - & - \\
Thermal fuse holder depth $(\mathrm{cm})$ & - & $1.852 \pm 0.001$ & - & - \\
Thermal fuse rod diameter $(\mathrm{cm})$ & $1.572 \pm 0.023$ & $1.582 \pm 0.001$ & $1.582 \pm 0.001$ & $1.567 \pm 0.001$ \\
Glory hole span $(\mathrm{cm})$ & $2.910 \pm 0.000$ & $3.007 \pm 0.039$ & - & - \\
Glory hole depth $\left(\mathrm{cm}^{2}\right)$ & 1.45 & 1.503 & - & - \\
Mass $(\mathrm{g})$ & $2058.333 \pm 0.030$ & $2033.240 \pm 0.030$ & $2163.353 \pm 0.030$ & $2155.887 \pm 0.030$ \\
\hline Calculated volume $\left(\mathrm{cm}^{3}\right)$ & $1685.4 \pm 4.275$ & $1682.9 \pm 5.690$ & $1787.7 \pm 6.818$ & $1785.0 \pm 7.062$ \\
Calculated density $\left(\mathrm{g} / \mathrm{cm}^{3}\right)$ & $1.221 \pm 0.003$ & $1.208 \pm 0.004$ & $1.210 \pm 0.005$ & $1.208 \pm 0.005$ \\
\hline
\end{tabular}

The fuse holder and stem were measured, and the best estimates of those dimensions are shown in Table 5-3. The piece was not weighed.

Table 5-3. Attributes of the Fuse Thimble and Stem

\begin{tabular}{lcc}
\hline & Holder & Stem \\
\hline Outside diameter $(\mathrm{cm})$ & $2.732 \pm 0.001$ & $1.587 \pm 0.004$ \\
Inside diameter $(\mathrm{cm})$ & $2.228 \pm 0.003$ & $1.290 \pm 0.013$ \\
Height $(\mathrm{cm})$ & $1.288 \pm 0.006$ & $28.773 \pm 0.004$ \\
\hline
\end{tabular}

The external attributes of the aluminum-clad control rod sections are provided in Table 5-4. The two safety rods and the coarse rod each contain $16 \mathrm{~cm}$ of fuel at the top (four $4 \mathrm{~cm}$ fuel disks) with $8 \mathrm{~cm}$ of graphite (two $4 \mathrm{~cm}$ disks), and a spring to hold the disks in place. The fine rod contains $12 \mathrm{~cm}$ of fuel at the top (three $4 \mathrm{~cm}$ fuel disks), followed by a $4 \mathrm{~cm}$ polyethylene disk and then $8 \mathrm{~cm}$ of graphite (two $4 \mathrm{~cm}$ disks), and a spring to hold the disks in place. The control rod sections were not weighed. 
Table 5-4. Attributes of the control rods

\begin{tabular}{lcccc}
\hline & Safety rod 1 & Safety rod 2 & $\begin{array}{c}\text { Course control } \\
\text { rod }\end{array}$ & Fine control rod \\
\hline Upper outside diameter $(\mathrm{cm})$ & $4.795 \pm 0.001$ & $4.794 \pm 0.001$ & $4.795 \pm 0.004$ & $2.531 \pm 0.005$ \\
Lower outside diameter $(\mathrm{cm})$ & $4.790 \pm 0.006$ & $4.788 \pm 0.005$ & $4.795 \pm 0.007$ & $2.535 \pm 0.001$ \\
Rod length $(\mathrm{cm})$ & 27.637 & 27.588 & 27.640 & 27.532 \\
Base outside diameter $(\mathrm{cm})$ & $5.051 \pm 0.001$ & $5.048 \pm 0.004$ & $5.056 \pm 0.006$ & $5.046 \pm 0.003$ \\
Base length $(\mathrm{cm})$ & $3.321 \pm 0.025$ & $3.388 \pm 0.001$ & $3.306 \pm 0.105$ & $3.393 \pm 0.019$ \\
\hline
\end{tabular}

The best estimates of the dimensions of the top and bottom graphite reflectors are shown in Table 5-5. Only one mass measurement was made for each piece. The mass uncertainty is estimated as $0.2 \mathrm{lb}$ or 0.09 $\mathrm{kg}$. Because there are voids, the uncertainty in the volume and density will be calculated using Eqs. (3) and (4). The top graphite reflector includes a threaded insert into which the T-handle is threaded. No adjustments were made to the volume or mass for the insert.

Table 5-5. Attributes of the graphite reflectors

\begin{tabular}{lcc}
\hline Attribute & Top graphite reflector & Bottom graphite reflector \\
\hline Top diameter $(\mathrm{cm})$ & $27.929 \pm 0.041$ & $27.010 \pm 0.029$ \\
Bottom diameter $(\mathrm{cm})$ & $27.236 \pm 0.014$ & $27.925 \pm 0.011$ \\
Inner diameter $(\mathrm{cm})$ & $25.883 \pm 0.005$ & $25.871 \pm 0.029$ \\
Wall thickness $(\mathrm{cm})$ & $0.676 \pm 0.008$ & $0.554 \pm 0.021$ \\
Inner height $(\mathrm{cm})$ & $11.443 \pm 0.031$ & $11.929 \pm 0.010$ \\
Outer height $(\mathrm{cm})$ & $31.532 \pm 0.040$ & - \\
FCR bottom diameter $(\mathrm{cm})$ & - & $5.856 \pm 0.007$ \\
CCR bottom diameter $(\mathrm{cm})$ & - & $5.745 \pm 0.027$ \\
SR 1 bottom diameter $(\mathrm{cm})$ & - & $5.849 \pm 0.002$ \\
SR 2 bottom diameter $(\mathrm{cm})$ & - & $5.839 \pm 0.001$ \\
Fuse rod bottom diameter $(\mathrm{cm})$ & - & $3.168 \pm 0.020$ \\
FCR upper diameter $(\mathrm{cm})$ & - & 2.90 \\
CCR upper diameter $(\mathrm{cm})$ & - & 5.82 \\
SR 1 upper diameter $(\mathrm{cm})$ & - & 5.79 \\
SR 2 upper diameter $(\mathrm{cm})$ & - & 5.82 \\
Fuse rod upper diameter $(\mathrm{cm})$ & - & 1.70 \\
FCR transition from bottom $(\mathrm{cm})$ & - & $16.153 \pm 0.261$ \\
Fuse rod transition from bottom $(\mathrm{cm})$ & - & $2.549 \pm 0.000$ \\
Mass $(\mathrm{g})$ & $22373( \pm 90)$ & $18370( \pm 90)$ \\
\hline Calculated volume $\left(\mathrm{cm}^{3}\right)$ & $12820.140 \pm 85.018$ & $10329.955 \pm 63.229$ \\
Calculated density $\left(\mathrm{g} / \mathrm{cm}^{3}\right)$ & $1.745 \pm 0.019$ & $1.778 \pm 0.020$ \\
\hline & & \\
\hline & - & -19 \\
\hline
\end{tabular}

The top graphite shells were measured, and the best estimates of the dimensions are given in Table 5-6. The mass of the upper north shell had been taken previously. The mass uncertainty is estimated at $10 \mathrm{~g}$ based on the scale used. 
Table 5-6. Attributes of the shells

\begin{tabular}{lcccc}
\hline Attribute & Upper north & Upper south & Upper east & Upper west \\
\hline Top thickness $(\mathrm{cm})$ & $1.488 \pm 0.006$ & $1.491 \pm 0.005$ & $1.495 \pm 0.008$ & $1.492 \pm 0.004$ \\
Top to lip $(\mathrm{cm})$ & 31.433 & $31.433 \pm 0.000$ & $31.433 \pm 0.000$ & $31.472 \pm 0.000$ \\
Lip height $(\mathrm{cm})$ & $1.483 \pm 0.012$ & $1.466 \pm 0.001$ & $1.474 \pm 0.006$ & $1.481 \pm 0.010$ \\
Lip thickness $(\mathrm{cm})$ & $2.853 \pm 0.002$ & $2.854 \pm 0.010$ & $2.852 \pm 0.006$ & $2.851 \pm 0.016$ \\
Flat width $(\mathrm{cm})$ & $1.915 \pm 0.000$ & $1.950 \pm 0.057$ & $1.948 \pm 0.014$ & $2.038 \pm 0.018$ \\
Notch width $(\mathrm{cm})$ & - & - & 2.98 & 2.911 \\
\hline Attribute & Lower north & Lower south & Lower east & Lower west \\
\hline Top thickness $(\mathrm{cm})$ & 1.499 & - & - & - \\
Bottom thickness $(\mathrm{cm})$ & 2.286 & - & - & - \\
Height $(\mathrm{cm})$ & 37.1 & - & - & - \\
Chord $(\mathrm{cm}) *$ & 22 & - & - & - \\
Chord to inner surface $(\mathrm{cm}) *$ & 3.12 & - & - & - \\
Mass $(\mathrm{g})$ & 2789.5 & - & & - \\
\hline
\end{tabular}

* The location where the chord was measured was not noted.

It should be noted that gaps can be seen between the shells when they are assembled and is assumed that the gaps would exist over the entire height of the shells. The shells overlap, so streaming is minimized. Using measurements taken from a digital photograph of the bottom shells, the gaps were measured using ImageJ [10]. Figure 5-1 shows the gaps and the enhanced image used for measurements. The letters A, B and $\mathrm{D}$ are used to identify the locations of the measurement. One gap cannot be seen in the picture since it is at the bottom. The measurements were taken across the gaps perpendicular to the mating surfaces and then along the mating surfaces.

Table 5-7. Measurement of gaps between bottom reflector shells

\begin{tabular}{c|ccc|c|cc|c}
\hline $\begin{array}{c}\text { Measurement } \\
\text { location }\end{array}$ & \multicolumn{3}{|c|}{ Gap (cm) } & \multicolumn{3}{c}{ Face (cm) } \\
Data & Data & Average & \multicolumn{3}{c}{ Ave } \\
\hline A & 0.152 & 0.124 & 0.103 & 0.126 & 2.893 & 2.934 & 2.914 \\
B & 0.215 & 0.247 & 0.227 & 0.230 & 3.229 & 3.179 & 3.204 \\
D & 0.196 & 0.182 & 0.182 & 0.187 & 3.223 & 3.089 & 3.156 \\
\hline
\end{tabular}

The face dimensions were measured at the tops of the bottom shells, which is their thickest point. The approximate angle between the radius and the face is $42^{\circ}$. Using this angle, based on observations, gap C would be about the same as gap A since two of the gaps are narrower and two are wider. The impact of the gaps is estimated at a $1 \%$ reduction in graphite volume compared to a solid annulus. 

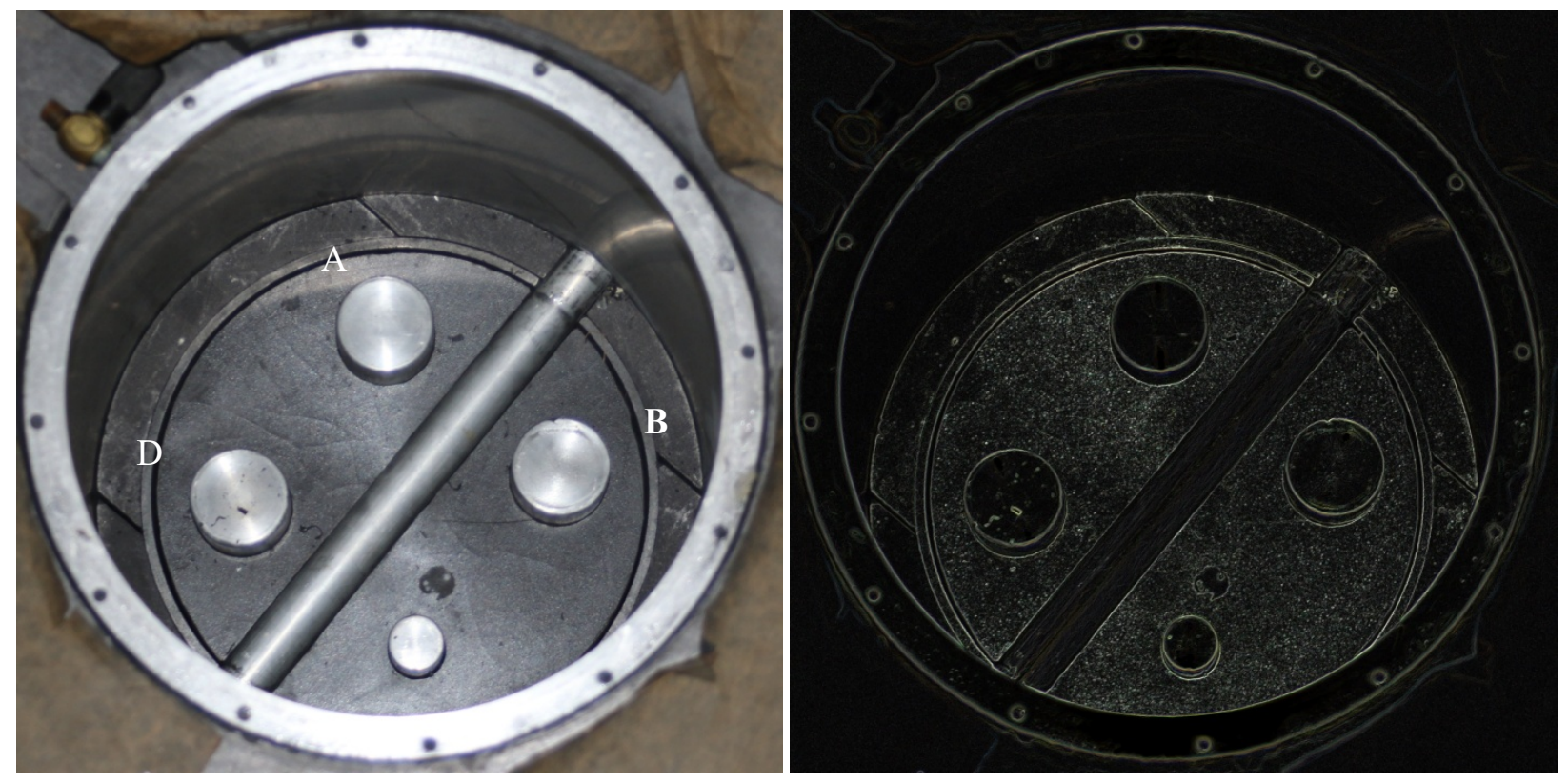

Figure 5-1. Gaps in the bottom shells.

The best estimates of the dimensions of the baffle plates are given in Table 5-8, the control rod thimble can dimensions are given in Table 5-9, and radial dimensions of graphite and lead around the core are listed in Table 5-10.

Table 5-8. Attributes of the baffle plates

\begin{tabular}{lcc}
\hline Attribute & North plate & South plate \\
\hline Rod hole diameter $(\mathrm{cm})$ & $6.333 \pm 0.011$ & $6.292 \pm 0.020$ \\
Rod hole diameter $(\mathrm{cm})$ & $3.442 \pm 0.001$ & $6.332 \pm 0.016$ \\
N - S distance $(\mathrm{cm})$ & 13.494 & 13.533 \\
E -W distance $(\mathrm{cm})$ & 30.956 & 30.956 \\
Thickness $(\mathrm{cm})$ & $0.081 \pm 0.001$ & $0.082 \pm 0.001$ \\
\hline
\end{tabular}

Table 5-9. Attributes of the control rod thimble cans

\begin{tabular}{lcccc}
\hline Attribute & Safety rod 1 & Safety rod 2 & Course control rod & Fine control rod \\
\hline Upper diameter $(\mathrm{cm})$ & $5.092 \pm 0.002$ & $5.103 \pm 0.016$ & $5.097 \pm 0.005$ & $2.868 \pm 0.002$ \\
Upper height $(\mathrm{cm})$ & 22.479 & 22.391 & 22.464 & 26.164 \\
Transition height $(\mathrm{cm})$ & 0.635 & 0.635 & 0.635 & 0 \\
Lower diameter $(\mathrm{cm})$ & $5.761 \pm 0.043$ & $5.725 \pm 0.002$ & $5.714 \pm 0.001$ & $5.719 \pm 0.001$ \\
Lower height $(\mathrm{cm})$ & 20.066 & 20.154 & 20.081 & 17.016 \\
\hline
\end{tabular}


Table 5-10. Attributes of the fixed reflectors

\begin{tabular}{lc}
\hline Attribute & $\begin{array}{c}\text { Dimension } \\
(\mathbf{c m})\end{array}$ \\
\hline Graphite inside diameter & $32.385 \pm 0.000$ \\
Radial thickness of the graphite & $16.510 \pm 0.000$ \\
Gap between graphite and lead & $0.342 \pm 0.099$ \\
Radial thickness of the lead & $9.525 \pm 0.000$ \\
\hline
\end{tabular}

The tops of the fixed graphite and lead have holes that may be for lifting. These can be seen in Figure 5-2 and Figure 5-3, and their dimensions are listed in Table 5-11.

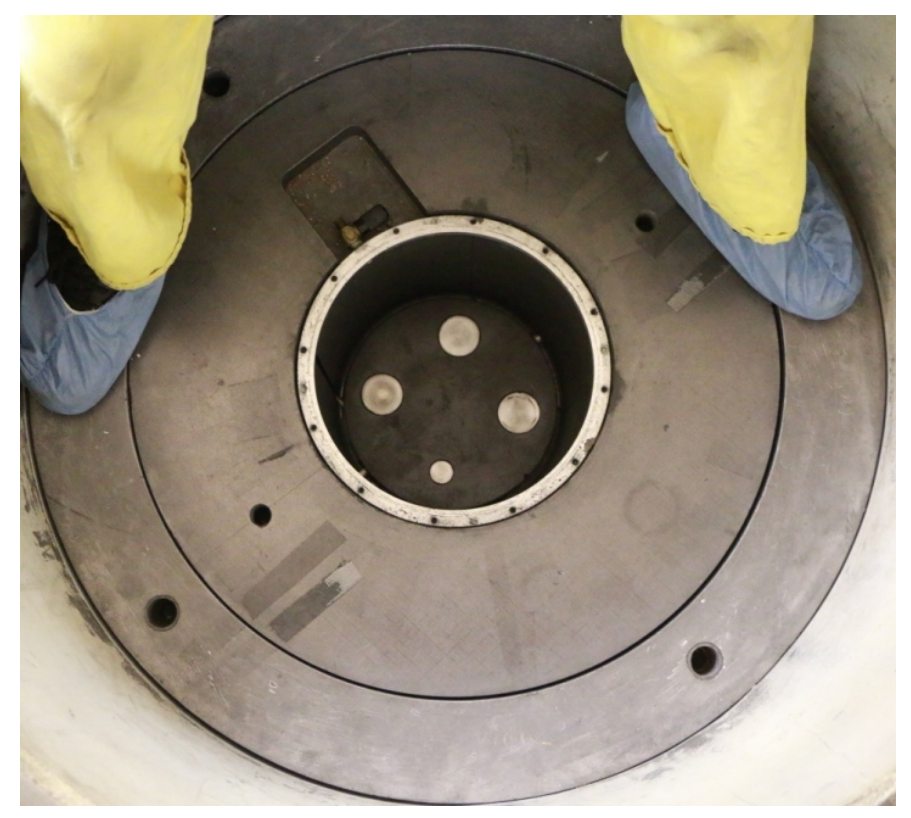

Figure 5-2. Top view of the radial graphite and lead.

Table 5-11. Locations of holes on the fixed reflector top

\begin{tabular}{lcccc}
\hline Graphite (cm) & West & \multicolumn{3}{c}{ East } \\
\hline Hole depth & 5.755 & & 6.109 & \\
Hole height & 1.938 & & 1.936 & \\
Edge-to-edge from inner radius to hole & 7.635 & & 7.275 & \\
\hline Lead (cm) & West & North & East & South \\
\hline Hole depth & 4.992 & 4.699 & 5.012 & 4.631 \\
Hole height & 2.748 & 2.663 & 2.883 & 2.866 \\
Edge-to-edge from inner radius to hole & 3.721 & 3.933 & 3.695 & 3.764 \\
\hline
\end{tabular}

In addition to these holes, there is a cutout at the top of the fixed graphite reflector to accommodate the fission gas valve. The dimensions of the cutout are shown in Figure 5-3. 


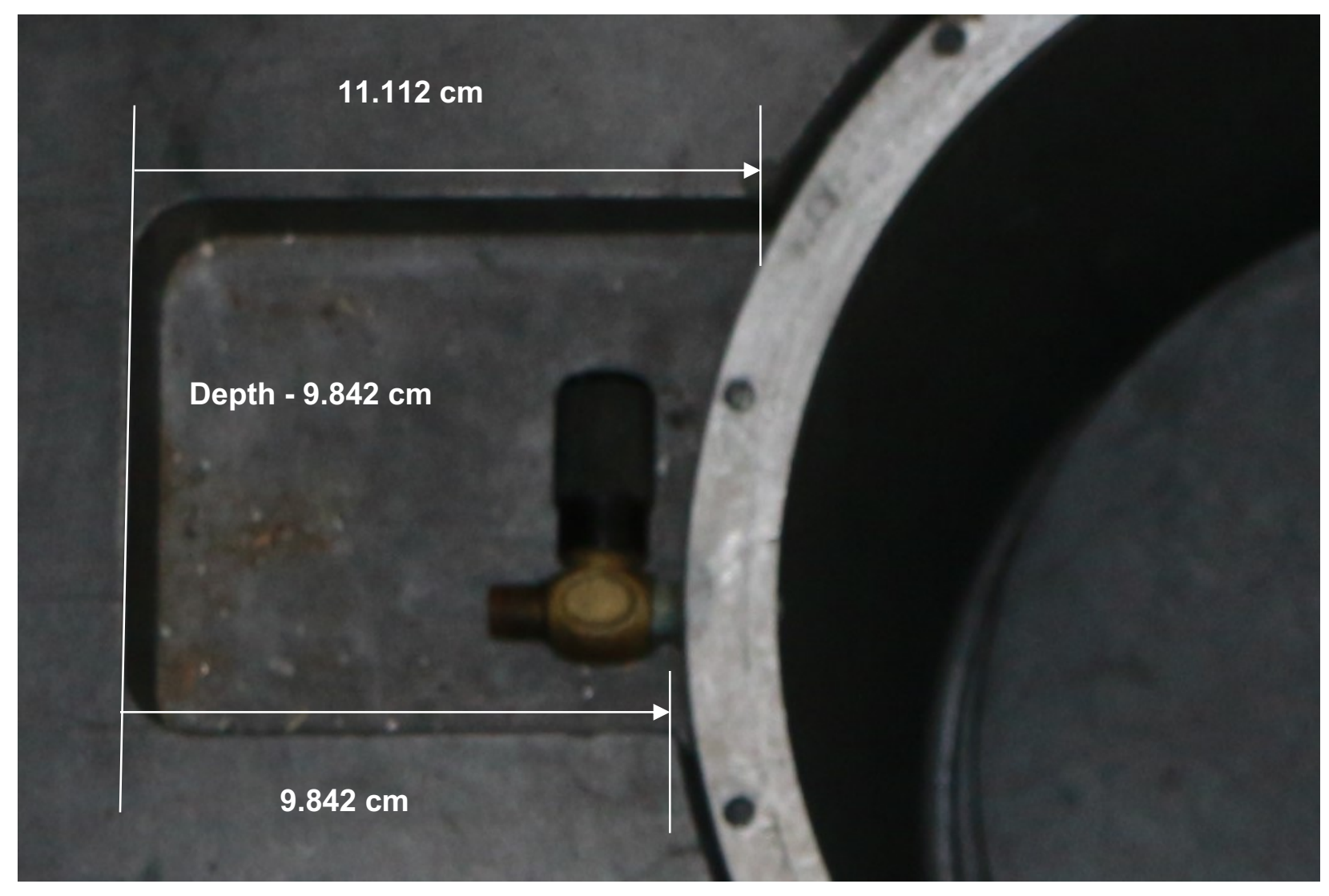

Figure 5-3. Valve cutout in fixed graphite reflector.

During the final assembly, several additional measurements were taken. The upper surface of the top graphite reflector was $13.44 \mathrm{~mm}$ below the top of the core tank. The top of the cover plate was about $0.5 \mathrm{~mm}$ below the top of the graphite fixed reflector. This allows for space for the bolt heads which attach the top cover plate to the core tank.

The core tank is made of 6061-T6 aluminum and has a wall thickness of $0.160 \mathrm{~cm}$. The outside diameter is $31.75 \mathrm{~cm}$ and the mass of the core tank shown in Figure $5-4$ is $4.35 \mathrm{~kg}$.
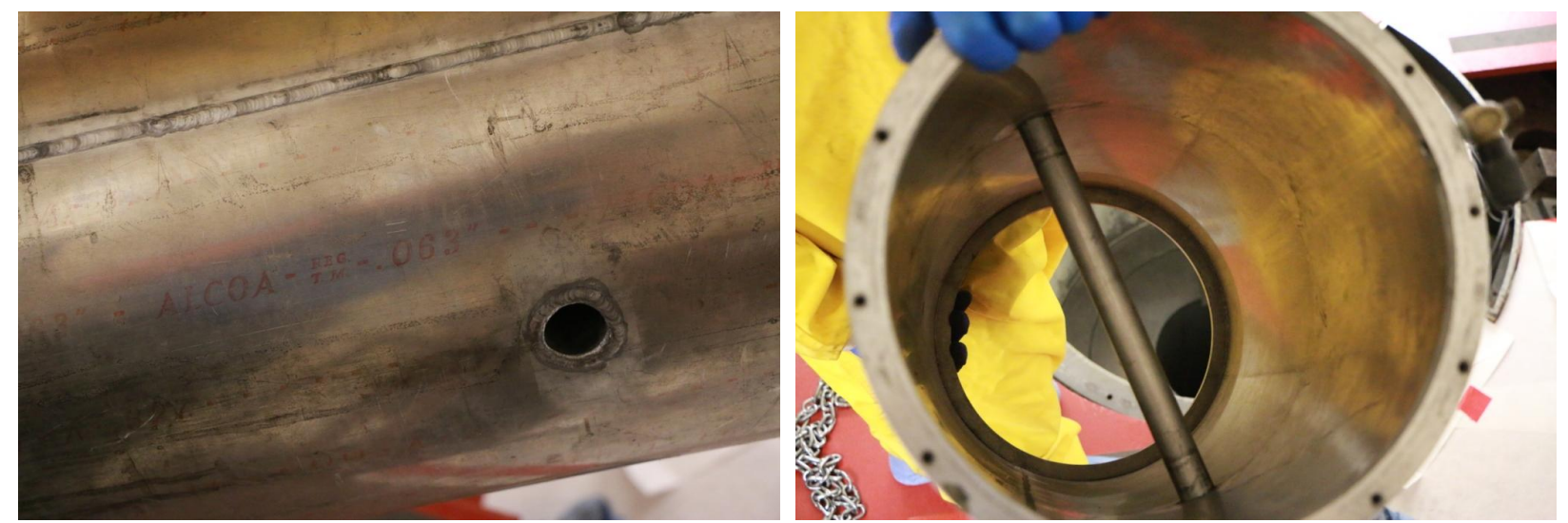

Figure 5-4. Core tank. 
The support rod is a solid $1.27 \mathrm{~cm}(0.5 \mathrm{inch})$ diameter 6061 aluminum rod which is threaded into the bottom core tank cover. The rod is $14{ }^{17} / 32$ inches $(36.909 \mathrm{~cm})$ measured from the top of the rod to the top surface of bottom cover plate.

The core tank wall is 0.093 inch $(0.236 \mathrm{~cm})$ thick sheet 6061 aluminum with an inside diameter is $12 \mathrm{3} / 8$ inches $(31.432 \mathrm{~cm})$. The mass of the tank including top and bottom flanges and glory hole guide is $9 \mathrm{lb}$ $9.5 \mathrm{oz}(435.2 \mathrm{~g})$.

\subsection{STACK-UP OF THE CORE PARTS}

A stacked set was created using the data provided in the previous section. The top half of the core consists of top graphite shells, the top six fuel disks (204100-204105), the top graphite reflector, and the baffle plates.

It is assumed that the baffle plate is centered on the centerline of the glory hole. The baffle plates rest on the top of fuel disk 20499. The exact position of the top of the bottom half of the core was not measured when it was assembled. The assumption is reasonable since the top half of the core cannot extend much lower than the centerline of the glory hole since the cutouts in the fuel and graphite shells would rest on the glory hole.

It is also assumed that the top graphite reflector is resting on the lip of the graphite shells, since the outside diameter of the top graphite reflector is the same as the inside diameter of the top graphite shells at the top of the lip on the shells.

The characteristics of the stack-up are shown in Table 5-12. An as-built sketch with dimensions for the top half of the core is shown in Figure 5-5.

Table 5-12. Stack-up of the upper half of the core

\begin{tabular}{lc}
\hline Location & $\begin{array}{c}\text { Height from } \\
\text { midline (cm) }\end{array}$ \\
\hline Top of graphite reflector & 33.029 \\
Top of shell & 32.959 \\
Bottom surface of top graphite reflector & 12.960 \\
Top of 204105 & 12.156 \\
Top of 204104 & 11.116 \\
Top of 204103 & 10.040 \\
Top of 204102 & 8.036 \\
Top of 204101 & 6.030 \\
Top of 204100 & 4.008 \\
Top of lip on shell & 1.517 \\
Top of baffle plate & 0.041 \\
Midline & 0.000 \\
\hline
\end{tabular}




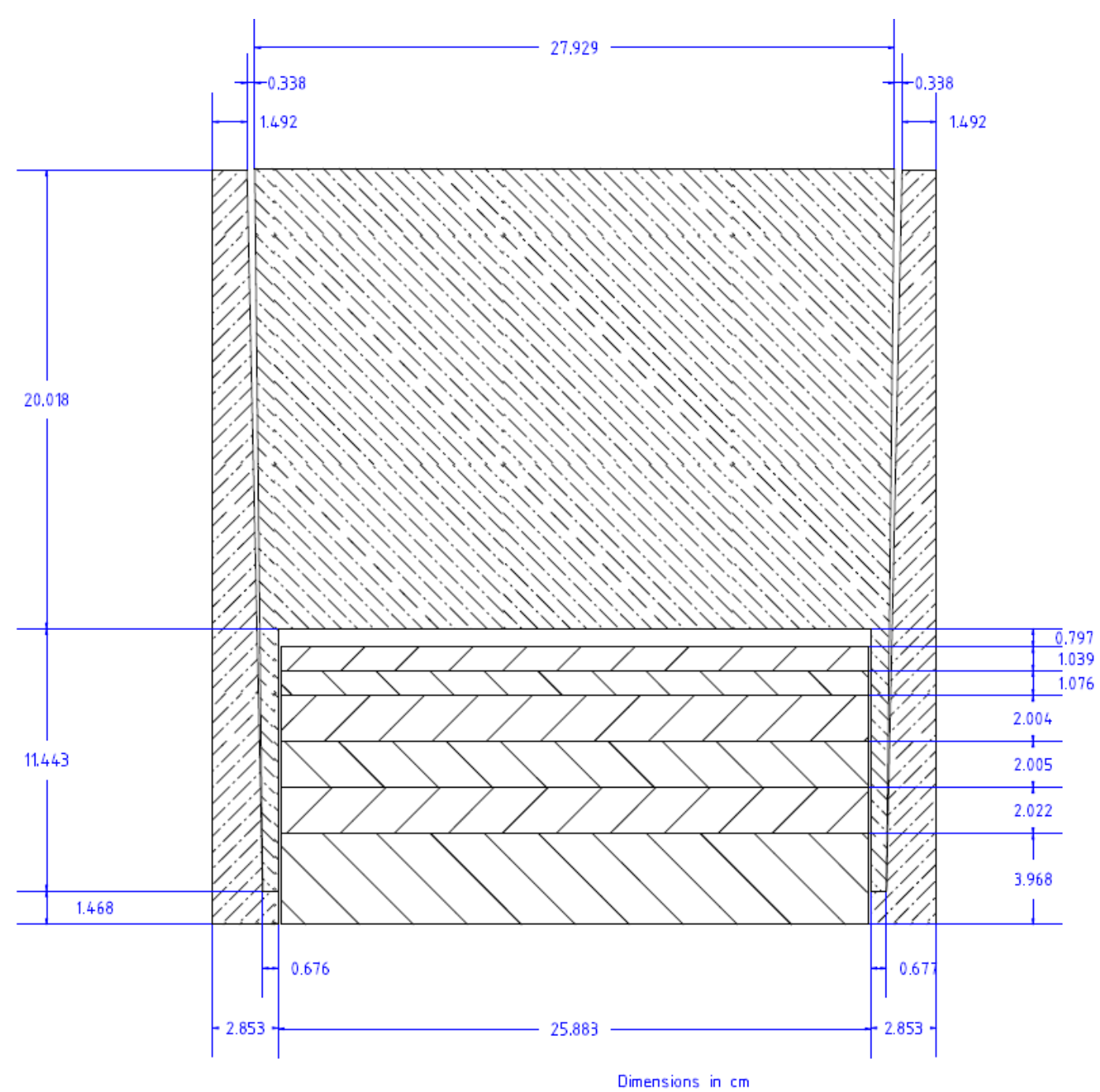

Figure 5-5. Upper half of the stack-up.

The bottom half of the core consists of the bottom shells, the bottom graphite reflector, fuel disks 2049720499, the thermal fuse, the fuse thimble, and the support rod. Unlike the top half, the bottom half fuel disks and bottom graphite reflector are kept in contact by the fuse thimble and a nut threaded onto the thimble at the bottom. The distance between the top of fuel disk 20499 and the top half of the core is controlled by the length of the support rod threaded into the bottom core tank cover. The support rod extends up through the fuse thimble, making contact with the thermal fuse. An as-built sketch of the fuse thimble is provided in Figure 5-6. 

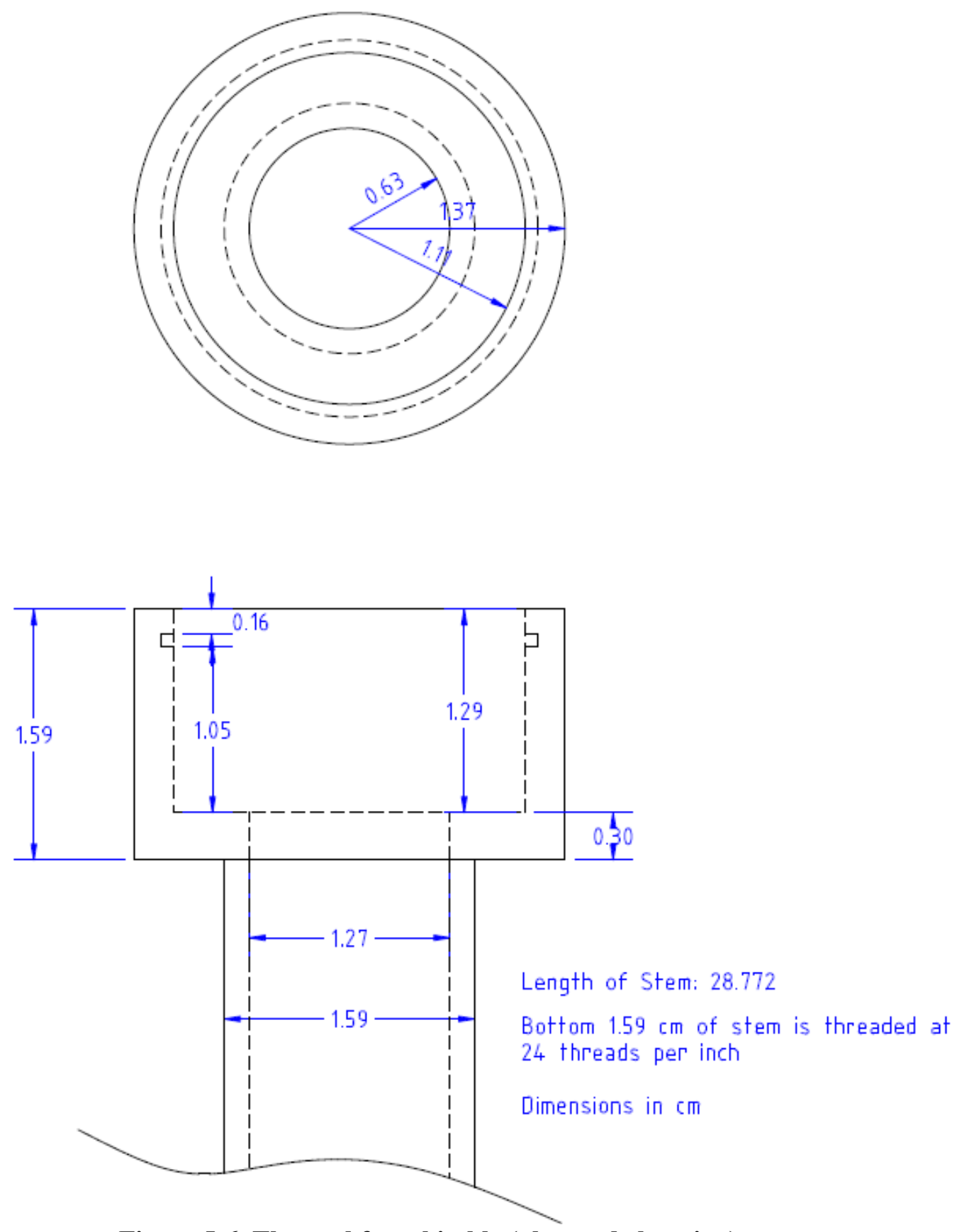

Figure 5-6. Thermal fuse thimble (plan and elevation).

The stack-up for the lower half of the core is shown in 
Table 5-13, and an as-built sketch of the bottom half is shown in Figure 5-7. 
Table 5-13. Stack up of the bottom half of the core

\begin{tabular}{lc}
\hline Location & Height from midline (cm) \\
\hline Midline of the baffle plate & 37.093 \\
Top of 20499 & 37.152 \\
Top of bottom graphite reflector & 37.100 \\
Top of 20498 & 33.158 \\
Top of 20497 & 29.153 \\
Bottom inside surface of the bottom graphite reflector & 25.171 \\
Bottom of graphite reflector & 5.071 \\
Bottom of the lower graphite shells & 0 \\
\hline
\end{tabular}

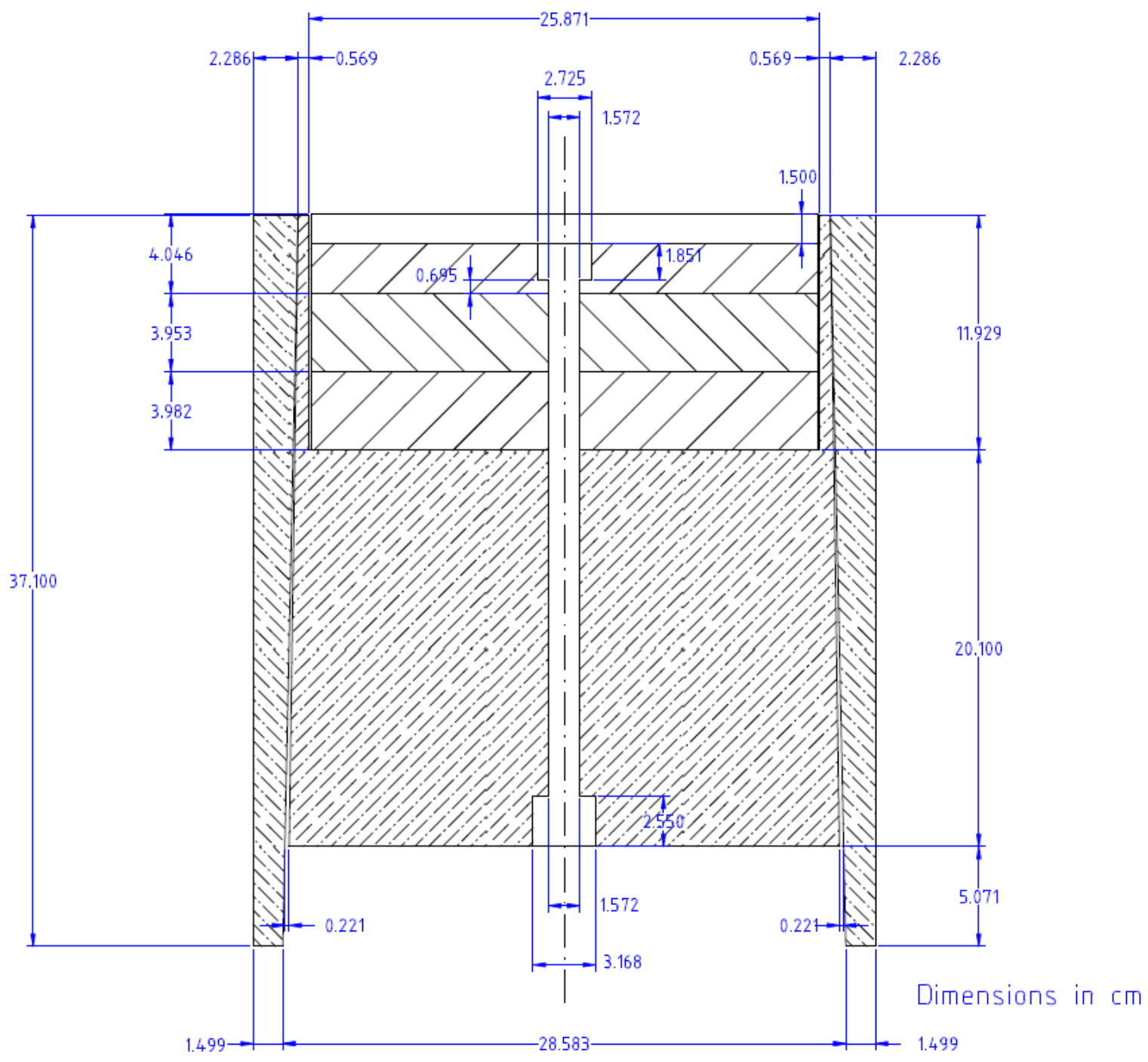

Figure 5-7. Bottom half stack up

An as-built sketch of the bottom graphite reflector is shown in Figure 5.8. 

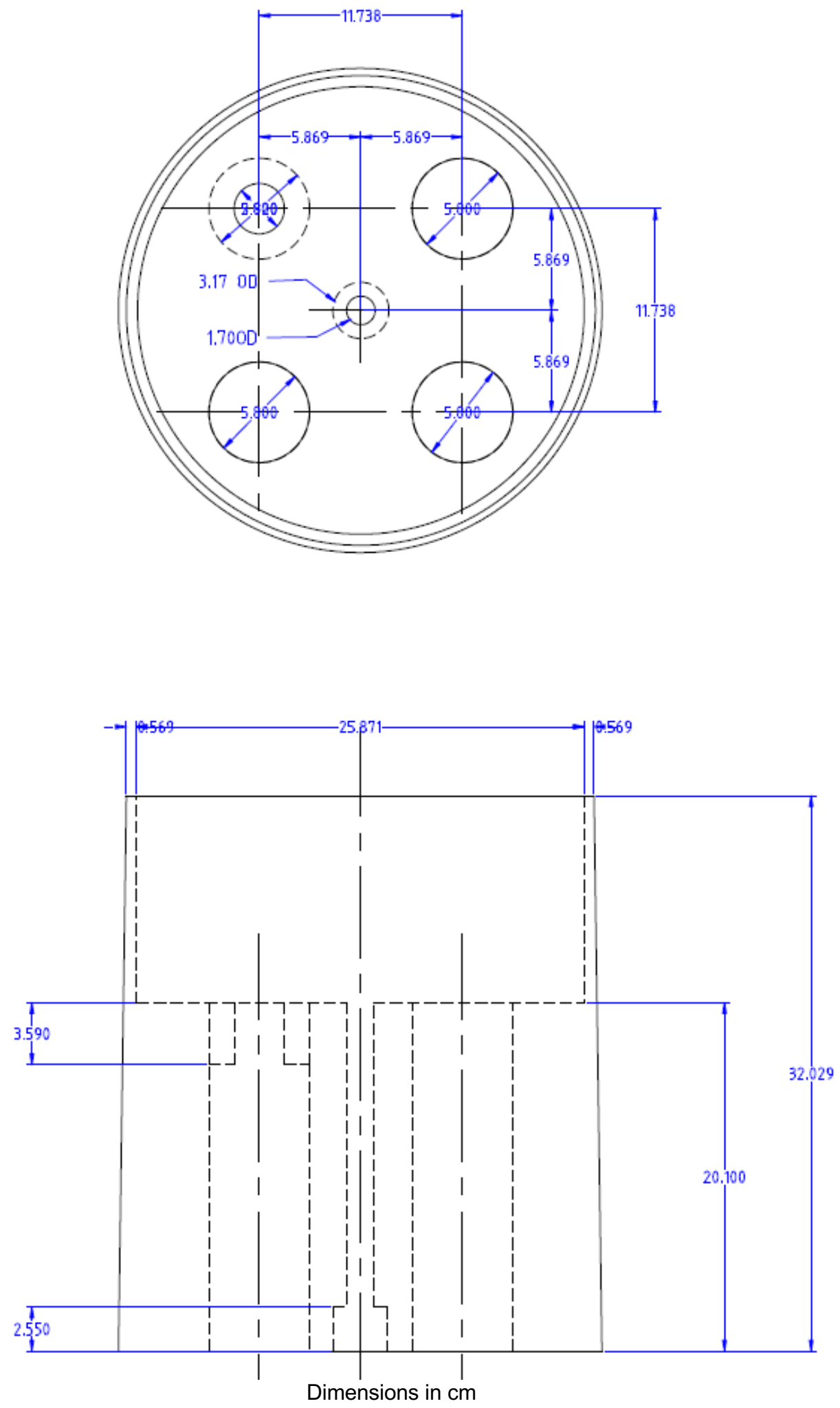

Figure 5-8. Bottom graphite reflector (plan and elevation views). 


\section{CHEMICAL ANALYSIS}

Chemical analysis was performed on the graphite, polyethylene and lead pieces from the University of Utah reactor which has been decommissioned. The lead, polyethylene, and graphite are still at the University of Utah (AGN-201-110).

Table 6-1. Chemical analysis from the University of Utah parts

\begin{tabular}{|c|c|c|c|c|c|c|c|}
\hline & $\mathbf{P b}$ & Poly & Graphite & & $\mathbf{P b}$ & Poly & Graphite \\
\hline Element & ppm & ppm & ppm & Element & ppm & ppm & ppm \\
\hline $\mathrm{Li}$ & $<1$ & $<1$ & 6.1 & $\mathrm{Pd}$ & $<1$ & $<1$ & $<0.05$ \\
\hline $\mathrm{Be}$ & $<1$ & $<1$ & $<0.05$ & $\mathrm{Ag}$ & $<1$ & 3 & $<0.05$ \\
\hline $\mathrm{B}$ & $<1$ & $<1$ & 4.5 & $\mathrm{Cd}$ & $<1$ & $<1$ & 0.09 \\
\hline $\mathrm{C}$ & - & - & Matrix & In & $<1$ & $<1$ & $<0.05$ \\
\hline $\mathrm{N}$ & - & 13 & 32 & $\mathrm{Sn}$ & $<1$ & $<1$ & 0.05 \\
\hline $\mathrm{O}$ & - & - & 700 & $\mathrm{Sb}$ & $<1$ & 41 & $<0.05$ \\
\hline $\mathrm{F}$ & - & - & $<0.1$ & $\mathrm{Te}$ & $<1$ & $<1$ & $<0.05$ \\
\hline $\mathrm{Na}$ & $<10$ & $<10$ & 24 & I & - & - & $<0.01$ \\
\hline $\mathrm{Mg}$ & 2 & $<1$ & 5.7 & $\mathrm{Cs}$ & $<1$ & $<1$ & $<0.05$ \\
\hline $\mathrm{Al}$ & 3 & $<1$ & 10 & $\mathrm{Ba}$ & $<1$ & $<1$ & 0.06 \\
\hline $\mathrm{Si}$ & $<25$ & $<25$ & 110 & $\mathrm{La}$ & $<1$ & $<1$ & $<0.05$ \\
\hline $\mathrm{P}$ & $<10$ & $<10$ & 6.2 & $\mathrm{Ce}$ & $<1$ & $<1$ & $<0.05$ \\
\hline $\mathrm{S}$ & - & - & 370 & $\operatorname{Pr}$ & $<1$ & $<1$ & $<0.05$ \\
\hline $\mathrm{Cl}$ & - & - & 11 & $\mathrm{Nd}$ & $<1$ & $<1$ & $<0.05$ \\
\hline $\mathrm{K}$ & $<10$ & $<10$ & 2 & $\mathrm{Sm}$ & $<1$ & $<1$ & $<0.01$ \\
\hline $\mathrm{Ca}$ & $<10$ & 25 & 400 & $\mathrm{Eu}$ & $<1$ & $<1$ & $<0.01$ \\
\hline $\mathrm{Sc}$ & $<1$ & $<1$ & 0.03 & $\mathrm{Gd}$ & $<1$ & $<1$ & $<0.01$ \\
\hline $\mathrm{Ti}$ & $<1$ & $<1$ & 14 & $\mathrm{~Tb}$ & $<1$ & $<1$ & $<0.01$ \\
\hline $\mathrm{V}$ & $<1$ & $<1$ & 280 & Dy & $<1$ & $<1$ & $<0.01$ \\
\hline $\mathrm{Cr}$ & 2 & $<1$ & 12 & Ho & $<1$ & $<1$ & $<0.01$ \\
\hline $\mathrm{Mn}$ & $<1$ & $<1$ & 0.13 & $\mathrm{Er}$ & $<1$ & $<1$ & $<0.01$ \\
\hline $\mathrm{Fe}$ & 13 & 140 & 17 & $\mathrm{Tm}$ & $<1$ & $<1$ & $<0.01$ \\
\hline Co & $<1$ & $<1$ & 0.03 & $\mathrm{Yb}$ & $<1$ & $<1$ & $<0.01$ \\
\hline $\mathrm{Ni}$ & 2 & $<1$ & 1.7 & $\mathrm{Lu}$ & $<1$ & $<1$ & $<0.01$ \\
\hline $\mathrm{Cu}$ & $<1$ & 120 & 1.3 & $\mathrm{Hf}$ & $<1$ & $<1$ & $<0.01$ \\
\hline $\mathrm{Zn}$ & $<1$ & $<1$ & 1.6 & $\mathrm{Ta}$ & $<1$ & $<1$ & $<100$ \\
\hline $\mathrm{Ga}$ & $<1$ & $<1$ & $<0.01$ & $\mathrm{~W}$ & $<1$ & $<1$ & 0.44 \\
\hline $\mathrm{Ge}$ & $<1$ & $<1$ & $<0.05$ & $\mathrm{Re}$ & $<1$ & $<1$ & $<0.01$ \\
\hline As & $<1$ & $<1$ & 0.06 & Os & $<1$ & $<1$ & $<0.01$ \\
\hline $\mathrm{Se}$ & $<1$ & $<1$ & $<0.05$ & $\mathrm{Ir}$ & $<1$ & $<1$ & $<0.01$ \\
\hline $\mathrm{Br}$ & - & - & $<0.1$ & $\mathrm{Pt}$ & $<1$ & $<1$ & $<0.01$ \\
\hline $\mathrm{Rb}$ & $<1$ & $<1$ & $<0.05$ & $\mathrm{Au}$ & $<1$ & $<1$ & $<0.1$ \\
\hline $\mathrm{Sr}$ & $<1$ & $<1$ & 2.8 & $\mathrm{Hg}$ & $<1$ & $<1$ & $<0.1$ \\
\hline $\mathrm{Y}$ & $<1$ & $<1$ & 0.12 & $\mathrm{Tl}$ & $<1$ & $<1$ & $<0.05$ \\
\hline $\mathrm{Zr}$ & $<1$ & $<1$ & 0.27 & $\mathrm{~Pb}$ & 5 & Matrix & 41 \\
\hline $\mathrm{Nb}$ & $<1$ & $<1$ & 0.09 & $\mathrm{Bi}$ & $<1$ & $<300$ & $<0.05$ \\
\hline Mo & $<1$ & $<1$ & 0.39 & Th & $<1$ & $<1$ & $<0.05$ \\
\hline $\mathrm{Ru}$ & $<1$ & $<1$ & $<0.05$ & $\mathrm{U}$ & $<1$ & $<1$ & $<0.05$ \\
\hline $\mathrm{Rh}$ & $<1$ & $<10$ & $<0.01$ & & & & \\
\hline
\end{tabular}


Two fuel samples were analyzed from the Idaho State University (ISU) AGN-201 reactor. The background on the source of the pieces is described in a master's thesis by Mackenzie Gorman [7].

To reduce uncertainty in the composition and to determine the content of impurities in the fuel, a mass spectroscopy analysis was performed using two samples of fuel shavings stored the Reactor Laboratory. These shavings are from the machining of the safety rod fuel pellets that were cut to $1 \mathrm{~cm}$ thickness to insert in the core disk. The analysis on both samples was performed at the Materials and Fuel Complex of the Idaho National Laboratory. The mass spectroscopy analysis determined the isotopic weight percents of the ${ }^{234} \mathrm{U},{ }^{235} \mathrm{U},{ }^{236} \mathrm{U}$, and ${ }^{238} \mathrm{U}$ isotopes. Inductively coupled plasma mass spectroscopy (ICP-MS) was also performed to determine the impurities present in the fuel. Both methods were used on the two samples, for a total of four composition analyses.

Gorman included the analysis reports which were provided by INL [8], [9] in her thesis, The results are provided in Table 6-2 and Table 6-3.

Table 6-2. Mass spectroscopy results of ISU fuel samples

\begin{tabular}{c|ccc|ccc}
\hline \multirow{2}{*}{ Isotope } & \multicolumn{3}{|c|}{ Sample 1 } & \multicolumn{3}{c}{ Sample 2 } \\
\cline { 2 - 7 } & Results & Units & 2 sigma error & Results & Units & 2 sigma error \\
\hline U total & 5847 & ug/sample & $0.50 \%$ & 6570 & ug/sample & $0.50 \%$ \\
${ }^{234} \mathrm{U}$ & 0.119 & $\mathrm{wt} \%$ & $2 \%$ & 0.118 & $\mathrm{wt} \%$ & $2 \%$ \\
${ }^{235} \mathrm{U}$ & 19.81 & $\mathrm{wt} \%$ & $0.50 \%$ & 19.73 & $\mathrm{wt} \%$ & $0.50 \%$ \\
${ }^{236} \mathrm{U}$ & 0.208 & $\mathrm{wt} \%$ & $2 \%$ & 0.208 & $\mathrm{wt} \%$ & $2 \%$ \\
${ }^{238} \mathrm{U}$ & 79.87 & $\mathrm{wt} \%$ & $0.50 \%$ & 79.95 & $\mathrm{wt} \%$ & $0.50 \%$ \\
\hline
\end{tabular}

Table 6-3. ICP-MS results of ISU fuel samples

\begin{tabular}{c|ccc|ccc}
\hline \multirow{2}{*}{ Isotope } & \multicolumn{3}{c|}{ Sample 1 } & \multicolumn{3}{c}{ Sample 2 } \\
\cline { 2 - 6 } & Results & Units & 2 sigma error & Results & Units & 2 sigma error \\
\hline${ }^{234} \mathrm{U}$ & 0.118 & $\mathrm{wt} \%$ & $4 \%$ & 0.117 & $\mathrm{wt} \%$ & $4 \%$ \\
${ }^{235} \mathrm{U}$ & 19.8 & $\mathrm{wt} \%$ & $1 \%$ & 19.71 & $\mathrm{wt} \%$ & $1 \%$ \\
${ }^{236} \mathrm{U}$ & 0.207 & $\mathrm{wt} \%$ & $4 \%$ & 0.208 & $\mathrm{wt} \%$ & $4 \%$ \\
${ }^{238} \mathrm{U}$ & 79.88 & $\mathrm{wt} \%$ & $1 \%$ & 79.96 & $\mathrm{wt} \%$ & $1 \%$ \\
$\mathrm{Al}$ & 23 & $\mu \mathrm{g} / \mathrm{sample}$ & $10 \%$ & 31.4 & $\mu \mathrm{g} / \mathrm{sample}$ & $10 \%$ \\
$\mathrm{Cd}$ & 0.1 & $\mu \mathrm{g} / \mathrm{sample}$ & $10 \%$ & 0.405 & $\mu \mathrm{g} / \mathrm{sample}$ & $10 \%$ \\
$\mathrm{Cr}$ & $<3$ & $\mu \mathrm{g} / \mathrm{sample}$ & $\mathrm{N} / \mathrm{A}$ & $<3$ & $\mu \mathrm{g} / \mathrm{sample}$ & $\mathrm{N} / \mathrm{A}$ \\
$\mathrm{Er}$ & $<0.04$ & $\mu \mathrm{g} / \mathrm{sample}$ & $\mathrm{N} / \mathrm{A}$ & $<0.04$ & $\mu \mathrm{g} / \mathrm{sample}$ & $\mathrm{N} / \mathrm{A}$ \\
$\mathrm{Gd}$ & $<0.04$ & $\mu \mathrm{g} / \mathrm{sample}$ & $\mathrm{N} / \mathrm{A}$ & $<0.04$ & $\mu \mathrm{g} / \mathrm{sample}$ & $\mathrm{N} / \mathrm{A}$ \\
$\mathrm{Mn}$ & 0.212 & $\mu \mathrm{g} / \mathrm{sample}$ & $10 \%$ & 0.41 & $\mu \mathrm{g} / \mathrm{sample}$ & $10 \%$ \\
$\mathrm{Mo}$ & $<10$ & $\mu \mathrm{g} / \mathrm{sample}$ & $\mathrm{N} / \mathrm{A}$ & $<10$ & $\mu \mathrm{g} / \mathrm{sample}$ & $\mathrm{N} / \mathrm{A}$ \\
$\mathrm{Ni}$ & 1.63 & $\mu \mathrm{g} / \mathrm{sample}$ & $10 \%$ & 2.6 & $\mu \mathrm{g} / \mathrm{sample}$ & $10 \%$ \\
$\mathrm{Sm}$ & $<0.01$ & $\mu \mathrm{g} / \mathrm{sample}$ & $\mathrm{N} / \mathrm{A}$ & $<0.01$ & $\mu \mathrm{g} / \mathrm{sample}$ & $\mathrm{N} / \mathrm{A}$ \\
$\mathrm{Ti}$ & 8 & $\mu \mathrm{g} / \mathrm{sample}$ & $10 \%$ & 9.49 & $\mu \mathrm{g} / \mathrm{sample}$ & $10 \%$ \\
$\mathrm{U}$ total & 5,864 & $\mu \mathrm{g} / \mathrm{sample}$ & $1 \%$ & 6,601 & $\mu \mathrm{g} / \mathrm{sample}$ & $1 \%$ \\
\hline
\end{tabular}


Using the four measurements of the uranium isotopic compositions, the average values and the propagated uncertainties were calculated and are given in Table 6-4.

Table 6-4. Average values of the uranium isotopic composition

\begin{tabular}{c|ccc}
\hline Isotope & Average & Units & Propagated 2 sigma error \\
\hline${ }^{234} \mathrm{U}$ & 0.118 & $\mathrm{wt} \%$ & $6.32 \%$ \\
${ }^{235} \mathrm{U}$ & 19.763 & $\mathrm{wt} \%$ & $1.58 \%$ \\
${ }^{236} \mathrm{U}$ & 0.208 & $\mathrm{wt} \%$ & $6.32 \%$ \\
${ }^{238} \mathrm{U}$ & 79.912 & $\mathrm{wt} \%$ & $1.58 \%$ \\
\hline
\end{tabular}

\section{NDA DATA}

A summary of the enrichment and ${ }^{235} \mathrm{U}$ mass based on the NDA analysis performed by Sandia National Laboratories [11] is provided in Table 7-1. The enrichment was estimated by the ratio of the $185 \mathrm{keV}$ to $1001 \mathrm{keV}$ peaks. The ${ }^{235} \mathrm{U}$ mass is based on the $185 \mathrm{keV}$ peak.

Table 7-1. Summary of Sandia NDA measurements

\begin{tabular}{|c|c|c|c|c|c|c|c|}
\hline \multirow[b]{2}{*}{ Item } & \multicolumn{4}{|c|}{ Enrichment } & \multicolumn{3}{|c|}{ Mass } \\
\hline & $\begin{array}{c}(185 \mathrm{keV} / \\
63 \mathrm{keV}) \\
\end{array}$ & $\begin{array}{c}\text { Abs. Unc. } \\
(1 \sigma)\end{array}$ & $\begin{array}{l}(185 \mathrm{keV} / \\
1001 \mathrm{keV})\end{array}$ & $\begin{array}{c}\text { Abs. Unc. } \\
(1 \sigma)\end{array}$ & $\begin{array}{c}{ }^{235} \text { U Mass } \\
(\mathrm{g})\end{array}$ & $\begin{array}{c}\text { Mass Unc. } \\
(1 \sigma)\end{array}$ & $\begin{array}{c}\text { Known } \\
\text { mass }\end{array}$ \\
\hline 105 & $27.18 \%$ & $3.85 \%$ & $19.02 \%$ & $2.07 \%$ & 31.31 & 3.13 & 29.79 \\
\hline 104 & $27.54 \%$ & $3.90 \%$ & $19.92 \%$ & $2.17 \%$ & 31.28 & 3.13 & 30.8 \\
\hline 103 & $30.99 \%$ & $4.39 \%$ & $19.55 \%$ & $2.12 \%$ & 61.26 & 6.13 & 58.05 \\
\hline 102 & $26.35 \%$ & $3.73 \%$ & $21.42 \%$ & $2.35 \%$ & 62.91 & 6.29 & 58.07 \\
\hline 101 & $28.25 \%$ & $4.00 \%$ & $18.99 \%$ & $2.07 \%$ & 62.62 & 6.26 & 58.01 \\
\hline 100 & $30.30 \%$ & $4.29 \%$ & $18.64 \%$ & $2.03 \%$ & 109.93 & 10.99 & 94.39 \\
\hline 99 & $28.62 \%$ & $4.06 \%$ & $19.26 \%$ & $2.09 \%$ & 107.02 & 10.70 & 93.17 \\
\hline 98 & $29.04 \%$ & $4.12 \%$ & $18.83 \%$ & $2.05 \%$ & 111.41 & 11.14 & 99.12 \\
\hline 97 & $29.97 \%$ & $4.25 \%$ & $19.79 \%$ & $2.15 \%$ & 116.92 & 11.69 & 98.89 \\
\hline CCR & $25.42 \%$ & $3.60 \%$ & $18.99 \%$ & $2.05 \%$ & 17.47 & 1.75 & 14.51 \\
\hline SR1 & $27.15 \%$ & $3.84 \%$ & $17.94 \%$ & $1.94 \%$ & 17.46 & 1.75 & 14.51 \\
\hline SR2 & $27.57 \%$ & $3.90 \%$ & $18.99 \%$ & $2.05 \%$ & 17.74 & 1.77 & 14.5 \\
\hline FCR & $26.33 \%$ & $3.73 \%$ & $19.21 \%$ & $2.10 \%$ & 3.03 & 0.30 & 2.71 \\
\hline FP & $24.17 \%$ & $3.42 \%$ & $19.79 \%$ & $2.13 \%$ & 20.04 & 2.00 & ----- \\
\hline UTAH & $38.25 \%$ & $5.50 \%$ & $33.22 \%$ & $4.15 \%$ & 0.60 & 0.06 & 0.438 \\
\hline UNM & $29.10 \%$ & $4.16 \%$ & $41.33 \%$ & $5.44 \%$ & 0.60 & 0.06 & ----- \\
\hline
\end{tabular}

FP - fission plate 


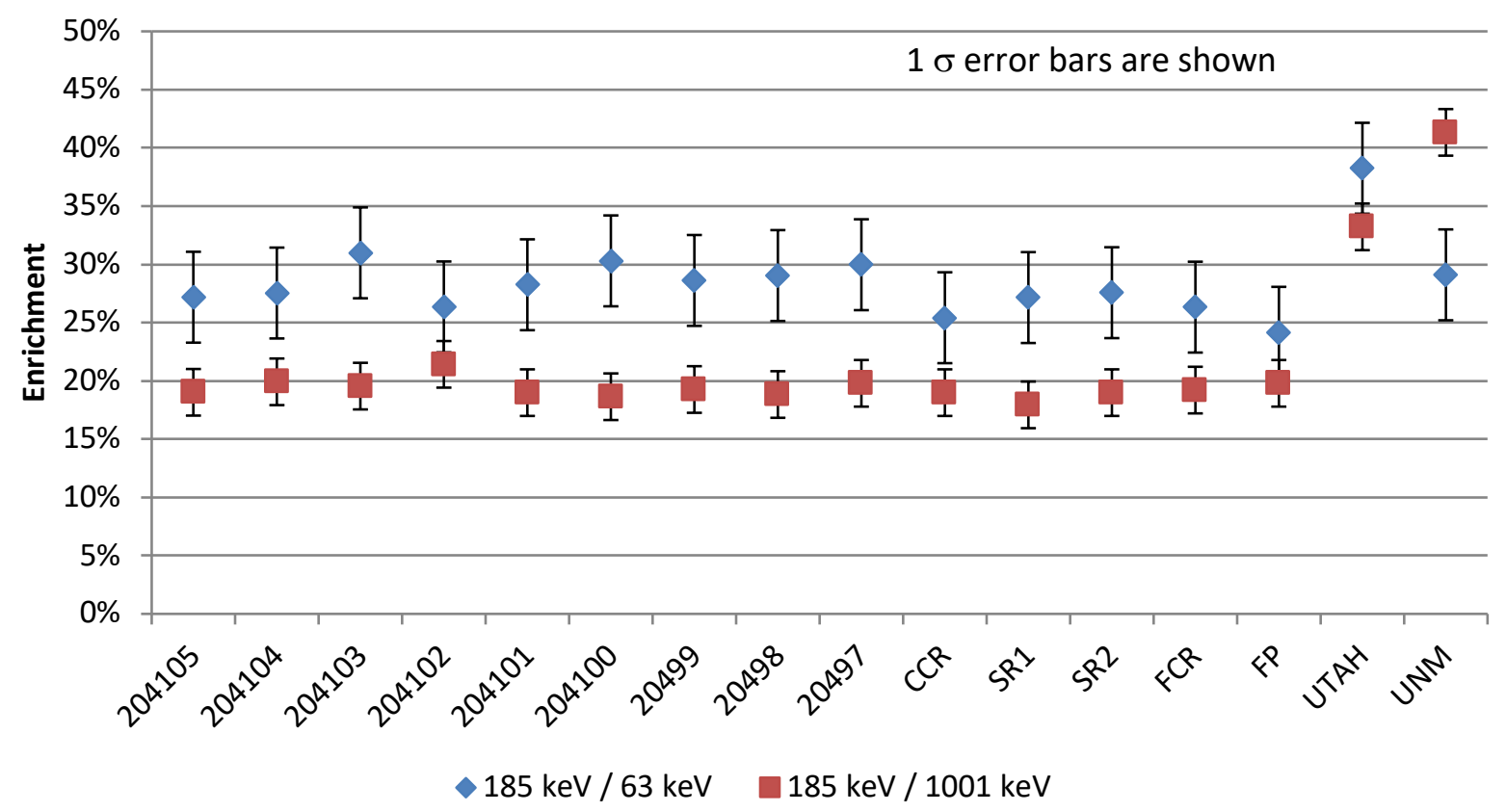

Figure 7-1. Enrichment as estimated by NDA.

The enrichment estimates are significantly higher based on 185 to $63 \mathrm{keV}$ ratio than when based on the $185 \mathrm{keV}$ to $1001 \mathrm{keV}$ ratio. For the disks, the 185 to $1001 \mathrm{keV}$ estimate is within one standard deviation of the design specification. For the fuses, this is a good measurement of the ${ }^{238} \mathrm{U}$. The counting statistics for the ${ }^{238} \mathrm{U}$, however, were poor due to the higher loading of fissions products, specifically La/Ba- 140 . The higher fission rate in the fuse is due to the higher uranium density. The ${ }^{235} \mathrm{U}$ mass estimates are compared against the stated values in Figure 7-2.

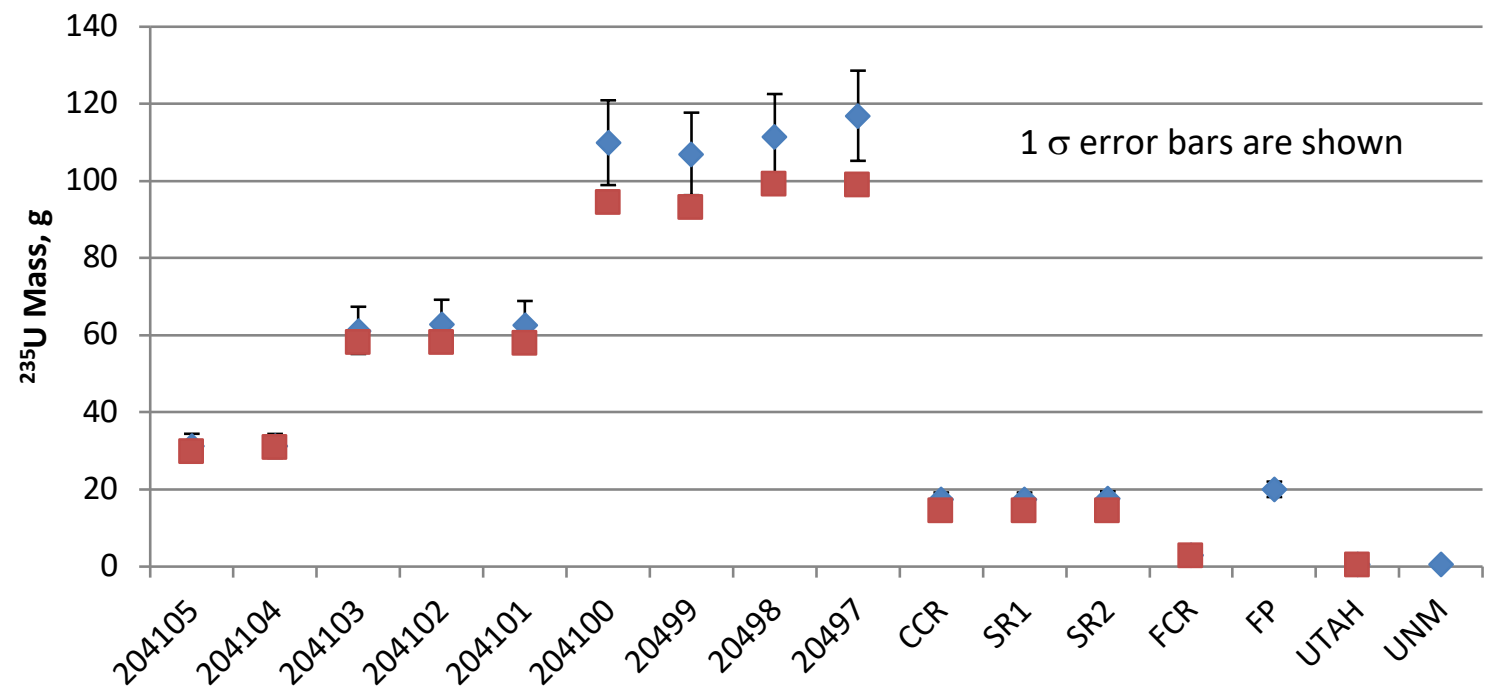

$\Delta$ Est. $235 \mathrm{U}$ mass $\quad$ Stated $235 \mathrm{U}$ mass

Figure 7-2. Estimated ${ }^{235} \mathrm{U}$ mass. 
The ${ }^{235} \mathrm{U}$ mass estimates are within two standard deviations of the stated mass values. The thicker fuel disks (20497-204100) tend have higher ${ }^{235} \mathrm{U}$ mass estimates, presumably due to having higher ${ }^{235} \mathrm{U}$ loading, so as a result, they have more total fission products. The NDA gave confidence to the original mass and enrichment values.

\section{RECOMMENDATION FOR MODELING}

\subsection{FUEL PARTS}

The best estimate of the ${ }^{235} \mathrm{U}$ loading for the fuel disks, control rods, and fuse is provided in the Reactor Operation and Training Manual [1], as shown in Table 1-1. The uranium isotopic data from the ISU AGN should be used as the source for the isotopic composition of the uranium. The average values are provided in Table 6-4. Based on this data, as well as the assumption that the uranium form is all $\mathrm{UO}_{2}$, along with the physical dimensions and total mass of the pieces, the recommended composition for the fuel pieces is given in Table 8-1.

\subsection{GRAPHITE}

The best estimate of the graphite density is based on the average of the top and bottom graphite reflectors, as given in Table 5-5. The best estimate of the density is $1.762 \mathrm{~g} / \mathrm{cm}^{3}$. The dimensions for the graphite reflectors and the removable shells should be taken from information provided in Figure 5-5 through

Figure 5-8. It should be noted that when assembled, gaps can be seen between the shells and is assumed the gaps would exist over the entire height of the shells. The shells do overlap, so there is not a streaming path. The effect of a gap would reduce the effective density of the graphite in that area. As discussed earlier, the gaps reduce the volume of the graphite shell by $1.0 \%$ over a solid annulus. Based on this, the graphite density should be reduced to $1.74 \mathrm{~g} / \mathrm{cm}^{3}$ if the gaps are not explicitly modeled.

\subsection{CONTROL RODS}

\subsubsection{Fine Control Rod}

Based on the information for the fuel disks that were installed in the fine control rod in 1968, the diameter of the fuel disks is $2.316 \mathrm{~cm}$, with a height of $4.008 \mathrm{~cm}$. Three of these fuel disks were installed. Since the order of installation is not known, the best assumption is to uniformly distribute the fuel over the volume as shown in Table 8-1. The lowest disk in the rod is polyethylene, which has a diameter of $2.311 \mathrm{~cm}$ and is $4.013 \mathrm{~cm}$ long.

\subsubsection{Course and Safety Control Rods}

The larger rods are assumed to have fuel disks that have a diameter of $4 \mathrm{~cm}$ and are $4 \mathrm{~cm}$ high. Since no physical measurements of the pieces were taken during this work, the assumed dimensions and mass values in Table 8-1 are used. 


\subsubsection{Aluminum Walls}

The outside diameters of the control rods and control rod guide tubes were directly measured. The outside diameters are reported above in Table 5-4 and Table 5-9. The fuel disks were encased in an aluminum can and then placed in the control rods. Assuming there is a gap of 0.005 inches $(0.0127 \mathrm{~cm})$ between metal surfaces, the thickness of the aluminum was calculated and is reported in Table 8.2.

Table 8-1. Recommended values for fuel part

\begin{tabular}{|c|c|c|c|c|c|c|c|}
\hline Part & ${ }^{234} \mathrm{U}, \mathrm{g}$ & ${ }^{235} \mathrm{U}, \mathrm{g}$ & ${ }^{236} \mathrm{U}, \mathrm{g}$ & ${ }^{238} \mathrm{U}, \mathrm{g}$ & $\mathbf{O}, \mathrm{g}$ & $\mathbf{H}, \mathbf{g}$ & $\mathrm{C}, \mathrm{g}$ \\
\hline 20497 & 0.590 & 98.890 & 1.040 & 399.872 & 67.435 & 1359.827 & 228.232 \\
\hline 20498 & 0.592 & 99.120 & 1.042 & 400.802 & 67.592 & 1365.090 & 229.115 \\
\hline 20499 & 0.556 & 93.170 & 0.979 & 376.743 & 63.535 & 1282.931 & 215.326 \\
\hline 204100 & 0.564 & 94.390 & 0.992 & 381.676 & 64.367 & 1298.419 & 217.925 \\
\hline 204101 & 0.346 & 58.010 & 0.610 & 234.570 & 39.558 & 802.630 & 134.713 \\
\hline 204102 & 0.347 & 58.070 & 0.610 & 234.812 & 39.599 & 801.233 & 134.478 \\
\hline 204103 & 0.347 & 58.050 & 0.610 & 234.731 & 39.586 & 800.515 & 134.358 \\
\hline 204104 & 0.184 & 30.800 & 0.324 & 124.543 & 21.003 & 427.210 & 71.703 \\
\hline 204105 & 0.178 & 29.790 & 0.313 & 120.459 & 20.315 & 413.306 & 69.369 \\
\hline UNM Fuse & 0.003 & 0.436 & 0.005 & 1.763 & 0.297 & 3.118 & 0.262 \\
\hline Utah Fuse & 0.003 & 0.438 & 0.005 & 1.771 & 0.299 & 3.141 & 0.264 \\
\hline SR1 & 0.087 & 14.510 & 0.153 & 58.673 & 9.895 & 199.046 & 33.408 \\
\hline SR2 & 0.087 & 14.500 & 0.152 & 58.632 & 9.888 & 198.889 & 33.381 \\
\hline $\mathrm{CCR}$ & 0.087 & 14.510 & 0.153 & 58.673 & 9.895 & 198.883 & 33.380 \\
\hline FCR & 0.016 & 2.710 & 0.028 & 10.958 & 1.848 & 25.928 & 4.352 \\
\hline Part & ${ }^{234} \mathrm{U}, \mathrm{g} / \mathrm{cm}^{3}$ & ${ }^{235} \mathrm{U}, \mathrm{g} / \mathrm{cm}^{3}$ & ${ }^{236} \mathrm{U}, \mathrm{g} / \mathrm{cm}^{3}$ & ${ }^{238} \mathrm{U}, \mathrm{g} / \mathrm{cm}^{3}$ & $\mathbf{O}, \mathbf{g} / \mathbf{c m}^{3}$ & $\mathrm{H}, \mathbf{g} / \mathrm{cm}^{3}$ & $\mathrm{C}, \mathrm{g} / \mathrm{cm}^{3}$ \\
\hline 20497 & $3.294 \mathrm{E}-04$ & $5.516 \mathrm{E}-02$ & $5.799 \mathrm{E}-04$ & $2.231 \mathrm{E}-01$ & $3.762 \mathrm{E}-02$ & $7.586 \mathrm{E}-01$ & $1.273 \mathrm{E}-01$ \\
\hline 20498 & $3.296 \mathrm{E}-04$ & $5.520 \mathrm{E}-02$ & 5.803E-04 & $2.232 \mathrm{E}-01$ & $3.764 \mathrm{E}-02$ & $7.603 \mathrm{E}-01$ & $1.276 \mathrm{E}-01$ \\
\hline 20499 & 3.307E-04 & $5.539 \mathrm{E}-02$ & $5.823 \mathrm{E}-04$ & $2.240 \mathrm{E}-01$ & $3.777 \mathrm{E}-02$ & $7.627 \mathrm{E}-01$ & $1.280 \mathrm{E}-01$ \\
\hline 204100 & $3.352 \mathrm{E}-04$ & $5.615 \mathrm{E}-02$ & $5.902 \mathrm{E}-04$ & $2.270 \mathrm{E}-01$ & $3.829 \mathrm{E}-02$ & 7.724E-01 & 1.296E-01 \\
\hline 204101 & $3.319 \mathrm{E}-04$ & $5.558 \mathrm{E}-02$ & $5.843 \mathrm{E}-04$ & $2.248 \mathrm{E}-01$ & $3.790 \mathrm{E}-02$ & 7.691E-01 & $1.291 \mathrm{E}-01$ \\
\hline 204102 & $3.352 \mathrm{E}-04$ & $5.614 \mathrm{E}-02$ & $5.901 \mathrm{E}-04$ & $2.270 \mathrm{E}-01$ & $3.828 \mathrm{E}-02$ & $7.745 \mathrm{E}-01$ & $1.300 \mathrm{E}-01$ \\
\hline 204103 & $3.351 \mathrm{E}-04$ & $5.612 \mathrm{E}-02$ & $5.899 \mathrm{E}-04$ & $2.269 \mathrm{E}-01$ & $3.827 \mathrm{E}-02$ & $7.739 \mathrm{E}-01$ & 1.299E-01 \\
\hline 204104 & $3.323 \mathrm{E}-04$ & $5.566 \mathrm{E}-02$ & $5.851 \mathrm{E}-04$ & $2.250 \mathrm{E}-01$ & $3.795 \mathrm{E}-02$ & $7.720 \mathrm{E}-01$ & $1.296 \mathrm{E}-01$ \\
\hline 204105 & $3.324 \mathrm{E}-04$ & $5.567 \mathrm{E}-02$ & $5.852 \mathrm{E}-04$ & $2.251 \mathrm{E}-01$ & $3.796 \mathrm{E}-02$ & 7.724E-01 & $1.296 \mathrm{E}-01$ \\
\hline UNM fuse & $7.126 \mathrm{E}-04$ & $1.193 \mathrm{E}-01$ & $1.255 \mathrm{E}-03$ & $4.826 \mathrm{E}-01$ & $8.139 \mathrm{E}-02$ & $8.535 \mathrm{E}-01$ & 7.163E-02 \\
\hline Utah fuse & $7.140 \mathrm{E}-04$ & $1.196 \mathrm{E}-01$ & $1.257 \mathrm{E}-03$ & $4.835 \mathrm{E}-01$ & $8.154 \mathrm{E}-02$ & $8.576 \mathrm{E}-01$ & 7.197E-02 \\
\hline SR1 & $3.405 \mathrm{E}-04$ & $5.702 \mathrm{E}-02$ & $5.994 \mathrm{E}-04$ & $2.306 \mathrm{E}-01$ & $3.888 \mathrm{E}-02$ & $7.822 \mathrm{E}-01$ & 1.313E-01 \\
\hline SR2 & $3.402 \mathrm{E}-04$ & $5.698 \mathrm{E}-02$ & $5.990 \mathrm{E}-04$ & $2.304 \mathrm{E}-01$ & $3.886 \mathrm{E}-02$ & 7.816E-01 & $1.312 \mathrm{E}-01$ \\
\hline $\mathrm{CCR}$ & $3.405 \mathrm{E}-04$ & $5.702 \mathrm{E}-02$ & $5.994 \mathrm{E}-04$ & $2.306 \mathrm{E}-01$ & $3.888 \mathrm{E}-02$ & 7.816E-01 & $1.312 \mathrm{E}-01$ \\
\hline FCR & $4.292 \mathrm{E}-04$ & $7.188 \mathrm{E}-02$ & 7.557E-04 & $2.907 \mathrm{E}-01$ & 4.902E-02 & $6.877 \mathrm{E}-01$ & $1.154 \mathrm{E}-01$ \\
\hline
\end{tabular}


Table 8-2. Calculated wall thickness for control $\operatorname{rod}(\mathrm{cm})$

\begin{tabular}{ccccccccc}
\hline Rod & Wall & Gap & Fuel OD & Can ID & $\begin{array}{c}\text { Estimated } \\
\text { can OD }\end{array}$ & Rod ID & Rod OD & $\begin{array}{c}\text { Measured } \\
\text { rod OD }\end{array}$ \\
\hline SR1 & 0.186 & 0.013 & 4.000 & 4.025 & 4.397 & 4.423 & 4.795 & 4.794 \\
SR2 & 0.186 & 0.013 & 4.000 & 4.025 & 4.397 & 4.423 & 4.795 & 4.794 \\
CCR & 0.186 & 0.013 & 4.000 & 4.025 & 4.397 & 4.423 & 4.795 & 4.796 \\
FCR & 0.041 & 0.013 & $2.316^{*}$ & 2.341 & 2.423 & 2.449 & 2.531 & 2.530 \\
\hline
\end{tabular}

* Actual based on 1968 measurements

Using the control rod outside diameter and the guide tube outside diameter and assuming a gap of 0.005 inches $(0.0127 \mathrm{~cm})$ between metal surfaces, the inside diameter of the guide tube and corresponding wall thickness were calculated. These are shown in Table 8-3.

Table 8-3. Calculated wall thickness for control rod guide tubes (cm)

\begin{tabular}{ccccccc}
\hline & & & Measured & \multicolumn{2}{c}{ Estimated } & Measured \\
Rod & Wall & Gap & rod OR & Tube IR & Tube OR & tube OR \\
\hline SR1 & 0.136 & 0.013 & 2.397 & 2.410 & 2.546 & 2.546 \\
SR2 & 0.136 & 0.013 & 2.397 & 2.410 & 2.552 & 2.552 \\
CCR & 0.136 & 0.013 & 2.398 & 2.410 & 2.548 & 2.548 \\
FCR & 0.136 & 0.013 & 1.265 & 1.278 & 1.434 & 1.434 \\
\hline
\end{tabular}

The control rods have $8 \mathrm{~cm}$ of graphite below the fuel or polyethylene disks. It is assumed the density is the same as that of the graphite reflector.

\subsection{OTHER PARTS}

The aluminum used in the model is 6061-T6 aluminum. The lead is assumed to be theoretical density.

\section{REFERENCES}

1. "The University of New Mexico AGN-201M Reactor: Reactor Operation and Training Manual," Revised January 2005.

2. EAG Laboratory ICP-MS Report, "Lead Plug," Job \# C0HWF571, Sample ID: S170703020, dated July 13, 2017

3.1 EAG Laboratory ICP-MS Report, "Graphite Reflector," Job \# C0HWF571, Sample ID: S170703018, dated July 13, 2017

4. $\quad$ EAG Laboratory ICP-MS Report, "Polyethylene Disk," Job \# C0HWF571, Sample ID: S170703019, dated July 13, 2017

5. $\quad$ EAG Laboratory IGA Report, “Lead Plug,” Job \# C0HWF571, Sample ID: S170703020, dated July 6, 2017

6. EAG Laboratory IGA Report, "Graphite Reflector,” Job \# C0HWF571, Sample ID: S170703018, dated July 6, 2017 
7. Gorman, Mackenzie (2012) Experimental Parameterization of the Idaho State University AGN201 Research and Training Reactor, Idaho State University (Master's Thesis), Idaho State University.

8. INL - Materials and Fuels Complex Analytical Laboratory, "ISU Uranium Oxide Fuel Sample," AL Log \#: 94120, dated August 16, 2011.

9. INL - Materials and Fuels Complex Analytical Laboratory, "ISU Uranium Oxide Fuel Sample," AL Log \#: 94121, dated August 16, 2011.

10. ImageJ, Image Processing and Analysis in Java, https://imagej.nih.gov/ij/.

11. SAND2019-8466 O, Sandia National Laboratories, Radiation Protection Sample Diagnostics Program, "Results for UNM AGN-201_6-19," dated June 26, 2019. 
APPENDIX A. ATTRIBUTE MEASUREMENTS 



\section{A.1 FUEL DISK DATA}

Cylindrical pieces used the following convention to identify where the measurements were taken.

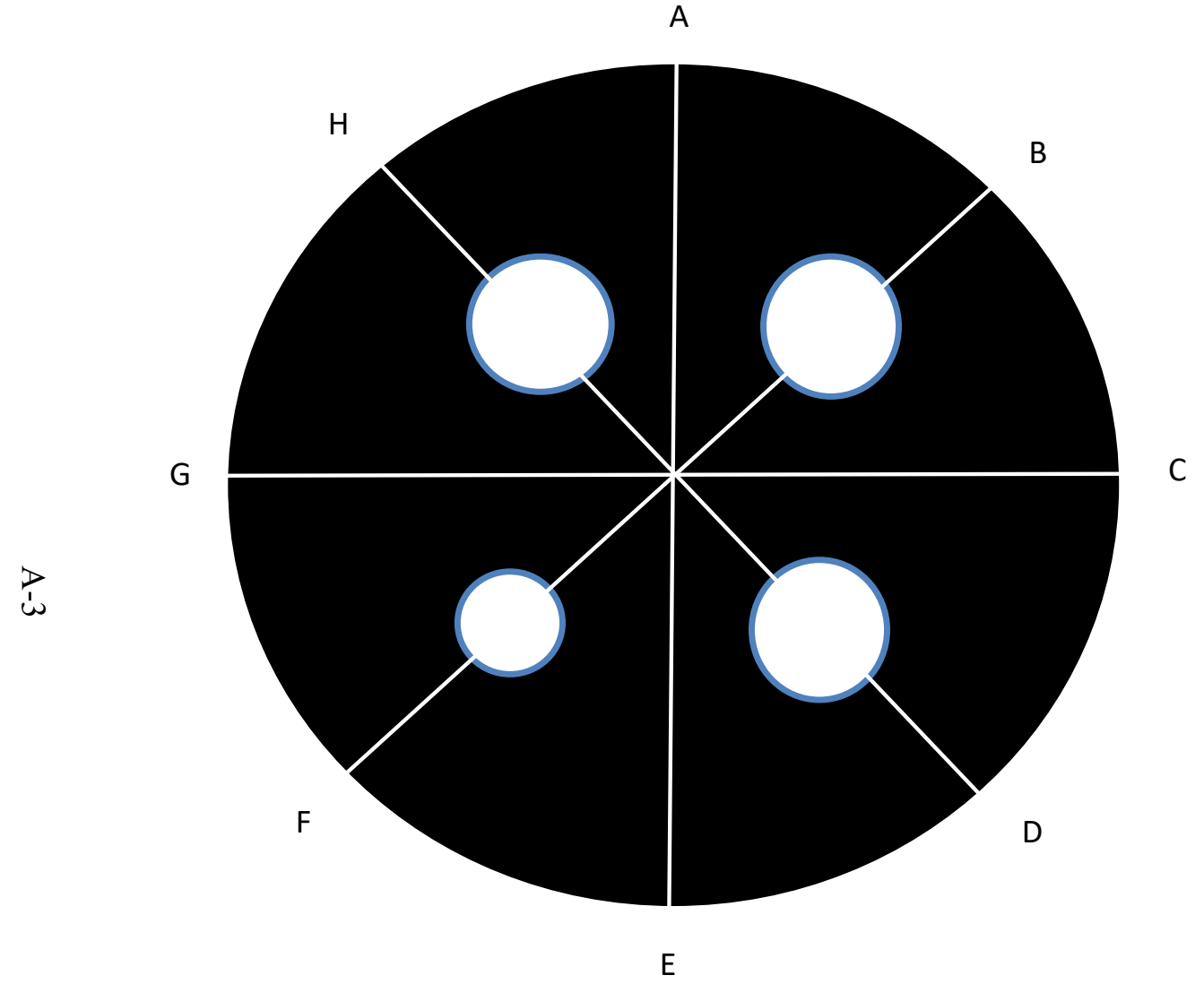


A measurement on the horizontal axis would be labeled C-G, and on the vertical axis, it would be labeled A-E.

Table A-1. Fuel disk data (cm)

\begin{tabular}{|c|c|c|c|c|c|c|c|c|c|c|c|}
\hline Disk & 105 & 104 & 103 & 102 & 101 & 100 & 99 & 98 & 97 & UNM fuse & Utah fuse \\
\hline Diameter & $(\mathrm{cm})$ & & & & & & & & & & \\
\hline A-E & 25.576 & 25.591 & 25.636 & 25.635 & 25.634 & 25.578 & 25.575 & 25.873 & 25.592 & 2.233 & 2.230 \\
\hline B-F & 25.571 & 25.593 & 25.633 & 25.625 & 25.634 & 25.516 & 25.701 & 25.597 & 25.592 & 2.235 & 2.228 \\
\hline C-G & 25.573 & 25.591 & 25.631 & 25.622 & 25.636 & 25.583 & 25.583 & 25.584 & 25.992 & & \\
\hline D-H & 25.690 & 25.585 & 25.633 & 25.628 & 25.629 & 25.557 & 25.583 & 25.583 & 25.593 & & \\
\hline Average & 25.603 & 25.590 & 25.633 & 25.628 & 25.633 & 25.559 & 25.611 & 25.659 & 25.692 & 2.234 & 2.229 \\
\hline \multicolumn{12}{|l|}{ Hole for SR 1} \\
\hline A-E & $\mathrm{x}$ & $\mathrm{x}$ & $\mathrm{x}$ & $X$ & $\mathrm{x}$ & 5.071 & 5.039 & 5.211 & 5.127 & $\mathrm{x}$ & $X$ \\
\hline B-F & $\mathrm{x}$ & $\mathrm{x}$ & $\mathrm{x}$ & $X$ & $\mathrm{x}$ & - & - & - & - & $\mathrm{x}$ & $\mathrm{X}$ \\
\hline C-G & $\mathrm{x}$ & $\mathrm{x}$ & $\mathrm{x}$ & $\mathrm{X}$ & $\mathrm{x}$ & 5.081 & 5.108 & 5.115 & 5.114 & $\mathrm{x}$ & $\mathrm{X}$ \\
\hline D-H & $\mathrm{x}$ & $\mathrm{x}$ & $\mathrm{x}$ & $\mathrm{X}$ & $\mathrm{x}$ & - & - & - & - & $\mathrm{x}$ & $\mathrm{X}$ \\
\hline Average & & & & & & 5.076 & 5.074 & 5.163 & 5.121 & & \\
\hline \multicolumn{12}{|l|}{ Hole for SR-2 } \\
\hline A-E & $\mathrm{x}$ & $\mathrm{x}$ & $\mathrm{x}$ & $\mathrm{X}$ & $\mathrm{x}$ & 5.099 & 5.117 & 5.102 & 5.079 & $\mathrm{x}$ & $\mathrm{X}$ \\
\hline B-F & $\mathrm{x}$ & $\mathrm{x}$ & $\mathrm{x}$ & $\mathrm{X}$ & $\mathrm{x}$ & - & - & - & - & $\mathrm{x}$ & $\mathrm{X}$ \\
\hline C-G & $\mathrm{x}$ & $\mathrm{x}$ & $\mathrm{x}$ & $X$ & $\mathrm{x}$ & 5.057 & 5.111 & 5.115 & 5.124 & $\mathrm{x}$ & $\mathrm{X}$ \\
\hline D-H & $\mathrm{x}$ & $\mathrm{x}$ & $\mathrm{x}$ & $\mathrm{X}$ & $\mathrm{x}$ & - & - & - & - & $\mathrm{x}$ & $X$ \\
\hline Average & & & & & & 5.078 & 5.114 & 5.109 & 5.102 & & \\
\hline \multicolumn{12}{|l|}{ Hole for CCR } \\
\hline A-E & $\mathrm{x}$ & $\mathrm{x}$ & $\mathrm{x}$ & $\mathrm{X}$ & $\mathrm{x}$ & 5.063 & 5.081 & 5.117 & 5.103 & $\mathrm{x}$ & $\mathrm{X}$ \\
\hline B-F & $\mathrm{x}$ & $\mathrm{x}$ & $\mathrm{x}$ & $\mathrm{X}$ & $\mathrm{x}$ & - & - & - & - & $\mathrm{x}$ & $\mathrm{x}$ \\
\hline C-G & $\mathrm{x}$ & $\mathrm{x}$ & $\mathrm{x}$ & $\mathrm{X}$ & $\mathrm{x}$ & 5.029 & 5.11 & 5.108 & 5.107 & $\mathrm{x}$ & $\mathrm{x}$ \\
\hline D-H & $\mathrm{x}$ & $\mathrm{x}$ & $\mathrm{x}$ & $\mathrm{X}$ & $\mathrm{x}$ & - & - & - & - & $\mathrm{x}$ & $\mathrm{x}$ \\
\hline Average & & & & & & 5.046 & 5.096 & 5.113 & 5.105 & & \\
\hline
\end{tabular}


Table A-1. Fuel disk data (cm) (continued)

\begin{tabular}{|c|c|c|c|c|c|c|c|c|c|c|c|}
\hline Disk & 105 & 104 & 103 & 102 & 101 & 100 & 99 & 98 & 97 & UNM Fuse & Utah Fuse \\
\hline \multicolumn{12}{|l|}{ Hole for FCR } \\
\hline A-E & $\mathrm{x}$ & $\mathrm{x}$ & $\mathrm{x}$ & $X$ & $\mathrm{x}$ & 2.882 & 2.951 & 2.946 & 2.945 & $\mathrm{x}$ & $\mathrm{x}$ \\
\hline B-F & $\mathrm{x}$ & $\mathrm{x}$ & $\mathrm{x}$ & $\mathrm{X}$ & $\mathrm{x}$ & - & - & - & - & $\mathrm{x}$ & $\mathrm{x}$ \\
\hline $\mathrm{C}-\mathrm{G}$ & $\mathrm{x}$ & $\mathrm{x}$ & $\mathrm{x}$ & $X$ & $\mathrm{x}$ & 2.805 & 2.951 & 2.949 & 2.928 & $\mathrm{x}$ & $\mathrm{x}$ \\
\hline D-H & $\mathrm{x}$ & $\mathrm{x}$ & $\mathrm{x}$ & $X$ & $\mathrm{x}$ & - & - & - & - & $\mathrm{x}$ & $\mathrm{x}$ \\
\hline Average & & & & & & 2.844 & 2.951 & 2.948 & 2.937 & & \\
\hline \multicolumn{12}{|l|}{ SR 1} \\
\hline \multicolumn{11}{|l|}{ SR-2 } & $\mathrm{x}$ \\
\hline \multicolumn{12}{|l|}{ CCR } \\
\hline \multicolumn{12}{|l|}{ FCR } \\
\hline Hole to edge & $\mathrm{x}$ & $\mathrm{x}$ & $\mathrm{x}$ & $X$ & $\mathrm{x}$ & 3.114 & 3.123 & 3.095 & 3.118 & $\mathrm{x}$ & $\mathrm{x}$ \\
\hline \multicolumn{12}{|l|}{ Thermal fuse } \\
\hline $\begin{array}{l}\text { A-E } \\
\text { B-F }\end{array}$ & $\mathrm{x}$ & $\mathrm{x}$ & $\mathrm{x}$ & $\mathrm{X}$ & $\mathrm{x}$ & $\begin{array}{l}2.730 \\
2.719\end{array}$ & $\mathrm{x}$ & $\mathrm{x}$ & $\mathrm{x}$ & $\mathrm{x}$ & $\mathrm{x}$ \\
\hline Average & & & & & & 2.724 & & & & & \\
\hline Depth & & & & & & 1.851 & & & & & \\
\hline \multicolumn{12}{|l|}{ Fuse rod } \\
\hline $\begin{array}{l}\text { A-E } \\
\text { B-F }\end{array}$ & & & & & & $\begin{array}{l}1.556 \\
1.588\end{array}$ & $\begin{array}{l}1.581 \\
1.582\end{array}$ & $\begin{array}{l}1.581 \\
1.582\end{array}$ & $\begin{array}{l}1.566 \\
1.568\end{array}$ & $\mathrm{x}$ & $\mathrm{x}$ \\
\hline \multicolumn{12}{|l|}{ Average } \\
\hline Depth & & & & & & 0.846 & 3.994 & 4.005 & 3.982 & & \\
\hline \multicolumn{12}{|l|}{ Glory hole } \\
\hline Span & & & & & & $\begin{array}{l}2.91 \\
2.91\end{array}$ & $\begin{array}{l}3.034 \\
2.979\end{array}$ & & & & \\
\hline Average & & & & & & 2.910 & 3.007 & & & & \\
\hline Depth & & & & & & 1.27 & 1.503375 & & & & \\
\hline
\end{tabular}


Table A-1. Fuel disk data (cm) (continued)

\begin{tabular}{|c|c|c|c|c|c|c|c|c|c|c|c|}
\hline Disk & 105 & 104 & 103 & 102 & 101 & 100 & 99 & 98 & 97 & UNM Fuse & Utah Fuse \\
\hline \multicolumn{12}{|l|}{ Thickness } \\
\hline & 1.060 & 1.077 & 1.989 & 2 & 2.005 & 3.978 & 3.994 & 3.959 & 3.963 & 0.932 & 0.941 \\
\hline & 1.029 & 1.069 & 1.999 & 2.02 & 2.008 & 3.955 & 3.994 & 3.98 & 3.971 & 0.932 & 0.941 \\
\hline & 1.025 & 1.067 & 2.005 & 1.993 & 2.065 & 3.96 & 4.052 & 3.963 & 3.988 & & 0.934 \\
\hline & 1.032 & 1.061 & 2.021 & 2.01 & 2 & 3.955 & 3.947 & 4.005 & 3.956 & & \\
\hline & 1.033 & 1.077 & 2.015 & 2.015 & 2.034 & 3.986 & 4.022 & 4.026 & 3.953 & & \\
\hline & 1.047 & 1.085 & 2.000 & 2.034 & 2.032 & 3.985 & 3.962 & 4.021 & 3.992 & & \\
\hline & 1.050 & 1.091 & 1.994 & 1.996 & 2.024 & 3.970 & 4.008 & 4.050 & 4.010 & & \\
\hline & & 1.077 & 2.025 & 1.990 & 2.008 & 3.951 & 3.972 & 4.037 & 4.025 & & \\
\hline & & 1.080 & 1.992 & 1.991 & 2.025 & & & & & & \\
\hline Average & 1.039 & 1.076 & 2.004 & 2.005 & 2.022 & 3.968 & 3.994 & 4.005 & 3.982 & 0.932 & 0.939 \\
\hline Mass & (g) & & & & & & & & & & \\
\hline & & 675.78 & 1268.21 & 1269.14 & 1270.4 & 2058.37 & 2032.86 & 2163.33 & 2155.84 & 5.89 & 5.92 \\
\hline & & 675.76 & 1268.17 & 1269.14 & 1270.41 & 2058.18 & 2033.81 & 2163.24 & 2155.85 & 5.88 & 5.93 \\
\hline Average & 653.730 & 675.767 & 1268.197 & 1269.150 & 1270.437 & 2058.333 & 2033.240 & 2163.353 & 2155.887 & 5.883 & 5.920 \\
\hline Volume $\left(\mathrm{cm}^{3}\right)$ & 535.118 & 553.405 & 1034.407 & 1034.458 & 1043.638 & 1724.077 & 1729.158 & 1795.576 & 1792.654 & 3.653 & 3.663 \\
\hline $\begin{array}{l}\text { density } \\
\left(\mathrm{g} / \mathrm{cm}^{3}\right)\end{array}$ & 1.222 & 1.221 & 1.226 & 1.227 & 1.217 & 1.194 & 1.176 & 1.205 & 1.203 & 1.610 & 1.616 \\
\hline
\end{tabular}


Table A-2. Top graphite reflector data

\begin{tabular}{|c|c|c|c|c|c|c|}
\hline & $\begin{array}{l}\text { Top diameter } \\
\text { (cm) }\end{array}$ & $\begin{array}{c}\text { Bottom diameter } \\
(\mathrm{cm})\end{array}$ & $\begin{array}{c}\text { Inner diameter } \\
(\mathrm{cm})\end{array}$ & $\begin{array}{l}\text { Thickness } \\
\text { (cm) }\end{array}$ & $\begin{array}{c}\text { Inner height } \\
\text { (cm) }\end{array}$ & $\begin{array}{l}\text { Outer height } \\
\text { (cm) }\end{array}$ \\
\hline & 27.91 & 27.25 & 25.883 & 0.685 & 11.50 & 31.591 \\
\hline & 27.91 & 27.22 & 25.888 & 0.667 & 11.42 & 31.512 \\
\hline & 27.91 & 27.24 & 25.877 & 0.681 & 11.45 & 31.512 \\
\hline & \multirow[t]{3}{*}{27.99} & 27.23 & 25.884 & 0.672 & 11.45 & 31.512 \\
\hline & & & & & 11.43 & \\
\hline & & & & & 11.41 & \\
\hline Average & 27.929 & 27.236 & 25.883 & 0.676 & 11.443 & 31.532 \\
\hline
\end{tabular}

The mass of the top graphite reflector was previously measured at $22.37 \mathrm{~kg}$.

Table A-3. Bottom graphite reflector data

\begin{tabular}{|c|c|c|c|c|c|c|}
\hline & $\begin{array}{c}\text { Top diameter } \\
(\mathrm{cm})\end{array}$ & $\begin{array}{c}\text { Bottom diameter } \\
(\mathrm{cm})\end{array}$ & $\begin{array}{c}\text { Inner diameter } \\
(\mathrm{cm})\end{array}$ & $\begin{array}{c}\text { Thickness } \\
\text { (cm) }\end{array}$ & $\begin{array}{c}\text { Inner height } \\
\text { (cm) }\end{array}$ & Mass \\
\hline & 26.99 & 27.92 & 25.85 & 0.56 & 27.92 & $40.50 \mathrm{lb}$ \\
\hline & \multirow[t]{3}{*}{27.03} & \multirow[t]{3}{*}{27.93} & \multirow[t]{3}{*}{25.89} & 0.58 & \multirow[t]{3}{*}{27.93} & \multirow[t]{3}{*}{$18.37 \mathrm{~kg}$} \\
\hline & & & & 0.53 & & \\
\hline & & & & 0.54 & & \\
\hline Average & 27.01 & 27.92 & 25.87 & 0.55 & 27.92 & \\
\hline
\end{tabular}


Table A-4. Penetrations in the bottom graphite reflector

\begin{tabular}{|c|c|c|c|c|c|}
\hline & $\begin{array}{l}\text { Fine control rod } \\
\text { diameter }(\mathbf{c m})\end{array}$ & $\begin{array}{c}\text { Coarse control rod } \\
\text { diameter }(\mathrm{cm})\end{array}$ & $\begin{array}{c}\text { Safety control rod } \\
\text { diameter }(\mathrm{cm})\end{array}$ & $\begin{array}{c}\text { Safety control rod } \\
\text { diameter }(\mathrm{cm})\end{array}$ & $\begin{array}{c}\text { Thermal fuse rod } \\
\text { diameter }(\mathrm{cm})\end{array}$ \\
\hline Top of reflector & 2.9 & 5.82 & 5.79 & 5.82 & 1.7 \\
\hline \multirow[t]{2}{*}{$\begin{array}{l}\text { Bottom of } \\
\text { reflector }\end{array}$} & 5.851 & 5.726 & 5.847 & 5.840 & 3.182 \\
\hline & 5.861 & 5.764 & 5.850 & 5.838 & 3.154 \\
\hline Bottom average & 5.86 & 5.75 & 5.85 & 5.84 & 3.17 \\
\hline \multirow[t]{2}{*}{ Depth } & 15.968 & (1) & (1) & (1) & 2.549 \\
\hline & 16.337 & & & & \\
\hline Depth average & 16.15 & & & & 2.55 \\
\hline
\end{tabular}

(1) Due to the shape and size of the transition on the safety and coarse rod penetrations, it was not possible to measure the transition depth. 
Table A-5. Upper graphite shell dimensions

\begin{tabular}{|c|c|c|c|c|c|c|}
\hline & $\begin{array}{l}\text { Thickness } \\
\text { (cm) }\end{array}$ & $\begin{array}{l}\text { Depth to lip } \\
\text { (cm) }\end{array}$ & $\begin{array}{l}\text { Lip height } \\
\text { (cm) }\end{array}$ & Lip thickness (cm) & $\begin{array}{l}\text { Cross section } \\
\text { thickness (cm) }\end{array}$ & $\begin{array}{l}\text { Notch width } \\
\text { (cm) }\end{array}$ \\
\hline \multirow[t]{3}{*}{ North } & 1.495 & 31.432 & 1.487 & 2.856 & 1.915 & \\
\hline & 1.486 & & 1.469 & 2.852 & 1.915 & \\
\hline & 1.484 & & 1.493 & 2.852 & & \\
\hline Average & 1.49 & 31.43 & 1.48 & 2.85 & 1.92 & \\
\hline \multirow{3}{*}{ South } & 1.494 & 31.4325 & 1.465 & 2.843 & 1.909 & \\
\hline & 1.486 & 31.4325 & 1.467 & 2.858 & 1.990 & \\
\hline & 1.494 & & & 2.861 & & \\
\hline Average & 1.49 & 31.43 & 1.47 & 2.85 & 1.95 & \\
\hline \multirow[t]{3}{*}{ East } & 1.49 & 31.4325 & 1.478 & 2.856 & 1.938 & 2.981 \\
\hline & 1.504 & 31.4325 & 1.47 & 2.848 & 1.958 & \\
\hline & 1.491 & & & & & \\
\hline Average & 1.50 & 31.43 & 1.47 & 2.85 & 1.95 & 2.98 \\
\hline \multirow[t]{3}{*}{ West } & 1.488 & 31.47219 & 1.488 & 2.862 & 2.05 & 2.911 \\
\hline & 1.491 & 31.47219 & 1.474 & 2.84 & 2.025 & \\
\hline & 1.496 & & & & & \\
\hline Average & 1.49 & 31.47 & 1.48 & 2.85 & 2.04 & 2.91 \\
\hline
\end{tabular}




\section{Table A-6. Control rods}

\begin{tabular}{|c|c|c|c|c|c|c|c|c|}
\hline & \multicolumn{4}{|c|}{ Upper section } & \multicolumn{4}{|c|}{ Lower section } \\
\hline & SR1 & SR2 & CCR & FCR & SR1 & SR2 & CCR & FCR \\
\hline \multirow[t]{2}{*}{ Diameter } & 5.09 & 5.114 & 5.093 & 2.866 & 5.791 & 5.726 & 5.713 & 5.719 \\
\hline & 5.093 & 5.092 & 5.1 & 2.869 & 5.73 & 5.723 & 5.714 & 5.718 \\
\hline Average & 5.0915 & 5.103 & 5.0965 & 2.8675 & 5.7605 & 5.7245 & 5.7135 & 5.7185 \\
\hline Height & 22.479 & 22.391 & 22.464 & 26.164 & 20.066 & 20.154 & 20.081 & 17.016 \\
\hline
\end{tabular}

The transition between upper and lower was $0.635 \mathrm{~cm}$. The total height of each was 17 inches or $43.18 \mathrm{~cm}$.

Table A-7. Fixed radial pieces

\begin{tabular}{|c|c|c|c|c|}
\hline \multicolumn{4}{|c|}{ Graphite } & \multirow{2}{*}{$\begin{array}{c}\text { Lead } \\
\text { thickness } \\
\text { (cm) }\end{array}$} \\
\hline & $\begin{array}{l}\text { Inside diameter } \\
\text { (cm) }\end{array}$ & $\begin{array}{c}\text { Thickness } \\
\text { (cm) }\end{array}$ & $\begin{array}{l}\text { Gap } \\
(\mathrm{cm})\end{array}$ & \\
\hline & 32.385 & 16.51 & 0.453 & 9.525 \\
\hline & 32.385 & 16.51 & 0.393 & 9.525 \\
\hline & & 16.51 & 0.28 & 9.525 \\
\hline & & 16.51 & 0.24 & 9.525 \\
\hline Average & 32.385 & 16.51 & 0.3415 & 9.525 \\
\hline
\end{tabular}


Table A-8. Fixed radial lifting holes

\begin{tabular}{l|ccc|ccc}
\hline & \multicolumn{3}{|c|}{ Graphite } & \multicolumn{3}{c}{ Lead } \\
\hline & $\begin{array}{c}\text { Depth } \\
(\mathbf{c m})\end{array}$ & $\begin{array}{c}\text { Diameter } \\
(\mathbf{c m})\end{array}$ & $\begin{array}{c}\text { Distance } \\
(\mathbf{c m})\end{array}$ & $\begin{array}{c}\text { Depth } \\
(\mathbf{c m})\end{array}$ & $\begin{array}{c}\text { Diameter } \\
(\mathbf{c m})\end{array}$ & $\begin{array}{c}\text { Distance }^{(\mathbf{1})} \\
(\mathbf{c m})\end{array}$ \\
\hline Position 1 & 5.755 & 1.938 & 7.635 & 4.992 & 2.748 & 3.721 \\
Position 2 & & & & 4.699 & 2.663 & 3.933 \\
Position 3 & 6.109 & 1.936 & 7.275 & 5.012 & 2.883 & 3.695 \\
Position 4 & & & & 4.631 & 2.866 & 3.764 \\
\hline
\end{tabular}

(1) - Distance is from the inside radius of the material.

Table A-9. Baffle plates

\begin{tabular}{lccccc}
\hline & $\begin{array}{c}\text { Rod hole } \\
\text { diameter } \\
(\mathbf{c m})\end{array}$ & $\begin{array}{c}\text { Rod hole } \\
\text { diameter } \\
(\mathbf{c m})\end{array}$ & $\begin{array}{c}\text { Short distance } \\
(\mathbf{c m})\end{array}$ & $\begin{array}{c}\text { Wide distance } \\
(\mathbf{c m})\end{array}$ & $\begin{array}{c}\text { Thickness } \\
(\mathbf{c m})\end{array}$ \\
\hline North & 6.325 & 3.442 & 13.494 & 30.956 & 0.080 \\
& 6.340 & 3.441 & & & 0.082 \\
\hline Average & 6.332 & 3.442 & 13.494 & 30.956 & 0.081 \\
\hline South & 6.306 & 6.321 & 13.53344 & 30.95625 & 0.082 \\
& 6.278 & 6.343 & & & 0.081 \\
\hline Average & 6.292 & 6.332 & 13.53344 & 30.95625 & 0.0815 \\
\hline
\end{tabular}


Table A-10. Fuse holder

\begin{tabular}{|c|c|c|c|c|c|c|}
\hline & \multicolumn{3}{|c|}{ Holder } & \multicolumn{3}{|c|}{ Stem } \\
\hline & $\begin{array}{c}\begin{array}{c}\text { Outside diameter } \\
(\mathrm{cm})\end{array} \\
\end{array}$ & $\begin{array}{c}\text { Inside diameter } \\
(\mathrm{cm})\end{array}$ & $\begin{array}{c}\text { Height } \\
\text { (cm) }\end{array}$ & $\begin{array}{c}\text { Outside diameter } \\
(\mathrm{cm})\end{array}$ & $\begin{array}{c}\text { Inside diameter } \\
(\mathrm{cm})\end{array}$ & $\begin{array}{c}\text { Height } \\
(\mathrm{cm})\end{array}$ \\
\hline & 2.731 & 2.230 & 1.284 & 1.590 & 1.299 & 28.775 \\
\hline & 2.732 & 2.226 & 1.292 & 1.584 & 1.280 & 28.770 \\
\hline Average & 2.732 & 2.228 & 1.288 & 1.587 & 1.290 & 28.773 \\
\hline
\end{tabular}

Table A-11. Control rods

\begin{tabular}{|c|c|c|c|c|c|}
\hline \multirow{6}{*}{ Safety rod 2} & $\begin{array}{c}\text { Upper outside diameter } \\
(\mathrm{cm})\end{array}$ & $\begin{array}{c}\begin{array}{l}\text { Lower outside diameter } \\
(\mathrm{cm})\end{array} \\
\end{array}$ & $\begin{array}{l}\text { Rod length } \\
\text { (cm) }\end{array}$ & $\begin{array}{c}\text { Base outside diameter } \\
(\mathrm{cm})\end{array}$ & $\begin{array}{c}\text { Base length } \\
(\mathrm{cm})\end{array}$ \\
\hline & 4.795 & 4.794 & 27.637 & 5.051 & 3.303 \\
\hline & 4.794 & 4.786 & & 5.05 & 3.338 \\
\hline & 4.794 & 4.790 & 27.637 & 5.0505 & 3.320 \\
\hline & 4.795 & 4.784 & 27.588 & 5.051 & 3.387 \\
\hline & 4.793 & 4.791 & & 5.045 & 3.388 \\
\hline Average & 4.794 & 4.788 & 27.588 & 5.048 & 3.388 \\
\hline Coarse control rod & 4.798 & 4.800 & 27.64 & 5.06 & 3.231 \\
\hline & 4.792 & 4.790 & & 5.052 & 3.380 \\
\hline Average & 4.795 & 4.795 & 27.64 & 5.056 & 3.306 \\
\hline Fine control rod & 2.527 & 2.535 & 27.532 & 5.044 & 3.406 \\
\hline & 2.534 & 2.534 & & 5.048 & 3.379 \\
\hline Average & 2.530 & 2.534 & 27.532 & 5.046 & 3.392 \\
\hline
\end{tabular}


APPENDIX B. CALCULATION OF PART VOLUMES 



\section{B.1 FUEL DISKS}

The calculation of the volume of the top 5 disks (204101-204105) is based on a right circular cylinder using the average diameter and average height. The uncertainty in the volume is based on Eq. (1) which is:

$$
\Delta V=\left(2 \frac{\Delta D}{D}+\frac{\Delta H}{H}\right) V
$$

Table B-1. Disk data

\begin{tabular}{|c|c|c|c|c|c|}
\hline Disk & 204105 & 204104 & 204103 & 204102 & 204101 \\
\hline Disk diameter, $\mathrm{cm}$ & $25.603 \pm 0.058$ & $25.590 \pm 0.003$ & $25.633 \pm 0.002$ & $25.628 \pm 0.006$ & $25.633 \pm 0.003$ \\
\hline Disk height, cm & $1.039 \pm 0.013$ & $1.076 \pm 0.009$ & $2.004 \pm 0.013$ & $2.005 \pm 0.015$ & $2.022 \pm 0.020$ \\
\hline Volume, $\mathrm{cm}^{3}$ & 535.118 & 553.405 & 1034.407 & 1034.458 & 1043.638 \\
\hline Volume unc., $\mathrm{cm}^{3}$ & \pm 9.105 & \pm 4.892 & \pm 6.895 & \pm 8.315 & \pm 10.677 \\
\hline
\end{tabular}

For the lower four disks, the gross volume is calculated based on right circular cylinder, and then the volume of each penetration (control rod, thermal fuse and glory hole) is subtracted. The uncertainty of each volume is calculated as above, and then the net uncertainty on the volume is given in Eq. (4) which is:

$$
\Delta V=\sqrt{\sum \Delta V_{i}^{2}}
$$




\section{B.2}

PART DATA

Table B-2. Part data

\begin{tabular}{|c|c|c|c|c|c|}
\hline Part & Attribute & 204100 & 20499 & 20498 & 20497 \\
\hline \multicolumn{6}{|l|}{ Dimension } \\
\hline \multirow[t]{2}{*}{ Fuel disk } & Diameter, $\mathrm{cm}$ & $25.559 \pm 0.030$ & $25.611 \pm 0.060$ & $25.659 \pm 0.143$ & $25.692 \pm 0.200$ \\
\hline & Height, cm & $3.968 \pm 0.014$ & $3.994 \pm 0.034$ & $4.005 \pm 0.034$ & $3.982 \pm 0.026$ \\
\hline SR1 & Diameter, $\mathrm{cm}$ & $5.076 \pm 0.007$ & $5.074 \pm 0.049$ & $5.163 \pm 0.068$ & $5.121 \pm 0.009$ \\
\hline $\mathrm{SR} 2$ & Diameter, $\mathrm{cm}$ & $5.078 \pm 0.030$ & $5.114 \pm 0.004$ & $5.109 \pm 0.009$ & $5.102 \pm 0.032$ \\
\hline CCR & Diameter, $\mathrm{cm}$ & $5.046 \pm 0.024$ & $5.096 \pm 0.021$ & $5.113 \pm 0.006$ & $5.105 \pm 0.003$ \\
\hline FCR & Diameter, cm & $2.844 \pm 0.054$ & $2.951 \pm 0.000$ & $2.948 \pm 0.002$ & $2.937 \pm 0.012$ \\
\hline \multirow[t]{2}{*}{ Thermal fuse } & Diameter, cm & & $2.725 \pm 0.008$ & & \\
\hline & Depth, cm & & $1.852 \pm 0.001$ & & \\
\hline Thermal fuse rod & Diameter, cm & & $1.572 \pm 0.023$ & $1.582 \pm 0.001$ & $1.567 \pm 0.001$ \\
\hline \multirow[t]{2}{*}{ Glory hole } & Span, cm & $2.910 \pm 0.000$ & $3.007 \pm 0.039$ & & \\
\hline & Depth, cm & 1.270 & 1.503 & & \\
\hline \multicolumn{6}{|c|}{ Volume } \\
\hline & Gross, $\mathrm{cm}^{3}$ & $2035.530 \pm 12.128$ & $2057.408 \pm 27.194$ & $2071.066 \pm 40.780$ & $2064.537 \pm 45.646$ \\
\hline & $\mathrm{SR} 1, \mathrm{~cm}^{3}$ & $80.288 \pm 0.510$ & $80.742 \pm 2.239$ & $83.851 \pm 2.924$ & $82.006 \pm 0.832$ \\
\hline & $\mathrm{SR} 2, \mathrm{~cm}^{3}$ & $80.351 \pm 1.226$ & $82.036 \pm 0.820$ & $82.090 \pm 1.021$ & $81.398 \pm 1.560$ \\
\hline & $\mathrm{CCR}, \mathrm{cm}^{3}$ & $79.342 \pm 1.052$ & $81.444 \pm 1.336$ & $82.219 \pm 0.928$ & $81.510 \pm 0.628$ \\
\hline & $\mathrm{FCR}, \mathrm{cm}^{3}$ & $25.195 \pm 3.361$ & $27.316 \pm 0.686$ & $27.328 \pm 0.839$ & $26.970 \pm 1.209$ \\
\hline & Thermal fuse, $\mathrm{cm}^{3}$ & & $10.794 \pm 0.066$ & & \\
\hline & Thermal fuse rod, $\mathrm{cm}^{3}$ & & $1.239 \pm 0.038$ & $7.868 \pm 0.000$ & $7.680 \pm 0.000$ \\
\hline & Glory hole, $\mathrm{cm}^{3}$ & $84.993 \pm 0.101$ & $90.908 \pm 2.566$ & & \\
\hline & Net volume, $\mathrm{cm}^{3}$ & $1685.362 \pm 4.275$ & $1682.929 \pm 5.690$ & $1787.709 \pm 6.818$ & $1784.974 \pm 7.062$ \\
\hline
\end{tabular}




\section{B-3. GRAPHITE TOP AND BOTTOM REFLECTORS}

The graphite reflectors are tapered cylinders. Their gross volume is calculated by using the average diameter since the taper is linear over the entire height. The FCR and the Fuse Rod had a discernible transition point in the bottom graphite reflector between diameters in the guide tubes. The larger control rods had such a small transition, an accurate measurement of the location could not be made. The measured top and bottom diameters of the holes for the large rods are very close, so the average diameter will be used to estimate the void volume.

Table B-3. Graphite reflector data

\begin{tabular}{|c|c|c|c|}
\hline Region & Attribute & Top graphite reflector & Bottom graphite reflector \\
\hline \multirow[t]{2}{*}{ Gross } & Avg. rad, cm & $13.791 \pm 0.022$ & $13.734 \pm 0.015$ \\
\hline & Height, cm & $31.532 \pm 0.040$ & $32.029 \pm 0.010$ \\
\hline \multirow[t]{2}{*}{ Fuel disk } & Avg. rad, cm & $12.942 \pm 0.002$ & $12.935 \pm 0.014$ \\
\hline & Height, cm & $11.443 \pm 0.031$ & $11.929 \pm 0.010$ \\
\hline \multirow[t]{2}{*}{ SR1 } & Bot. avg. rad, cm & & $2.895 \pm 0.001$ \\
\hline & Bot. height, cm & & $20.100 \pm 0.017$ \\
\hline \multirow[t]{2}{*}{$\mathrm{SR} 2$} & Bot. avg. rad, cm & & $2.910 \pm 0.001$ \\
\hline & Bot. height, cm & & $20.100 \pm 0.017$ \\
\hline \multirow[t]{2}{*}{ CCR } & Bot. avg. rad, cm & & $2.910 \pm 0.019$ \\
\hline & Bot. height, cm & & $20.100 \pm 0.017$ \\
\hline \multirow[t]{4}{*}{ FCR } & Bot. avg. rad, cm & & $2.928 \pm 0.004$ \\
\hline & Bot. height, cm & & $16.153 \pm 0.261$ \\
\hline & Top avg. rad, cm & & $2.900 \pm 0.004$ \\
\hline & Top height, cm & & $3.948 \pm 0.369$ \\
\hline \multirow[t]{2}{*}{ Rod } & Avg. rad, cm & & $1.700 \pm 0.010$ \\
\hline & Height, cm & & $17.551 \pm 0.010$ \\
\hline \multirow[t]{2}{*}{ Nut pocket } & Avg. rad, cm & & $3.168 \pm 0.010$ \\
\hline & Height, cm & & $2.549 \pm 0.010$ \\
\hline
\end{tabular}

Note: If uncertainty on a dimension could be established based on multiple measurements, then an uncertainty was assigned based on similar measurements. 


\section{B.4 GRAPHITE REFLECTOR VOLUMES}

The gross volume of the graphite reflectors and their uncertainties are calculated based on the average diameters and heights. The volumes of the void spaces are then calculated and subtracted from the gross volumes to determine the best estimate of the graphite reflector volumes.

Table B-4. Graphite reflector volumes

\begin{tabular}{lcc}
\hline Region of the reflector & Top graphite reflector & Bottom graphite reflector \\
\hline Gross volume, $\mathrm{cm}^{3}$ & $18840.831 \pm 82.976$ & $18978.082 \pm 58.322$ \\
\hline Fuel disk region, $\mathrm{cm}^{3}$ & $6020.691 \pm 18.525$ & $6270.389 \pm 19.228$ \\
Safety rod $1, \mathrm{~cm}^{3}$ & & $529.228 \pm 0.985$ \\
Safety rod $2, \mathrm{~cm}^{3}$ & & $534.727 \pm 0.809$ \\
Course control rod, $\mathrm{cm}^{3}$ & $534.727 \pm 7.424$ \\
Bottom region of the fine control rod, $\mathrm{cm}^{3}$ & & $435.043 \pm 8.078$ \\
Upper region of the fine control rod, $\mathrm{cm}^{3}$ & & $104.296 \pm 10.004$ \\
Thermal fuse support rod, $\mathrm{cm}^{3}$ & & $159.349 \pm 1.947$ \\
Nut pocket, $\mathrm{cm}^{3}$ & $12820.140 \pm 85.018$ & $80.369 \pm 0.818$ \\
\hline Net volume, $\mathrm{cm}^{3}$ & $22373 \pm 90$ & $10329.955 \pm 63.229$ \\
\hline Mass, $\mathrm{g}$ & $1.745 \pm 0.019$ & $18370 \pm 90$ \\
\hline Density, $\mathrm{g} / \mathrm{cm}^{3}$ & & $1.778 \pm 0.020$ \\
\hline
\end{tabular}




\section{APPENDIX C. UNIVERSITY OF NEW MEXICO PROCEDURES}





\title{
C.1 AGN-201. FUEL REMOVAL PROCEDURE FOR DISASSEMBLY OF CORE TANK
}

\author{
AGN-201 Fuel Removal Procedure for Disassembly of Core Tank [TS 6.6.b] \\ Date: $\frac{\text { May } 10,2019}{\gamma}$
}

BEFORE STARTING:

CONSOLE MUST BE DE-ENERGIZED AND KEY IN CONTROL OF A REACTOR SUPERVISOR.

RB SRO inits.

Permission to proceed with Disassembly

1. Contact Radiation Safety to do an air sampling before opening the core tank

a) Before Radiation Safety arrives:

i) Make sure Reactor Supervisor is on-site $R D$

$$
\text { SRO inits }
$$

ii) Perform a radiation survey of the top of the reactor

iii) Remove the thermal column

3.5 $\mathrm{mR} / \mathrm{hr}$. after thermol column removed

b) With Radiation Safety present and prepared for air sample:

i) Loosen the bolts on the core tank cover and install jack bolts

ii) Have radiation safety open valve to tank air sample and start the sampler

iii) Use jack bolts to lift the core tank cover to provide pressure relief

iv) After 1 minute of sampling, stop sampler

v) Replace core tank cover and secure core tank (closing valve)

Reactor Core Tank Disassembly

2. When core tank results are reported by Radiation Safety and go ahead is received:

a) Make sure Reactor Supervisor is on-site $R B$ SRO inits

b) Prepare Areas for tools, fuel disks, and personnel:

i) Prepare Ledge on South side of Reactor for Fuel Disks

ii) Prepare area on South side for tools, core tank cover, and graphite plugs

iii) Prepare area for personnel and low level waste bag

c) Have UNM Radiation Safety set up portable gas-flow counting system for swipe analysis.

d) Remove core tank cover and O-ring - place in appropriate location

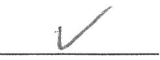

e) Remove the graphite plug and place in appropriate location

f) Perform initial survey of radiation levels at top of core tank (approx.. $30 \mathrm{~cm}$ above top fuel disk). Radiation level $=2 / \mathrm{mR} / \mathrm{hC}$. If level above $200 \mathrm{mr} / \mathrm{hr}$ - stop work. Have NTESS personnel leave the area. If level below $200 \mathrm{mr} / \mathrm{hr}$, allow NTESS personnel access to top of reactor. 


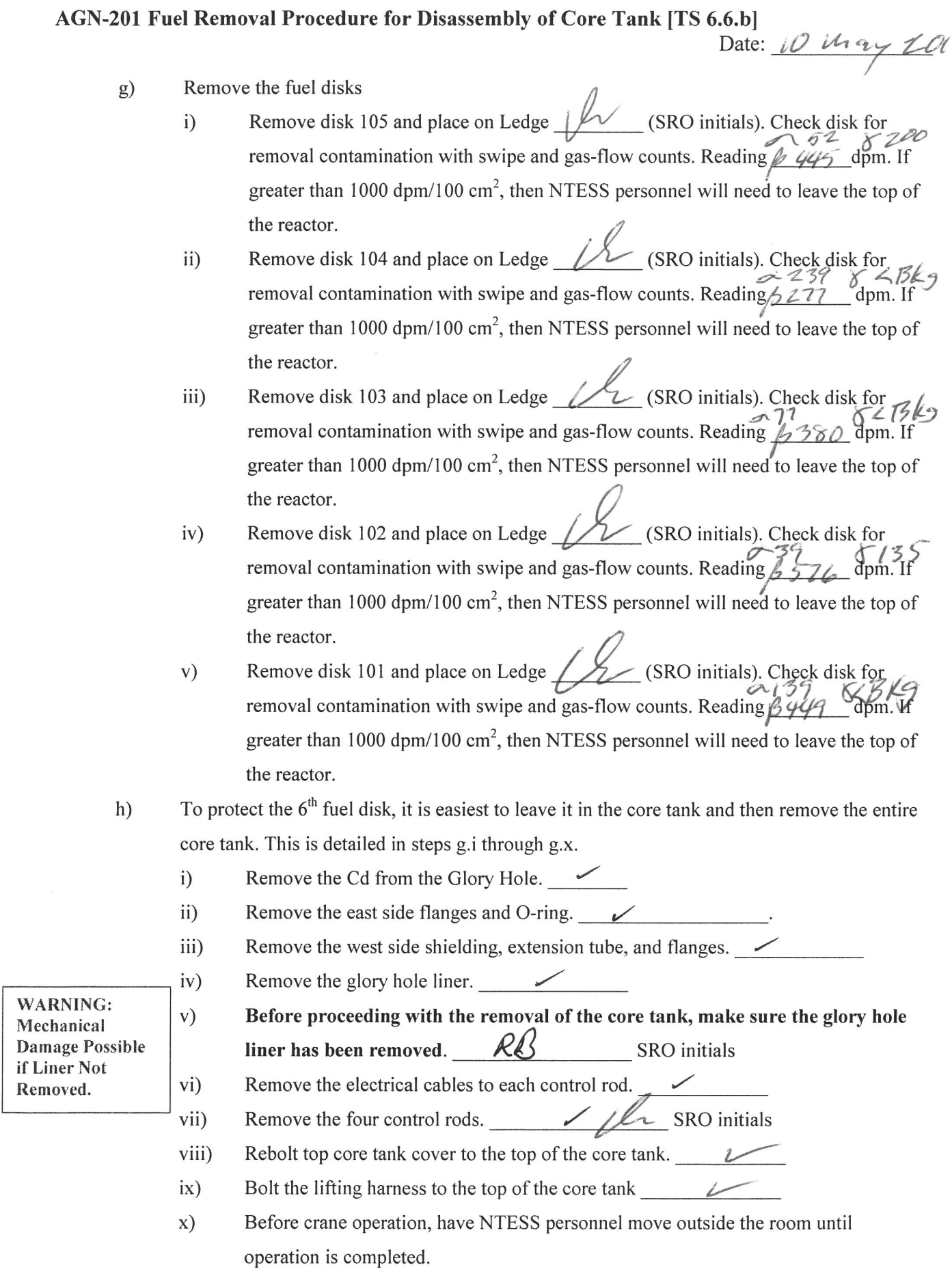


AGN-201 Fuel Removal Procedure for Disassembly of Core Tank [TS 6.6.b]

Date: 10 moxy 2019

xi) Lift the core tank out of the reactor and lay it on its side in the designated area.

i) Remove the control rod guide tubes from the bottom of the core tank

j) Unbolt the top cover of the core tank and perform a cadiation survey about $30 \mathrm{~cm}$ above the $6^{\text {th }}$ fuel disk. Radiation level $=14.4 \mathrm{~m} / \mathrm{M}$. If level above $200 \mathrm{mr} / \mathrm{hr}-$ stop work. Have NTESS personnel leave the area. If level below $200 \mathrm{mr} / \mathrm{hr}$, allow NTESS personnel access to top of reactor.

i) Remove the $6^{\text {th }}$ fuel disk, \#100, and place on Ledge disk for removal contamination with swipe and gas-flow counts. Reading $43, \quad \gamma 212$ $\mathrm{dpm}$. If greater than $1000 \mathrm{dpm} / 100 \mathrm{~cm}^{2}$, then NTESS personnel will need to leave the top of the reactor. If total contamination is greater than $5000 \mathrm{dpm} / 100 \mathrm{~cm}^{2}$, then

NTESS personnel will need to leave the top of the reactor. $P$ top faing North

k) Remove the TOP and BOTTOM graphite liners and place them in the designated area. with valve Ul on top

1) Remove the EAST and WEST graphite liners and place them in the designated area.

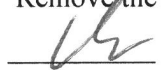

m)

Remove the two aluminum baffle plates and prace them in the designated area

n) Remove the bottom core tank cover.

o) Slide the graphite plug, fuel disks, and thermal fuscassembly from the core tank. Set this assembly resting on the top fuel disk.

Disassemble thermal fuse assembly.

p)

Remove the graphite plug and set it in the designated area.

r) Bring fuel and thermal fuse assembly to the fuel handling area.

s) Remove the thermal fuse holder.

t) Remove the core fuse from the holder and set in designated area.

u) Unstack the fuel disks. SRO initials

v) Place fuel disk $\# 99$ on the Ledge. (SRO initials). Check disk for removal

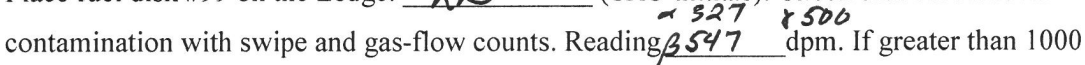
$\mathrm{dpm} / 100 \mathrm{~cm}^{2}$, then NTESS personnel will need to leave the top of the reactor. If total contamination is greater than $5000 \mathrm{dpm} / 100 \mathrm{~cm}^{2}$, then NTESS personnel will need to leave the top of the reactor. 
AGN-201 Fuel Removal Procedure for Disassembly of Core Tank [TS 6.6.b]

Date: Mry 14,2019

w) Place fuel disk \#98 on the Ledge. contamination with swipe and gas-flow counts. Reading $\underline{598} 400 \mathrm{dpm}$. If greater than 1000 $\mathrm{dpm} / 100 \mathrm{~cm}^{2}$, then NTESS personnel will need to leave the top of the reactor. If total contamination is greater than $5000 \mathrm{dpm} / 100 \mathrm{~cm}^{2}$, then NTESS personnel will need to leave the top of the reactor.

$\mathrm{x})$

Place fuel disk \#97 on the Ledge. (SRO initials). Check disk for removal contamination with swipe and gas-flow counts. Reading $362 \quad 100 \mathrm{dpm}$. If greater than 1000 $\mathrm{dpm} / 100 \mathrm{~cm}^{2}$, then NTESS personnel will need to leave the top of the reactor. If total contamination is greater than $5000 \mathrm{dpm} / 100 \mathrm{~cm}^{2}$, then NTESS personnel will need to leave the top of the reactor.

y) Remove the bottom 4 graphite liners and place in designated area. $\mathrm{AB}$

This completes the disassembly of the core tank.

Reviewed By:

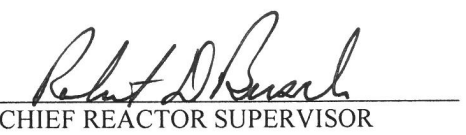




\section{C.2 TRANSFER OF AGN-201 INDIVIDUAL FUEL DISKS FOR CHARACTERIZATION}

Transfer of AGN-201 Individual Fuel Disks for Characterization [TS 6.6.b]

Date: May 14, 2019

Transfer of Individual Fuel Disks to Characterization Area

1. Make sure Reactor Supervisor is on-site

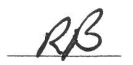

\section{SRO inits}

2. Prepare Fuel Characterization Area on North Bench in Room 069, Nuclear Engineering Lab

a) Lay out areas for Weighing (with scale), Dimensional Measurements (with caliper), and isotopics (with measurement stand):

b) Perform an initial survey of the area $\quad 0.05 \quad \mathrm{mR} / \mathrm{hr}$.

3. Transporting Disks from Radiation Handling Area at Top of Reactor to Fuel Characterization Area.

a) With gloved hand, pick up individual disk to be characterized and verify number \# 105 RB SRO inits

b) Walk disk to top of Stairs and hand disk to personnel on stairs.

c) $\longrightarrow$ Personnel on Stairs receives disk with gloved hand, and then transfers disk to personnel at bottom of Stairs.

d) $\_$Personnel at bottom of Stairs receives disk with gloved hand and walks disk to Fuel Characterization Area.

e) Disk is placed in the Weighing Area for Analysis. RD SRO inits

4. Characterization of Fuel Disk
a) All Disk handling is done by gloved personnel.
b)
c)
Fuel Disk number is verified \# 105
RB
SRO inits
RB SRO inits

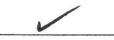
Fuel Disk is Weighed. $\quad 653.73$ grams

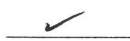
d)
Fuel Disk is Measured for Diameter $\quad \mathbf{2 5 . 6 0} \mathrm{cm}$, and Thickness
$1.039 \mathrm{~cm} . \quad \mathrm{RB}$ SRO inits
e) $\_$Fuel Disk is Transferred to Isotopics Characterization Stand and Secured in Stand. RQ SRO inits
f) Fuel Disk Isotopics are characterized. RR SRO inits
g) Fuel Disk is placed back in Weighing Area. RR SRO inits

Revised April 12, 2019 
Transfer of AGN-201 Individual Fuel Disks for Characterization [TS 6.6.b]

Date:

May 14,2019

5. Transporting Disks from Fuel Characterization Area to Radiation Handling Area at Top of Reactor.

a) W With gloved hand, pick up individual disk to be returned and verify number \# $105 \quad$ RQS SRO inits

b) ᄂ Walk disk to Bottom of Stairs and hand disk to personnel on stairs.

c) Personnel on Stairs receives disk with gloved hand, and then transfers disk to personnel at Top of Stairs.

d) $\longleftarrow$ Personnel at Top of Stairs receives disk with gloved hand and walks disk to Radiation Handling Area at Top of Reactor.

e) Disk is placed in proper location in the Radiation Handling Area.

RD SRO inits

This completes the characterization of an individual fuel disk.

Reviewed By:

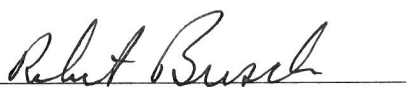




\section{Transfer of AGN-201 Individual Fuel Disks for Characterization [TS 6.6.b]}

Transfer of Individual Fuel Disks to Characterization Area

1. Make sure Reactor Supervisor is on-site

SRO inits

2. Prepare Fuel Characterization Area on North Bench in Room 069, Nuclear Engineering Lab.

a) Lay out areas for Weighing (with scale), Dimensional Measurements (with caliper), and isotopics (with measurement stand):

b) Perform an initial survey of the area $0.05 \mathrm{mR} / \mathrm{hr}$.

3. Transporting Disks from Radiation Handling Area at Top of Reactor to Fuel Characterization Area.

a) $\perp$ With gloved hand, pick up individual disk to be characterized and verify number \#104 RB SRO inits

b) Walk disk to top of Stairs and hand disk to personnel on stairs.

c) $\_$Personnel on Stairs receives disk with gloved hand, and then transfers disk to personnel at bottom of Stairs.

d) Personnel at bottom of Stairs receives disk with gloved hand and walks disk to Fuel Characterization Area.

e)

Disk is placed in the Weighing Area for Analysis. $\quad \underline{R B}$ SRO inits

4. Characterization of Fuel Disk
a) $\longleftarrow$ All Disk handling is done by gloved personnel.
b)
RB SRO inits RB SRO inits
c)
- 675.76 grams RB SRO inits
d) Fuel Disk is Measured for Diameter $25.59 \mathrm{~cm}$, and Thickness. $1.076 \mathrm{~cm} . \quad$ RR SRO inits

e) Fuel Disk is Transferred to Isotopics Characterization Stand and Secured in Stand. $\quad$ RR SRO inits

f) Fuel Disk Isotopics are characterized. $\quad$ RB SRO inits

g) Fuel Disk is placed back in Weighing Area. RQ SRO inits 


\section{Transfer of AGN-201 Individual Fuel Disks for Characterization [TS 6.6.b]}

Date: $\frac{\text { May } 15,2019}{\sqrt{ }}$

5. Transporting Disks from Fuel Characterization Area to Radiation Handling Area at Top of Reactor.

a)

\# 104 With gloved hand, pick up individual disk to be returned and verify number

b) Walk disk to Bottom of Stairs and hand disk to personnel on stairs.
Personnel on Stairs receives disk with gloved hand, and then transfers disk to

c) personnel at Top of Stairs.

d) - Personnel at Top of Stairs receives disk with gloved hand and walks disk to Radiation Handling Area at Top of Reactor.

e) $\checkmark$ Disk is placed in proper location in the Radiation Handling Area. RB SRO inits

This completes the characterization of an individual fuel disk.

Reviewed By: 
Transfer of AGN-201 Individual Fuel Disks for Characterization [TS 6.6.b]

Date: $\frac{\text { May } 15,2019}{\sqrt{ }}$

Transfer of Individual Fuel Disks to Characterization Area

1. Make sure Reactor Supervisor is on-site

$$
\text { RB SRO inits }
$$

2. Prepare Fuel Characterization Area on North Bench in Room 069, Nuclear Engineering Lab.

a) Lay out areas for Weighing (with scale), Dimensional Measurements (with caliper), and isotopics (with measurement stand):

b) Perform an initial survey of the area $0.05 \mathrm{mR} / \mathrm{hr}$.

3. Transporting Disks from Radiation Handling Area at Top of Reactor to Fuel Characterization Area.

a) $\_$With gloved hand, pick up individual disk to be characterized and verify number \# $103 \quad$ RQ SRO inits

b) Walk disk to top of Stairs and hand disk to personnel on stairs.

c) Personnel on Stairs receives disk with gloved hand, and then transfers disk to personnel at bottom of Stairs.

d) Personnel at bottom of Stairs receives disk with gloved hand and walks disk to Fuel Characterization Area.

e) Disk is placed in the Weighing Area for Analysis. RB SRO inits

4. Characterization of Fuel Disk
a)
b)
c)
All Disk handling is done by gloved personnel.
Fuel Disk number is verified \# 103
Fuel Disk is Weighed. 1268.19 grams RB SRO inits
$R \beta$ SRO inits
$R B$ SRO inits
d)
1268.19 grams
$\checkmark$ Fuel Disk is Measured for Diameter
$25.63 \mathrm{~cm}$, and Thickness.
$2.004 \mathrm{~cm} . \quad R B$ SRO inits
e) $\_$Fuel Disk is Transferred to Isotopics Characterization Stand and Secured in Stand. $\quad$ RB SRO inits
f) $\checkmark$ Fuel Disk Isotopics are characterized. $R O$ SRO inits
g) Fuel Disk is placed back in Weighing Area. RB SRO inits 


\section{Transfer of AGN-201 Individual Fuel Disks for Characterization [TS 6.6.b}

Date: $\frac{M a y / 5,2019}{\sqrt{2}}$

5. Transporting Disks from Fuel Characterization Area to Radiation Handling Area at Top of Reactor.
a) With gloved hand, pick up individual disk to be returned and verify number \#103 RB SRO inits
b) Walk disk to Bottom of Stairs and hand disk to personnel on stairs.
c) Personnel on Stairs receives disk with gloved hand, and then transfers disk to personnel at Top of Stairs.
d) Personnel at Top of Stairs receives disk with gloved hand and walks disk to Radiation Handling Area at Top of Reactor.
e) Disk is placed in proper location in the Radiation Handling Area. $R \mathcal{B}$ SRO inits

This completes the characterization of an individual fuel disk.

Reviewed By:

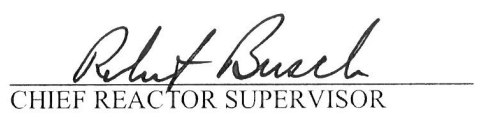

Revised April 12, 2019 
Transfer of AGN-201 Individual Fuel Disks for Characterization [TS 6.6.b]

Date: $\frac{\text { May } 15,2019}{2}$

Transfer of Individual Fuel Disks to Characterization Area

1. Make sure Reactor Supervisor is on-site

\section{$R B$}

\section{SRO inits}

2. Prepare Fuel Characterization Area on North Bench in Room 069, Nuclear Engineering Lab.

a) Lay out areas for Weighing (with scale), Dimensional Measurements (with caliper), and isotopics (with measurement stand):

b) Perform an initial survey of the area

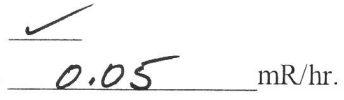

3. Transporting Disks from Radiation Handling Area at Top of Reactor to Fuel Characterization Area.

a) $\checkmark$ With gloved hand, pick up individual disk to be characterized and verify number \# 102 RR SRO inits

b) Walk disk to top of Stairs and hand disk to personnel on stairs.

c) Personnel on Stairs receives disk with gloved hand, and then transfers disk to personnel at bottom of Stairs.

d) $\_$Personnel at bottom of Stairs receives disk with gloved hand and walks disk to Fuel Characterization Area.

e) Disk is placed in the Weighing Area for Analysis.

4. Characterization of Fuel Disk

a) All Disk handling is done by gloved personnel. $\angle \mathcal{B}$ SRO inits

b) $\quad \angle$ Fuel Disk number is verified \# $102 \quad R B$ SRO inits

c) $\simeq$ Fuel Disk is Weighed. 1269.15 grams $\quad R B$ SRO inits

d) Fuel Disk is Measured for Diameter $25.628 \mathrm{~cm}$, and Thickness. $2.005 \mathrm{~cm} . \quad R B \quad$ SRO inits

e) Fuel Disk is Transferred to Isotopics Characterization Stand and Secured in Stand. RB SRO inits

f) $\checkmark$ Fuel Disk Isotopics are characterized. $\quad R B$ sRO inits

g) Fuel Disk is placed back in Weighing Area. RB SRO inits 


\section{Transfer of AGN-201 Individual Fuel Disks for Characterization [TS 6.6.b]}

Date: Mag 15, 2019

5. Transporting Disks from Fuel Characterization Area to Radiation Handling Area at Top of Reactor.

a)

With gloved hand, pick up individual disk to be returned and verify number
\# 102 SRO inits

b)

Walk disk to Bottom of Stairs and hand disk to personnel on stairs.

c)

Personnel on Stairs receives disk with gloved hand, and then transfers disk to personnel at Top of Stairs.

d)

Personnel at Top of Stairs receives disk with gloved hand and walks disk to Radiation Handling Area at Top of Reactor.

e) Disk is placed in proper location in the Radiation Handling Area. RQ SRO inits

This completes the characterization of an individual fuel disk.

Reviewed By:

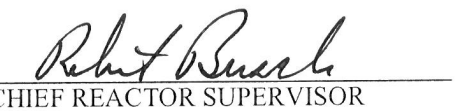

Revised April 12, 2019 


\section{Transfer of AGN-201 Individual Fuel Disks for Characterization [TS 6.6.b]}

Date: May 15,2019

Transfer of Individual Fuel Disks to Characterization Area

1. Make sure Reactor Supervisor is on-site

$R B$

\section{SRO inits}

2. Prepare Fuel Characterization Area on North Bench in Room 069, Nuclear Engineering Lab.

a) Lay out areas for Weighing (with scale), Dimensional Measurements (with caliper), and isotopics (with measurement stand):

b) Perform an initial survey of the area

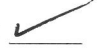

$0.05 \mathrm{mR} / \mathrm{hr}$.

3. Transporting Disks from Radiation Handling Area at Top of Reactor to Fuel Characterization Area.

a) W With gloved hand, pick up individual disk to be characterized and verify number \# $101 \quad R 2$ SRO inits

b) Walk disk to top of Stairs and hand disk to personnel on stairs.

c) Personnel on Stairs receives disk with gloved hand, and then transfers disk to personnel at bottom of Stairs.

d) Personnel at bottom of Stairs receives disk with gloved hand and walks disk to Fuel Characterization Area.

e) Disk is placed in the Weighing Area for Analysis. $2 B$ SRO inits

4. Characterization of Fuel Disk

a) All Disk handling is done by gloved personnel. RQ SRO inits

b) Fuel Disk number is verified \#101 RB SRO inits

c) Fuel Disk is Weighed. 1270.44 grams RB SRO inits

d) Fuel Disk is Measured for Diameter $25.63 \mathrm{~cm}$, and Thickness. $2.022 \mathrm{~cm}$. RB SRO inits

e) Fuel Disk is Transferred to Isotopics Characterization Stand and Secured in Stand. $\quad$ PB SRO inits

f) Fuel Disk Isotopics are characterized. $\quad R B$ SRO inits

g) Fuel Disk is placed back in Weighing Area. RB SRO inits 


\section{Transfer of AGN-201 Individual Fuel Disks for Characterization [TS 6.6.b]}

Date: $\frac{\text { May } 15,2019}{\sqrt{2}}$

5. Transporting Disks from Fuel Characterization Area to Radiation Handling Area at Top of Reactor.

a)

With gloved hand, pick up individual disk to be returned and verify number
\# 101

b) Walk disk to Bottom of Stairs and hand disk to personnel on stairs.

c) Personnel on Stairs receives disk with gloved hand, and then transfers disk to personnel at Top of Stairs.

d) Personnel at Top of Stairs receives disk with gloved hand and walks disk to Radiation Handling Area at Top of Reactor.

e) Disk is placed in proper location in the Radiation Handling Area. RBS SRO inits

This completes the characterization of an individual fuel disk.

Reviewed By:

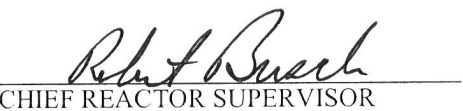

Revised April 12, 2019 
Transfer of AGN-201 Individual Fuel Disks for Characterization [TS 6.6.b]

Date: $\operatorname{May} 15,2019$

Transfer of Individual Fuel Disks to Characterization Area

1. Make sure Reactor Supervisor is on-site RB

SRO inits

2. Prepare Fuel Characterization Area on North Bench in Room 069, Nuclear Engineering Lab.

a) Lay out areas for Weighing (with scale), Dimensional Measurements (with caliper), and isotopics (with measurement stand):

b) Perform an initial survey of the area $0.05 \mathrm{mR} / \mathrm{hr}$.

3. Transporting Disks from Radiation Handling Area at Top of Reactor to Fuel Characterization Area.

a) With gloved hand, pick up individual disk to be characterized and verify

b) W Walk disk to top of Stairs and hand disk to personnel on stairs.

c) Personnel on Stairs receives disk with gloved hand, and then transfers disk to personnel at bottom of Stairs.

d) Personnel at bottom of Stairs receives disk with gloved hand and walks disk to Fuel Characterization Area.

e) Disk is placed in the Weighing Area for Analysis. RS SRO inits

4. Characterization of Fuel Disk

a) All Disk handling is done by gloved personnel. RB SRO inits

b) Fuel Disk number is verified \#100 RB SRO inits

c) Fuel Disk is Weighed. 2058.33 grams $\longrightarrow$ RQ SRO inits

d) Fuel Disk is Measured for Diameter $25.56 \mathrm{~cm}$, and Thickness. $3.968 \mathrm{~cm} . \quad R B \quad$ SRO inits

e) Fuel Disk is Transferred to Isotopics Characterization Stand and Secured in Stand. RB SRO inits

f) Fuel Disk Isotopics are characterized. $\quad$ FB SRO inits

g) $\quad$ Fuel Disk is placed back in Weighing Area. RBS SRO inits 


\section{Transfer of AGN-201 Individual Fuel Disks for Characterization [TS 6.6.b]}

Date: $\frac{\text { May } 15,2019}{7}$

5. Transporting Disks from Fuel Characterization Area to Radiation Handling Area at Top of Reactor.

a) With gloved hand, pick up individual disk to be returned and verify number \#100 RQS SRO inits

b) Walk disk to Bottom of Stairs and hand disk to personnel on stairs.

c) Personnel on Stairs receives disk with gloved hand, and then transfers disk to personnel at Top of Stairs.

d) $\angle$ Personnel at Top of Stairs receives disk with gloved hand and walks disk to Radiation Handling Area at Top of Reactor.

e) Disk is placed in proper location in the Radiation Handling Area. RB SRO inits

This completes the characterization of an individual fuel disk.

Reviewed By:

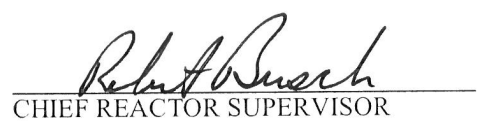


Transfer of AGN-201 Individual Fuel Disks for Characterization [TS 6.6.b]

Date: May 15,2019

Transfer of Individual Fuel Disks to Characterization Area

1. Make sure Reactor Supervisor is on-site $R$

SRO inits

2. Prepare Fuel Characterization Area on North Bench in Room 069, Nuclear Engineering Lab.

a) Lay out areas for Weighing (with scale), Dimensional Measurements (with caliper), and isotopics (with measurement stand):

b) Perform an initial survey of the area $0.05 \mathrm{mR} / \mathrm{hr}$.

3. Transporting Disks from Radiation Handling Area at Top of Reactor to Fuel Characterization Area.

a) $\quad$ With gloved hand, pick up individual disk to be characterized and verify number \# $99 \quad$ RO SRO inits

b) Walk disk to top of Stairs and hand disk to personnel on stairs.

c) $\_$Personnel on Stairs receives disk with gloved hand, and then transfers disk to personnel at bottom of Stairs.

d) Personnel at bottom of Stairs receives disk with gloved hand and walks disk to Fuel Characterization Area.

e) Disk is placed in the Weighing Area for Analysis. $\quad$ RS SRO inits

4. Characterization of Fuel Disk

a) All Disk handling is done by gloved personnel. RB SROinits

b)

c)

Fuel Disk number is verified \# 99
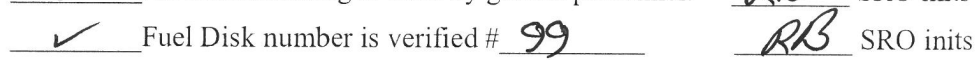

Fuel Disk is Weighed. 2033.24 grams

RH SRO inits

d)

Fuel Disk is Measured for Diameter

25.61 $\mathrm{cm}$, and Thickness.

$3.994 \mathrm{~cm} . \quad$ RB SRO inits

e) Fuel Disk is Transferred to Isotopics Characterization Stand and Secured in Stand. RßSRO inits

f) $\longleftarrow$ Fuel Disk Isotopics are characterized. $\mathscr{R}$ SRO inits

g) $\_$Fuel Disk is placed back in Weighing Area. R/B SRO inits

Revised April 12, 2019 
Transfer of AGN-201 Individual Fuel Disks for Characterization [TS 6.6.b]

Date: Moy 15,2019

5. Transporting Disks from Fuel Characterization Area to Radiation Handling Area at Top of Reactor.

a)

$$
\begin{aligned}
& \text { \# } 99 \text { With gloved hand, pick up individual disk to be returned and verify number } \\
& \text { R }
\end{aligned}
$$

b) Walk disk to Bottom of Stairs and hand disk to personnel on stairs.

c) Personnel on Stairs receives disk with gloved hand, and then transfers disk to personnel at Top of Stairs.

d)

Personnel at Top of Stairs receives disk with gloved hand and walks disk to Radiation Handling Area at Top of Reactor.

e)

Disk is placed in proper location in the Radiation Handling Area. RB SRO inits

This completes the characterization of an individual fuel disk.

Reviewed By:

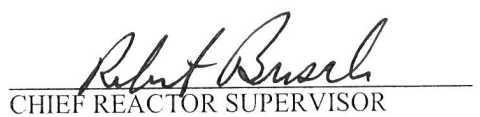

Revised April 12, 2019 
Transfer of AGN-201 Individual Fuel Disks for Characterization [TS 6.6.b]

Date: $\frac{\text { May } 16,2019}{\sqrt{2}}$

Transfer of Individual Fuel Disks to Characterization Area

1. Make sure Reactor Supervisor is on-site

\section{RB \\ SRO inits}

2. Prepare Fuel Characterization Area on North Bench in Room 069, Nuclear Engineering Lab.

a) Lay out areas for Weighing (with scale), Dimensional Measurements (with caliper), and isotopics (with measurement stand):

b) Perform an initial survey of the area $0.05 \mathrm{mR} / \mathrm{hr}$.

3. Transporting Disks from Radiation Handling Area at Top of Reactor to Fuel Characterization Area.

a) With gloved hand, pick up individual disk to be characterized and verify number \# $98 \quad$ RB SRO inits

b) Walk disk to top of Stairs and hand disk to personnel on stairs.

c) Personnel on Stairs receives disk with gloved hand, and then transfers disk to personnel at bottom of Stairs.

d) Personnel at bottom of Stairs receives disk with gloved hand and walks disk to Fuel Characterization Area.

e) Disk is placed in the Weighing Area for Analysis

4. Characterization of Fuel Disk
a) $ـ$ All Disk handling is done by gloved personnel. R/S SRO inits
b) Fuel Disk number is verified \# 98
RB SRO inits
c) Fuel Disk is Weighed. 2163.35 grams RB SRO inits
d) Fuel Disk is Measured for Diameter $25.66 \mathrm{~cm}$, and Thickness. 4.005 .7. RB $\mathrm{cm}$. SRO inits

e) Fuel Disk is Transferred to Isotopics Characterization Stand and Secured in Stand. Re SRO inits

f) $\longrightarrow$ Fuel Disk Isotopics are characterized. $\quad$ RB SRO inits

g) Fuel Disk is placed back in Weighing Area $R B$ SRO inits 
Transfer of AGN-201 Individual Fuel Disks for Characterization [TS 6.6.b]

Date: May 16,2019

5. Transporting Disks from Fuel Characterization Area to Radiation Handling Area at Top of Reactor.

a) W With gloved hand, pick up individual disk to be returned and verify number \# $98 \quad$ RB SRO inits

b) Walk disk to Bottom of Stairs and hand disk to personnel on stairs.

c) Personnel on Stairs receives disk with gloved hand, and then transfers disk to personnel at Top of Stairs.

d) $\longrightarrow$ Personnel at Top of Stairs receives disk with gloved hand and walks disk to Radiation Handling Area at Top of Reactor.

e)

Disk is placed in proper location in the Radiation Handling Area. RB SRO inits

This completes the characterization of an individual fuel disk.

Reviewed By:

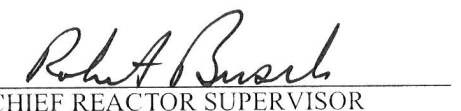

Revised April 12, 2019 
Transfer of AGN-201 Individual Fuel Disks for Characterization [TS 6.6.b]

Date: Moy 16,2012

Transfer of Individual Fuel Disks to Characterization Area

1. Make sure Reactor Supervisor is on-site

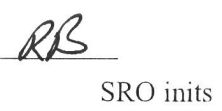

2. Prepare Fuel Characterization Area on North Bench in Room 069, Nuclear Engineering Lab.

a) Lay out areas for Weighing (with scale), Dimensional Measurements (with caliper), and isotopics (with measurement stand):

b) Perform an initial survey of the area $\mathrm{mR} / \mathrm{hr}$.

3. Transporting Disks from Radiation Handling Area at Top of Reactor to Fuel Characterization Area.

a) With gloved hand, pick up individual disk to be characterized and verify number \# $97 \quad$ RB SRO inits

b) Walk disk to top of Stairs and hand disk to personnel on stairs.

c) Personnel on Stairs receives disk with gloved hand, and then transfers disk to personnel at bottom of Stairs.

d) Personnel at bottom of Stairs receives disk with gloved hand and walks disk to Fuel Characterization Area.

e) Disk is placed in the Weighing Area for Analysis. RR SRO inits

4. Characterization of Fuel Disk

a)

b)

1 All Disk handling is done by gloved personnel.

RB SRO inits

c) Fuel Disk number is verified \# 97

$R B$ SRO inits Fuel Disk is Weighed. $\quad 2155.89$ grams

$R B$ SRO inits

d)

Fuel Disk is Measured for Diameter $25.69 \mathrm{~cm}$, and Thickness. $3.982 \mathrm{~cm} . \quad$ RB SRO inits

e) Fuel Disk is Transferred to Isotopics Characterization Stand and Secured in Stand. $\quad R B$ SRO inits

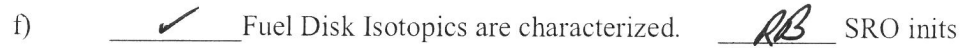

g) $\_$Fuel Disk is placed back in Weighing Area. $R \mathcal{R}$ SRO inits 
Transfer of AGN-201 Individual Fuel Disks for Characterization [TS 6.6.b]

Date: May 16, 2019

5. Transporting Disks from Fuel Characterization Area to Radiation Handling Area at Top of Reactor.

a)

\# 97 With gloved hand, pick up individual disk to be returned and verify number

b) Walk disk to Bottom of Stairs and hand disk to personnel on stairs.

c) Personnel on Stairs receives disk with gloved hand, and then transfers disk to personnel at Top of Stairs.

d)

Personnel at Top of Stairs receives disk with gloved hand and walks disk to Radiation Handling Area at Top of Reactor.

e)

Disk is placed in proper location in the Radiation Handling Area. RO SRO inits

This completes the characterization of an individual fuel disk.

Reviewed By:

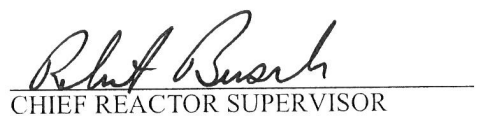

Revised April 12, 2019 


\section{C.3 AGN-201 FUEL INSERTION PROCEDURE FOR RE-ASSEMBLY OF CORE TANK}

AGN-201 Fuel Insertion and Procedure for Re-Assembly of Core Tank [TS 6.6.b]

Date: Moy 16, 2019

Reactor Core Tank Re-Assembly

1. Make sure low-level waste bag is in place and proper radiation safety areas identified.

2. Make sure Reactor Supervisor is on-site

a) Start with the bottom support and grease the O-ring.

b) $\triangle$ Place core fuse fuel into holder and secure with snap ring. $\quad$ R SRO initials

c) $\longleftarrow$ Put core fuse holder through \#3 fuel element (\#99), then \#2 element (\#98), then \#1 element (\#97).

d) Slide fuel assembly into bottom graphite reflector. Use 2 (1 large and 1 small) of the rod drive guide tubes to align fuel elements and graphite reflector position. $\quad R B$ SRO initials

e) $\measuredangle$ With the tubes inserted from the top (into fuel element $\# 99$ first), put the spring and washer on the bottom of the thermal fuse holder and tighten with the small needle nose pliers.

f) _ Make sure the nut is tight and as close to flush with bottom of graphite plug as possible.

g) _ Place graphite/fuel assembly on the bottom support._RS_SRO initials

h) $\_$Now place the core tank on its side with the top towards the North, the glory hole vertical and the valve towards the East.

i) $\_$Place the East lower graphite liner on the bottom of the tank (thick edges at the top), and then place the West lower graphite liner on the top of the tank holding it in place.

j) Have a second person rotate the core tank so the valve is on the top. Then slide the North bottom liner in between the East and West liners

k) Slide the lower graphite/fuel assembly into the bottom of the tank. Move it up so that it touches the glory hole tube in the core tank.

1) $\_$Use silicon grease on the bottom O-ring and then place it on the bottom support plate. 


\section{AGN-201 Fuel Insertion and Procedure for Re-Assembly of Core Tank [TS 6.6.b]}

Date: May 16,2019

m) Assembly of core tank

a. L Line up 3 tick marks on bottom support plate and core tank.

b. $\angle$ Then line up the fine rod marking on the bottom support plate with the fine rod holes in the graphite reflector and the fuel disks.

c. $\_$Insert the bottom core support plate into the fuse rod and then use the 11 screws (one of the 12 screw positions is not available as indicated on the tank) to tighten the bottom support plate to the core tank.

n) $\checkmark$ Before bringing the control rod guide tubes up to the top of the reactor, grease the Oring on each tube. Insert each can into the core tank and secure.

o) $\measuredangle$ Carefully move the core tank to a vertical position, minimizing the stress on the control rod guide tubes.

p) $\_$Rebolt the top cover on the core tank.

q) Inserting the Core Tank into the Reactor Water Tank

a. $\_$Using the four jack bolts, connect core tank to crane with chains and lower into reactor water tank. May need to lubricate around glory hole weld in the water tank to enable tank to slide completely down.

b. $\checkmark$ Have someone with safety glasses underneath the reactor tank to make sure alignment is correct. Remember, valve on top of core tank should be on the south side.

c. After tank is in position, remove the harness by removing the 4 jack bolts.

r) $\angle$ Insert the glory hole liner and secure O-rings. Liner should extend about $1 / 4$ inch beyond each inner flange.

s) Glory Hole Flanges and Extension

a. $\triangle$ Attach outer flange covers on each side.

b. $\_$Align the extension and glory hole using the $\mathrm{Cd}$ rod and check with the sample holder rod.

c. Then on the west side, bolt the extension to the flange.

d. $\quad$ On the east side, lock the glory hole cover to secure and then replace the shielding.

e. $\_$Replace shielding on the west side after extension is securely bolted. 
AGN-201 Fuel Insertion and Procedure for Re-Assembly of Core Tank [TS 6.6.b]

Date: $\frac{M 2 y}{\gamma} 16,2019$

t) $\quad$ Re-install the 4 control rods on the bottom of the reactor.

$R B$ SRO initials

u) $\angle$ Unscrew the 12 bolts from the top core tank cover and insert the jack bolts.

v) $\quad$ Put the NORTH and SOUTH baffles beside the glory hole in the core tank. Make sure they go over the appropriate control rod cans.

w) $\angle$ Replace the top graphite reflector liners with lips at the bottom (first EAST, then WEST, then NORTH, and finally the SOUTH liner).

x) $\quad$ Replace the 6th fuel disk (\#100) centering around the rod guide tubes. $\quad R$ SRO initials

y) Replace the last five fuel disks (each disk should have serial number on top when inserted. Replace the last five fuel disks in ascending number order.
a) $\checkmark$ Replace disk 249101 $\quad$ RB SRO initials
b) $\quad$ Replace disk 249102.
c) $\quad$ Replace disk 249103. SRO initials
d) $\quad$ Replace disk 249104. Rß SRO initials
e) $\quad \sim$ Replace disk 249105. RB SRO initials

z) Use a long welding rod or similar thin cylinder to center the fuel disks in the core tank.

a) $\_$Replace the graphite reflector plug and remove the T-bar. 


\section{AGN-201 Fuel Insertion and Procedure for Re-Assembly of Core Tank [TS 6.6.b]}

Date: Moy 20,2019

bb) Sealing the core tank.

a. $\quad$ Apply vacuum grease to the cover O-ring

b. $\checkmark$ Replace the top core tank cover

c. $\checkmark$ Remove the jack bolts.

d. Replace the 12 bolts and secure the core tank top cover. (Do not over-tighten as this may strip the holes.)

cc) $\measuredangle$ Replace the thermal column using the crane and then bolt to reactor water tank.

This completes the re-assembly of the core tank.

Reviewed By:

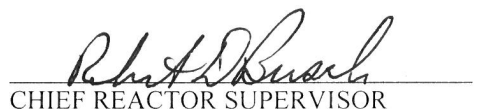


APPENDIX D. LAB RESULTS OF UNIVERSITY OF UTAH LEAD AND GRAPHITE AND IDAHO STATE UNIVERSITY FUEL SAMPLES 



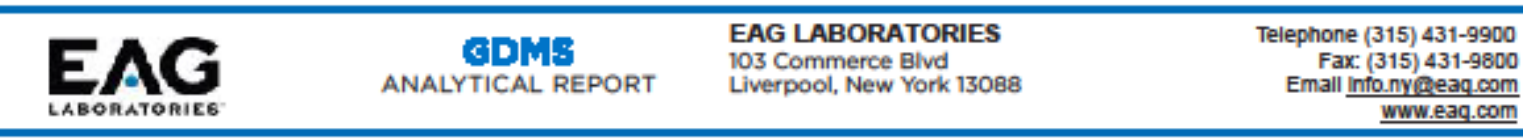

$\begin{array}{llll}\text { Customer: } & \begin{array}{l}\text { Idaho National Laboratory } \\ \text { 1765 N.Yellowstone Hwy. Idaho Falls, ID 83415-3779 }\end{array} & \text { P.O.\# } & \mathbf{1 8 8 4 7 8} \\ \text { Date: } & \text { 13-Jul-2017 } & \text { Job \# } & \text { COHWF571 } \\ \text { Customer ID: Graphite } & \text { Sample ID: } & \text { S170703018 } \\ & \text { Graphite Plug } & & \\ \end{array}$

\begin{tabular}{|c|c|c|c|}
\hline Element & $\begin{array}{l}\text { Concentration } \\
\text { [ppm wt ] }\end{array}$ & Element & $\begin{array}{l}\text { Concentration } \\
\text { [ppm wt ] }\end{array}$ \\
\hline Li & 6.1 & Pd & $<0.05$ \\
\hline$\overline{B e}$ & $<0.05$ & $\overline{\mathrm{Ag}}$ & $<0.05$ \\
\hline B & 4.5 & Cd & 0.09 \\
\hline $\bar{C}$ & Matrix & $\ln$ & $<0.05$ \\
\hline $\bar{N}$ & - & Sn & 0.05 \\
\hline $\mathrm{O}$ & - & $\mathrm{Sb}$ & $<0.05$ \\
\hline $\bar{F}$ & $<0.1$ & $\overline{\mathrm{Te}}$ & $<0.05$ \\
\hline $\mathrm{Na}$ & 24 & 1 & $<0.01$ \\
\hline$\overline{\mathrm{Mq}}$ & 5.7 & $\mathrm{Cs}$ & $<0.05$ \\
\hline $\mathrm{Al}$ & 10 & $\mathrm{Ba}$ & 0.06 \\
\hline Si & 110 & $\mathrm{La}$ & $<0.05$ \\
\hline$P$ & 6.2 & $\mathrm{Ce}$ & $<0.05$ \\
\hline$\underline{\mathrm{S}}$ & 370 & $\mathrm{Pr}$ & $<0.05$ \\
\hline $\mathrm{Cl}$ & 11 & $\mathrm{Nd}$ & $<0.05$ \\
\hline $\mathrm{K}$ & 2 & Sm & $<0.01$ \\
\hline $\mathrm{Ca}$ & 400 & $\mathrm{Eu}$ & $<0.01$ \\
\hline $\mathrm{Sc}$ & 0.03 & Gd & $<0.01$ \\
\hline $\mathrm{Ti}$ & 14 & $\mathrm{~Tb}$ & $<0.01$ \\
\hline $\mathrm{V}$ & 280 & Dy & $<0.01$ \\
\hline $\mathrm{Cr}$ & 12 & Ho & $<0.01$ \\
\hline $\mathrm{Mn}$ & 0.13 & $\mathrm{Er}$ & $<0.01$ \\
\hline $\mathrm{Fe}$ & 17 & $\mathrm{Tm}$ & $<0.01$ \\
\hline $\mathrm{Co}$ & 0.03 & $\mathrm{Yb}$ & $<0.01$ \\
\hline $\mathrm{Ni}$ & 1.7 & Lu & $<0.01$ \\
\hline $\mathrm{Cu}$ & 1.3 & $\mathrm{Hf}$ & $<0.01$ \\
\hline $\mathrm{Zn}$ & 1.6 & Ta & $<100$ \\
\hline $\mathrm{Ga}$ & $<0.01$ & W & 0.44 \\
\hline $\mathrm{Ge}$ & $<0.05$ & $\operatorname{Re}$ & $<0.01$ \\
\hline As & 0.06 & Os & $<0.01$ \\
\hline $\mathrm{Se}$ & $<0.05$ & Ir & $<0.01$ \\
\hline $\mathrm{Br}$ & $<0.1$ & $\mathrm{Pt}$ & $<0.01$ \\
\hline $\mathrm{Rb}$ & $<0.05$ & $\mathrm{Au}$ & $<0.1$ \\
\hline $\mathrm{Sr}$ & 2.8 & $\mathrm{Hq}$ & $<0.1$ \\
\hline$Y$ & 0.12 & $\mathrm{TI}$ & $<0.05$ \\
\hline $\mathrm{Zr}$ & 0.27 & $\mathrm{~Pb}$ & 41 \\
\hline $\mathrm{Nb}$ & 0.09 & $\mathrm{Bi}$ & $<0.05$ \\
\hline Mo & 0.39 & Th & $<0.05$ \\
\hline $\mathrm{Ru}$ & $<0.05$ & $\mathrm{U}$ & $<0.05$ \\
\hline Rh & $<0.01$ & & \\
\hline
\end{tabular}

ISO 17025

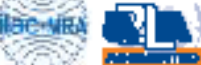

Testing Cert. \#2797.03
Page 1 of 1 - GDMS

Analyzed according to WI F rev. 12/06/12 Reviewed by
B.CIARLEI (Nnayst)<smiles>C=C1CCCC1</smiles>

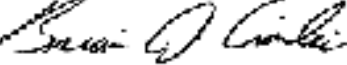

Precision and blas typical of GDMS measurements are discussed under ASTM F1503.

This shall not be reproduced except in full without wrttten approval of the laboratory. 


\begin{tabular}{|c|c|c|c|}
\hline LABORATORIE & $\|_{\text {ANALYTICAL REPORT }}^{\text {CAs }}$ & $\begin{array}{l}\text { EAG LABORATORIES } \\
103 \text { Commerce Blvd } \\
\text { Liverpool, New York } 13088\end{array}$ & $\begin{array}{r}\text { Telephone (315) 431-9900 } \\
\text { Fax: (315) } 431-9800 \\
\text { Emall Into.myqeag.com } \\
\text { wwweag.com }\end{array}$ \\
\hline
\end{tabular}

Customer. Idaho National Laboratory

1765 N.Yellowstone Hwy, Idaho Falls, ID 83415-3779

Date:

\begin{abstract}
6-Jul-17
\end{abstract}
Customer ID: Graphite

\section{Graphite Plug}

P.O.\# $\quad 188478$

Job \# COHWF571

Sample ID: S170703018

[Row: 2017-07-06 14:68:17]

\begin{tabular}{|c|c|}
\hline Element & $\begin{array}{c}\text { Concentration } \\
\text { [ ppm wt ] }\end{array}$ \\
\hline $\mathrm{C}$ & - \\
\hline $\mathrm{N}$ & 32 \\
\hline 0 & 700 \\
\hline $\mathrm{S}$ & - \\
\hline $\mathrm{H}$ & 34 \\
\hline
\end{tabular}

C,s determined by CemtuationtR

NH debersined by leF-TC

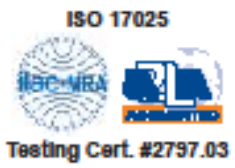

Page 1 of 1 - IGA

Reviewed by

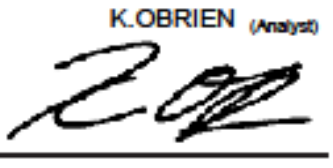

Precision and blas typical of IGA measurements are discussed under ASTM E1010 and E1447.

This shall not be reproduced except in full without wrttten approval of the laboratory. 


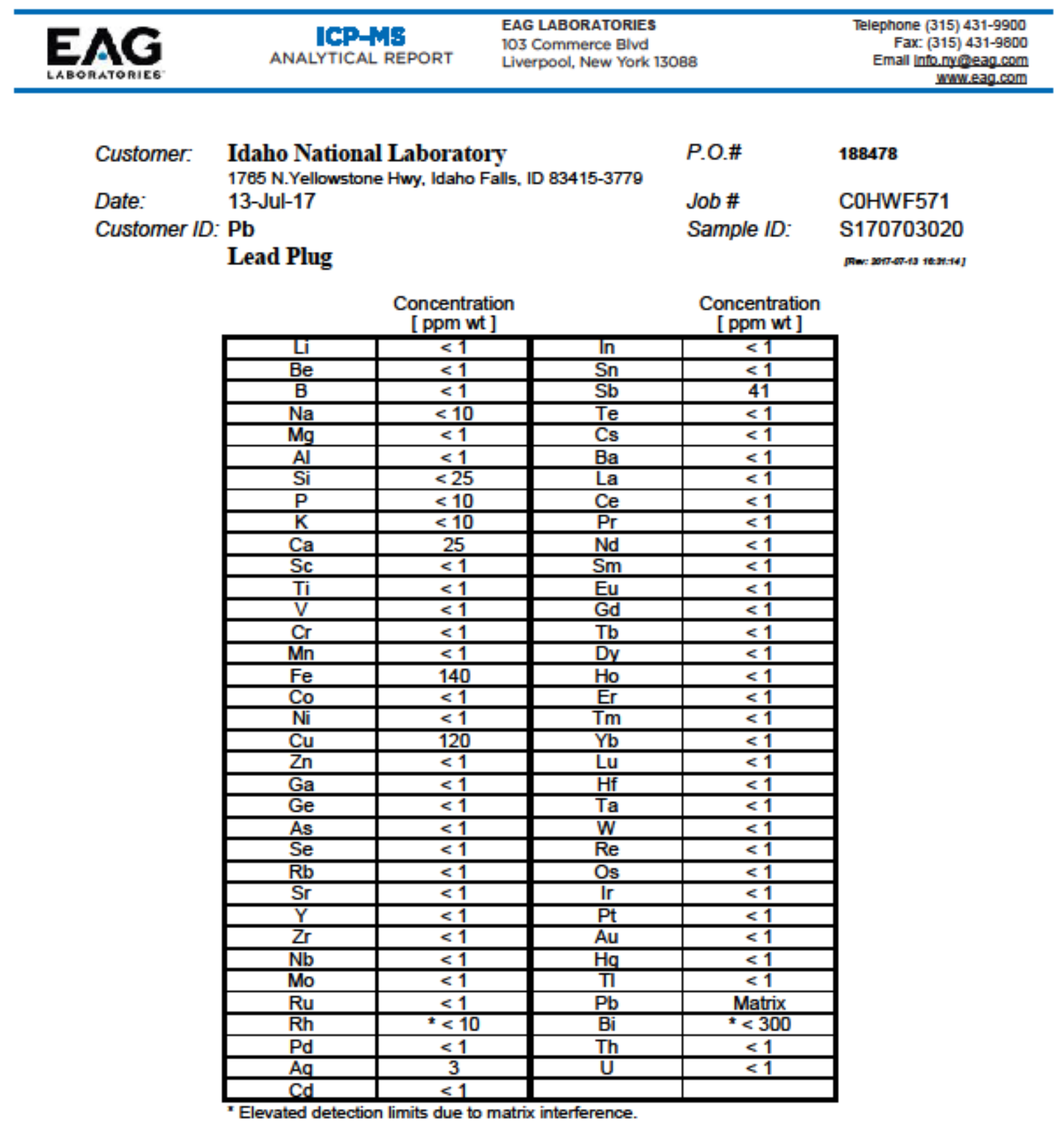

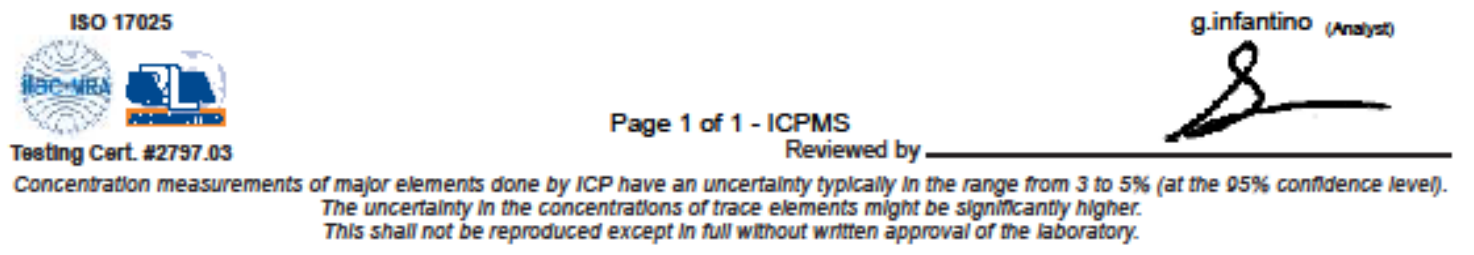




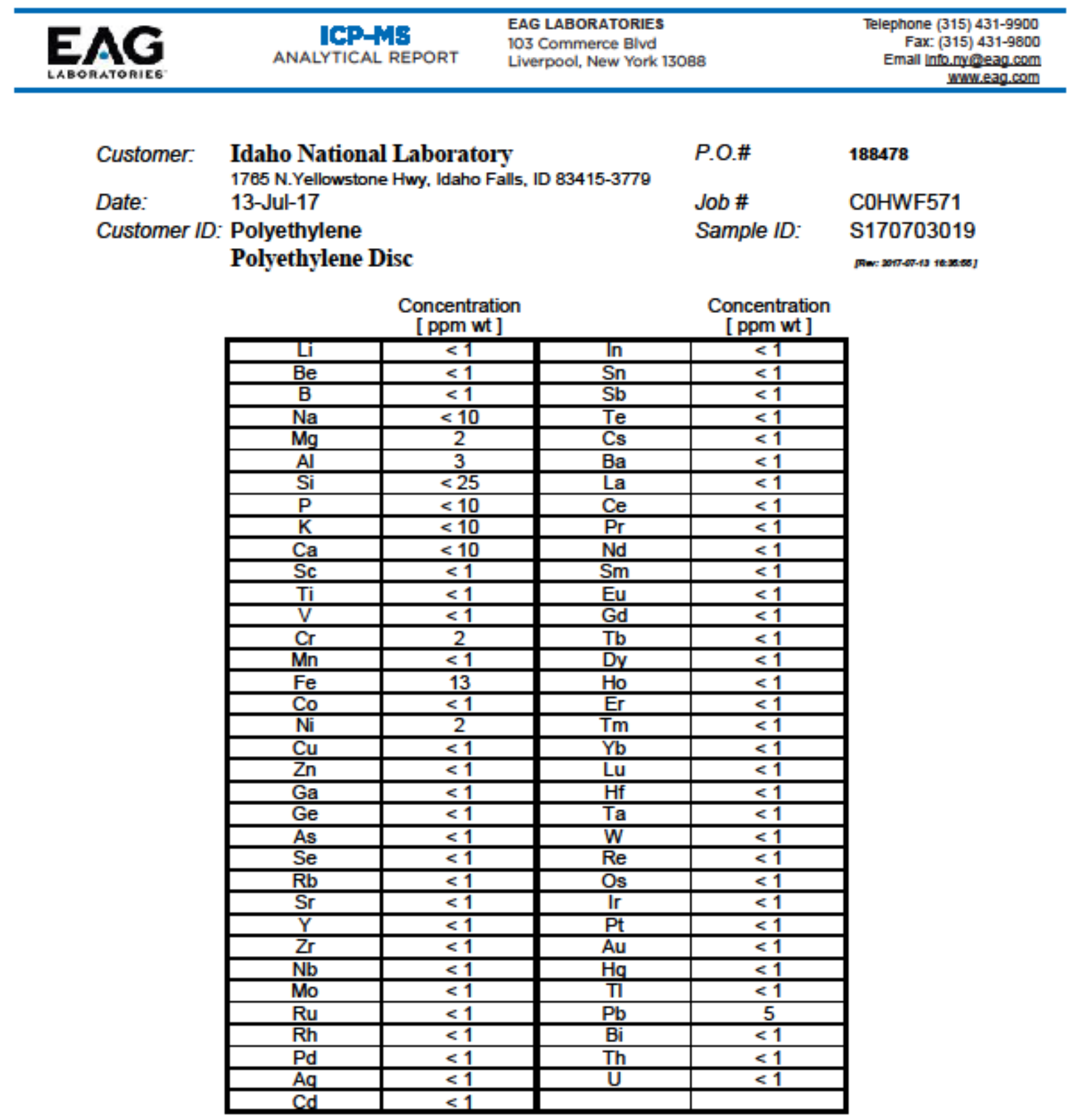

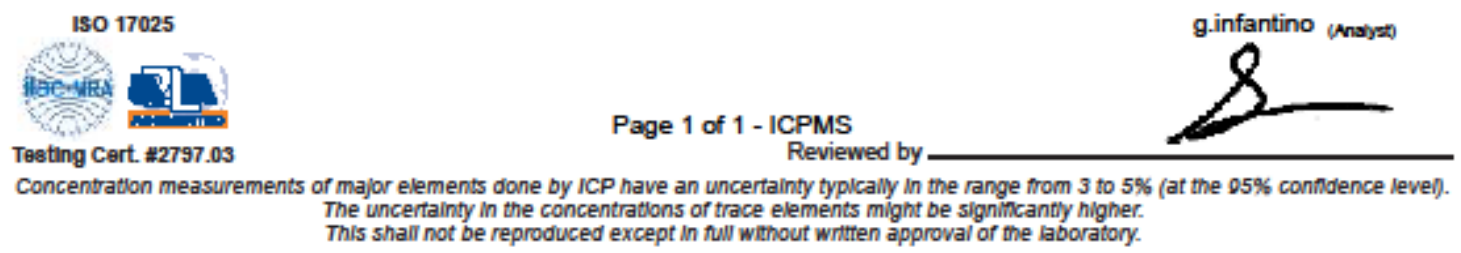




\section{INL - Materials and Fuels Complex}

Analytical Laboratory

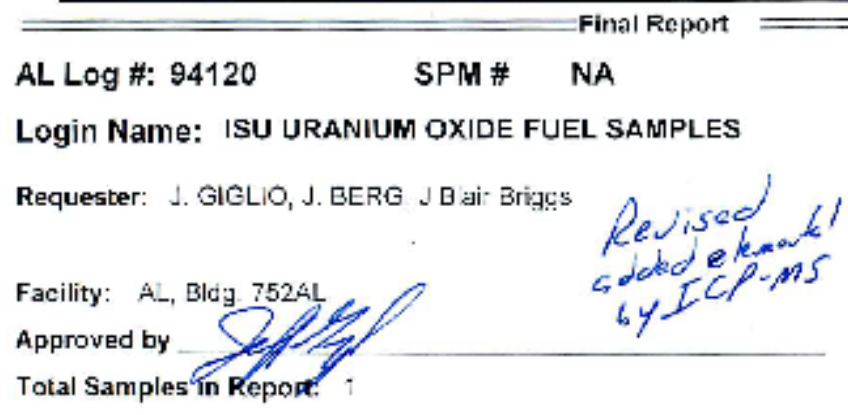

[. 4 - $1 \cdot 12: 38$

COC \#: NA

Charge \#: 550138255

Date Received: $07-5 a p-114.0 \% .00 \mathrm{P}$

Date: $10 / 4 / 1 /$

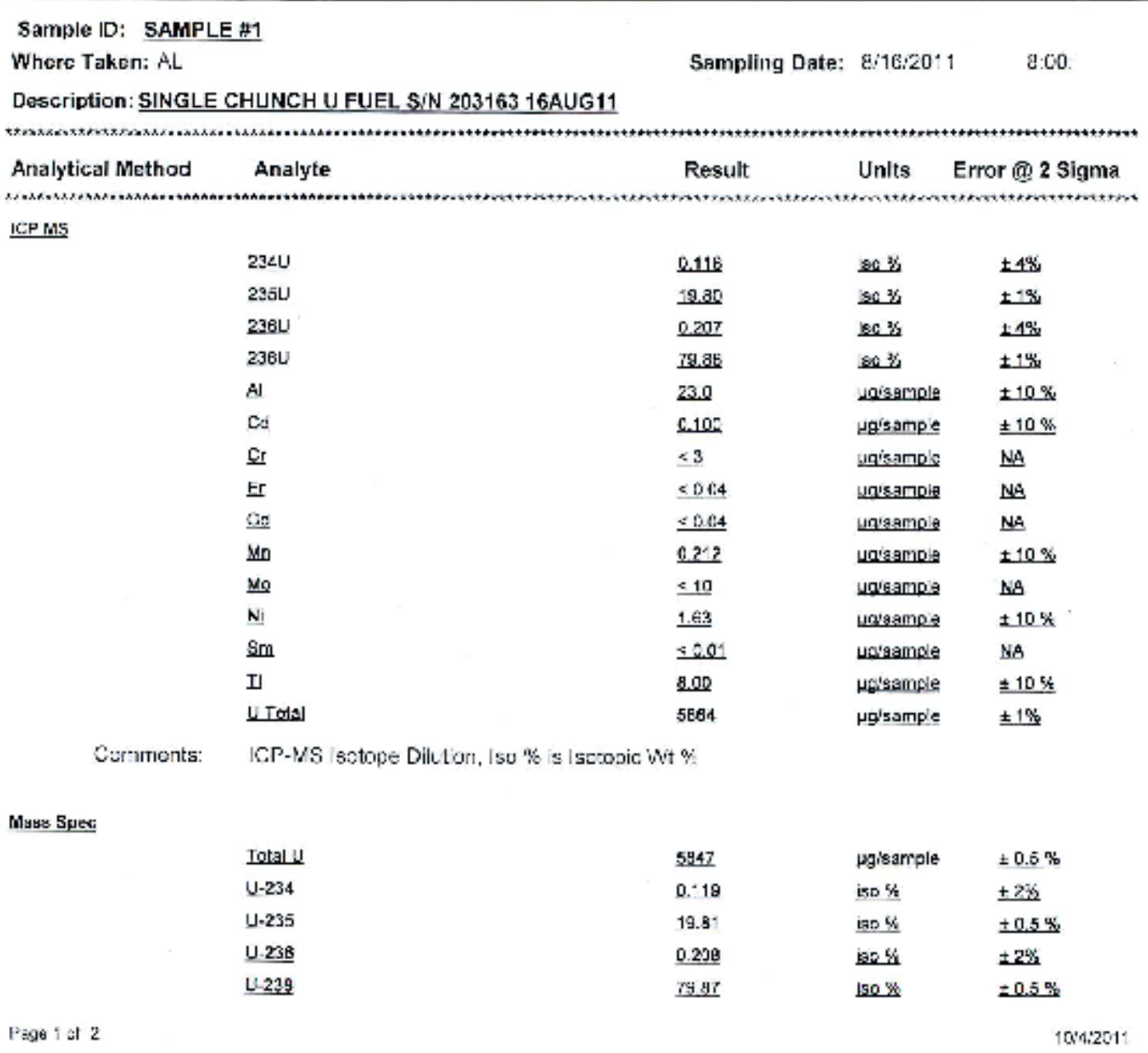




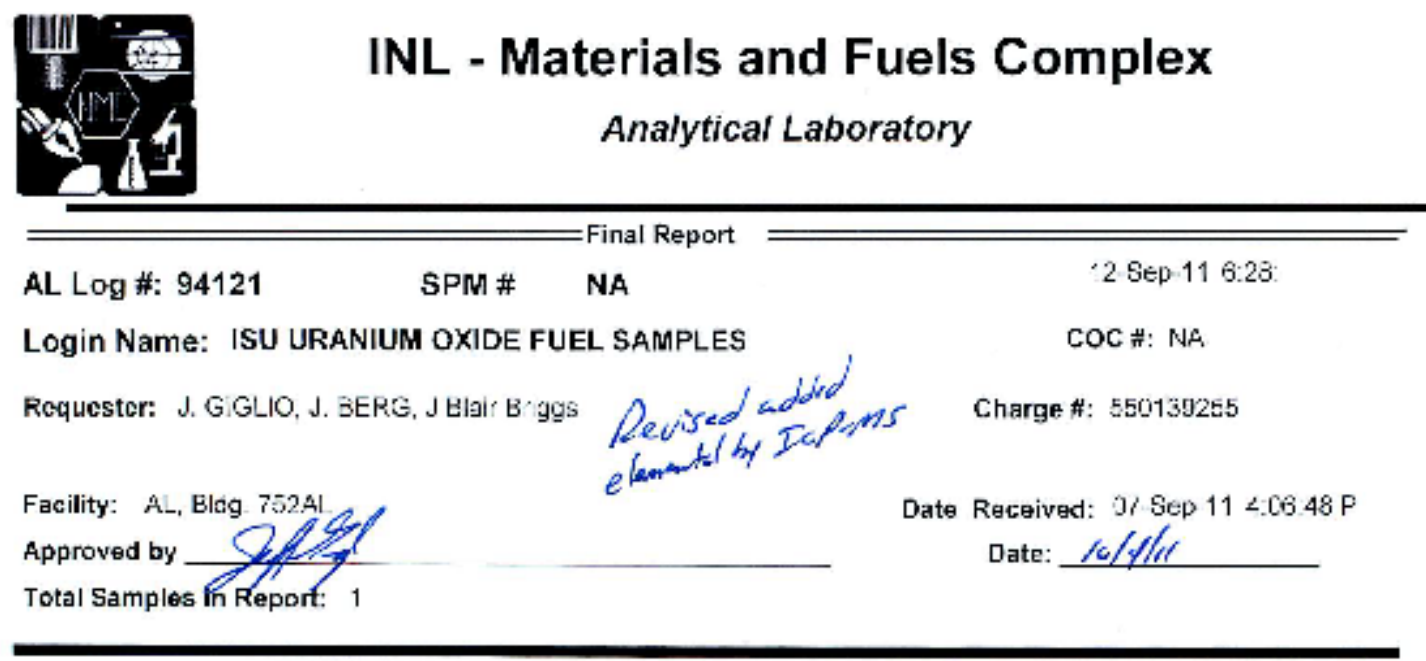

Sample ID: SAMPLE \#2

Where Taken: AL

Sampling Date: $2 / 13 / 2011 \quad 12 \% 00$

Description: SEVERAL LATHE TURNINGS U FUEL

\begin{tabular}{|c|c|c|c|c|}
\hline \multirow{3}{*}{$\begin{array}{l}\text { Analytical Method } \\
\text { ICP Mns }\end{array}$} & \multirow{2}{*}{ Analyte } & \multirow[t]{2}{*}{ Result } & \multirow[t]{2}{*}{ Units } & \multirow{2}{*}{ Error \&2 2 Sigma } \\
\hline & & & & \\
\hline & & & & \\
\hline & 23414 & $0.1 \cdot 7$ & iso $\%$ & $\pm+4 x$ \\
\hline & $235: 1$ & $\underline{19.71}$ & $180 \%$ & $\pm 1 \%$ \\
\hline & 23에 & $0.2 \mathrm{Cs}$ & $150 \%$ & \pm 18 \\
\hline & 2380 & $79 \mathrm{s6}$ & $150 \%$ & $=1 \%$ \\
\hline & Al & $\underline{31.4}$ & Ha'gemale & $=128$ \\
\hline & $\underline{c d}$ & 0.405 & Lolasmole & $\pm 0 \%$ \\
\hline & $\mathrm{Cr}$ & $\leq 3$ & Laisample & $\mathrm{NA}$ \\
\hline & Er & $<0.04$ & Hitsamzles & $\mathrm{NA}$ \\
\hline & Gsd & $<0.04$ & Lisamale & NA \\
\hline & Mo & 0.410 & 1.giakmgle & \pm 108 \\
\hline & Mo & $<10$ & ugikamels & NS \\
\hline & $\mathrm{Ni}$ & 260 & ugisamole & $\pm 10 \%$ \\
\hline & Sin & $=0.01$ & yoisambla & $\mathrm{NB}$ \\
\hline & $\underline{\underline{T}}$ & 049 & Jgiesmple & $\pm 10 \%$ \\
\hline & $\underline{U}$ Total & $=601$ & ugigariple & $\pm 1 \%$ \\
\hline Comments & \multicolumn{4}{|c|}{ ICP-MS I sotope Dil tisn, Isc "\% is Isclopic $1 / \mathrm{t}$ t\% } \\
\hline \multicolumn{5}{|l|}{ Maes Scec } \\
\hline & Tㅁaㅣㄴ & 6570 & Hgisatpie & $\pm 0.5 \%$ \\
\hline & $\underline{u-234}$ & 0.118 & $\underline{i=0}$ & $\pm 2 \underline{4}$ \\
\hline & $\underline{\mathbf{u}-235}$ & 19.73 & $150 \%$ & \pm 0.53 \\
\hline & U-23E & 0.2018 & $150 \%$ & \pm 25 \\
\hline & L-23A & $\underline{7995}$ & 1904 & $\pm 0.5 \%$ \\
\hline
\end{tabular}

Pagn $1 x ;$

11'4:\%11' 
APPENDIX E. SANDIA NATIONAL LABORATORIES NDA RESULTS 

Sandia

National

Laboratories
Radiation Protection Sample Diagnostics Program

1515 Eubank Ave, MS 1103 Albuquerque, NM 87185-1103 (505) 844- 4069

\section{Results For: $\quad$ UNM AGN-201_6-19 $\begin{gathered}\text { Report Date: } \\ \text { Report Time: }\end{gathered} \quad \begin{aligned} & 6 / 26 / 2019 \\ & 1.143131 \mathrm{MM}\end{aligned}$}

Customer

Email:

Phone:
Org:00631 , Analytical Services

Mail Stop: 1103

Cell:

Customer Samples Within This Report

\begin{tabular}{|c|c|l|c|c|c|c|}
\hline Batch ID & Sample No & Customer Sample ID & $\begin{array}{c}\text { Validation } \\
\text { Date }\end{array}$ & Login Batch & Analysis Code & Drop off Location \\
\hline GAMMA-12364 & AB51155 & AGN Plate 97 & $06 / 26 / 2019$ & 190613009 & \$GAMMA & RPSD TA2 Lab \\
GAMMA-12364 & AB51156 & AGN Plate 98 & $06 / 26 / 2019$ & 190613009 & \$GAMMA & RPSD TA2 Lab \\
GAMMA-12364 & AB51157 & AGN Plate 99 & $06 / 26 / 2019$ & 190613009 & \$GAMMA & RPSD TA2 Lab \\
GAMMA-12364 & AB51158 & AGN Plate 100 & $06 / 26 / 2019$ & 190613009 & \$GAMMA & RPSD TA2 Lab \\
GAMMA-12364 & AB51159 & AGN Plate 101 & $06 / 26 / 2019$ & 190613009 & \$GAMMA & RPSD TA2 Lab \\
GAMMA-12364 & AB51160 & AGN Plate 102 & $06 / 26 / 2019$ & 190613009 & \$GAMMA & RPSD TA2 Lab \\
GAMMA-12364 & AB51161 & AGN Plate 103 & $06 / 26 / 2019$ & 190613009 & \$GAMMA & RPSD TA2 Lab \\
GAMMA-12364 & AB51162 & AGN Plate 104 & $06 / 26 / 2019$ & 190613009 & \$GAMMA & RPSD TA2 Lab \\
GAMMA-12364 & AB51163 & AGN Plate 105 & $06 / 26 / 2019$ & 190613009 & \$GAMMA & RPSD TA2 Lab \\
GAMMA-12364 & AB51164 & AGN Fission Plate & $06 / 26 / 2019$ & 190613009 & \$GAMMA & RPSD TA2 Lab \\
GAMMA-12365 & AB51165 & AGN Corse Rod & $06 / 26 / 2019$ & 190613009 & \$GAMMA & RPSD TA2 Lab \\
GAMMA-12365 & AB51166 & AGN Fine Rod & $06 / 26 / 2019$ & 190613009 & \$GAMMA & RPSD TA2 Lab \\
GAMMA-12365 & AB51167 & AGN Safety Rod 1 & $06 / 26 / 2019$ & 190613009 & \$GAMMA & RPSD TA2 Lab \\
GAMMA-12365 & AB51168 & AGN Safety Rod 2 & $06 / 26 / 2019$ & 190613009 & \$GAMMA & RPSD TA2 Lab \\
\hline
\end{tabular}

\section{Quality Samples Within This Report}

\begin{tabular}{|c|c|l|c|c|c|}
\hline Batch ID & Sample No & Sample Type & Validation Date & Analysis Code & Analysis Name \\
\hline GAMMA-12364 & AB51170 & Quality & $06 / 26 / 2019$ & \$F_GAMMA & Field Blank Gamma Spectroscopy \\
GAMMA-12365 & AB51171 & Quality & $06 / 26 / 2019$ & \$F_GAMMA & Field Blank Gamma Spectroscopy \\
\hline
\end{tabular}

\begin{tabular}{|r|lll|}
\hline Waste Flags: & +- Segregate as Radioactive & * - Do Not Recycle \\
\hline Quality Flags: & A - Accepted & J - Estimated & R - Rejected \\
\hline Detection Flags: & (Blank) - Detected & U - Not Detected & N - Poor Statistics \\
\hline
\end{tabular}

UNM AGN-201_6-19 


\section{Gamma Spectroscopy}

\section{GAMMA-12364}

\section{AB51155 - AGN Plate 97}

\begin{abstract}
Live Time (s): 3600
Real Time (s): 4542

Detector: PGE14
\end{abstract}

Geometry: AGN-97-IS

Library: AGN-201M

Background: 14_PGE_190514
Count Date: 5/16/2019 10:30:09AM Collection Date: 5/13/2019 12:00:00PM Quantity (each): $1.00 e+000$

Analyzed By:
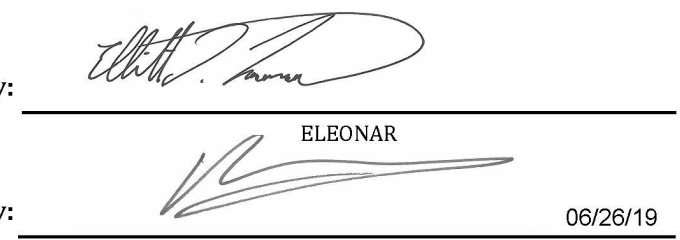

RPREESE

\begin{tabular}{|c|c|c|c|c|c|}
\hline Analyte & $\begin{array}{c}\text { Activity } \\
\text { (dpm) }\end{array}$ & $\begin{array}{c}\text { Unc } \\
(2.0 \sigma)\end{array}$ & $\begin{array}{l}\text { Lab } \\
\text { Flag }\end{array}$ & $\begin{array}{c}\text { MDA } \\
\text { (dpm) }\end{array}$ & $\begin{array}{c}\text { CL } \\
\text { (dpm) }\end{array}$ \\
\hline U-238 & $3.79 e+008$ & $4.73 e+007$ & A & $5.72 e+007$ & $2.85 e+007$ \\
\hline RA-226 & $8.95 e+009$ & $1.61 e+009$ & $\mathrm{AU}$ & $4.01 e+007$ & $2.00 \mathrm{e}+007$ \\
\hline PB-214 & $1.36 e+006$ & $1.71 e+006$ & $\mathrm{AU}$ & $2.16 e+006$ & $1.08 e+006$ \\
\hline $\mathrm{Bl}-214$ & $-6.07 e+004$ & $2.43 e+005$ & $\mathrm{AU}$ & $1.90 e+006$ & $9.48 e+005$ \\
\hline PB-210 & $-5.43 e+007$ & $8.68 e+007$ & $\mathrm{AU}$ & $1.06 e+008$ & $5.30 e+007$ \\
\hline AC-228 & $2.44 e+006$ & $1.46 e+006$ & $\mathrm{AU}$ & $1.87 e+006$ & $9.36 e+005$ \\
\hline RA-224 & $1.51 \mathrm{e}+005$ & $9.74 e+004$ & A & $1.55 e+005$ & $7.62 e+004$ \\
\hline PB-212 & $-1.72 e+006$ & $1.68 e+006$ & $\mathrm{AU}$ & $2.18 \mathrm{e}+006$ & $1.09 e+006$ \\
\hline Bl-212 & $-8.43 e+007$ & $1.08 e+007$ & $\mathrm{AU}$ & $2.77 e+007$ & $1.39 e+007$ \\
\hline TL-208 & $3.61 e+005$ & $7.41 e+005$ & $\mathrm{AU}$ & $9.78 e+005$ & $4.89 e+005$ \\
\hline U-235 & $5.61 e+008$ & $1.01 e+008$ & A & $2.52 e+006$ & $1.26 e+006$ \\
\hline TH-231 & $3.41 e+009$ & $6.84 e+008$ & A & $1.50 e+008$ & $7.50 e+007$ \\
\hline PA-231 & $2.03 e+008$ & $5.17 e+007$ & $\mathrm{AU}$ & $5.12 e+007$ & $2.56 e+007$ \\
\hline TH-227 & $1.76 e+007$ & $6.21 e+006$ & $\mathrm{AU}$ & $7.32 e+006$ & $3.67 e+006$ \\
\hline RA-223 & $3.70 e+008$ & $7.42 e+007$ & $\mathrm{AU}$ & $7.14 \mathrm{e}+006$ & $3.57 e+006$ \\
\hline RN-219 & $1.80 e+006$ & $6.05 e+006$ & $\mathrm{AU}$ & $1.20 \mathrm{e}+007$ & $5.99 e+006$ \\
\hline
\end{tabular}

\begin{tabular}{|r|lll|}
\hline Waste Flags: & \multicolumn{4}{|l|}{ +- Segregate as Radioactive } & ${ }^{*}$ - Do Not Recycle \\
\hline Quality Flags: & A - Accepted & J - Estimated & R - Rejected \\
\hline Detection Flags: & (Blank) - Detected & U - Not Detected & N - Poor Statistics \\
\hline
\end{tabular}

UNM AGN-201_6-19 
AB51155

\begin{tabular}{|c|c|c|c|c|c|}
\hline Analyte & $\begin{array}{l}\text { Activity } \\
\text { (dpm) }\end{array}$ & $\begin{array}{c}\text { Unc } \\
(2.0 \sigma)\end{array}$ & $\begin{array}{l}\text { Lab } \\
\text { Flag }\end{array}$ & $\begin{array}{c}\text { MDA } \\
(\mathrm{dpm})\end{array}$ & $\begin{array}{c}\text { CL } \\
\text { (dpm) }\end{array}$ \\
\hline PB-211 & $1.58 e+005$ & $1.53 e+007$ & $\mathrm{AU}$ & $2.09 e+007$ & $1.04 e+007$ \\
\hline TL-207 & $-7.39 \mathrm{e}+006$ & $1.44 e+008$ & $\mathrm{AU}$ & $1.85 e+008$ & $9.24 \mathrm{e}+007$ \\
\hline NP-237 & $-1.97 e+010$ & $3.94 e+009$ & $\mathrm{AU}$ & $4.00 e+008$ & $2.00 \mathrm{e}+008$ \\
\hline PA-233 & $-2.41 e+004$ & $1.78 \mathrm{e}+006$ & $\mathrm{AU}$ & $2.26 e+006$ & $1.13 e+006$ \\
\hline TH-229 & $-7.26 e+007$ & $1.50 e+007$ & $\mathrm{AU}$ & $2.05 e+007$ & $1.02 e+007$ \\
\hline BA-133 & $-1.95 e+006$ & $1.07 e+006$ & $A U$ & $1.30 e+006$ & $6.48 \mathrm{e}+005$ \\
\hline Ba-140 & $2.13 e+008$ & $2.61 \mathrm{e}+007$ & A & $3.99 \mathrm{e}+006$ & $1.99 e+006$ \\
\hline CD-115 & $1.08 \mathrm{e}+006$ & $1.44 e+006$ & $\mathrm{AU}$ & $1.82 e+006$ & $9.06 e+005$ \\
\hline CE-141 & $4.71 \mathrm{e}+008$ & $9.46 e+007$ & A & $3.43 \mathrm{e}+006$ & $1.72 \mathrm{e}+006$ \\
\hline CE-144 & $3.84 e+008$ & $7.72 e+007$ & A & $1.56 \mathrm{e}+007$ & $7.80 e+006$ \\
\hline $\mathrm{CO}-60$ & $1.23 e+005$ & $3.85 e+005$ & $\mathrm{AU}$ & $5.14 \mathrm{e}+005$ & $2.56 \mathrm{e}+005$ \\
\hline CS-137 & $1.68 \mathrm{e}+008$ & $2.03 e+007$ & A & $7.14 e+005$ & $3.57 e+005$ \\
\hline $\mathrm{Ce}-143$ & $2.13 e+005$ & $7.54 e+005$ & $\mathrm{AU}$ & $2.11 \mathrm{e}+006$ & $1.06 \mathrm{e}+006$ \\
\hline I-131 & $4.55 e+007$ & $6.78 e+006$ & A & $1.28 \mathrm{e}+006$ & $6.36 \mathrm{e}+005$ \\
\hline I-132 & $1.46 \mathrm{e}+007$ & $1.74 e+006$ & A & $9.60 \mathrm{e}+005$ & $4.79 \mathrm{e}+005$ \\
\hline $1-133$ & $1.04 e+007$ & $1.32 e+006$ & $\mathrm{AU}$ & $1.13 e+006$ & $5.66 e+005$ \\
\hline In- $115 m$ & $1.17 e+006$ & $1.57 e+006$ & $\mathrm{AU}$ & $1.99 e+006$ & $9.90 \mathrm{e}+005$ \\
\hline La-140 & $2.50 e+008$ & $2.00 e+007$ & A & $7.44 e+005$ & $3.70 e+005$ \\
\hline MO-99 & $8.52 e+006$ & $2.75 e+006$ & A & $4.16 e+006$ & $2.08 e+006$ \\
\hline NB-95m & $7.75 e+006$ & $1.81 e+006$ & A & $4.21 e+006$ & $2.11 e+006$ \\
\hline ND-147 & $6.80 \mathrm{e}+007$ & $8.54 e+006$ & A & $7.38 \mathrm{e}+006$ & $3.69 \mathrm{e}+006$ \\
\hline NP-239 & $1.34 \mathrm{e}+007$ & $5.11 e+006$ & $\mathrm{AU}$ & $6.12 \mathrm{e}+006$ & $3.07 e+006$ \\
\hline $\mathrm{Nb}-95$ & $8.14 e+008$ & $9.77 e+007$ & A & $6.30 \mathrm{e}+005$ & $3.16 \mathrm{e}+005$ \\
\hline PM-149 & $-6.61 e+006$ & $7.11 e+006$ & $\mathrm{AU}$ & $2.81 e+007$ & $1.40 \mathrm{e}+007$ \\
\hline Pr-144 & $1.67 \mathrm{e}+009$ & $2.27 \mathrm{e}+008$ & A & $1.69 \mathrm{e}+008$ & $8.46 e+007$ \\
\hline RU-103 & $3.07 e+008$ & $3.70 e+007$ & A & $9.36 e+005$ & $4.66 \mathrm{e}+005$ \\
\hline RU-106 & $2.97 e+007$ & $4.11 e+006$ & A & $6.36 e+006$ & $3.19 \mathrm{e}+006$ \\
\hline SB-124 & $-9.77 e+005$ & $5.87 e+005$ & $\mathrm{AU}$ & $7.86 e+005$ & $3.94 \mathrm{e}+005$ \\
\hline SB-125 & $-2.87 e+005$ & $9.24 e+005$ & $\mathrm{AU}$ & $2.73 e+006$ & $1.36 \mathrm{e}+006$ \\
\hline SB-127 & $2.42 e+006$ & $1.24 e+006$ & $\mathrm{AU}$ & $1.61 e+006$ & $8.04 e+005$ \\
\hline Tc-99m & $1.37 \mathrm{e}+007$ & $2.82 e+006$ & A & $2.18 \mathrm{e}+006$ & $1.09 e+006$ \\
\hline Te-127m & $-1.43 e+009$ & $5.63 e+008$ & $\mathrm{AU}$ & $5.87 e+008$ & $2.93 e+008$ \\
\hline
\end{tabular}

Page 3 of 49

\begin{tabular}{|r|lll|}
\hline Waste Flags: & + - Segregate as Radioactive & * - Do Not Recycle \\
\hline Quality Flags: & A - Accepted & J - Estimated & R - Rejected \\
\hline Detection Flags: & (Blank) - Detected & U - Not Detected & N - Poor Statistics \\
\hline
\end{tabular}

UNM AGN-201_6-19 


\section{AB51155}

\begin{tabular}{|c|c|c|c|c|c|}
\hline Analyte & $\begin{array}{c}\text { Activity } \\
\text { (dpm) }\end{array}$ & $\begin{array}{c}\text { Unc } \\
(2.0 \sigma)\end{array}$ & $\begin{array}{l}\text { Lab } \\
\text { Flag }\end{array}$ & $\begin{array}{c}\text { MDA } \\
(\mathrm{dpm})\end{array}$ & $\begin{array}{c}\text { CL } \\
\text { (dpm) }\end{array}$ \\
\hline Te-129m & $2.29 e+008$ & $3.11 e+007$ & $\mathrm{AU}$ & $2.32 \mathrm{e}+007$ & $1.16 e+007$ \\
\hline Te-131m & $-6.03 e+005$ & $4.06 e+005$ & $A U$ & $1.76 e+006$ & $8.82 \mathrm{e}+005$ \\
\hline Te-132 & $1.29 e+007$ & $2.49 \mathrm{e}+006$ & A & $1.16 e+006$ & $5.78 e+005$ \\
\hline U-232 & $-1.94 e+009$ & $1.26 \mathrm{e}+009$ & $A U$ & $1.48 \mathrm{e}+009$ & $7.38 \mathrm{e}+008$ \\
\hline U-234 & $-3.40 \mathrm{e}+007$ & $3.77 e+009$ & $\mathrm{AU}$ & $5.18 \mathrm{e}+009$ & $2.59 e+009$ \\
\hline U-237 & $-4.07 e+007$ & $1.06 e+007$ & $A U$ & $8.16 e+006$ & $4.09 e+006$ \\
\hline XE-131m & $1.99 e+009$ & $4.00 \mathrm{e}+008$ & $\mathrm{AU}$ & $7.92 \mathrm{e}+007$ & $3.95 \mathrm{e}+007$ \\
\hline XE-133 & $1.18 \mathrm{e}+008$ & $2.39 e+007$ & A & $5.20 \mathrm{e}+006$ & $2.60 e+006$ \\
\hline$Y-88$ & $1.27 e+005$ & $1.63 e+005$ & $\mathrm{AU}$ & $2.17 e+005$ & $1.07 e+005$ \\
\hline$Y-91$ & $5.58 \mathrm{e}+008$ & $1.20 \mathrm{e}+008$ & A & $1.76 e+008$ & $8.76 e+007$ \\
\hline Y-91m & $4.82 e+006$ & $1.24 e+006$ & $\mathrm{AU}$ & $1.79 e+006$ & $8.94 \mathrm{e}+005$ \\
\hline ZR-95 & $7.22 e+008$ & $8.67 e+007$ & A & $1.10 \mathrm{e}+006$ & $5.47 e+005$ \\
\hline
\end{tabular}

Page 4 of 49

\begin{tabular}{|r|lll|}
\hline Waste Flags: & + - Segregate as Radioactive & ${ }^{*}$ - Do Not Recycle \\
\hline Quality Flags: & A - Accepted & J - Estimated & R - Rejected \\
\hline Detection Flags: & (Blank) - Detected & U - Not Detected & N - Poor Statistics \\
\hline
\end{tabular}

UNM AGN-201_6-19 


\section{AB51156 - AGN Plate 98}

Live Time (s): 3600

Real Time (s): 4834

Detector: PGE14
Geometry: AGN-98-IS

Library: AGN-201M

Background: 14_PGE_190514
Count Date: 5/16/2019 8:57:56AM Collection Date: 5/13/2019 12:00:00PM Quantity (each): $1.00 \mathrm{e}+000$

Analyzed By:

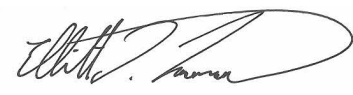

Reviewed By

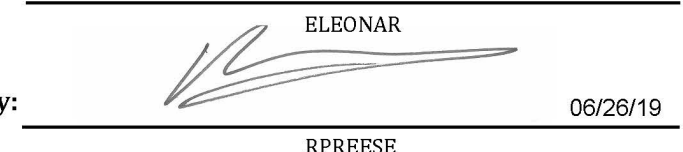

RPREESE

AB51156

\begin{tabular}{|c|c|c|c|c|c|}
\hline Analyte & $\begin{array}{c}\text { Activity } \\
\text { (dpm) }\end{array}$ & $\begin{array}{c}\text { Unc } \\
(2.0 \sigma)\end{array}$ & $\begin{array}{c}\text { Lab } \\
\text { Flag }\end{array}$ & $\begin{array}{c}\text { MDA } \\
\text { (dpm) }\end{array}$ & $\begin{array}{c}\text { CL } \\
\text { (dpm) }\end{array}$ \\
\hline U-238 & $3.77 e+008$ & $1.09 e+008$ & A & $7.26 e+007$ & $3.62 \mathrm{e}+007$ \\
\hline RA-226 & $8.93 e+009$ & $3.21 \mathrm{e}+009$ & $\mathrm{AU}$ & $4.64 \mathrm{e}+007$ & $2.32 e+007$ \\
\hline PB-214 & $1.41 e+006$ & $4.02 e+006$ & $\mathrm{AU}$ & $2.54 e+006$ & $1.27 e+006$ \\
\hline $\mathrm{Bl}-214$ & $-1.32 \mathrm{e}+005$ & $5.84 e+005$ & $\mathrm{AU}$ & $2.26 e+006$ & $1.13 e+006$ \\
\hline PB-210 & $-2.35 e+008$ & $2.42 \mathrm{e}+008$ & $\mathrm{AU}$ & $1.25 e+008$ & $6.24 \mathrm{e}+007$ \\
\hline AC-228 & $2.84 e+006$ & $3.72 \mathrm{e}+006$ & $\mathrm{AU}$ & $2.38 e+006$ & $1.19 e+006$ \\
\hline RA-224 & $1.70 e+005$ & $2.18 \mathrm{e}+005$ & A & $1.75 e+005$ & $8.58 e+004$ \\
\hline PB-212 & $-2.74 e+006$ & $3.98 \mathrm{e}+006$ & $\mathrm{AU}$ & $2.55 e+006$ & $1.27 e+006$ \\
\hline BI-212 & $-1.41 e+008$ & $3.51 \mathrm{e}+007$ & $\mathrm{AU}$ & $3.19 e+007$ & $1.59 e+007$ \\
\hline TL-208 & $-8.85 e+005$ & $1.78 e+006$ & $\mathrm{AU}$ & $1.16 e+006$ & $5.83 e+005$ \\
\hline U-235 & $5.60 e+008$ & $2.02 e+008$ & A & $2.92 \mathrm{e}+006$ & $1.46 e+006$ \\
\hline TH-231 & $4.67 e+009$ & $1.87 e+009$ & A & $1.82 e+008$ & $9.06 e+007$ \\
\hline PA-231 & $1.95 e+008$ & $1.12 e+008$ & $\mathrm{AU}$ & $6.00 e+007$ & $3.00 e+007$ \\
\hline $\mathrm{TH}-227$ & $1.69 e+007$ & $1.41 \mathrm{e}+007$ & $\mathrm{AU}$ & $8.58 e+006$ & $4.30 e+006$ \\
\hline RA-223 & $4.40 e+008$ & $1.76 e+008$ & $\mathrm{AU}$ & $8.58 e+006$ & $4.30 \mathrm{e}+006$ \\
\hline $\mathrm{RN}-219$ & $-2.46 e+006$ & $2.07 e+007$ & $\mathrm{AU}$ & $1.42 e+007$ & $7.08 e+006$ \\
\hline PB-211 & $2.51 e+006$ & $3.60 \mathrm{e}+007$ & $\mathrm{AU}$ & $2.47 e+007$ & $1.23 e+007$ \\
\hline TL-207 & $-3.19 e+007$ & $3.72 \mathrm{e}+008$ & $\mathrm{AU}$ & $2.38 e+008$ & $1.19 \mathrm{e}+008$ \\
\hline NP-237 & $-2.37 e+010$ & $9.52 e+009$ & $\mathrm{AU}$ & $4.49 e+008$ & $2.24 \mathrm{e}+008$ \\
\hline PA-233 & $-6.67 e+005$ & $4.18 e+006$ & $\mathrm{AU}$ & $2.65 e+006$ & $1.32 e+006$ \\
\hline TH-229 & $-1.06 e+008$ & $4.34 e+007$ & $\mathrm{AU}$ & $2.29 e+007$ & $1.15 e+007$ \\
\hline BA-133 & $-1.84 e+006$ & $2.49 e+006$ & $\mathrm{AU}$ & $1.53 e+006$ & $7.62 e+005$ \\
\hline Ba-140 & $2.88 \mathrm{e}+008$ & $7.03 e+007$ & A & $4.93 e+006$ & $2.46 e+006$ \\
\hline \multirow{3}{*}{ Page 5 of 49} & Wast & \multicolumn{3}{|c|}{ + - Segregate as Radioactive } & \\
\hline & Quali & A - Accepted & $\mathbf{J}$ - Estimated & R - Rejected & \\
\hline & Detectio & (Blank) - Detected & U - Not Detected & $\mathrm{N}$ - Poor Statistics & \\
\hline
\end{tabular}


AB51156

\begin{tabular}{|c|c|c|c|c|c|}
\hline Analyte & $\begin{array}{l}\text { Activity } \\
\text { (dpm) }\end{array}$ & $\begin{array}{c}\text { Unc } \\
(2.0 \sigma)\end{array}$ & $\begin{array}{l}\text { Lab } \\
\text { Flag }\end{array}$ & $\begin{array}{c}\text { MDA } \\
(\mathrm{dpm})\end{array}$ & $\begin{array}{c}\text { CL } \\
(\mathrm{dpm})\end{array}$ \\
\hline CD-115 & $-1.78 e+006$ & $3.42 \mathrm{e}+006$ & $\mathrm{AU}$ & $2.14 e+006$ & $1.07 e+006$ \\
\hline CE-141 & $8.43 e+008$ & $3.37 e+008$ & A & $4.85 e+006$ & $2.42 \mathrm{e}+006$ \\
\hline CE-144 & $6.09 e+008$ & $2.44 e+008$ & A & $1.84 e+007$ & $9.24 e+006$ \\
\hline $\mathrm{CO}-60$ & $4.36 \mathrm{e}+005$ & $9.27 e+005$ & $A U$ & $6.18 \mathrm{e}+005$ & $3.08 \mathrm{e}+005$ \\
\hline CS-137 & $2.24 e+008$ & $5.39 e+007$ & A & $8.94 e+005$ & $4.46 e+005$ \\
\hline $\mathrm{Ce}-143$ & $4.19 \mathrm{e}+006$ & $4.12 \mathrm{e}+006$ & $\mathrm{AU}$ & $2.48 \mathrm{e}+006$ & $1.24 \mathrm{e}+006$ \\
\hline $\mid-131$ & $6.12 e+007$ & $1.82 e+007$ & A & $1.44 e+006$ & $7.20 e+005$ \\
\hline |-132 & $1.99 \mathrm{e}+007$ & $4.70 \mathrm{e}+006$ & A & $1.28 \mathrm{e}+006$ & $6.42 \mathrm{e}+005$ \\
\hline $1-133$ & $1.31 \mathrm{e}+007$ & $3.29 \mathrm{e}+006$ & $\mathrm{AU}$ & $1.38 \mathrm{e}+006$ & $6.90 \mathrm{e}+005$ \\
\hline In-115m & $-1.95 e+006$ & $3.76 e+006$ & $\mathrm{AU}$ & $2.35 \mathrm{e}+006$ & $1.17 e+006$ \\
\hline La-140 & $3.33 e+008$ & $5.34 \mathrm{e}+007$ & A & $5.78 \mathrm{e}+005$ & $2.88 \mathrm{e}+005$ \\
\hline MO-99 & $1.71 \mathrm{e}+007$ & $8.36 e+006$ & A & $5.55 \mathrm{e}+006$ & $2.77 e+006$ \\
\hline NB-95m & $9.14 e+006$ & $4.07 e+006$ & A & $4.94 e+006$ & $2.47 e+006$ \\
\hline ND-147 & $8.55 e+007$ & $2.13 e+007$ & A & $9.00 \mathrm{e}+006$ & $4.48 \mathrm{e}+006$ \\
\hline NP-239 & $1.79 \mathrm{e}+007$ & $1.23 e+007$ & $\mathrm{AU}$ & $7.20 \mathrm{e}+006$ & $3.61 e+006$ \\
\hline $\mathrm{Nb}-95$ & $1.08 \mathrm{e}+009$ & $2.60 e+008$ & A & $8.28 e+005$ & $4.12 \mathrm{e}+005$ \\
\hline PM-149 & $1.93 e+006$ & $1.66 \mathrm{e}+007$ & $\mathrm{AU}$ & $3.31 \mathrm{e}+007$ & $1.65 e+007$ \\
\hline Pr-144 & $2.25 e+009$ & $6.11 e+008$ & A & $2.29 e+008$ & $1.14 e+008$ \\
\hline RU-103 & $4.11 e+008$ & $9.90 e+007$ & A & $1.42 e+006$ & $7.08 \mathrm{e}+005$ \\
\hline RU-106 & $4.19 e+007$ & $1.80 e+007$ & A & $7.62 e+006$ & $3.82 e+006$ \\
\hline SB-124 & $-9.73 e+005$ & $1.40 \mathrm{e}+006$ & $A U$ & $9.48 \mathrm{e}+005$ & $4.72 \mathrm{e}+005$ \\
\hline SB-125 & $-7.04 e+007$ & $1.95 e+007$ & $\mathrm{AU}$ & $3.22 e+006$ & $1.61 e+006$ \\
\hline SB-127 & $2.98 \mathrm{e}+006$ & $3.04 e+006$ & $\mathrm{AU}$ & $1.97 e+006$ & $9.84 \mathrm{e}+005$ \\
\hline Tc-99m & $1.44 e+007$ & $5.91 e+006$ & A & $3.04 e+006$ & $1.52 \mathrm{e}+006$ \\
\hline Te-127m & $-1.83 e+009$ & $1.34 \mathrm{e}+009$ & $A U$ & $6.78 \mathrm{e}+008$ & $3.39 \mathrm{e}+008$ \\
\hline Te-129m & $2.92 \mathrm{e}+008$ & $7.94 e+007$ & $\mathrm{AU}$ & $2.98 \mathrm{e}+007$ & $1.48 \mathrm{e}+007$ \\
\hline Te-131m & $3.10 \mathrm{e}+004$ & $7.29 \mathrm{e}+005$ & $\mathrm{AU}$ & 2. $19 \mathrm{e}+006$ & $1.09 \mathrm{e}+006$ \\
\hline Te-132 & $1.75 e+007$ & $6.38 \mathrm{e}+006$ & A & $1.39 \mathrm{e}+006$ & $6.96 \mathrm{e}+005$ \\
\hline U-232 & $-3.35 e+009$ & $3.09 \mathrm{e}+009$ & $\mathrm{AU}$ & $1.70 \mathrm{e}+009$ & $8.52 e+008$ \\
\hline U-234 & $-3.02 e+009$ & $8.73 e+009$ & $\mathrm{AU}$ & $5.93 e+009$ & $2.96 \mathrm{e}+009$ \\
\hline U-237 & $-3.54 e+007$ & $2.10 \mathrm{e}+007$ & $\mathrm{AU}$ & $9.42 \mathrm{e}+006$ & $4.71 e+006$ \\
\hline XE-131m & $2.20 \mathrm{e}+009$ & $8.89 e+008$ & $\mathrm{AU}$ & $9.12 e+007$ & $4.55 e+007$ \\
\hline
\end{tabular}

Page 6 of 49

\begin{tabular}{|r|lll|}
\hline Waste Flags: & + - Segregate as Radioactive & * - Do Not Recycle \\
\hline Quality Flags: & A - Accepted & J - Estimated & R - Rejected \\
\hline Detection Flags: & (Blank $)$ - Detected & U - Not Detected & N - Poor Statistics \\
\hline
\end{tabular}

UNM AGN-201_6-19 
AB51156

\begin{tabular}{|c|c|c|c|c|c|}
\hline Analyte & $\begin{array}{c}\text { Activity } \\
\text { (dpm) }\end{array}$ & $\begin{array}{c}\text { Unc } \\
(2.0 \sigma)\end{array}$ & $\begin{array}{l}\text { Lab } \\
\text { Flag }\end{array}$ & $\begin{array}{c}\text { MDA } \\
\text { (dpm) }\end{array}$ & $\begin{array}{c}\text { CL } \\
\text { (dpm) }\end{array}$ \\
\hline XE-133 & $1.62 e+008$ & $6.55 e+007$ & A & $6.30 e+006$ & $3.15 e+006$ \\
\hline$Y-88$ & $-2.53 e+004$ & $4.22 e+005$ & $A U$ & $2.74 \mathrm{e}+005$ & $1.36 e+005$ \\
\hline $\mathrm{Y}-91$ & $7.84 e+008$ & $3.39 e+008$ & A & $2.50 e+008$ & $1.25 e+008$ \\
\hline Y-91m & $9.49 e+006$ & $7.45 e+006$ & A & $2.06 e+006$ & $1.03 e+006$ \\
\hline ZR-95 & $9.63 e+008$ & $2.31 e+008$ & A & $1.42 \mathrm{e}+006$ & $7.08 e+005$ \\
\hline
\end{tabular}

Page 7 of 49

\begin{tabular}{|r|lll|}
\hline Waste Flags: & + - Segregate as Radioactive & * - Do Not Recycle \\
\hline Quality Flags: & A - Accepted & J - Estimated & R - Rejected \\
\hline Detection Flags: & (Blank) - Detected & U - Not Detected & N - Poor Statistics \\
\hline
\end{tabular}

UNM AGN-201_6-19 


\section{AB51157 - AGN Plate 99}

Live Time (s): 3600 Real Time (s): 4810

Detector: PGE14
Geometry: AGN-99-IS

Library: AGN-201M

Background: 14_PGE_190514
Count Date: 5/15/2019 5:06:57PM Collection Date: 5/13/2019 12:00:00PM Quantity (each): $1.00 \mathrm{e}+000$

Analyzed By:

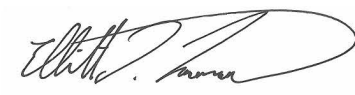

Reviewed By

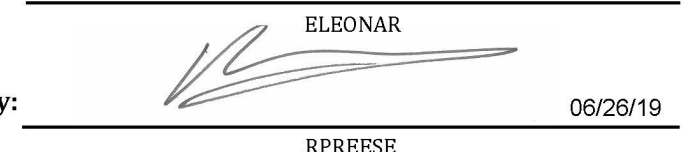

AB51157

\begin{tabular}{|c|c|c|c|c|c|}
\hline Analyte & $\begin{array}{c}\text { Activity } \\
\text { (dpm) }\end{array}$ & $\begin{array}{l}\text { Unc } \\
(2.0 \sigma)\end{array}$ & $\begin{array}{l}\text { Lab } \\
\text { Flag }\end{array}$ & $\begin{array}{c}\text { MDA } \\
\text { (dpm) }\end{array}$ & $\begin{array}{c}\text { CL } \\
\text { (dpm) }\end{array}$ \\
\hline U-238 & $3.39 e+008$ & $4.96 e+007$ & A & $6.60 \mathrm{e}+007$ & $3.31 e+007$ \\
\hline RA-226 & $8.28 e+009$ & $1.49 e+009$ & $\mathrm{AU}$ & $4.63 e+007$ & $2.32 e+007$ \\
\hline PB-214 & $-4.21 e+005$ & $1.99 e+006$ & $\mathrm{AU}$ & $2.52 e+006$ & $1.26 e+006$ \\
\hline $\mathrm{Bl}-214$ & $-9.46 e+004$ & $2.90 \mathrm{e}+005$ & $\mathrm{AU}$ & $2.24 \mathrm{e}+006$ & $1.12 e+006$ \\
\hline PB-210 & $3.63 e+007$ & $6.57 e+007$ & $\mathrm{AU}$ & $1.24 \mathrm{e}+008$ & $6.18 \mathrm{e}+007$ \\
\hline AC-228 & $2.52 e+006$ & $6.74 e+005$ & A & $2.23 e+006$ & $1.11 e+006$ \\
\hline RA-224 & $2.15 e+005$ & $1.10 e+005$ & A & $1.74 \mathrm{e}+005$ & $8.52 e+004$ \\
\hline PB-212 & $-3.04 e+006$ & $1.99 e+006$ & $\mathrm{AU}$ & $2.53 e+006$ & $1.27 e+006$ \\
\hline $\mathrm{BI}-212$ & $-1.35 e+008$ & $1.69 \mathrm{e}+007$ & $\mathrm{AU}$ & $3.16 e+007$ & $1.58 e+007$ \\
\hline TL-208 & $-4.05 e+005$ & $8.78 e+005$ & $\mathrm{AU}$ & $1.16 e+006$ & $5.78 e+005$ \\
\hline U-235 & $5.19 e+008$ & $9.35 e+007$ & A & $2.90 \mathrm{e}+006$ & $1.45 e+006$ \\
\hline TH-231 & $4.73 e+009$ & $9.48 e+008$ & A & $1.82 e+008$ & $9.06 e+007$ \\
\hline PA-231 & $2.32 e+008$ & $5.98 e+007$ & $\mathrm{AU}$ & $5.98 e+007$ & $2.99 e+007$ \\
\hline TH-227 & $1.78 e+007$ & $7.06 e+006$ & $\mathrm{AU}$ & $8.58 e+006$ & $4.27 e+006$ \\
\hline $\mathrm{RA}-223$ & $4.26 e+008$ & $8.54 e+007$ & $\mathrm{AU}$ & $8.58 e+006$ & $4.30 e+006$ \\
\hline $\mathrm{RN}-219$ & $-1.17 e+006$ & $1.03 e+007$ & $\mathrm{AU}$ & $1.41 \mathrm{e}+007$ & $7.02 e+006$ \\
\hline PB-211 & $-1.24 e+007$ & $1.80 e+007$ & $\mathrm{AU}$ & $2.45 e+007$ & $1.22 e+007$ \\
\hline TL-207 & $3.59 e+007$ & $1.82 e+008$ & $\mathrm{AU}$ & $2.34 \mathrm{e}+008$ & $1.16 e+008$ \\
\hline NP-237 & $-2.24 e+010$ & $4.49 e+009$ & $\mathrm{AU}$ & $4.46 e+008$ & $2.23 e+008$ \\
\hline PA-233 & $-4.82 e+005$ & $2.08 e+006$ & $\mathrm{AU}$ & $2.63 e+006$ & $1.31 e+006$ \\
\hline TH-229 & $-1.09 e+008$ & $2.21 e+007$ & $\mathrm{AU}$ & $2.26 e+007$ & $1.13 e+007$ \\
\hline BA-133 & $-2.20 e+006$ & $1.25 e+006$ & $\mathrm{AU}$ & $1.52 e+006$ & $7.62 e+005$ \\
\hline Ba-140 & $2.90 \mathrm{e}+008$ & $3.53 e+007$ & A & $4.99 e+006$ & $2.49 e+006$ \\
\hline \multirow{3}{*}{ Page 8 of 49} & Wast & \multicolumn{3}{|c|}{ + - Segregate as Radioactive } & \multirow{3}{*}{$201 \_6-19$} \\
\hline & Quali & A - Accepted & $\mathbf{J}$ - Estimated & R - Rejected & \\
\hline & Detectio & (Blank) - Detected & U - Not Detected & $\mathrm{N}$ - Poor Statistics & \\
\hline
\end{tabular}


AB51157

\begin{tabular}{|c|c|c|c|c|c|}
\hline Analyte & $\begin{array}{l}\text { Activity } \\
\text { (dpm) }\end{array}$ & $\begin{array}{c}\text { Unc } \\
(2.0 \sigma)\end{array}$ & $\begin{array}{l}\text { Lab } \\
\text { Flag }\end{array}$ & $\begin{array}{c}\text { MDA } \\
(\mathrm{dpm})\end{array}$ & $\begin{array}{c}\text { CL } \\
(\mathrm{dpm})\end{array}$ \\
\hline CD-115 & $-1.29 e+006$ & $1.69 e+006$ & $\mathrm{AU}$ & $2.12 e+006$ & $1.06 e+006$ \\
\hline CE-141 & $8.32 e+008$ & $1.67 e+008$ & A & $4.84 e+006$ & $2.42 \mathrm{e}+006$ \\
\hline CE-144 & $6.11 e+008$ & $1.23 e+008$ & A & $1.84 e+007$ & $9.24 e+006$ \\
\hline $\mathrm{CO}-60$ & $2.34 \mathrm{e}+005$ & $2.45 e+005$ & A & $4.01 e+005$ & $1.99 \mathrm{e}+005$ \\
\hline CS-137 & $2.18 e+008$ & $2.63 e+007$ & A & $8.88 e+005$ & $4.43 e+005$ \\
\hline $\mathrm{Ce}-143$ & $3.84 e+006$ & $1.95 \mathrm{e}+006$ & A & $3.04 \mathrm{e}+006$ & $1.52 \mathrm{e}+006$ \\
\hline $\mid-131$ & $6.23 e+007$ & $9.35 \mathrm{e}+006$ & A & $2.48 e+006$ & $1.24 e+006$ \\
\hline I-132 & $2.25 \mathrm{e}+007$ & $2.65 \mathrm{e}+006$ & A & $1.26 \mathrm{e}+006$ & $6.30 \mathrm{e}+005$ \\
\hline $1-133$ & $1.44 \mathrm{e}+007$ & $1.79 \mathrm{e}+006$ & $\mathrm{AU}$ & $1.39 \mathrm{e}+006$ & $6.96 \mathrm{e}+005$ \\
\hline In-115m & $-1.42 e+006$ & $1.85 e+006$ & $\mathrm{AU}$ & $2.33 e+006$ & $1.16 e+006$ \\
\hline La-140 & $3.37 e+008$ & $2.70 \mathrm{e}+007$ & A & $5.81 \mathrm{e}+005$ & $2.89 e+005$ \\
\hline MO-99 & $1.58 \mathrm{e}+007$ & $3.94 e+006$ & A & $5.63 \mathrm{e}+006$ & $2.81 e+006$ \\
\hline NB-95m & $1.17 e+007$ & $2.34 e+006$ & A & $5.38 \mathrm{e}+006$ & $2.68 \mathrm{e}+006$ \\
\hline ND-147 & $9.35 \mathrm{e}+007$ & $1.16 e+007$ & A & $9.06 \mathrm{e}+006$ & $4.53 \mathrm{e}+006$ \\
\hline NP-239 & $1.55 e+007$ & $4.80 \mathrm{e}+006$ & A & $7.32 e+006$ & $3.65 \mathrm{e}+006$ \\
\hline $\mathrm{Nb}-95$ & $1.06 e+009$ & $1.27 e+008$ & A & $8.16 e+005$ & $4.07 e+005$ \\
\hline PM-149 & $-1.04 e+007$ & $8.39 e+006$ & $\mathrm{AU}$ & $3.29 \mathrm{e}+007$ & $1.64 \mathrm{e}+007$ \\
\hline Pr-144 & $2.29 e+009$ & $3.09 e+008$ & A & $2.25 e+008$ & $1.12 \mathrm{e}+008$ \\
\hline RU-103 & $4.04 e+008$ & $4.87 e+007$ & A & $1.41 \mathrm{e}+006$ & $7.02 \mathrm{e}+005$ \\
\hline RU-106 & $4.27 e+007$ & $8.90 e+006$ & A & $7.80 e+006$ & $3.90 e+006$ \\
\hline SB-124 & $-5.13 e+005$ & $3.67 e+005$ & $A U$ & $9.36 \mathrm{e}+005$ & $4.69 \mathrm{e}+005$ \\
\hline SB-125 & $3.46 e+006$ & $1.00 e+006$ & A & $3.46 e+006$ & $1.73 e+006$ \\
\hline SB-127 & $2.42 e+006$ & $1.50 \mathrm{e}+006$ & $\mathrm{AU}$ & $1.96 e+006$ & $9.78 \mathrm{e}+005$ \\
\hline Tc-99m & $1.85 e+007$ & $3.76 e+006$ & A & $2.98 e+006$ & $1.49 e+006$ \\
\hline Te-127m & $-1.70 e+009$ & $6.55 e+008$ & $A U$ & $6.78 \mathrm{e}+008$ & $3.38 \mathrm{e}+008$ \\
\hline Te-129m & $2.99 \mathrm{e}+008$ & $4.03 e+007$ & $\mathrm{AU}$ & $2.94 \mathrm{e}+007$ & $1.47 e+007$ \\
\hline Te-131m & $-2.50 e+005$ & $4.31 e+005$ & $\mathrm{AU}$ & $2.20 \mathrm{e}+006$ & $1.10 \mathrm{e}+006$ \\
\hline Te-132 & $2.10 \mathrm{e}+007$ & $3.67 e+006$ & A & $1.51 \mathrm{e}+006$ & $7.56 \mathrm{e}+005$ \\
\hline U-232 & $-1.66 e+009$ & $1.33 e+009$ & $\mathrm{AU}$ & $1.70 \mathrm{e}+009$ & $8.46 \mathrm{e}+008$ \\
\hline U-234 & $-4.85 e+009$ & $4.44 \mathrm{e}+009$ & AN & $5.94 \mathrm{e}+009$ & $2.96 \mathrm{e}+009$ \\
\hline U-237 & $6.01 e+006$ & $5.01 e+006$ & $\mathrm{AU}$ & $9.42 \mathrm{e}+006$ & $4.70 \mathrm{e}+006$ \\
\hline$X E-131 m$ & $2.11 \mathrm{e}+009$ & $4.27 e+008$ & $\mathrm{AU}$ & $9.12 e+007$ & $4.55 e+007$ \\
\hline
\end{tabular}

Page 9 of 49

\begin{tabular}{|r|lll|}
\hline Waste Flags: & + - Segregate as Radioactive & ${ }^{*}$ - Do Not Recycle \\
\hline Quality Flags: & A - Accepted & J - Estimated & R - Rejected \\
\hline Detection Flags: & (Blank) - Detected & U - Not Detected & N - Poor Statistics \\
\hline
\end{tabular}

UNM AGN-201_6-19 


\section{AB51157}

\begin{tabular}{|lcccc|}
\hline Analyte & $\begin{array}{c}\text { Activity } \\
(\mathrm{dpm})\end{array}$ & $\begin{array}{c}\text { Unc } \\
(2.0 \sigma)\end{array}$ & $\begin{array}{c}\text { Lab } \\
\text { Flag }\end{array}$ & $\begin{array}{c}\text { MDA } \\
(\mathrm{dpm})\end{array}$ \\
\hline $\mathrm{XE}-133$ & $\mathbf{1 . 6 4 \mathrm { e } + 0 0 8}$ & $3.32 \mathrm{e}+007$ & $\mathrm{~A}$ & $\mathbf{6 . 3 0 e + 0 0 6}$ \\
$\mathrm{Y}-88$ & $1.86 \mathrm{e}+005$ & $2.11 \mathrm{e}+005$ & $\mathrm{AU}$ & $2.80 \mathrm{e}+005$ \\
$\mathrm{Y}-91$ & $8.18 \mathrm{e}+008$ & $1.56 \mathrm{e}+008$ & $\mathrm{~A}$ & $\mathbf{2 . 2 3 e + 0 0 8}+006$ \\
$\mathrm{Y}-91 \mathrm{~m}$ & $5.48 \mathrm{e}+006$ & $1.42 \mathrm{e}+006$ & $\mathrm{AU}$ & $2.06 \mathrm{e}+006$ \\
$\mathrm{ZR}-95$ & $9.44 \mathrm{e}+008$ & $1.13 \mathrm{e}+008$ & $\mathrm{~A}$ & $1.11 \mathrm{e}+008$ \\
\hline
\end{tabular}

Page 10 of 49

\begin{tabular}{|r|lll|}
\hline Waste Flags: & + - Segregate as Radioactive & ${ }^{*}$ - Do Not Recycle \\
\hline Quality Flags: & A - Accepted & J - Estimated & R - Rejected \\
\hline Detection Flags: & (Blank) - Detected & U - Not Detected & N - Poor Statistics \\
\hline
\end{tabular}

UNM AGN-201_6-19 


\section{AB51158 - AGN Plate 100}

Live Time (s): 3600 Real Time (s): 4855

Detector: PGE14
Geometry: AGN-100-I

Library: AGN-201M

Background: 14_PGE_190514
Count Date: 5/15/2019 3:32:27PM Collection Date: 5/13/2019 12:00:00PM Quantity (each): $1.00 \mathrm{e}+000$

Analyzed By:

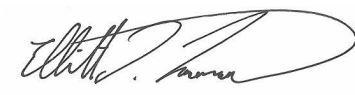

Reviewed By

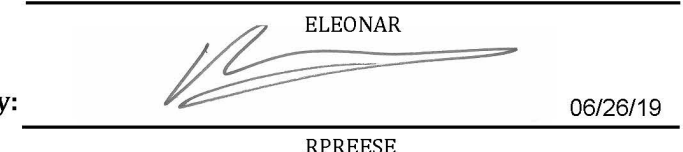

RPREESE

AB51158

\begin{tabular}{|c|c|c|c|c|c|}
\hline Analyte & $\begin{array}{c}\text { Activity } \\
\text { (dpm) }\end{array}$ & $\begin{array}{c}\text { Unc } \\
(2.0 \sigma)\end{array}$ & $\begin{array}{l}\text { Lab } \\
\text { Flag }\end{array}$ & $\begin{array}{c}\text { MDA } \\
\text { (dpm) }\end{array}$ & $\begin{array}{c}\text { CL } \\
\text { (dpm) }\end{array}$ \\
\hline U-238 & $1.42 \mathrm{e}+008$ & $2.94 e+007$ & A & $2.73 e+007$ & $1.36 e+007$ \\
\hline RA-226 & $3.13 e+009$ & $5.63 e+008$ & $\mathrm{AU}$ & $1.73 e+007$ & $8.64 e+006$ \\
\hline PB-214 & $3.06 e+005$ & $7.63 e+005$ & $\mathrm{AU}$ & $9.66 e+005$ & $4.83 e+005$ \\
\hline $\mathrm{BI}-214$ & $-8.41 e+004$ & $1.12 e+005$ & $\mathrm{AU}$ & $8.64 e+005$ & $4.31 e+005$ \\
\hline PB-210 & $-8.78 e+007$ & $4.42 e+007$ & $\mathrm{AU}$ & $4.50 e+007$ & $2.25 e+007$ \\
\hline AC-228 & $6.16 e+005$ & $7.18 e+005$ & $\mathrm{AU}$ & $9.24 e+005$ & $4.60 e+005$ \\
\hline RA-224 & $6.28 \mathrm{e}+004$ & $4.11 e+004$ & A & $6.60 e+004$ & $3.23 e+004$ \\
\hline PB-212 & $-1.08 e+006$ & $7.52 \mathrm{e}+005$ & $\mathrm{AU}$ & $9.60 e+005$ & $4.80 e+005$ \\
\hline $\mathrm{BI}-212$ & $-5.27 e+007$ & $6.56 e+006$ & $\mathrm{AU}$ & $1.22 e+007$ & $6.12 e+006$ \\
\hline TL-208 & $-1.01 e+005$ & $3.40 \mathrm{e}+005$ & $\mathrm{AU}$ & $4.49 e+005$ & $2.24 \mathrm{e}+005$ \\
\hline U-235 & $1.96 e+008$ & $3.54 e+007$ & A & $1.09 e+006$ & $5.44 e+005$ \\
\hline TH-231 & $1.80 e+009$ & $3.60 e+008$ & A & $6.66 e+007$ & $3.34 \mathrm{e}+007$ \\
\hline PA-231 & $9.73 e+007$ & $2.38 e+007$ & $\mathrm{AU}$ & $2.27 e+007$ & $1.13 e+007$ \\
\hline TH-227 & $6.10 e+006$ & $2.64 e+006$ & $\mathrm{AU}$ & $3.24 e+006$ & $1.62 e+006$ \\
\hline RA-223 & $1.59 e+008$ & $3.19 \mathrm{e}+007$ & $\mathrm{AU}$ & $3.16 e+006$ & $1.58 \mathrm{e}+006$ \\
\hline RN-219 & $-1.76 e+006$ & $2.55 e+006$ & $\mathrm{AU}$ & $5.38 e+006$ & $2.68 e+006$ \\
\hline PB-211 & $-9.83 e+006$ & $6.99 e+006$ & $\mathrm{AU}$ & $9.36 e+006$ & $4.67 e+006$ \\
\hline TL-207 & $-1.37 e+007$ & $7.19 \mathrm{e}+007$ & $\mathrm{AU}$ & $9.24 \mathrm{e}+007$ & $4.60 e+007$ \\
\hline NP-237 & $-8.72 e+009$ & $1.75 e+009$ & $\mathrm{AU}$ & $1.67 e+008$ & $8.34 e+007$ \\
\hline PA-233 & $-4.66 e+005$ & $7.96 e+005$ & $\mathrm{AU}$ & $1.00 e+006$ & $5.02 e+005$ \\
\hline TH-229 & $-4.06 e+007$ & $8.27 e+006$ & $\mathrm{AU}$ & $8.46 e+006$ & $4.22 e+006$ \\
\hline BA-133 & $-1.19 e+006$ & $4.95 e+005$ & $\mathrm{AU}$ & $5.83 e+005$ & $2.91 e+005$ \\
\hline $\mathrm{Ba}-140$ & $1.14 \mathrm{e}+008$ & $1.38 e+007$ & A & $1.88 \mathrm{e}+006$ & $9.42 e+005$ \\
\hline \multirow{3}{*}{ Page 11 of 49} & Wast & \multicolumn{3}{|c|}{ + - Segregate as Radioactive } & \multirow{3}{*}{ 201_6-19 } \\
\hline & Quali & A - Accepted & $\mathbf{J}$ - Estimated & R - Rejected & \\
\hline & Detectio & (Blank) - Detected & U - Not Detected & N - Poor Statistics & \\
\hline
\end{tabular}




\section{AB51158}

\begin{tabular}{|c|c|c|c|c|c|}
\hline Analyte & $\begin{array}{c}\text { Activity } \\
\text { (dpm) }\end{array}$ & $\begin{array}{c}\text { Unc } \\
(2.0 \sigma)\end{array}$ & $\begin{array}{l}\text { Lab } \\
\text { Flag }\end{array}$ & $\begin{array}{c}\text { MDA } \\
\text { (dpm) }\end{array}$ & $\begin{array}{c}\text { CL } \\
(\mathrm{dpm})\end{array}$ \\
\hline CD-115 & $3.77 e+004$ & $2.58 e+005$ & $\mathrm{AU}$ & $8.16 e+005$ & $4.06 e+005$ \\
\hline CE-141 & $3.18 \mathrm{e}+008$ & $6.36 e+007$ & A & $2.83 e+006$ & $1.42 \mathrm{e}+006$ \\
\hline CE-144 & $2.17 e+008$ & $4.37 e+007$ & A & $8.40 \mathrm{e}+006$ & $4.20 e+006$ \\
\hline $\mathrm{CO}-60$ & $1.32 \mathrm{e}+005$ & $1.80 e+005$ & $\mathrm{AU}$ & $2.41 \mathrm{e}+005$ & $1.20 \mathrm{e}+005$ \\
\hline CS-137 & $8.62 e+007$ & $1.04 e+007$ & A & $3.44 \mathrm{e}+005$ & $1.72 e+005$ \\
\hline $\mathrm{Ce}-143$ & $-2.76 e+005$ & $4.43 e+005$ & $\mathrm{AU}$ & $9.42 \mathrm{e}+005$ & $4.71 \mathrm{e}+005$ \\
\hline $\mid-131$ & $2.46 e+007$ & $3.65 e+006$ & A & $5.48 e+005$ & $2.74 e+005$ \\
\hline $\mid-132$ & $9.16 e+006$ & $1.08 \mathrm{e}+006$ & A & $4.88 \mathrm{e}+005$ & $2.44 e+005$ \\
\hline 1-133 & $5.41 e+006$ & $6.75 e+005$ & $\mathrm{AU}$ & $5.36 \mathrm{e}+005$ & $2.68 \mathrm{e}+005$ \\
\hline In-115m & $4.14 \mathrm{e}+004$ & $2.83 e+005$ & $\mathrm{AU}$ & $8.94 e+005$ & $4.46 e+005$ \\
\hline La-140 & $1.33 e+008$ & $1.06 \mathrm{e}+007$ & A & $2.24 e+005$ & $1.12 \mathrm{e}+005$ \\
\hline MO-99 & $6.74 \mathrm{e}+006$ & $1.86 \mathrm{e}+006$ & $\mathrm{AU}$ & $2.26 \mathrm{e}+006$ & $1.13 \mathrm{e}+006$ \\
\hline NB-95m & $3.26 \mathrm{e}+006$ & $7.25 e+005$ & A & $1.91 e+006$ & $9.54 e+005$ \\
\hline ND-147 & $3.52 \mathrm{e}+007$ & $4.38 e+006$ & A & $3.49 \mathrm{e}+006$ & $1.75 e+006$ \\
\hline NP-239 & $8.54 \mathrm{e}+006$ & $2.47 e+006$ & $\mathrm{AU}$ & $2.73 e+006$ & $1.36 \mathrm{e}+006$ \\
\hline $\mathrm{Nb}-95$ & $4.14 \mathrm{e}+008$ & $4.97 e+007$ & A & $3.14 e+005$ & $1.57 e+005$ \\
\hline PM-149 & $2.93 e+005$ & $3.14 e+006$ & $\mathrm{AU}$ & $1.25 e+007$ & $6.24 e+006$ \\
\hline Pr-144 & $8.56 e+008$ & $1.17 e+008$ & A & $8.88 e+007$ & $4.43 e+007$ \\
\hline RU-103 & $1.58 \mathrm{e}+008$ & $1.90 e+007$ & A & $5.42 e+005$ & $2.71 e+005$ \\
\hline RU-106 & $9.29 e+006$ & $4.06 e+006$ & A & $2.77 e+006$ & $1.38 e+006$ \\
\hline SB-124 & $-5.51 e+005$ & $2.72 e+005$ & $\mathrm{AU}$ & $3.62 e+005$ & $1.81 e+005$ \\
\hline SB-125 & $-7.31 e+005$ & $4.68 e+005$ & $\mathrm{AU}$ & $1.23 e+006$ & $6.12 e+005$ \\
\hline SB-127 & $-2.27 e+004$ & $1.41 e+005$ & $\mathrm{AU}$ & $7.56 e+005$ & $3.79 \mathrm{e}+005$ \\
\hline Tc-99m & $-1.04 e+008$ & $2.09 e+007$ & $\mathrm{AU}$ & $9.48 e+005$ & $4.73 e+005$ \\
\hline Te-127m & $-7.89 e+008$ & $2.60 \mathrm{e}+008$ & $A U$ & $2.47 e+008$ & $1.23 e+008$ \\
\hline Te-129m & $1.11 \mathrm{e}+008$ & $1.51 e+007$ & $\mathrm{AU}$ & $1.15 e+007$ & $5.73 e+006$ \\
\hline Te-131m & $-1.13 e+006$ & $6.65 e+005$ & $\mathrm{AU}$ & $8.58 \mathrm{e}+005$ & $4.28 \mathrm{e}+005$ \\
\hline Te-132 & $7.33 e+006$ & $1.32 \mathrm{e}+006$ & A & $4.70 \mathrm{e}+005$ & $2.35 e+005$ \\
\hline U-232 & $-1.11 e+009$ & $5.51 e+008$ & $\mathrm{AU}$ & $6.18 \mathrm{e}+008$ & $3.09 \mathrm{e}+008$ \\
\hline U-234 & $-4.50 e+009$ & $1.84 e+009$ & $\mathrm{AU}$ & 2.19e+009 & $1.10 \mathrm{e}+009$ \\
\hline U-237 & $-1.38 e+007$ & $3.94 e+006$ & $\mathrm{AU}$ & $3.43 e+006$ & $1.71 e+006$ \\
\hline$X E-131 m$ & $8.01 e+008$ & $1.62 e+008$ & $\mathrm{AU}$ & $3.40 \mathrm{e}+007$ & $1.70 \mathrm{e}+007$ \\
\hline
\end{tabular}

Page 12 of 49

\begin{tabular}{|r|lll|}
\hline Waste Flags: & + - Segregate as Radioactive & ${ }^{*}$ - Do Not Recycle \\
\hline Quality Flags: & A - Accepted & J - Estimated & R - Rejected \\
\hline Detection Flags: & (Blank) - Detected & U - Not Detected & N - Poor Statistics \\
\hline
\end{tabular}

UNM AGN-201_6-19 


\section{AB51158}

\begin{tabular}{|c|c|c|c|c|c|}
\hline Analyte & $\begin{array}{c}\text { Activity } \\
\text { (dpm) }\end{array}$ & $\begin{array}{c}\text { Unc } \\
(2.0 \sigma)\end{array}$ & $\begin{array}{l}\text { Lab } \\
\text { Flag }\end{array}$ & $\begin{array}{c}\text { MDA } \\
(\mathrm{dpm})\end{array}$ & $\begin{array}{c}\text { CL } \\
\text { (dpm) }\end{array}$ \\
\hline XE-133 & $6.23 e+007$ & $1.26 e+007$ & A & $2.32 \mathrm{e}+006$ & $1.16 e+006$ \\
\hline$Y-88$ & $2.41 e+004$ & $8.32 e+004$ & $\mathrm{AU}$ & $1.09 \mathrm{e}+005$ & $5.39 \mathrm{e}+004$ \\
\hline$Y-91$ & $3.98 e+008$ & $6.93 e+007$ & A & $9.60 e+007$ & $4.78 e+007$ \\
\hline Y-91m & $3.41 \mathrm{e}+006$ & $1.38 e+006$ & $A U$ & $7.92 \mathrm{e}+005$ & $3.95 \mathrm{e}+005$ \\
\hline ZR-95 & $3.70 \mathrm{e}+008$ & $4.44 e+007$ & A & $5.41 \mathrm{e}+005$ & $2.70 e+005$ \\
\hline
\end{tabular}

Page 13 of 49

\begin{tabular}{|r|lll|}
\hline Waste Flags: & + - Segregate as Radioactive & * - Do Not Recycle \\
\hline Quality Flags: & A - Accepted & J - Estimated & R - Rejected \\
\hline Detection Flags: & (Blank) - Detected & U - Not Detected & N - Poor Statistics \\
\hline
\end{tabular}

UNM AGN-201_6-19 


\section{AB51159 - AGN Plate 101}

Live Time (s): 3600 Real Time (s): 4429

Detector: PGE14
Geometry: AGN-101-I

Library: AGN-201M

Background: 14_PGE_190514
Count Date: 5/15/2019 1:57:57PM Collection Date: 5/13/2019 12:00:00PM Quantity (each): $1.00 \mathrm{e}+000$

Analyzed By:

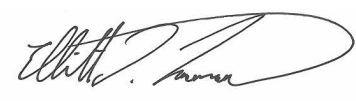

Reviewed By

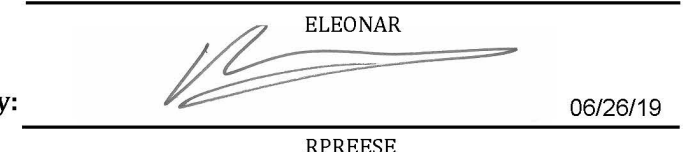

AB51159

\begin{tabular}{|c|c|c|c|c|c|}
\hline Analyte & $\begin{array}{c}\text { Activity } \\
\text { (dpm) }\end{array}$ & $\begin{array}{c}\text { Unc } \\
(2.0 \sigma)\end{array}$ & $\begin{array}{l}\text { Lab } \\
\text { Flag }\end{array}$ & $\begin{array}{c}\text { MDA } \\
\text { (dpm) }\end{array}$ & $\begin{array}{c}\text { CL } \\
\text { (dpm) }\end{array}$ \\
\hline U-238 & $2.10 e+008$ & $3.35 e+007$ & A & $4.61 e+007$ & $2.30 \mathrm{e}+007$ \\
\hline RA-226 & $4.98 e+009$ & $8.97 e+008$ & $\mathrm{AU}$ & $2.53 e+007$ & $1.27 e+007$ \\
\hline PB-214 & $1.11 e+006$ & $1.26 \mathrm{e}+006$ & $\mathrm{AU}$ & $1.58 e+006$ & $7.92 e+005$ \\
\hline $\mathrm{Bl}-214$ & $-1.43 e+005$ & $1.89 e+005$ & $\mathrm{AU}$ & $1.49 e+006$ & $7.44 e+005$ \\
\hline PB-210 & $-1.47 e+008$ & $6.13 e+007$ & $\mathrm{AU}$ & $5.50 e+007$ & $2.75 e+007$ \\
\hline AC-228 & $1.46 e+006$ & $4.31 e+005$ & A & $1.37 e+006$ & $6.84 \mathrm{e}+005$ \\
\hline RA-224 & $8.22 e+005$ & $1.00 \mathrm{e}+005$ & $\mathrm{AU}$ & $1.57 e+005$ & $7.68 \mathrm{e}+004$ \\
\hline PB-212 & $-1.33 e+006$ & $1.15 e+006$ & $\mathrm{AU}$ & $1.49 e+006$ & $7.44 e+005$ \\
\hline BI-212 & $-5.44 e+007$ & $7.10 \mathrm{e}+006$ & $\mathrm{AU}$ & $2.24 \mathrm{e}+007$ & $1.12 e+007$ \\
\hline TL-208 & $-1.37 e+004$ & $5.75 e+005$ & $\mathrm{AU}$ & $7.62 e+005$ & $3.80 e+005$ \\
\hline U-235 & $3.13 e+008$ & $5.63 e+007$ & A & $1.59 e+006$ & $7.92 \mathrm{e}+005$ \\
\hline TH-231 & $2.59 e+009$ & $5.19 e+008$ & A & $8.52 e+007$ & $4.27 e+007$ \\
\hline PA-231 & $1.24 e+008$ & $3.49 e+007$ & $\mathrm{AU}$ & $3.70 e+007$ & $1.85 e+007$ \\
\hline $\mathrm{TH}-227$ & $1.19 e+007$ & $4.23 e+006$ & $\mathrm{AU}$ & $5.01 e+006$ & $2.50 e+006$ \\
\hline $\mathrm{RA}-223$ & $2.08 e+008$ & $4.17 e+007$ & $\mathrm{AU}$ & $4.18 e+006$ & $2.09 e+006$ \\
\hline $\mathrm{RN}-219$ & $-4.41 e+006$ & $6.57 e+006$ & $\mathrm{AU}$ & $8.94 \mathrm{e}+006$ & $4.46 e+006$ \\
\hline PB-211 & $7.44 \mathrm{e}+005$ & $1.14 e+007$ & $\mathrm{AU}$ & $1.55 e+007$ & $7.74 \mathrm{e}+006$ \\
\hline TL-207 & $-9.15 e+006$ & $1.15 e+008$ & $\mathrm{AU}$ & $1.48 e+008$ & $7.38 e+007$ \\
\hline NP-237 & $-1.14 e+010$ & $2.28 \mathrm{e}+009$ & $\mathrm{AU}$ & $2.57 e+008$ & $1.28 \mathrm{e}+008$ \\
\hline PA-233 & $-9.34 e+005$ & $1.31 e+006$ & $\mathrm{AU}$ & $1.65 e+006$ & $8.22 e+005$ \\
\hline TH-229 & $-3.78 e+007$ & $7.91 e+006$ & $\mathrm{AU}$ & $1.33 e+007$ & $6.60 \mathrm{e}+006$ \\
\hline BA-133 & $-9.11 e+005$ & $7.70 \mathrm{e}+005$ & $\mathrm{AU}$ & $9.60 e+005$ & $4.78 e+005$ \\
\hline $\mathrm{Ba}-140$ & $1.70 e+008$ & $2.09 e+007$ & A & $3.08 \mathrm{e}+006$ & $1.54 \mathrm{e}+006$ \\
\hline \multirow{3}{*}{ Page 14 of 49} & Wast & \multicolumn{3}{|c|}{ + - Segregate as Radioactive } & \multirow{3}{*}{$201 \_6-19$} \\
\hline & Quali & A - Accepted & $\mathbf{J}$ - Estimated & R - Rejected & \\
\hline & Detectio & (Blank) - Detected & U - Not Detected & $\mathrm{N}$ - Poor Statistics & \\
\hline
\end{tabular}




\section{AB51159}

\begin{tabular}{|c|c|c|c|c|c|}
\hline Analyte & $\begin{array}{c}\text { Activity } \\
\text { (dpm) }\end{array}$ & $\begin{array}{c}\text { Unc } \\
(2.0 \sigma)\end{array}$ & $\begin{array}{l}\text { Lab } \\
\text { Flag }\end{array}$ & $\begin{array}{c}\text { MDA } \\
(\mathrm{dpm})\end{array}$ & $\begin{array}{c}\text { CL } \\
(\mathrm{dpm})\end{array}$ \\
\hline CD-115 & $4.31 e+005$ & $1.05 e+006$ & $\mathrm{AU}$ & $1.34 e+006$ & $6.66 e+005$ \\
\hline CE-141 & $4.20 \mathrm{e}+008$ & $8.44 e+007$ & A & $1.97 \mathrm{e}+006$ & $9.84 e+005$ \\
\hline CE-144 & $3.53 e+008$ & $7.10 e+007$ & A & $1.12 e+007$ & $5.57 e+006$ \\
\hline $\mathrm{CO}-60$ & $2.48 \mathrm{e}+005$ & $1.93 e+005$ & A & $3.14 e+005$ & $1.56 \mathrm{e}+005$ \\
\hline CS-137 & $1.27 e+008$ & $1.53 e+007$ & A & $5.55 e+005$ & $2.77 e+005$ \\
\hline $\mathrm{Ce}-143$ & $1.98 \mathrm{e}+006$ & $1.25 \mathrm{e}+006$ & $\mathrm{AU}$ & $1.54 \mathrm{e}+006$ & $7.68 \mathrm{e}+005$ \\
\hline $\mid-131$ & $3.75 \mathrm{e}+007$ & $5.58 \mathrm{e}+006$ & A & $9.42 \mathrm{e}+005$ & $4.71 e+005$ \\
\hline $\mid-132$ & $1.30 \mathrm{e}+007$ & $1.54 e+006$ & A & $7.14 e+005$ & $3.56 e+005$ \\
\hline 1-133 & $7.92 e+006$ & $9.99 e+005$ & $\mathrm{AU}$ & $8.76 e+005$ & $4.37 e+005$ \\
\hline In-115m & $4.69 \mathrm{e}+005$ & $1.15 e+006$ & $\mathrm{AU}$ & $1.45 e+006$ & $7.26 \mathrm{e}+005$ \\
\hline La-140 & $1.95 \mathrm{e}+008$ & $1.56 \mathrm{e}+007$ & A & $3.98 e+005$ & $1.98 \mathrm{e}+005$ \\
\hline MO-99 & $1.32 \mathrm{e}+007$ & $3.13 e+006$ & A & $4.39 \mathrm{e}+006$ & $2.19 \mathrm{e}+006$ \\
\hline NB-95m & $6.22 \mathrm{e}+006$ & $1.29 \mathrm{e}+006$ & A & $2.72 \mathrm{e}+006$ & $1.36 \mathrm{e}+006$ \\
\hline ND-147 & $5.17 e+007$ & $6.49 e+006$ & A & $5.71 e+006$ & $2.85 e+006$ \\
\hline NP-239 & $1.16 e+007$ & $3.79 e+006$ & $\mathrm{AU}$ & $4.40 \mathrm{e}+006$ & $2.20 \mathrm{e}+006$ \\
\hline $\mathrm{Nb}-95$ & $6.04 e+008$ & $7.25 e+007$ & A & $4.90 e+005$ & $2.44 e+005$ \\
\hline PM-149 & $-7.53 e+005$ & $5.10 e+006$ & $\mathrm{AU}$ & $2.04 e+007$ & $1.02 e+007$ \\
\hline Pr-144 & $1.16 e+009$ & $1.59 e+008$ & A & $1.22 e+008$ & $6.12 e+007$ \\
\hline RU-103 & $2.36 e+008$ & $2.85 e+007$ & A & $9.18 \mathrm{e}+005$ & $4.58 \mathrm{e}+005$ \\
\hline RU-106 & $2.52 e+007$ & $5.41 e+006$ & A & $4.77 e+006$ & $2.38 \mathrm{e}+006$ \\
\hline SB-124 & $-4.54 e+005$ & $4.50 e+005$ & $A U$ & $6.12 e+005$ & $3.06 \mathrm{e}+005$ \\
\hline SB-125 & $1.48 e+006$ & $5.61 e+005$ & $A$ & $2.02 e+006$ & $1.01 e+006$ \\
\hline SB-127 & $2.13 e+006$ & $9.61 e+005$ & $\mathrm{AU}$ & $1.24 e+006$ & $6.18 \mathrm{e}+005$ \\
\hline Tc-99m & $1.26 e+007$ & $2.56 e+006$ & A & $1.08 e+006$ & $5.40 e+005$ \\
\hline Te-127m & $-8.74 e+008$ & $3.10 \mathrm{e}+008$ & $A U$ & $3.08 \mathrm{e}+008$ & $1.54 \mathrm{e}+008$ \\
\hline Te-129m & $1.62 e+008$ & $2.23 e+007$ & $\mathrm{AU}$ & $1.72 \mathrm{e}+007$ & $8.58 \mathrm{e}+006$ \\
\hline Te-131m & $-1.79 e+006$ & $4.16 e+005$ & $\mathrm{AU}$ & $1.43 e+006$ & $7.14 \mathrm{e}+005$ \\
\hline Te-132 & $1.16 e+007$ & $2.08 \mathrm{e}+006$ & $A$ & $6.96 e+005$ & $3.47 e+005$ \\
\hline U-232 & $-1.29 e+009$ & $6.80 e+008$ & $\mathrm{AU}$ & $7.74 e+008$ & $3.86 \mathrm{e}+008$ \\
\hline U-234 & $-6.84 e+008$ & $2.07 e+009$ & $\mathrm{AU}$ & $2.84 e+009$ & $1.42 e+009$ \\
\hline U-237 & $-2.48 e+007$ & $6.12 e+006$ & $\mathrm{AU}$ & $4.30 \mathrm{e}+006$ & $2.15 e+006$ \\
\hline$X E-131 m$ & $1.32 \mathrm{e}+009$ & $2.65 e+008$ & $\mathrm{AU}$ & $4.98 e+007$ & $2.49 \mathrm{e}+007$ \\
\hline
\end{tabular}

Page 15 of 49

\begin{tabular}{|r|lll|}
\hline Waste Flags: & + - Segregate as Radioactive & ${ }^{*}$ - Do Not Recycle \\
\hline Quality Flags: & A - Accepted & J - Estimated & R - Rejected \\
\hline Detection Flags: & (Blank) - Detected & U - Not Detected & N - Poor Statistics \\
\hline
\end{tabular}

UNM AGN-201_6-19 


\section{AB51159}

\begin{tabular}{|c|c|c|c|c|c|}
\hline Analyte & $\begin{array}{c}\text { Activity } \\
\text { (dpm) }\end{array}$ & $\begin{array}{c}\text { Unc } \\
(2.0 \sigma)\end{array}$ & $\begin{array}{l}\text { Lab } \\
\text { Flag }\end{array}$ & $\begin{array}{c}\text { MDA } \\
(\mathrm{dpm})\end{array}$ & $\begin{array}{c}\text { CL } \\
\text { (dpm) }\end{array}$ \\
\hline XE-133 & $8.98 e+007$ & $1.81 e+007$ & A & $2.96 e+006$ & $1.48 e+006$ \\
\hline$Y-88$ & $1.94 \mathrm{e}+005$ & $1.36 e+005$ & $\mathrm{AU}$ & $1.84 \mathrm{e}+005$ & $9.06 e+004$ \\
\hline$Y-91$ & $3.40 \mathrm{e}+008$ & $9.89 e+007$ & A & $1.52 \mathrm{e}+008$ & $7.62 e+007$ \\
\hline Y-91m & $2.68 \mathrm{e}+006$ & $7.31 e+005$ & $A U$ & $1.07 e+006$ & $5.35 \mathrm{e}+005$ \\
\hline ZR-95 & $5.39 \mathrm{e}+008$ & $6.47 e+007$ & A & $8.40 \mathrm{e}+005$ & $4.18 \mathrm{e}+005$ \\
\hline
\end{tabular}

Page 16 of 49

\begin{tabular}{|r|lll|}
\hline Waste Flags: & + - Segregate as Radioactive & * - Do Not Recycle \\
\hline Quality Flags: & A - Accepted & J - Estimated & R - Rejected \\
\hline Detection Flags: & (Blank) - Detected & U - Not Detected & N - Poor Statistics \\
\hline
\end{tabular}

UNM AGN-201_6-19 


\section{AB51160 - AGN Plate 102}

Live Time (s): 3600 Real Time (s): 4388

Detector: PGE14
Geometry: AGN-102-I

Library: AGN-201M

Background: 14_PGE_190514
Count Date: 5/15/2019 12:06:48PM Collection Date: 5/13/2019 12:00:00PM Quantity (each): $1.00 \mathrm{e}+000$

Analyzed By:

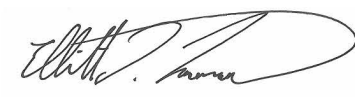

Reviewed By

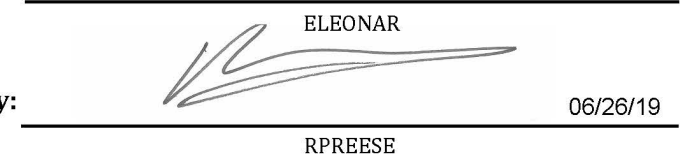

RPREESE

AB51160

\begin{tabular}{|c|c|c|c|c|c|}
\hline Analyte & $\begin{array}{l}\text { Activity } \\
\text { (dpm) }\end{array}$ & $\begin{array}{c}\text { Unc } \\
(2.0 \sigma)\end{array}$ & $\begin{array}{l}\text { Lab } \\
\text { Flag }\end{array}$ & $\begin{array}{c}\text { MDA } \\
\text { (dpm) }\end{array}$ & $\begin{array}{c}\text { CL } \\
\text { (dpm) }\end{array}$ \\
\hline U-238 & $2.45 e+008$ & $4.02 e+007$ & A & $5.58 \mathrm{e}+007$ & $2.78 \mathrm{e}+007$ \\
\hline RA-226 & $6.30 e+009$ & $1.13 e+009$ & $\mathrm{AU}$ & $3.10 \mathrm{e}+007$ & $1.55 e+007$ \\
\hline PB-214 & $3.93 e+004$ & $1.53 e+006$ & $\mathrm{AU}$ & $1.94 e+006$ & $9.66 e+005$ \\
\hline Bl-214 & $-1.80 e+005$ & $2.29 e+005$ & $\mathrm{AU}$ & $1.81 \mathrm{e}+006$ & $9.06 e+005$ \\
\hline PB-210 & $-8.57 e+007$ & $5.95 e+007$ & $\mathrm{AU}$ & $6.72 \mathrm{e}+007$ & $3.35 e+007$ \\
\hline AC-228 & $2.86 e+006$ & $1.40 \mathrm{e}+006$ & $\mathrm{AU}$ & $1.79 e+006$ & $8.94 e+005$ \\
\hline RA-224 & $9.55 e+004$ & $1.01 \mathrm{e}+005$ & A & $1.66 \mathrm{e}+005$ & $8.04 e+004$ \\
\hline PB-212 & $-1.47 e+006$ & $1.40 \mathrm{e}+006$ & $\mathrm{AU}$ & $1.81 e+006$ & $9.06 e+005$ \\
\hline $\mathrm{BI}-212$ & $-5.70 e+007$ & $7.63 e+006$ & $\mathrm{AU}$ & $2.75 e+007$ & $1.37 e+007$ \\
\hline TL-208 & $8.41 e+005$ & $7.04 \mathrm{e}+005$ & $\mathrm{AU}$ & $9.24 \mathrm{e}+005$ & $4.63 e+005$ \\
\hline U-235 & $3.95 e+008$ & $7.12 e+007$ & A & $1.94 e+006$ & $9.72 e+005$ \\
\hline TH-231 & $3.09 e+009$ & $6.18 e+008$ & A & $1.05 e+008$ & $5.24 e+007$ \\
\hline PA-231 & $1.60 e+008$ & $4.35 e+007$ & $\mathrm{AU}$ & $4.52 \mathrm{e}+007$ & $2.26 e+007$ \\
\hline TH-227 & $1.10 e+007$ & $4.93 e+006$ & $\mathrm{AU}$ & $6.12 \mathrm{e}+006$ & $3.05 e+006$ \\
\hline RA-223 & $2.55 e+008$ & $5.11 e+007$ & $\mathrm{AU}$ & $5.15 e+006$ & $2.57 e+006$ \\
\hline RN-219 & $-8.05 e+005$ & $6.58 e+006$ & $\mathrm{AU}$ & $1.09 e+007$ & $5.45 e+006$ \\
\hline PB-211 & $3.16 e+005$ & $1.39 e+007$ & $A U$ & $1.90 \mathrm{e}+007$ & $9.48 e+006$ \\
\hline TL-207 & $1.05 e+008$ & $1.38 e+008$ & $A U$ & $1.79 e+008$ & $8.88 e+007$ \\
\hline NP-237 & $-1.39 e+010$ & $2.79 e+009$ & $A U$ & $3.18 e+008$ & $1.59 \mathrm{e}+008$ \\
\hline PA-233 & $4.37 e+005$ & $1.59 \mathrm{e}+006$ & $A U$ & $2.02 \mathrm{e}+006$ & $1.01 e+006$ \\
\hline TH-229 & $-4.55 e+007$ & $9.54 e+006$ & $A U$ & $1.64 \mathrm{e}+007$ & $8.16 e+006$ \\
\hline BA-133 & $-8.92 e+005$ & $9.36 e+005$ & $\mathrm{AU}$ & $1.17 e+006$ & $5.85 e+005$ \\
\hline Ba-140 & $1.99 e+008$ & $2.44 e+007$ & A & $3.70 e+006$ & $1.84 \mathrm{e}+006$ \\
\hline \multirow{3}{*}{ Page 17 of 49} & Wast & \multicolumn{3}{|c|}{ + - Segregate as Radioactive } & \multirow{3}{*}{$01 \_6-19$} \\
\hline & Quali & A - Accepted & $\mathbf{J}$ - Estimated & R - Rejected & \\
\hline & Detectio & (Blank) - Detected & U - Not Detected & N - Poor Statistics & \\
\hline
\end{tabular}




\section{AB51160}

\begin{tabular}{|c|c|c|c|c|c|}
\hline Analyte & $\begin{array}{c}\text { Activity } \\
\text { (dpm) }\end{array}$ & $\begin{array}{c}\text { Unc } \\
(2.0 \sigma)\end{array}$ & $\begin{array}{l}\text { Lab } \\
\text { Flag }\end{array}$ & $\begin{array}{c}\text { MDA } \\
(\mathrm{dpm})\end{array}$ & $\begin{array}{c}\text { CL } \\
(\mathrm{dpm})\end{array}$ \\
\hline CD-115 & $-6.13 e+005$ & $1.29 \mathrm{e}+006$ & $\mathrm{AU}$ & $1.63 e+006$ & $8.10 e+005$ \\
\hline CE-141 & $4.86 e+008$ & $9.74 e+007$ & A & $2.37 \mathrm{e}+006$ & $1.19 e+006$ \\
\hline CE-144 & $4.05 e+008$ & $8.12 e+007$ & A & $1.04 e+007$ & $5.22 e+006$ \\
\hline $\mathrm{CO}-60$ & $1.92 \mathrm{e}+005$ & $3.91 e+005$ & $\mathrm{AU}$ & $5.23 e+005$ & $2.60 \mathrm{e}+005$ \\
\hline CS-137 & $1.50 \mathrm{e}+008$ & $1.81 e+007$ & A & $6.66 \mathrm{e}+005$ & $3.33 e+005$ \\
\hline $\mathrm{Ce}-143$ & $2.23 e+006$ & $8.12 \mathrm{e}+005$ & A & $1.97 \mathrm{e}+006$ & $9.84 e+005$ \\
\hline $\mid-131$ & $4.53 e+007$ & $6.75 e+006$ & A & $1.15 e+006$ & $5.73 e+005$ \\
\hline $\mid-132$ & $1.58 \mathrm{e}+007$ & $1.87 e+006$ & A & $8.76 \mathrm{e}+005$ & $4.35 e+005$ \\
\hline |-133 & $9.72 \mathrm{e}+006$ & $1.23 e+006$ & A & $1.04 e+006$ & $5.23 e+005$ \\
\hline In-115m & $-6.67 e+005$ & $1.40 \mathrm{e}+006$ & $\mathrm{AU}$ & $1.77 e+006$ & $8.82 e+005$ \\
\hline La-140 & $2.31 e+008$ & $1.85 e+007$ & A & $6.96 \mathrm{e}+005$ & $3.46 \mathrm{e}+005$ \\
\hline MO-99 & $1.30 \mathrm{e}+007$ & $3.42 e+006$ & A & $4.94 e+006$ & $2.47 e+006$ \\
\hline NB-95m & $6.19 \mathrm{e}+006$ & $1.39 e+006$ & A & $3.22 \mathrm{e}+006$ & $1.61 e+006$ \\
\hline ND-147 & $6.34 \mathrm{e}+007$ & $7.98 e+006$ & A & $6.84 \mathrm{e}+006$ & $3.41 e+006$ \\
\hline NP-239 & $1.21 \mathrm{e}+007$ & $4.48 \mathrm{e}+006$ & $\mathrm{AU}$ & $5.36 e+006$ & $2.68 \mathrm{e}+006$ \\
\hline Nb-95 & $7.22 e+008$ & $8.66 e+007$ & A & $5.92 e+005$ & $2.95 e+005$ \\
\hline PM-149 & $9.36 e+007$ & $2.41 e+007$ & $\mathrm{AU}$ & $2.49 \mathrm{e}+007$ & $1.24 \mathrm{e}+007$ \\
\hline Pr-144 & $1.44 e+009$ & $1.98 e+008$ & A & $1.54 e+008$ & $7.68 e+007$ \\
\hline RU-103 & $2.80 \mathrm{e}+008$ & $3.37 e+007$ & A & $1.12 \mathrm{e}+006$ & $5.59 \mathrm{e}+005$ \\
\hline RU-106 & $2.79 e+007$ & $3.87 e+006$ & A & $6.00 e+006$ & $3.01 e+006$ \\
\hline SB-124 & $-2.90 e+004$ & $5.40 \mathrm{e}+005$ & $A U$ & $7.44 e+005$ & $3.71 e+005$ \\
\hline SB-125 & $-5.55 e+007$ & $7.66 e+006$ & $\mathrm{AU}$ & $2.50 e+006$ & $1.25 \mathrm{e}+006$ \\
\hline SB-127 & $-6.23 e+002$ & 2.12e+005 & $A U$ & $1.50 \mathrm{e}+006$ & $7.50 \mathrm{e}+005$ \\
\hline Tc-99m & $1.57 \mathrm{e}+007$ & $3.18 \mathrm{e}+006$ & A & $1.49 e+006$ & $7.44 e+005$ \\
\hline Te-127m & $-1.17 e+009$ & $3.94 \mathrm{e}+008$ & $A U$ & $3.78 \mathrm{e}+008$ & $1.89 \mathrm{e}+008$ \\
\hline Te-129m & $2.03 e+008$ & $2.79 e+007$ & $\mathrm{AU}$ & $2.17 e+007$ & $1.08 \mathrm{e}+007$ \\
\hline Te-131m & $1.01 \mathrm{e}+007$ & $1.72 \mathrm{e}+006$ & $\mathrm{AU}$ & $1.73 e+006$ & $8.64 \mathrm{e}+005$ \\
\hline Te-132 & $1.39 \mathrm{e}+007$ & $2.51 \mathrm{e}+006$ & A & $9.06 e+005$ & $4.52 \mathrm{e}+005$ \\
\hline U-232 & $-1.34 e+009$ & $8.16 e+008$ & $\mathrm{AU}$ & $9.48 \mathrm{e}+008$ & $4.74 \mathrm{e}+008$ \\
\hline U-234 & $1.02 \mathrm{e}+009$ & $2.54 \mathrm{e}+009$ & $\mathrm{AU}$ & $3.48 \mathrm{e}+009$ & $1.74 \mathrm{e}+009$ \\
\hline U-237 & $-2.92 e+007$ & $7.31 e+006$ & $\mathrm{AU}$ & $5.29 e+006$ & $2.65 e+006$ \\
\hline$X E-131 m$ & $1.48 \mathrm{e}+009$ & $3.02 \mathrm{e}+008$ & $\mathrm{AU}$ & $8.88 e+007$ & $4.43 e+007$ \\
\hline
\end{tabular}

Page 18 of 49

\begin{tabular}{|r|lll|}
\hline Waste Flags: & + - Segregate as Radioactive & ${ }^{*}$ - Do Not Recycle \\
\hline Quality Flags: & A - Accepted & J - Estimated & R - Rejected \\
\hline Detection Flags: & (Blank) - Detected & U - Not Detected & N - Poor Statistics \\
\hline
\end{tabular}

UNM AGN-201_6-19 


\section{AB51160}

\begin{tabular}{|c|c|c|c|c|c|}
\hline Analyte & $\begin{array}{c}\text { Activity } \\
\text { (dpm) }\end{array}$ & $\begin{array}{c}\text { Unc } \\
(2.0 \sigma)\end{array}$ & $\begin{array}{l}\text { Lab } \\
\text { Flag }\end{array}$ & $\begin{array}{c}\text { MDA } \\
(\mathrm{dpm})\end{array}$ & $\begin{array}{c}\text { CL } \\
\text { (dpm) }\end{array}$ \\
\hline XE-133 & $1.07 e+008$ & $2.16 e+007$ & A & $3.64 e+006$ & $1.82 e+006$ \\
\hline$Y-88$ & $8.93 e+004$ & $1.62 e+005$ & $\mathrm{AU}$ & $2.15 \mathrm{e}+005$ & $1.06 \mathrm{e}+005$ \\
\hline$Y-91$ & $5.67 e+008$ & $1.35 e+008$ & A & $2.02 e+008$ & $1.00 e+008$ \\
\hline Y-91m & $4.01 \mathrm{e}+006$ & $9.31 e+005$ & $A U$ & $1.30 \mathrm{e}+006$ & $6.48 \mathrm{e}+005$ \\
\hline ZR-95 & $6.44 e+008$ & $7.74 e+007$ & A & $1.01 e+006$ & $5.04 e+005$ \\
\hline
\end{tabular}

Page 19 of 49

\begin{tabular}{|r|lll|}
\hline Waste Flags: & + - Segregate as Radioactive & ${ }^{*}$ - Do Not Recycle \\
\hline Quality Flags: & A - Accepted & J - Estimated & R - Rejected \\
\hline Detection Flags: & (Blank) - Detected & U - Not Detected & N - Poor Statistics \\
\hline
\end{tabular}

UNM AGN-201_6-19 


\section{AB51161 - AGN Plate 103}

Live Time (s): 3600 Real Time (s): 5529

Detector: PGE14
Geometry: AGN-103-I

Library: $A G N-201 \mathrm{M}$

Background: 14_PGE_190514
Count Date: 5/15/2019 10:24:33AM Collection Date: 5/13/2019 12:00:00PM Quantity (each): $1.00 \mathrm{e}+000$

Analyzed By:

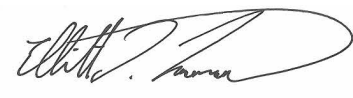

Reviewed By

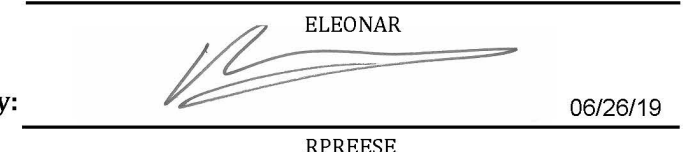

AB51161

\begin{tabular}{|c|c|c|c|c|c|}
\hline Analyte & $\begin{array}{c}\text { Activity } \\
\text { (dpm) }\end{array}$ & $\begin{array}{l}\text { Unc } \\
(2.0 \sigma)\end{array}$ & $\begin{array}{l}\text { Lab } \\
\text { Flag }\end{array}$ & $\begin{array}{c}\text { MDA } \\
\text { (dpm) }\end{array}$ & $\begin{array}{c}\text { CL } \\
\text { (dpm) }\end{array}$ \\
\hline U-238 & $5.79 e+008$ & $7.59 e+007$ & $\mathrm{AU}$ & $8.52 e+007$ & $4.26 e+007$ \\
\hline RA-226 & $1.23 e+010$ & $2.21 e+009$ & $\mathrm{AU}$ & $3.66 e+007$ & $1.83 e+007$ \\
\hline PB-214 & $7.58 e+005$ & $1.99 e+006$ & $\mathrm{AU}$ & $2.51 e+006$ & $1.25 e+006$ \\
\hline Bl-214 & $-6.02 e+005$ & $4.15 e+005$ & $\mathrm{AU}$ & $2.42 e+006$ & $1.21 e+006$ \\
\hline PB-210 & $-3.02 e+008$ & $1.10 \mathrm{e}+008$ & $\mathrm{AU}$ & $8.46 e+007$ & $4.24 e+007$ \\
\hline AC-228 & $6.26 e+006$ & $1.05 e+006$ & A & $2.87 e+006$ & $1.43 e+006$ \\
\hline RA-224 & $1.75 e+005$ & $1.28 \mathrm{e}+005$ & A & $2.07 e+005$ & $1.02 \mathrm{e}+005$ \\
\hline PB-212 & $-4.56 e+006$ & $1.86 e+006$ & $\mathrm{AU}$ & $2.24 e+006$ & $1.12 \mathrm{e}+006$ \\
\hline BI-212 & $-1.31 e+008$ & $1.65 e+007$ & $\mathrm{AU}$ & $3.24 e+007$ & $1.62 \mathrm{e}+007$ \\
\hline TL-208 & $-7.43 e+004$ & $9.55 e+005$ & $\mathrm{AU}$ & $1.26 e+006$ & $6.30 e+005$ \\
\hline U-235 & $7.73 e+008$ & $1.39 e+008$ & A & $2.30 \mathrm{e}+006$ & $1.15 e+006$ \\
\hline TH-231 & $6.94 \mathrm{e}+009$ & $1.39 e+009$ & A & $1.55 e+008$ & $7.74 e+007$ \\
\hline PA-231 & $3.05 e+008$ & $6.70 \mathrm{e}+007$ & $\mathrm{AU}$ & $5.63 e+007$ & $2.81 e+007$ \\
\hline TH-227 & $2.30 e+007$ & $6.79 e+006$ & $\mathrm{AU}$ & $7.56 e+006$ & $3.78 \mathrm{e}+006$ \\
\hline RA-223 & $6.10 e+008$ & $1.22 \mathrm{e}+008$ & $\mathrm{AU}$ & $7.56 e+006$ & $3.79 e+006$ \\
\hline RN-219 & $-9.17 e+006$ & $1.06 e+007$ & $\mathrm{AU}$ & $1.43 e+007$ & $7.20 \mathrm{e}+006$ \\
\hline PB-211 & $-3.34 e+006$ & $1.83 e+007$ & $\mathrm{AU}$ & $2.50 e+007$ & $1.25 e+007$ \\
\hline TL-207 & $1.74 e+008$ & $2.32 \mathrm{e}+008$ & $\mathrm{AU}$ & $2.98 e+008$ & $1.48 e+008$ \\
\hline NP-237 & $-1.99 e+010$ & $4.00 e+009$ & $\mathrm{AU}$ & $3.66 e+008$ & $1.83 e+008$ \\
\hline PA-233 & $-3.67 e+005$ & $2.02 e+006$ & $\mathrm{AU}$ & $2.56 e+006$ & $1.28 e+006$ \\
\hline TH-229 & $1.71 e+009$ & $3.43 e+008$ & $\mathrm{AU}$ & $1.87 e+007$ & $9.36 e+006$ \\
\hline BA-133 & $-3.38 e+006$ & $1.31 e+006$ & $\mathrm{AU}$ & $1.52 \mathrm{e}+006$ & $7.62 e+005$ \\
\hline $\mathrm{Ba}-140$ & $3.79 e+008$ & $4.60 e+007$ & A & $5.81 e+006$ & $2.90 \mathrm{e}+006$ \\
\hline \multirow{3}{*}{ Page 20 of 49} & Was & \multicolumn{3}{|c|}{ + - Segregate as Radioactive } & \multirow{3}{*}{ 01_6-19 } \\
\hline & Qual & A - Accepted & $\mathbf{J}$ - Estimated & R - Rejected & \\
\hline & Detectic & (Blank) - Detected & U - Not Detected & N - Poor Statistics & \\
\hline
\end{tabular}


AB51161

\begin{tabular}{|c|c|c|c|c|c|}
\hline Analyte & $\begin{array}{c}\text { Activity } \\
\text { (dpm) }\end{array}$ & $\begin{array}{c}\text { Unc } \\
(2.0 \sigma)\end{array}$ & $\begin{array}{l}\text { Lab } \\
\text { Flag }\end{array}$ & $\begin{array}{c}\text { MDA } \\
\text { (dpm) }\end{array}$ & $\begin{array}{c}\text { CL } \\
(\mathrm{dpm})\end{array}$ \\
\hline CD-115 & $-4.06 e+006$ & $1.78 e+006$ & $\mathrm{AU}$ & $2.10 e+006$ & $1.05 e+006$ \\
\hline CE-141 & $1.12 \mathrm{e}+009$ & $2.24 e+008$ & A & $3.82 \mathrm{e}+006$ & $1.91 e+006$ \\
\hline CE-144 & $7.56 e+008$ & $1.51 e+008$ & A & $1.36 \mathrm{e}+007$ & $6.78 e+006$ \\
\hline $\mathrm{CO}-60$ & $3.02 \mathrm{e}+005$ & $5.35 e+005$ & $\mathrm{AU}$ & $7.14 \mathrm{e}+005$ & $3.55 \mathrm{e}+005$ \\
\hline CS-137 & $2.73 e+008$ & $3.28 e+007$ & A & $1.03 e+006$ & $5.15 e+005$ \\
\hline Ce-143 & $2.59 e+006$ & $1.42 \mathrm{e}+006$ & A & $2.23 e+006$ & $1.12 \mathrm{e}+006$ \\
\hline $\mid-131$ & $8.03 e+007$ & $1.19 e+007$ & A & $1.51 \mathrm{e}+006$ & $7.56 e+005$ \\
\hline $\mid-132$ & $3.60 \mathrm{e}+007$ & $4.22 \mathrm{e}+006$ & A & $1.75 e+006$ & $8.70 e+005$ \\
\hline |-133 & $1.84 e+007$ & $2.28 \mathrm{e}+006$ & A & $1.66 \mathrm{e}+006$ & $8.28 e+005$ \\
\hline In-115m & $-4.51 e+006$ & $1.98 e+006$ & $\mathrm{AU}$ & $2.34 \mathrm{e}+006$ & $1.17 e+006$ \\
\hline La-140 & $4.27 e+008$ & $3.42 \mathrm{e}+007$ & A & $7.56 e+005$ & $3.77 e+005$ \\
\hline MO-99 & $2.21 \mathrm{e}+007$ & $5.54 e+006$ & A & $7.98 \mathrm{e}+006$ & $3.98 \mathrm{e}+006$ \\
\hline NB-95m & $1.23 e+007$ & $2.34 \mathrm{e}+006$ & A & $5.05 e+006$ & $2.52 \mathrm{e}+006$ \\
\hline ND-147 & $1.20 \mathrm{e}+008$ & $1.48 e+007$ & A & $1.08 \mathrm{e}+007$ & $5.38 e+006$ \\
\hline NP-239 & $2.16 \mathrm{e}+007$ & $6.52 e+006$ & A & $6.84 e+006$ & $3.41 \mathrm{e}+006$ \\
\hline $\mathrm{Nb}-95$ & $1.35 \mathrm{e}+009$ & $1.62 e+008$ & A & $1.05 e+006$ & $5.23 e+005$ \\
\hline PM-149 & $1.98 \mathrm{e}+008$ & $4.92 \mathrm{e}+007$ & $\mathrm{AU}$ & $4.21 \mathrm{e}+007$ & $2.11 e+007$ \\
\hline Pr-144 & $3.12 e+009$ & $4.14 e+008$ & A & $2.83 e+008$ & $1.41 e+008$ \\
\hline RU-103 & $5.03 e+008$ & $6.06 e+007$ & A & $1.46 e+006$ & $7.32 \mathrm{e}+005$ \\
\hline RU-106 & $5.24 e+007$ & $1.02 e+007$ & A & $9.42 e+006$ & $4.70 e+006$ \\
\hline SB-124 & $-4.85 e+006$ & $9.80 e+005$ & $\mathrm{AU}$ & $1.03 e+006$ & $5.14 \mathrm{e}+005$ \\
\hline SB-125 & $-2.01 e+006$ & $1.15 e+006$ & $\mathrm{AU}$ & $3.31 e+006$ & $1.65 e+006$ \\
\hline SB-127 & $2.48 \mathrm{e}+006$ & $1.71 e+006$ & $\mathrm{AU}$ & $2.24 \mathrm{e}+006$ & $1.12 \mathrm{e}+006$ \\
\hline Tc-99m & $1.15 e+007$ & $2.39 e+006$ & A & $2.44 \mathrm{e}+006$ & $1.22 e+006$ \\
\hline Te-127m & $-2.10 e+009$ & $5.50 \mathrm{e}+008$ & $A U$ & $4.51 \mathrm{e}+008$ & $2.26 \mathrm{e}+008$ \\
\hline Te-129m & $3.60 \mathrm{e}+008$ & $4.77 e+007$ & $\mathrm{AU}$ & $3.26 \mathrm{e}+007$ & $1.63 \mathrm{e}+007$ \\
\hline Te-131m & $-7.79 e+007$ & $9.30 \mathrm{e}+006$ & $\mathrm{AU}$ & $2.66 \mathrm{e}+006$ & $1.33 e+006$ \\
\hline Te-132 & $2.62 e+007$ & $4.50 \mathrm{e}+006$ & A & $1.15 \mathrm{e}+006$ & $5.74 \mathrm{e}+005$ \\
\hline U-232 & $-3.27 e+009$ & $1.02 e+009$ & $\mathrm{AU}$ & $1.13 e+009$ & $5.65 e+008$ \\
\hline U-234 & $-7.91 e+009$ & $3.30 \mathrm{e}+009$ & $\mathrm{AU}$ & $3.96 \mathrm{e}+009$ & $1.98 \mathrm{e}+009$ \\
\hline U-237 & $4.43 e+006$ & $2.79 e+006$ & $\mathrm{AU}$ & $6.24 e+006$ & $3.12 \mathrm{e}+006$ \\
\hline$X E-131 m$ & $3.01 \mathrm{e}+009$ & $6.04 e+008$ & $\mathrm{AU}$ & $6.90 \mathrm{e}+007$ & $3.44 \mathrm{e}+007$ \\
\hline
\end{tabular}

Page 21 of 49

\begin{tabular}{|r|lll|}
\hline Waste Flags: & + - Segregate as Radioactive & ${ }^{*}$ - Do Not Recycle \\
\hline Quality Flags: & A - Accepted & J - Estimated & R - Rejected \\
\hline Detection Flags: & (Blank) - Detected & U - Not Detected & N - Poor Statistics \\
\hline
\end{tabular}

UNM AGN-201_6-19 
AB51161

\begin{tabular}{|c|c|c|c|c|c|}
\hline Analyte & $\begin{array}{c}\text { Activity } \\
\text { (dpm) }\end{array}$ & $\begin{array}{c}\text { Unc } \\
(2.0 \sigma)\end{array}$ & $\begin{array}{l}\text { Lab } \\
\text { Flag }\end{array}$ & $\begin{array}{c}\text { MDA } \\
(\mathrm{dpm})\end{array}$ & $\begin{array}{c}\text { CL } \\
(\mathrm{dpm})\end{array}$ \\
\hline$X E-133$ & $2.41 e+008$ & $4.86 e+007$ & A & $5.39 e+006$ & $2.69 e+006$ \\
\hline Y-88 & $1.96 \mathrm{e}+005$ & $2.82 e+005$ & $\mathrm{AU}$ & $3.70 \mathrm{e}+005$ & $1.84 \mathrm{e}+005$ \\
\hline Y-91 & $8.57 e+008$ & $3.13 e+008$ & A & $4.99 e+008$ & $2.49 e+008$ \\
\hline Y-91m & $9.11 e+006$ & $1.92 \mathrm{e}+006$ & $\mathrm{AU}$ & $2.57 e+006$ & $1.29 \mathrm{e}+006$ \\
\hline ZR-95 & $1.20 \mathrm{e}+009$ & $1.44 e+008$ & A & $1.84 e+006$ & $9.18 e+005$ \\
\hline
\end{tabular}

Page 22 of 49

\begin{tabular}{|r|lll|}
\hline Waste Flags: & + - Segregate as Radioactive & * - Do Not Recycle \\
\hline Quality Flags: & A - Accepted & J - Estimated & R - Rejected \\
\hline Detection Flags: & (Blank) - Detected & U - Not Detected & N - Poor Statistics \\
\hline
\end{tabular}

UNM AGN-201_6-19 
AB51162 - AGN Plate 104

Live Time (s): 3600 Real Time (s): 4533

Detector: PGE14
Geometry: AGN-201-1

Library: AGN-201M

Background: 14_PGE_190515
Count Date: 5/15/2019 9:00:28AM Collection Date: 5/13/2019 12:00:00PM Quantity (each): $1.00 \mathrm{e}+000$

Analyzed By:

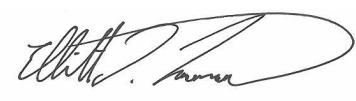

Reviewed By

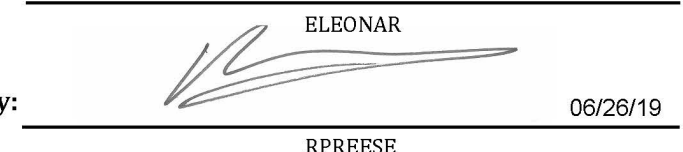

AB51162

\begin{tabular}{|c|c|c|c|c|c|}
\hline Analyte & $\begin{array}{c}\text { Activity } \\
\text { (dpm) }\end{array}$ & $\begin{array}{c}\text { Unc } \\
(2.0 \sigma)\end{array}$ & $\begin{array}{c}\text { Lab } \\
\text { Flag }\end{array}$ & $\begin{array}{c}\text { MDA } \\
\text { (dpm) }\end{array}$ & $\begin{array}{c}\text { CL } \\
\text { (dpm) }\end{array}$ \\
\hline U-238 & $9.92 e+007$ & $1.40 e+007$ & A & $1.84 e+007$ & $9.18 \mathrm{e}+006$ \\
\hline RA-226 & $2.38 e+009$ & $4.28 e+008$ & $\mathrm{AU}$ & $6.84 \mathrm{e}+006$ & $3.43 e+006$ \\
\hline PB-214 & $8.46 e+004$ & $3.76 e+005$ & $\mathrm{AU}$ & $4.99 e+005$ & $2.49 e+005$ \\
\hline $\mathrm{Bl}-214$ & $-1.80 e+004$ & $6.37 e+004$ & $\mathrm{AU}$ & $5.02 e+005$ & $2.50 e+005$ \\
\hline PB-210 & $-4.49 e+007$ & $1.58 e+007$ & $\mathrm{AU}$ & $1.13 e+007$ & $5.62 e+006$ \\
\hline AC-228 & $7.38 e+005$ & $4.29 e+005$ & $\mathrm{AU}$ & $5.50 e+005$ & $2.74 e+005$ \\
\hline RA-224 & $4.69 e+004$ & $2.79 e+004$ & A & $4.43 e+004$ & $2.17 e+004$ \\
\hline PB-212 & $-6.13 e+005$ & $3.42 \mathrm{e}+005$ & $\mathrm{AU}$ & $4.30 e+005$ & $2.15 e+005$ \\
\hline BI-212 & $-2.29 e+007$ & $2.92 \mathrm{e}+006$ & $\mathrm{AU}$ & $7.50 e+006$ & $3.74 e+006$ \\
\hline TL-208 & $-1.84 e+005$ & $1.95 e+005$ & $\mathrm{AU}$ & $2.56 e+005$ & $1.28 \mathrm{e}+005$ \\
\hline $\mathrm{U}-235$ & $1.49 e+008$ & $2.68 e+007$ & A & $4.30 e+005$ & $2.15 e+005$ \\
\hline TH-231 & $8.60 e+008$ & $1.72 e+008$ & A & $2.15 e+007$ & $1.07 e+007$ \\
\hline PA-231 & $5.53 e+007$ & $1.26 e+007$ & $\mathrm{AU}$ & $1.12 \mathrm{e}+007$ & $5.57 e+006$ \\
\hline TH-227 & $3.52 e+006$ & $1.23 e+006$ & $\mathrm{AU}$ & $1.45 e+006$ & $7.20 e+005$ \\
\hline RA-223 & $7.41 e+007$ & $1.48 e+007$ & A & $1.07 e+006$ & $5.36 e+005$ \\
\hline RN-219 & $-1.60 e+006$ & $1.74 e+006$ & $\mathrm{AU}$ & $2.86 e+006$ & $1.43 e+006$ \\
\hline PB-211 & $-8.51 e+005$ & $3.65 e+006$ & $\mathrm{AU}$ & $4.99 e+006$ & $2.49 e+006$ \\
\hline TL-207 & $2.96 e+007$ & $4.22 e+007$ & $\mathrm{AU}$ & $5.43 e+007$ & $2.71 e+007$ \\
\hline NP-237 & $-2.79 e+009$ & $5.61 e+008$ & $\mathrm{AU}$ & $7.08 e+007$ & $3.55 e+007$ \\
\hline PA-233 & $1.72 e+005$ & $4.02 e+005$ & $\mathrm{AU}$ & $5.09 e+005$ & $2.54 \mathrm{e}+005$ \\
\hline TH-229 & $-1.26 e+007$ & $2.61 e+006$ & $\mathrm{AU}$ & $3.60 e+006$ & $1.80 \mathrm{e}+006$ \\
\hline BA-133 & $-1.10 e+005$ & $1.09 e+005$ & $\mathrm{AU}$ & $3.01 e+005$ & $1.51 e+005$ \\
\hline Ba-140 & $6.00 e+007$ & $7.33 e+006$ & A & $1.03 e+006$ & $5.15 e+005$ \\
\hline \multirow{3}{*}{ Page 23 of 49} & Waste Flags: & \multicolumn{3}{|c|}{ + - Segregate as Radioactive } & \multirow{3}{*}{$201 \_6-19$} \\
\hline & Quality Flags: & A - Accepted & $\mathbf{J}$ - Estimated & $\mathbf{R}$ - Rejected & \\
\hline & Detection Flags: & (Blank) - Detected & U - Not Detected & $\mathrm{N}$ - Poor Statistics & \\
\hline
\end{tabular}


AB51162

\begin{tabular}{|c|c|c|c|c|c|}
\hline Analyte & $\begin{array}{l}\text { Activity } \\
\text { (dpm) }\end{array}$ & $\begin{array}{c}\text { Unc } \\
(2.0 \sigma)\end{array}$ & $\begin{array}{l}\text { Lab } \\
\text { Flag }\end{array}$ & $\begin{array}{c}\text { MDA } \\
(\mathrm{dpm})\end{array}$ & $\begin{array}{c}\text { CL } \\
(\mathrm{dpm})\end{array}$ \\
\hline CD-115 & $2.40 \mathrm{e}+004$ & $1.63 e+005$ & $\mathrm{AU}$ & $4.15 e+005$ & $2.08 e+005$ \\
\hline CE-141 & $1.49 e+008$ & $2.99 \mathrm{e}+007$ & A & $4.93 e+005$ & $2.46 \mathrm{e}+005$ \\
\hline CE-144 & $1.23 e+008$ & $2.46 e+007$ & A & $2.07 e+006$ & $1.03 e+006$ \\
\hline $\mathrm{CO}-60$ & $-2.87 e+004$ & $1.16 e+005$ & $A U$ & $1.54 \mathrm{e}+005$ & $7.62 \mathrm{e}+004$ \\
\hline CS-137 & $4.46 e+007$ & $5.37 e+006$ & A & $1.90 \mathrm{e}+005$ & $9.48 e+004$ \\
\hline $\mathrm{Ce}-143$ & $-9.36 e+004$ & $1.50 \mathrm{e}+005$ & $\mathrm{AU}$ & $4.68 \mathrm{e}+005$ & $2.34 \mathrm{e}+005$ \\
\hline $\mid-131$ & $1.38 e+007$ & $2.06 e+006$ & A & $4.97 e+005$ & $2.48 e+005$ \\
\hline |-132 & $5.04 \mathrm{e}+006$ & $5.95 e+005$ & A & $2.77 e+005$ & $1.38 \mathrm{e}+005$ \\
\hline $1-133$ & $2.76 \mathrm{e}+006$ & $3.48 \mathrm{e}+005$ & $\mathrm{AU}$ & $2.93 e+005$ & $1.46 \mathrm{e}+005$ \\
\hline In-115m & $2.62 e+004$ & $1.77 e+005$ & $\mathrm{AU}$ & $4.53 e+005$ & $2.26 e+005$ \\
\hline La-140 & $6.94 e+007$ & $5.56 \mathrm{e}+006$ & A & $1.48 \mathrm{e}+005$ & $7.38 \mathrm{e}+004$ \\
\hline MO-99 & $4.54 \mathrm{e}+006$ & $1.10 \mathrm{e}+006$ & A & $1.55 e+006$ & $7.74 e+005$ \\
\hline NB-95m & $2.13 e+006$ & $3.85 e+005$ & A & $8.04 e+005$ & $4.02 \mathrm{e}+005$ \\
\hline ND-147 & $1.80 \mathrm{e}+007$ & $2.26 e+006$ & A & $1.91 \mathrm{e}+006$ & $9.54 e+005$ \\
\hline NP-239 & $3.33 e+006$ & $1.12 \mathrm{e}+006$ & $\mathrm{AU}$ & $1.31 e+006$ & $6.54 \mathrm{e}+005$ \\
\hline $\mathrm{Nb}-95$ & $2.14 e+008$ & $2.57 e+007$ & A & $1.76 e+005$ & $8.82 e+004$ \\
\hline PM-149 & $-1.99 e+006$ & $1.56 e+006$ & $\mathrm{AU}$ & $6.18 \mathrm{e}+006$ & $3.07 e+006$ \\
\hline Pr-144 & $4.47 e+008$ & $6.07 e+007$ & A & $4.51 e+007$ & $2.25 e+007$ \\
\hline RU-103 & $8.33 e+007$ & $1.00 e+007$ & A & $3.04 e+005$ & $1.52 \mathrm{e}+005$ \\
\hline RU-106 & $7.97 e+006$ & $1.87 e+006$ & A & $1.63 e+006$ & $8.10 e+005$ \\
\hline SB-124 & $-1.20 \mathrm{e}+005$ & $1.51 e+005$ & $A U$ & $2.07 e+005$ & $1.03 e+005$ \\
\hline SB-125 & $-1.52 e+007$ & $2.10 \mathrm{e}+006$ & $\mathrm{AU}$ & $6.66 e+005$ & $3.32 e+005$ \\
\hline SB-127 & $4.55 e+005$ & $3.25 \mathrm{e}+005$ & $\mathrm{AU}$ & $4.28 \mathrm{e}+005$ & $2.14 \mathrm{e}+005$ \\
\hline Tc-99m & $5.00 e+006$ & $1.01 e+006$ & A & $2.99 e+005$ & $1.49 e+005$ \\
\hline Te-127m & $-3.82 e+008$ & $9.69 \mathrm{e}+007$ & $A U$ & $6.54 \mathrm{e}+007$ & $3.26 \mathrm{e}+007$ \\
\hline Te-129m & $6.13 e+007$ & $8.33 e+006$ & $\mathrm{AU}$ & $6.18 \mathrm{e}+006$ & $3.09 e+006$ \\
\hline Te-131m & $1.67 \mathrm{e}+006$ & $4.27 e+005$ & $\mathrm{AU}$ & $5.14 e+005$ & $2.56 e+005$ \\
\hline Te-132 & $4.29 e+006$ & $7.07 e+005$ & A & $2.24 \mathrm{e}+005$ & $1.12 \mathrm{e}+005$ \\
\hline U-232 & $-5.31 e+008$ & $1.74 e+008$ & $\mathrm{AU}$ & $1.64 \mathrm{e}+008$ & $8.22 e+007$ \\
\hline U-234 & $6.43 e+008$ & $4.83 e+008$ & $\mathrm{AU}$ & $6.42 \mathrm{e}+008$ & $3.20 \mathrm{e}+008$ \\
\hline U-237 & $-1.05 e+007$ & $2.25 \mathrm{e}+006$ & $\mathrm{AU}$ & $9.24 \mathrm{e}+005$ & $4.60 \mathrm{e}+005$ \\
\hline XE-131m & $5.61 e+008$ & $1.13 e+008$ & $\mathrm{AU}$ & $1.21 \mathrm{e}+007$ & $6.06 \mathrm{e}+006$ \\
\hline
\end{tabular}

Page 24 of 49

\begin{tabular}{|r|lll|}
\hline Waste Flags: & + - Segregate as Radioactive & * - Do Not Recycle \\
\hline Quality Flags: & A - Accepted & J - Estimated & R - Rejected \\
\hline Detection Flags: & (Blank) - Detected & U - Not Detected & N - Poor Statistics \\
\hline
\end{tabular}

UNM AGN-201_6-19 


\section{AB51162}

\begin{tabular}{|c|c|c|c|c|c|}
\hline Analyte & $\begin{array}{c}\text { Activity } \\
\text { (dpm) }\end{array}$ & $\begin{array}{c}\text { Unc } \\
(2.0 \sigma)\end{array}$ & $\begin{array}{l}\text { Lab } \\
\text { Flag }\end{array}$ & $\begin{array}{c}\text { MDA } \\
(\mathrm{dpm})\end{array}$ & $\begin{array}{c}\text { CL } \\
\text { (dpm) }\end{array}$ \\
\hline XE-133 & $2.98 e+007$ & $6.03 e+006$ & A & $7.44 e+005$ & $3.73 e+005$ \\
\hline$Y-88$ & $3.47 e+004$ & $5.47 e+004$ & $\mathrm{AU}$ & $7.26 \mathrm{e}+004$ & $3.58 \mathrm{e}+004$ \\
\hline$Y-91$ & $1.56 e+008$ & $3.32 \mathrm{e}+007$ & A & $4.85 e+007$ & $2.42 e+007$ \\
\hline Y-91m & $1.19 \mathrm{e}+006$ & $2.97 e+005$ & $A U$ & $4.24 \mathrm{e}+005$ & $2.12 \mathrm{e}+005$ \\
\hline ZR-95 & $1.91 e+008$ & $2.29 e+007$ & A & $3.03 e+005$ & $1.51 e+005$ \\
\hline
\end{tabular}

Page 25 of 49

\begin{tabular}{|r|lll|}
\hline Waste Flags: & + - Segregate as Radioactive & ${ }^{*}$ - Do Not Recycle \\
\hline Quality Flags: & A - Accepted & J - Estimated & R - Rejected \\
\hline Detection Flags: & (Blank) - Detected & U - Not Detected & N - Poor Statistics \\
\hline
\end{tabular}

UNM AGN-201_6-19 


\section{AB51163 - AGN Plate 105}

Live Time (s): 3600

Real Time (s): 4410

Detector: PGE14
Geometry: AGN-105

Library: AGN-201M

Background: 14_PGE_190514
Count Date: 5/14/2019 3:39:22PM Collection Date: 5/13/2019 12:00:00PM Quantity (each): $1.00 \mathrm{e}+000$

Analyzed By:

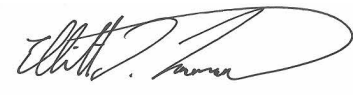

Reviewed By

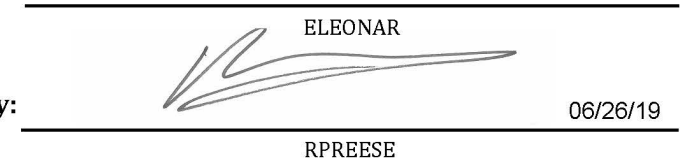

AB51163

\begin{tabular}{|c|c|c|c|c|c|}
\hline Analyte & $\begin{array}{c}\text { Activity } \\
\text { (dpm) }\end{array}$ & $\begin{array}{l}\text { Unc } \\
(2.0 \sigma)\end{array}$ & $\begin{array}{l}\text { Lab } \\
\text { Flag }\end{array}$ & $\begin{array}{c}\text { MDA } \\
\text { (dpm) }\end{array}$ & $\begin{array}{c}\text { CL } \\
\text { (dpm) }\end{array}$ \\
\hline U-238 & $1.01 e+008$ & $1.27 e+007$ & A & $1.55 e+007$ & $7.68 \mathrm{e}+006$ \\
\hline RA-226 & $2.38 e+009$ & $4.29 e+008$ & $\mathrm{AU}$ & $6.42 e+006$ & $3.20 \mathrm{e}+006$ \\
\hline PB-214 & $4.36 e+005$ & $3.69 e+005$ & $\mathrm{AU}$ & $4.63 e+005$ & $2.31 e+005$ \\
\hline $\mathrm{Bl}-214$ & $-6.40 e+004$ & $7.53 e+004$ & $\mathrm{AU}$ & $4.64 \mathrm{e}+005$ & $2.32 e+005$ \\
\hline PB-210 & $-4.84 e+007$ & $1.62 e+007$ & $\mathrm{AU}$ & $1.03 e+007$ & $5.13 e+006$ \\
\hline AC-228 & $5.74 e+005$ & $1.49 e+005$ & A & $4.56 e+005$ & $2.27 e+005$ \\
\hline RA-224 & $3.66 e+004$ & $2.68 \mathrm{e}+004$ & A & $4.30 e+004$ & $2.10 e+004$ \\
\hline PB-212 & $-6.69 e+005$ & $3.23 e+005$ & $\mathrm{AU}$ & $3.99 e+005$ & $1.99 e+005$ \\
\hline $\mathrm{BI}-212$ & $-1.59 e+007$ & $2.11 \mathrm{e}+006$ & $\mathrm{AU}$ & $7.02 e+006$ & $3.52 e+006$ \\
\hline TL-208 & $-5.60 e+004$ & $1.78 \mathrm{e}+005$ & $\mathrm{AU}$ & $2.35 e+005$ & $1.18 e+005$ \\
\hline U-235 & $1.49 e+008$ & $2.69 e+007$ & A & $4.02 e+005$ & $2.00 \mathrm{e}+005$ \\
\hline TH-231 & $7.66 e+008$ & $1.53 e+008$ & A & $1.94 e+007$ & $9.72 e+006$ \\
\hline PA-231 & $4.20 e+007$ & $1.05 e+007$ & $\mathrm{AU}$ & $1.03 e+007$ & $5.14 e+006$ \\
\hline $\mathrm{TH}-227$ & $3.97 e+006$ & $1.19 \mathrm{e}+006$ & $\mathrm{AU}$ & $1.34 e+006$ & $6.72 e+005$ \\
\hline RA-223 & $7.01 e+007$ & $1.40 \mathrm{e}+007$ & A & $1.00 \mathrm{e}+006$ & $4.99 e+005$ \\
\hline $\mathrm{RN}-219$ & $6.46 e+005$ & $1.25 e+006$ & $\mathrm{AU}$ & $2.65 e+006$ & $1.33 e+006$ \\
\hline PB-211 & $1.54 e+006$ & $3.38 e+006$ & $\mathrm{AU}$ & $4.62 e+006$ & $2.30 \mathrm{e}+006$ \\
\hline TL-207 & $6.66 e+006$ & $3.77 e+007$ & $\mathrm{AU}$ & $4.86 e+007$ & $2.42 e+007$ \\
\hline NP-237 & $-2.53 e+009$ & $5.08 e+008$ & $\mathrm{AU}$ & $6.78 e+007$ & $3.40 \mathrm{e}+007$ \\
\hline PA-233 & $-2.63 e+005$ & $3.74 e+005$ & $\mathrm{AU}$ & $4.70 e+005$ & $2.35 e+005$ \\
\hline TH-229 & $-9.77 e+006$ & $2.05 e+006$ & $\mathrm{AU}$ & $3.44 \mathrm{e}+006$ & $1.72 e+006$ \\
\hline BA-133 & $-4.51 e+005$ & $2.31 e+005$ & $\mathrm{AU}$ & $2.79 e+005$ & $1.39 e+005$ \\
\hline Ba-140 & $5.23 e+007$ & $6.41 e+006$ & A & $9.30 e+005$ & $4.64 \mathrm{e}+005$ \\
\hline \multirow{3}{*}{ Page 26 of 49} & Waste Flags: & \multicolumn{3}{|c|}{ + - Segregate as Radioactive } & \multirow{3}{*}{$201 \_6-19$} \\
\hline & Quality Flags: & A - Accepted & $\mathbf{J}$ - Estimated & R - Rejected & \\
\hline & Detection Flags: & (Blank) - Detected & U - Not Detected & $\mathrm{N}$ - Poor Statistics & \\
\hline
\end{tabular}


AB51163

\begin{tabular}{|c|c|c|c|c|c|}
\hline Analyte & $\begin{array}{l}\text { Activity } \\
\text { (dpm) }\end{array}$ & $\begin{array}{c}\text { Unc } \\
(2.0 \sigma)\end{array}$ & $\begin{array}{l}\text { Lab } \\
\text { Flag }\end{array}$ & $\begin{array}{c}\text { MDA } \\
(\mathrm{dpm})\end{array}$ & $\begin{array}{c}\text { CL } \\
(\mathrm{dpm})\end{array}$ \\
\hline CD-115 & $1.71 e+005$ & $3.04 e+005$ & $\mathrm{AU}$ & $3.84 e+005$ & $1.92 e+005$ \\
\hline CE-141 & $1.25 \mathrm{e}+008$ & $2.50 \mathrm{e}+007$ & A & $4.42 \mathrm{e}+005$ & $2.21 e+005$ \\
\hline CE-144 & $1.04 e+008$ & $2.08 \mathrm{e}+007$ & A & $2.46 \mathrm{e}+006$ & $1.23 e+006$ \\
\hline $\mathrm{CO}-60$ & $2.46 \mathrm{e}+004$ & $1.06 e+005$ & $A U$ & $1.41 \mathrm{e}+005$ & $7.02 e+004$ \\
\hline CS-137 & $3.74 \mathrm{e}+007$ & $4.50 \mathrm{e}+006$ & A & $1.73 e+005$ & $8.64 e+004$ \\
\hline $\mathrm{Ce}-143$ & $-9.68 \mathrm{e}+004$ & $1.22 \mathrm{e}+005$ & $\mathrm{AU}$ & $4.33 e+005$ & $2.17 e+005$ \\
\hline $\mid-131$ & $1.20 \mathrm{e}+007$ & $1.77 e+006$ & A & $2.01 e+005$ & $1.00 e+005$ \\
\hline |-132 & $5.56 \mathrm{e}+006$ & $6.54 e+005$ & A & $2.26 \mathrm{e}+005$ & $1.13 e+005$ \\
\hline $1-133$ & $2.44 e+006$ & $3.09 e+005$ & $\mathrm{AU}$ & $2.63 e+005$ & $1.31 e+005$ \\
\hline In-115m & $1.87 e+005$ & $3.31 e+005$ & $\mathrm{AU}$ & $4.18 \mathrm{e}+005$ & $2.09 e+005$ \\
\hline La-140 & $6.10 \mathrm{e}+007$ & $4.88 \mathrm{e}+006$ & A & $1.37 e+005$ & $6.78 \mathrm{e}+004$ \\
\hline MO-99 & $3.30 \mathrm{e}+006$ & $8.39 e+005$ & A & $1.20 \mathrm{e}+006$ & $5.99 e+005$ \\
\hline NB-95m & $1.81 e+006$ & $3.62 e+005$ & A & $7.26 e+005$ & $3.63 e+005$ \\
\hline ND-147 & $1.59 \mathrm{e}+007$ & $2.01 e+006$ & A & $1.72 \mathrm{e}+006$ & $8.58 \mathrm{e}+005$ \\
\hline NP-239 & $4.52 e+006$ & $1.15 e+006$ & A & $1.16 e+006$ & $5.79 \mathrm{e}+005$ \\
\hline $\mathrm{Nb}-95$ & $1.81 \mathrm{e}+008$ & $2.18 e+007$ & A & $1.52 e+005$ & $7.56 e+004$ \\
\hline PM-149 & $-5.92 e+005$ & $1.65 e+006$ & $\mathrm{AU}$ & $5.69 \mathrm{e}+006$ & $2.84 e+006$ \\
\hline Pr-144 & $3.70 \mathrm{e}+008$ & $5.11 e+007$ & A & $4.00 e+007$ & $2.00 e+007$ \\
\hline RU-103 & $7.12 \mathrm{e}+007$ & $8.58 e+006$ & A & $2.81 e+005$ & $1.40 \mathrm{e}+005$ \\
\hline RU-106 & $7.07 e+006$ & $9.81 e+005$ & A & $1.49 e+006$ & $7.44 e+005$ \\
\hline SB-124 & $-2.95 e+005$ & $1.49 \mathrm{e}+005$ & $A U$ & $1.90 \mathrm{e}+005$ & $9.48 \mathrm{e}+004$ \\
\hline SB-125 & $-1.39 e+007$ & $1.92 e+006$ & $\mathrm{AU}$ & $6.12 e+005$ & $3.07 e+005$ \\
\hline SB-127 & $5.25 e+005$ & $2.99 e+005$ & $\mathrm{AU}$ & $3.91 e+005$ & $1.95 e+005$ \\
\hline Tc-99m & $4.71 \mathrm{e}+006$ & $9.47 e+005$ & A & $2.45 e+005$ & $1.22 e+005$ \\
\hline Te-127m & $-3.48 e+008$ & $8.88 \mathrm{e}+007$ & $A U$ & $6.06 e+007$ & $3.04 \mathrm{e}+007$ \\
\hline $\mathrm{Te}-129 \mathrm{~m}$ & $5.20 \mathrm{e}+007$ & $7.18 e+006$ & A & $5.63 e+006$ & $2.81 e+006$ \\
\hline Te-131m & $3.72 \mathrm{e}+006$ & $5.50 e+005$ & $\mathrm{AU}$ & 4.76e+005 & $2.38 \mathrm{e}+005$ \\
\hline Te-132 & $4.34 e+006$ & $7.43 e+005$ & A & $1.91 \mathrm{e}+005$ & $9.54 \mathrm{e}+004$ \\
\hline U-232 & $-3.70 e+008$ & $1.46 e+008$ & $\mathrm{AU}$ & $1.53 e+008$ & $7.62 \mathrm{e}+007$ \\
\hline U-234 & $1.14 e+009$ & $4.93 e+008$ & $\mathrm{AU}$ & $6.06 \mathrm{e}+008$ & $3.01 e+008$ \\
\hline U-237 & $-1.03 e+007$ & $2.20 \mathrm{e}+006$ & $\mathrm{AU}$ & $8.64 \mathrm{e}+005$ & $4.30 \mathrm{e}+005$ \\
\hline$X E-131 m$ & $5.45 e+008$ & $1.09 e+008$ & $\mathrm{AU}$ & $1.13 e+007$ & $5.68 \mathrm{e}+006$ \\
\hline
\end{tabular}

Page 27 of 49

\begin{tabular}{|r|lll|}
\hline Waste Flags: & + - Segregate as Radioactive & ${ }^{*}$ - Do Not Recycle \\
\hline Quality Flags: & A - Accepted & J - Estimated & R - Rejected \\
\hline Detection Flags: & (Blank) - Detected & U - Not Detected & N - Poor Statistics \\
\hline
\end{tabular}

UNM AGN-201_6-19 


\section{AB51163}

\begin{tabular}{|c|c|c|c|c|c|}
\hline Analyte & $\begin{array}{c}\text { Activity } \\
\text { (dpm) }\end{array}$ & $\begin{array}{c}\text { Unc } \\
(2.0 \sigma)\end{array}$ & $\begin{array}{l}\text { Lab } \\
\text { Flag }\end{array}$ & $\begin{array}{c}\text { MDA } \\
(\mathrm{dpm})\end{array}$ & $\begin{array}{c}\text { CL } \\
\text { (dpm) }\end{array}$ \\
\hline XE-133 & $2.66 e+007$ & $5.36 e+006$ & A & $6.72 \mathrm{e}+005$ & $3.37 e+005$ \\
\hline Y-88 & $3.97 e+004$ & $4.77 e+004$ & $\mathrm{AU}$ & $6.36 \mathrm{e}+004$ & $3.14 \mathrm{e}+004$ \\
\hline Y-91 & $1.29 \mathrm{e}+008$ & $3.55 e+007$ & A & $5.45 e+007$ & $2.71 e+007$ \\
\hline Y-91m & $1.31 \mathrm{e}+006$ & $3.24 e+005$ & A & $4.63 e+005$ & $2.31 e+005$ \\
\hline ZR-95 & $1.63 e+008$ & $1.96 e+007$ & A & $2.64 \mathrm{e}+005$ & $1.31 e+005$ \\
\hline
\end{tabular}

Page 28 of 49

\begin{tabular}{|r|lll|}
\hline Waste Flags: & + - Segregate as Radioactive & ${ }^{*}$ - Do Not Recycle \\
\hline Quality Flags: & A - Accepted & J - Estimated & R - Rejected \\
\hline Detection Flags: & (Blank) - Detected & U - Not Detected & N - Poor Statistics \\
\hline
\end{tabular}

UNM AGN-201_6-19 


\section{AB51164 - AGN Fission Plate}

Live Time (s): 46800

Real Time (s): 56322

Detector: PGE14
Geometry: AGN-FP

Library: RPSD

Background: 14_PGE_190514
Count Date: 5/16/2019 4:53:32PM Collection Date: 5/13/2019 12:00:00PM Quantity (each): $1.00 \mathrm{e}+000$

Analyzed By:

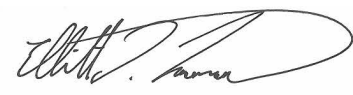

Reviewed By:

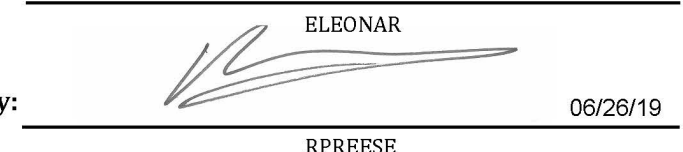

AB51164

\begin{tabular}{|c|c|c|c|c|c|}
\hline Analyte & $\begin{array}{c}\text { Activity } \\
\text { (dpm) }\end{array}$ & $\begin{array}{c}\text { Unc } \\
(2.0 \sigma)\end{array}$ & $\begin{array}{l}\text { Lab } \\
\text { Flag }\end{array}$ & $\begin{array}{c}\text { MDA } \\
\text { (dpm) }\end{array}$ & $\begin{array}{c}\text { CL } \\
\text { (dpm) }\end{array}$ \\
\hline U-238 & $1.01 \mathrm{e}+008$ & $8.07 e+006$ & A & $3.07 e+005$ & $1.53 e+005$ \\
\hline RA-226 & $2.61 e+009$ & $4.69 e+008$ & $\mathrm{AU}$ & $2.13 e+005$ & $1.07 e+005$ \\
\hline PB-214 & $4.91 e+004$ & $1.10 \mathrm{e}+004$ & $\mathrm{AU}$ & $1.06 e+004$ & $5.29 e+003$ \\
\hline BI-214 & $5.71 e+003$ & $5.01 e+003$ & A & $8.16 e+003$ & $4.07 e+003$ \\
\hline PB-210 & $-7.52 e+005$ & $3.57 e+005$ & $\mathrm{AU}$ & $7.50 e+005$ & $3.74 e+005$ \\
\hline AC-228 & $7.41 e+004$ & $1.07 e+004$ & $\mathrm{AU}$ & $1.07 e+004$ & $5.35 e+003$ \\
\hline RA-224 & $3.62 e+004$ & $3.46 e+003$ & A & $2.69 e+003$ & $1.34 \mathrm{e}+003$ \\
\hline PB-212 & $1.23 e+005$ & $2.02 e+004$ & A & $1.28 \mathrm{e}+004$ & $6.42 e+003$ \\
\hline $\mathrm{BI}-212$ & $1.60 e+005$ & $2.26 e+004$ & A & $3.30 e+004$ & $1.64 \mathrm{e}+004$ \\
\hline TL-208 & $4.03 e+004$ & $5.38 e+003$ & A & $3.76 e+003$ & $1.87 e+003$ \\
\hline U-235 & $1.64 \mathrm{e}+008$ & $2.94 e+007$ & A & $1.34 \mathrm{e}+004$ & $6.66 e+003$ \\
\hline TH-231 & $2.02 e+008$ & $4.04 e+007$ & A & $1.09 e+006$ & $5.47 e+005$ \\
\hline PA-231 & $-1.05 e+006$ & $2.94 e+005$ & $\mathrm{AU}$ & $3.05 e+005$ & $1.52 \mathrm{e}+005$ \\
\hline TH-227 & $1.32 e+005$ & $4.46 e+004$ & $\mathrm{AU}$ & $5.18 e+004$ & $2.59 e+004$ \\
\hline RA-223 & $5.64 e+007$ & $1.13 e+007$ & A & $6.96 e+004$ & $3.49 e+004$ \\
\hline RN-219 & $-1.06 e+004$ & $8.47 e+003$ & $\mathrm{AU}$ & $4.38 e+004$ & $2.19 e+004$ \\
\hline PB-211 & $1.60 e+005$ & $5.02 e+004$ & A & $7.02 e+004$ & $3.49 e+004$ \\
\hline TL-207 & $2.45 e+006$ & $5.58 e+005$ & A & $7.50 e+005$ & $3.73 e+005$ \\
\hline NP-237 & $-8.03 e+008$ & $1.61 \mathrm{e}+008$ & $\mathrm{AU}$ & $5.32 e+006$ & $2.66 e+006$ \\
\hline PA-233 & $1.45 e+003$ & $8.77 e+003$ & $\mathrm{AU}$ & $1.11 e+004$ & $5.55 e+003$ \\
\hline TH-229 & $1.70 e+008$ & $3.41 e+007$ & $\mathrm{AU}$ & $2.71 e+005$ & $1.35 e+005$ \\
\hline BA-133 & $3.18 \mathrm{e}+003$ & $1.53 e+003$ & A & $5.41 e+003$ & $2.70 e+003$ \\
\hline Ba-140 & $-1.25 e+004$ & $9.09 e+003$ & $\mathrm{AU}$ & $1.18 e+004$ & $5.89 e+003$ \\
\hline \multirow{3}{*}{ Page 29 of 49} & Waste Flags: & \multicolumn{3}{|c|}{ + - Segregate as Radioactive } & \multirow{3}{*}{ 201_6-19 } \\
\hline & Quality Flags: & A - Accepted & $\mathbf{J}$ - Estimated & $\mathbf{R}$ - Rejected & \\
\hline & Detection Flags: & (Blank) - Detected & U - Not Detected & N-Poor Statistics & \\
\hline
\end{tabular}


AB51164

\begin{tabular}{|c|c|c|c|c|c|}
\hline Analyte & $\begin{array}{c}\text { Activity } \\
\text { (dpm) }\end{array}$ & $\begin{array}{c}\text { Unc } \\
(2.0 \sigma)\end{array}$ & $\begin{array}{l}\text { Lab } \\
\text { Flag }\end{array}$ & $\begin{array}{c}\text { MDA } \\
(\mathrm{dpm})\end{array}$ & $\begin{array}{c}\text { CL } \\
\text { (dpm) }\end{array}$ \\
\hline CD-115 & $-4.21 e+003$ & $4.11 e+003$ & $\mathrm{AU}$ & $9.42 e+003$ & $4.69 \mathrm{e}+003$ \\
\hline CE-141 & $-1.16 e+005$ & $2.44 e+004$ & $\mathrm{AU}$ & $5.34 \mathrm{e}+004$ & $2.67 e+004$ \\
\hline CE-144 & $4.70 \mathrm{e}+005$ & $1.36 e+005$ & A & $1.10 e+005$ & $5.50 e+004$ \\
\hline $\mathrm{CO}-60$ & $-3.10 \mathrm{e}+002$ & $1.25 e+003$ & $\mathrm{AU}$ & $1.67 e+003$ & $8.28 \mathrm{e}+002$ \\
\hline CS -137 & $-2.33 e+003$ & $2.56 e+003$ & $\mathrm{AU}$ & $3.35 e+003$ & $1.67 e+003$ \\
\hline $\mathrm{Ce}-143$ & $1.52 \mathrm{e}+005$ & $2.66 \mathrm{e}+004$ & $\mathrm{AU}$ & $1.39 \mathrm{e}+004$ & $6.96 \mathrm{e}+003$ \\
\hline $\mid-131$ & $-2.63 e+004$ & $5.17 e+003$ & $\mathrm{AU}$ & $4.55 e+003$ & $2.27 e+003$ \\
\hline $1-132$ & $-7.78 \mathrm{e}+005$ & $9.24 e+004$ & $\mathrm{AU}$ & $1.87 e+004$ & $9.30 \mathrm{e}+003$ \\
\hline $1-133$ & $2.43 e+003$ & $3.16 e+003$ & $A U$ & $4.18 \mathrm{e}+003$ & $2.09 \mathrm{e}+003$ \\
\hline In-115m & $-1.01 e+004$ & $9.87 e+003$ & $\mathrm{AU}$ & $2.26 \mathrm{e}+004$ & $1.13 e+004$ \\
\hline La-140 & $-1.40 e+003$ & $5.41 e+002$ & $\mathrm{AU}$ & $1.72 \mathrm{e}+003$ & $8.52 \mathrm{e}+002$ \\
\hline MO-99 & $-5.41 e+004$ & $1.15 e+004$ & $\mathrm{AU}$ & $3.28 \mathrm{e}+004$ & $1.63 \mathrm{e}+004$ \\
\hline NB-95m & $1.02 \mathrm{e}+005$ & $1.77 e+004$ & A & $2.47 e+004$ & $1.24 e+004$ \\
\hline ND-147 & $1.83 e+004$ & $1.68 \mathrm{e}+004$ & $\mathrm{AU}$ & $2.21 \mathrm{e}+004$ & $1.10 \mathrm{e}+004$ \\
\hline NP-239 & $9.01 e+005$ & $1.47 e+005$ & $\mathrm{AU}$ & $4.33 e+004$ & $2.16 e+004$ \\
\hline $\mathrm{Nb}-95$ & $3.35 e+005$ & $4.03 e+004$ & $\mathrm{AU}$ & $5.23 e+003$ & $2.61 e+003$ \\
\hline PM-149 & $1.36 e+006$ & $2.60 e+005$ & $\mathrm{AU}$ & $1.79 e+005$ & $8.94 e+004$ \\
\hline Pr-144 & $-4.01 e+007$ & $7.91 e+006$ & $\mathrm{AU}$ & $8.04 e+006$ & $4.02 e+006$ \\
\hline RU-103 & $1.43 e+003$ & $2.14 e+003$ & $\mathrm{AU}$ & $2.93 e+003$ & $1.46 e+003$ \\
\hline RU-106 & $-9.46 e+003$ & $2.13 e+004$ & $\mathrm{AU}$ & $2.81 e+004$ & $1.40 \mathrm{e}+004$ \\
\hline SB-124 & $-4.08 e+003$ & $2.15 e+003$ & $\mathrm{AU}$ & $2.87 e+003$ & $1.43 e+003$ \\
\hline SB-125 & $8.00 e+003$ & $6.78 e+003$ & $\mathrm{AU}$ & $9.18 e+003$ & $4.59 e+003$ \\
\hline SB-127 & $9.89 e+002$ & $5.13 e+003$ & $\mathrm{AU}$ & $8.10 e+003$ & $4.03 e+003$ \\
\hline Tc- $99 \mathrm{~m}$ & $9.69 e+005$ & $1.94 e+005$ & A & $2.43 e+004$ & $1.21 e+004$ \\
\hline Te-127m & $8.91 e+007$ & $1.85 e+007$ & A & $3.68 \mathrm{e}+006$ & $1.84 e+006$ \\
\hline Te-129m & $-4.69 \mathrm{e}+005$ & $9.23 e+004$ & $\mathrm{AU}$ & $9.42 e+004$ & $4.70 \mathrm{e}+004$ \\
\hline Te-131m & $-2.48 e+004$ & $7.52 e+003$ & $A U$ & $9.06 e+003$ & $4.51 e+003$ \\
\hline Te-132 & $3.78 \mathrm{e}+004$ & $8.57 e+003$ & $\mathrm{AU}$ & $8.04 \mathrm{e}+003$ & $4.01 e+003$ \\
\hline U-232 & $2.24 e+008$ & $4.63 e+007$ & A & $9.24 e+006$ & $4.62 e+006$ \\
\hline$U-234$ & $2.08 \mathrm{e}+009$ & $4.16 e+008$ & A & $3.77 \mathrm{e}+007$ & $1.88 e+007$ \\
\hline$U-237$ & $1.34 \mathrm{e}+006$ & $2.78 e+005$ & A & $5.54 e+004$ & $2.77 e+004$ \\
\hline$X E-131 m$ & $4.35 \mathrm{e}+008$ & $8.70 e+007$ & $\mathrm{AU}$ & $6.72 \mathrm{e}+005$ & $3.37 e+005$ \\
\hline
\end{tabular}

Page 30 of 49

\begin{tabular}{|r|lll|}
\hline Waste Flags: & + - Segregate as Radioactive & ${ }^{*}$ - Do Not Recycle \\
\hline Quality Flags: & A - Accepted & J - Estimated & R - Rejected \\
\hline Detection Flags: & (Blank) - Detected & U - Not Detected & N - Poor Statistics \\
\hline
\end{tabular}

UNM AGN-201_6-19 


\section{AB51164}

\begin{tabular}{|lccccc|}
\hline Analyte & $\begin{array}{c}\text { Activity } \\
\text { (dpm) }\end{array}$ & $\begin{array}{c}\text { Unc } \\
(\mathbf{2 . 0 \sigma})\end{array}$ & $\begin{array}{c}\text { Lab } \\
\text { Flag }\end{array}$ & $\begin{array}{c}\text { MDA } \\
(\mathbf{d p m})\end{array}$ & $\begin{array}{c}\text { CL } \\
(\mathbf{d p m})\end{array}$ \\
\hline XE-133 & $7.28 \mathrm{e}+006$ & $1.47 \mathrm{e}+006$ & $\mathrm{~A}$ & $3.95 \mathrm{e}+004$ & $1.97 \mathrm{e}+004$ \\
Y-88 & $1.58 \mathrm{e}+001$ & $4.54 \mathrm{e}+002$ & $\mathrm{AU}$ & $1.27 \mathrm{e}+003$ & $6.30 \mathrm{e}+002$ \\
Y-91 & $5.52 \mathrm{e}+005$ & $6.11 \mathrm{e}+005$ & $\mathrm{AU}$ & $8.16 \mathrm{e}+005$ & $4.06 \mathrm{e}+005$ \\
Y-91m & $-4.02 \mathrm{e}+003$ & $2.95 \mathrm{e}+004$ & $\mathrm{AU}$ & $3.91 \mathrm{e}+004$ & $1.95 \mathrm{e}+004$ \\
ZR-95 & $5.33 \mathrm{e}+003$ & $4.09 \mathrm{e}+003$ & $\mathrm{AU}$ & $5.38 \mathrm{e}+003$ & $2.68 \mathrm{e}+003$ \\
\hline
\end{tabular}

Page 31 of 49

\begin{tabular}{|r|lll|}
\hline Waste Flags: & + - Segregate as Radioactive & ${ }^{*}$ - Do Not Recycle \\
\hline Quality Flags: & A - Accepted & J - Estimated & R - Rejected \\
\hline Detection Flags: & (Blank) - Detected & U - Not Detected & N - Poor Statistics \\
\hline
\end{tabular}

UNM AGN-201_6-19 
AB51170 - Blank

Live Time (s): 55800 Real Time (s): 57056

Detector: PGE14
Geometry: EMPTYSHLD

Library: AGN-201M

Background: 14_PGE_190514
Count Date: 5/14/2019 5:07:28PM Collection Date: 6/13/2019 12:00:00AM Quantity (each): $1.00 \mathrm{e}+000$

Analyzed By:

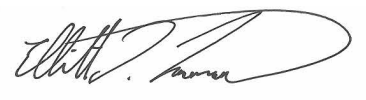

Reviewed By:

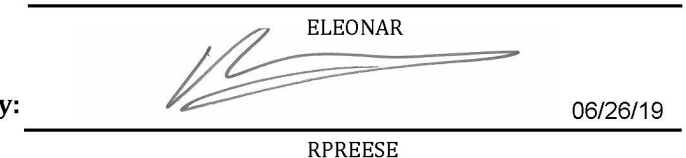

RPREESE

AB51170

\begin{tabular}{|c|c|c|c|c|c|}
\hline Analyte & $\begin{array}{c}\text { Activity } \\
\text { (dpm) }\end{array}$ & $\begin{array}{c}\text { Unc } \\
(2.0 \sigma)\end{array}$ & $\begin{array}{l}\text { Lab } \\
\text { Flag }\end{array}$ & $\begin{array}{c}\text { MDA } \\
\text { (dpm) }\end{array}$ & $\begin{array}{c}\text { CL } \\
\text { (dpm) }\end{array}$ \\
\hline U-238 & $1.68 e+002$ & $5.54 \mathrm{e}+002$ & $\mathrm{AU}$ & $6.84 e+001$ & $3.39 e+001$ \\
\hline RA-226 & $8.57 e+002$ & $5.49 e+003$ & $\mathrm{AU}$ & $1.06 e+002$ & $5.29 e+001$ \\
\hline PB-214 & $4.58 e+001$ & $2.95 e+002$ & $\mathrm{AU}$ & $4.69 e+000$ & $2.35 e+000$ \\
\hline $\mathrm{BI}-214$ & $5.00 e+001$ & $2.47 e+002$ & $\mathrm{AU}$ & $2.17 e+000$ & $1.08 \mathrm{e}+000$ \\
\hline PB-210 & $-1.93 e+002$ & $1.31 e+003$ & $\mathrm{AU}$ & $7.26 e+001$ & $3.62 e+001$ \\
\hline TH-232 & $3.87 e+001$ & $2.51 e+002$ & $\mathrm{AU}$ & $1.53 e+001$ & $7.62 e+000$ \\
\hline RA-228 & $3.21 \mathrm{e}+001$ & $1.06 \mathrm{e}+002$ & AN & $3.25 e+000$ & $1.61 e+000$ \\
\hline AC-228 & $3.15 e+001$ & $1.07 e+002$ & $\mathrm{AU}$ & $1.88 e+000$ & $9.36 \mathrm{e}-001$ \\
\hline TH-228 & $3.07 e+001$ & $2.03 e+002$ & $\mathrm{AU}$ & $4.78 e+001$ & $2.38 e+001$ \\
\hline RA-224 & $1.14 e+001$ & $1.89 e+002$ & $\mathrm{AU}$ & $6.90 \mathrm{e}-002$ & $3.31 \mathrm{e}-002$ \\
\hline PB-212 & $3.22 e+001$ & $2.14 \mathrm{e}+002$ & $\mathrm{AU}$ & $4.39 e+000$ & $2.20 \mathrm{e}+000$ \\
\hline BI-212 & $-2.04 e+001$ & $8.62 e+001$ & $\mathrm{AU}$ & $2.26 e+001$ & $1.13 e+001$ \\
\hline TL-208 & $1.12 e+001$ & $5.72 e+001$ & $\mathrm{AU}$ & $1.24 e+000$ & $6.18 \mathrm{e}-001$ \\
\hline U-235 & $-9.24 \mathrm{e}-002$ & $1.06 e+001$ & $\mathrm{AU}$ & $4.07 e+001$ & $2.03 e+001$ \\
\hline TH-231 & $-3.02 e+003$ & $1.28 e+004$ & AN & $4.27 e+002$ & $2.13 e+002$ \\
\hline PA-231 & $4.36 e+001$ & $3.03 e+002$ & $\mathrm{AU}$ & $1.18 e+002$ & $5.86 e+001$ \\
\hline TH-227 & $-7.99 e+001$ & $5.31 e+002$ & $\mathrm{AU}$ & $2.11 e+001$ & $1.05 e+001$ \\
\hline RA-223 & $1.08 e+003$ & $4.67 e+003$ & $\mathrm{AU}$ & $1.85 e+001$ & $9.24 \mathrm{e}+000$ \\
\hline $\mathrm{RN}-219$ & $3.50 e+000$ & $2.71 e+001$ & $\mathrm{AU}$ & $2.24 e+001$ & $1.12 e+001$ \\
\hline PB-211 & $-1.59 e+001$ & $1.02 e+002$ & $\mathrm{AU}$ & $3.88 e+001$ & $1.93 e+001$ \\
\hline TL-207 & $-6.46 e+001$ & $2.80 e+002$ & $\mathrm{AU}$ & $2.25 e+002$ & $1.12 e+002$ \\
\hline AM-241 & $1.56 e+000$ & $1.06 e+001$ & $\mathrm{AU}$ & $1.28 e+001$ & $6.36 e+000$ \\
\hline PU-239 & $3.15 e+003$ & $6.07 e+004$ & $\mathrm{AU}$ & $7.62 e+004$ & $3.82 e+004$ \\
\hline \multirow{3}{*}{ Page 32 of 49} & Wast & \multicolumn{3}{|c|}{ + - Segregate as Radioactive } & \multirow{3}{*}{$201 \_6-19$} \\
\hline & Quali & A - Accepted & $\mathbf{J}$ - Estimated & $\mathbf{R}$ - Rejected & \\
\hline & Detectio & (Blank) - Detected & U - Not Detected & N - Poor Statistics & \\
\hline
\end{tabular}


AB51170

\begin{tabular}{|c|c|c|c|c|c|}
\hline Analyte & $\begin{array}{l}\text { Activity } \\
\text { (dpm) }\end{array}$ & $\begin{array}{c}\text { Unc } \\
(2.0 \sigma)\end{array}$ & $\begin{array}{l}\text { Lab } \\
\text { Flag }\end{array}$ & $\begin{array}{c}\text { MDA } \\
\text { (dpm) }\end{array}$ & $\begin{array}{c}\text { CL } \\
\text { (dpm) }\end{array}$ \\
\hline NP-237 & $-5.13 e+002$ & $2.74 e+003$ & $\mathrm{AU}$ & $1.58 e+003$ & $7.92 e+002$ \\
\hline PA-233 & $2.90 \mathrm{e}+000$ & $1.94 e+001$ & $\mathrm{AU}$ & $4.88 \mathrm{e}+000$ & $2.44 \mathrm{e}+000$ \\
\hline TH-229 & $4.92 e+000$ & $3.06 e+001$ & $\mathrm{AU}$ & $6.18 \mathrm{e}+001$ & $3.10 \mathrm{e}+001$ \\
\hline$A G-108 m$ & $-1.81 e-001$ & $7.99 \mathrm{e}-001$ & $\mathrm{AU}$ & $1.73 e+000$ & $8.64 \mathrm{e}-001$ \\
\hline AG-110m & $-2.94 \mathrm{e}-001$ & $1.43 e+000$ & $\mathrm{AU}$ & $1.21 e+000$ & $6.06 \mathrm{e}-001$ \\
\hline BA-133 & $1.10 \mathrm{e}-001$ & $1.66 \mathrm{e}+000$ & $\mathrm{AU}$ & $2.63 e+000$ & $1.31 \mathrm{e}+000$ \\
\hline BE-7 & $1.71 e+000$ & $1.35 e+001$ & $\mathrm{AU}$ & $1.27 e+001$ & $6.36 \mathrm{e}+000$ \\
\hline CD-115 & $-1.58 e+000$ & $1.04 e+001$ & $\mathrm{AU}$ & $4.23 e+000$ & $2.11 e+000$ \\
\hline CE-139 & $-1.12 e+000$ & $7.23 e+000$ & $\mathrm{AU}$ & $4.93 e+000$ & $2.46 \mathrm{e}+000$ \\
\hline CE-141 & $4.42 e+001$ & $2.62 e+002$ & AN & $1.08 e+001$ & $5.41 e+000$ \\
\hline CE-144 & $-4.78 e+000$ & $4.22 e+001$ & $\mathrm{AU}$ & $4.24 \mathrm{e}+001$ & $2.12 \mathrm{e}+001$ \\
\hline $\mathrm{CO}-56$ & $3.69 \mathrm{e}-001$ & $1.42 e+000$ & $\mathrm{AU}$ & $6.06 \mathrm{e}-001$ & $3.03 e-001$ \\
\hline $\mathrm{CO}-57$ & $6.29 e+000$ & $3.44 e+001$ & $\mathrm{AU}$ & $5.53 e+000$ & $2.76 \mathrm{e}+000$ \\
\hline $\mathrm{CO}-58$ & $-2.45 e+001$ & $9.26 e+001$ & $\mathrm{AU}$ & $6.84 \mathrm{e}-001$ & $3.40 \mathrm{e}-001$ \\
\hline $\mathrm{CO}-60$ & $2.02 \mathrm{e}-001$ & $1.00 e+000$ & $\mathrm{AU}$ & $5.10 \mathrm{e}-001$ & $2.53 e-001$ \\
\hline CR-51 & $3.58 e+000$ & $2.76 e+001$ & $\mathrm{AU}$ & $1.86 e+001$ & $9.30 e+000$ \\
\hline CS-134 & $-4.34 e+000$ & $2.16 e+001$ & $\mathrm{AU}$ & $1.12 \mathrm{e}+000$ & $5.58 e-001$ \\
\hline CS-137 & $3.64 e+001$ & $1.68 e+002$ & AN & $9.66 \mathrm{e}-001$ & $4.81 e-001$ \\
\hline EU-152 & $1.35 e+001$ & $7.43 e+001$ & $\mathrm{AU}$ & $1.65 e+001$ & $8.28 \mathrm{e}+000$ \\
\hline EU-154 & $-5.15 e-001$ & $2.34 e+000$ & $\mathrm{AU}$ & $7.86 e+000$ & $3.92 \mathrm{e}+000$ \\
\hline EU-155 & $-3.57 e+001$ & $1.78 \mathrm{e}+002$ & $\mathrm{AU}$ & $2.40 \mathrm{e}+001$ & $1.20 \mathrm{e}+001$ \\
\hline FE-59 & $-7.31 e-001$ & $2.59 e+000$ & $\mathrm{AU}$ & $9.48 \mathrm{e}-001$ & 4.71e-001 \\
\hline GD-153 & $4.82 e+001$ & $2.28 e+002$ & $\mathrm{AU}$ & $1.83 e+001$ & $9.12 \mathrm{e}+000$ \\
\hline HG-203 & $-5.75 e-002$ & $8.35 \mathrm{e}-001$ & $\mathrm{AU}$ & $2.51 \mathrm{e}+000$ & $1.25 \mathrm{e}+000$ \\
\hline $\mid-131$ & $7.93 e+000$ & $5.05 e+001$ & $\mathrm{AU}$ & $2.13 e+000$ & $1.06 \mathrm{e}+000$ \\
\hline$K-40$ & $6.70 e+002$ & $3.74 e+003$ & AN & $4.24 \mathrm{e}+000$ & $2.11 e+000$ \\
\hline MN-52 & $-3.74 e-002$ & $3.67 e-001$ & $\mathrm{AU}$ & $4.09 \mathrm{e}-001$ & $2.03 e-001$ \\
\hline MN-54 & $9.11 e-003$ & $4.92 \mathrm{e}-001$ & $\mathrm{AU}$ & $6.30 \mathrm{e}-001$ & $3.14 \mathrm{e}-001$ \\
\hline MO-99 & $-1.28 e+000$ & $5.55 e+000$ & $\mathrm{AU}$ & $7.50 e+000$ & $3.74 \mathrm{e}+000$ \\
\hline NA-22 & $-1.38 \mathrm{e}-001$ & $6.84 \mathrm{e}-001$ & $\mathrm{AU}$ & $5.25 \mathrm{e}-001$ & $2.61 e-001$ \\
\hline NA-24 & $2.00 \mathrm{e}-001$ & $1.10 e+000$ & $\mathrm{AU}$ & $6.90 \mathrm{e}-001$ & $3.44 \mathrm{e}-001$ \\
\hline ND-147 & $-3.63 e+001$ & $1.98 e+002$ & $\mathrm{AU}$ & $9.90 \mathrm{e}+000$ & $4.94 \mathrm{e}+000$ \\
\hline
\end{tabular}

Page 33 of 49

\begin{tabular}{|r|lll|}
\hline Waste Flags: & + - Segregate as Radioactive & * - Do Not Recycle \\
\hline Quality Flags: & A - Accepted & J - Estimated & R - Rejected \\
\hline Detection Flags: & (Blank $)$ - Detected & U - Not Detected & N - Poor Statistics \\
\hline
\end{tabular}

UNM AGN-201_6-19 
AB51170

\begin{tabular}{|c|c|c|c|c|c|}
\hline Analyte & $\begin{array}{c}\text { Activity } \\
\text { (dpm) }\end{array}$ & $\begin{array}{c}\text { Unc } \\
(2.0 \sigma)\end{array}$ & $\begin{array}{l}\text { Lab } \\
\text { Flag }\end{array}$ & $\begin{array}{c}\text { MDA } \\
(\mathrm{dpm})\end{array}$ & $\begin{array}{c}\text { CL } \\
(\mathrm{dpm})\end{array}$ \\
\hline NP-239 & $8.28 e+000$ & $5.63 e+001$ & $\mathrm{AU}$ & $1.58 e+001$ & $7.86 e+000$ \\
\hline RU-103 & $5.65 e+001$ & $3.19 \mathrm{e}+002$ & AN & $1.75 e+000$ & $8.76 e-001$ \\
\hline RU-106 & $8.11 \mathrm{e}+000$ & $4.02 e+001$ & $\mathrm{AU}$ & $1.04 e+001$ & $5.18 \mathrm{e}+000$ \\
\hline SB-122 & $4.58 \mathrm{e}-002$ & $6.35 \mathrm{e}-001$ & $A U$ & $1.84 \mathrm{e}+000$ & $9.18 \mathrm{e}-001$ \\
\hline SB-124 & $-5.53 e+000$ & $2.75 e+001$ & $\mathrm{AU}$ & $1.09 e+000$ & $5.44 \mathrm{e}-001$ \\
\hline SB-125 & $4.49 \mathrm{e}-001$ & $3.01 e+000$ & $A U$ & $4.73 e+000$ & $2.36 \mathrm{e}+000$ \\
\hline SN-113 & $1.10 \mathrm{e}+000$ & $7.09 \mathrm{e}+000$ & $\mathrm{AU}$ & $2.31 e+000$ & $1.15 \mathrm{e}+000$ \\
\hline SR-85 & $-1.19 e+000$ & $6.59 e+000$ & $A U$ & $1.40 \mathrm{e}+000$ & $6.96 e-001$ \\
\hline TA-182 & $-9.17 e-001$ & $3.21 e+000$ & $A U$ & $1.90 e+000$ & $9.42 \mathrm{e}-001$ \\
\hline TA-183 & $3.52 \mathrm{e}+000$ & $2.40 e+001$ & $\mathrm{AU}$ & $9.66 e+000$ & $4.81 e+000$ \\
\hline TL-201 & $-1.35 e+001$ & $5.57 e+001$ & $\mathrm{AU}$ & $1.48 \mathrm{e}+001$ & $7.38 \mathrm{e}+000$ \\
\hline$Y-88$ & $2.35 \mathrm{e}-001$ & $2.11 e+000$ & $\mathrm{AU}$ & $1.90 \mathrm{e}-001$ & $9.36 \mathrm{e}-002$ \\
\hline ZN-65 & $-4.59 e-001$ & $1.66 \mathrm{e}+000$ & $\mathrm{AU}$ & $1.14 \mathrm{e}+000$ & $5.67 e-001$ \\
\hline ZR-95 & $1.72 \mathrm{e}+002$ & $6.95 e+002$ & $\mathrm{AU}$ & $1.26 e+000$ & $6.24 \mathrm{e}-001$ \\
\hline
\end{tabular}

Page 34 of 49

\begin{tabular}{|r|lll|}
\hline Waste Flags: & + - Segregate as Radioactive & * - Do Not Recycle \\
\hline Quality Flags: & A - Accepted & J - Estimated & R - Rejected \\
\hline Detection Flags: & (Blank) - Detected & U - Not Detected & N - Poor Statistics \\
\hline
\end{tabular}

UNM AGN-201_6-19 


\section{Gamma Spectroscopy}

\section{GAMMA-12365}

\section{AB51165 - AGN Corse Rod}

Live Time (s): 14400

Real Time (s): 17794

Detector: FAL07
Geometry: AGN-SR-IS

Library: AGN-201M

Background: 07_FAL_190515
Count Date: 5/14/2019 3:01:47PM Collection Date: 5/13/2019 12:00:00PM Quantity (each): $1.00 e+000$

Analyzed By:
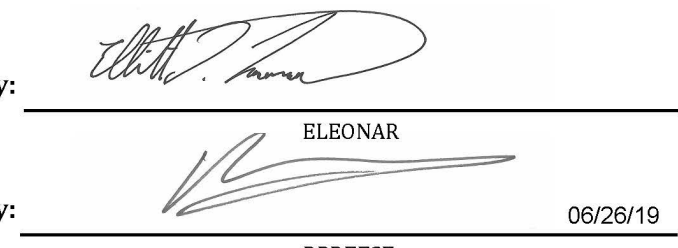

RPREESE

\begin{tabular}{|c|c|c|c|c|c|}
\hline Analyte & $\begin{array}{c}\text { Activity } \\
\text { (dpm) }\end{array}$ & $\begin{array}{c}\text { Unc } \\
(2.0 \sigma)\end{array}$ & $\begin{array}{l}\text { Lab } \\
\text { Flag }\end{array}$ & $\begin{array}{c}\text { MDA } \\
\text { (dpm) }\end{array}$ & $\begin{array}{c}\text { CL } \\
\text { (dpm) }\end{array}$ \\
\hline U-238 & $5.35 e+007$ & $4.56 e+006$ & A & $3.29 e+006$ & $1.64 \mathrm{e}+006$ \\
\hline RA-226 & $1.25 e+009$ & $2.25 e+008$ & $\mathrm{AU}$ & $1.64 \mathrm{e}+006$ & $8.22 e+005$ \\
\hline PB-214 & $1.29 e+005$ & $1.31 e+005$ & $\mathrm{AU}$ & $1.61 e+005$ & $8.04 e+004$ \\
\hline $\mathrm{Bl}-214$ & $-2.36 e+004$ & $2.83 e+004$ & $\mathrm{AU}$ & $1.56 e+005$ & $7.80 e+004$ \\
\hline PB-210 & $-2.93 e+006$ & $5.19 e+006$ & $\mathrm{AU}$ & $8.16 e+006$ & $4.07 e+006$ \\
\hline$A C-228$ & $5.28 \mathrm{e}+005$ & $1.05 e+005$ & A & $1.48 \mathrm{e}+005$ & $7.38 e+004$ \\
\hline RA-224 & $1.39 e+004$ & $9.28 e+003$ & A & $1.50 e+004$ & $7.38 e+003$ \\
\hline PB-212 & $-1.93 e+006$ & $3.27 e+005$ & $\mathrm{AU}$ & $1.37 e+005$ & $6.84 e+004$ \\
\hline Bl-212 & $-1.61 e+007$ & $1.97 e+006$ & $\mathrm{AU}$ & $1.69 e+006$ & $8.40 e+005$ \\
\hline TL-208 & $1.70 e+004$ & $5.98 e+004$ & $\mathrm{AU}$ & $7.86 e+004$ & $3.94 \mathrm{e}+004$ \\
\hline U-235 & $7.85 e+007$ & $1.41 e+007$ & A & $1.03 e+005$ & $5.16 e+004$ \\
\hline TH-231 & $3.77 e+008$ & $7.54 e+007$ & A & $7.08 \mathrm{e}+006$ & $3.53 e+006$ \\
\hline PA-231 & $-4.70 e+005$ & $6.66 e+005$ & $\mathrm{AU}$ & $3.47 e+006$ & $1.73 e+006$ \\
\hline TH-227 & $2.26 e+006$ & $5.07 e+005$ & $\mathrm{AU}$ & $4.67 e+005$ & $2.33 e+005$ \\
\hline RA-223 & $2.41 e+007$ & $4.81 e+006$ & $\mathrm{AU}$ & $3.33 e+005$ & $1.66 e+005$ \\
\hline RN-219 & $5.18 e+005$ & $6.13 e+005$ & $\mathrm{AU}$ & $9.18 e+005$ & $4.58 e+005$ \\
\hline
\end{tabular}

\begin{tabular}{|r|lll|}
\hline Waste Flags: & + - Segregate as Radioactive & * - Do Not Recycle \\
\hline Quality Flags: & A - Accepted & J - Estimated & R - Rejected \\
\hline Detection Flags: & (Blank) - Detected & U - Not Detected & N - Poor Statistics \\
\hline
\end{tabular}

UNM AGN-201_6-19 
AB51165

\begin{tabular}{|c|c|c|c|c|c|}
\hline Analyte & $\begin{array}{l}\text { Activity } \\
\text { (dpm) }\end{array}$ & $\begin{array}{c}\text { Unc } \\
(2.0 \sigma)\end{array}$ & $\begin{array}{l}\text { Lab } \\
\text { Flag }\end{array}$ & $\begin{array}{c}\text { MDA } \\
(\mathrm{dpm})\end{array}$ & $\begin{array}{c}\text { CL } \\
\text { (dpm) }\end{array}$ \\
\hline PB-211 & $-2.65 e+005$ & $1.29 e+006$ & $\mathrm{AU}$ & $1.60 e+006$ & $7.98 e+005$ \\
\hline TL-207 & $5.44 e+006$ & $9.25 e+006$ & $\mathrm{AU}$ & $1.18 \mathrm{e}+007$ & $5.87 e+006$ \\
\hline NP-237 & $-4.41 e+009$ & $8.81 e+008$ & $\mathrm{AU}$ & $2.04 e+007$ & $1.02 \mathrm{e}+007$ \\
\hline PA-233 & $-3.12 e+004$ & $1.09 \mathrm{e}+005$ & $\mathrm{AU}$ & $1.52 e+005$ & $7.56 e+004$ \\
\hline TH-229 & $-6.27 e+006$ & $1.26 e+006$ & $\mathrm{AU}$ & $1.15 e+006$ & $5.75 e+005$ \\
\hline BA-133 & $4.63 e+003$ & $7.83 e+004$ & $A U$ & $9.72 e+004$ & $4.87 e+004$ \\
\hline Ba-140 & $3.91 \mathrm{e}+007$ & $4.71 \mathrm{e}+006$ & A & $2.84 e+005$ & $1.42 \mathrm{e}+005$ \\
\hline CD-115 & $-8.63 e+003$ & $5.89 e+004$ & $\mathrm{AU}$ & $1.37 e+005$ & $6.84 e+004$ \\
\hline CE-141 & $9.58 \mathrm{e}+007$ & $1.92 \mathrm{e}+007$ & A & $1.62 \mathrm{e}+005$ & $8.10 e+004$ \\
\hline CE-144 & $7.76 e+007$ & $1.56 e+007$ & A & $8.28 \mathrm{e}+005$ & $4.15 e+005$ \\
\hline$c 0-60$ & $8.68 \mathrm{e}+004$ & $1.90 \mathrm{e}+004$ & A & $4.57 e+004$ & $2.28 \mathrm{e}+004$ \\
\hline CS-137 & $2.99 \mathrm{e}+007$ & $3.60 e+006$ & A & $4.80 \mathrm{e}+004$ & $2.40 e+004$ \\
\hline Ce-143 & $1.23 e+005$ & $4.28 e+004$ & A & $1.18 e+005$ & $5.89 e+004$ \\
\hline $\mid-131$ & $9.04 e+006$ & $1.34 e+006$ & A & $9.30 e+004$ & $4.64 e+004$ \\
\hline I-132 & $5.44 \mathrm{e}+006$ & $6.37 e+005$ & A & $8.34 e+004$ & $4.17 e+004$ \\
\hline I-133 & $1.88 \mathrm{e}+006$ & $2.30 e+005$ & A & $8.58 e+004$ & $4.28 \mathrm{e}+004$ \\
\hline In-115m & $-1.20 e+004$ & $8.16 e+004$ & $\mathrm{AU}$ & $1.90 e+005$ & $9.48 e+004$ \\
\hline La-140 & $4.68 e+007$ & $3.75 e+006$ & A & $3.60 e+004$ & $1.79 e+004$ \\
\hline MO-99 & $2.81 e+006$ & $3.59 e+005$ & A & $2.84 e+005$ & $1.42 \mathrm{e}+005$ \\
\hline NB-95m & $1.44 e+006$ & $2.44 e+005$ & A & $1.96 e+005$ & $9.78 e+004$ \\
\hline ND-147 & $1.16 \mathrm{e}+007$ & $1.41 e+006$ & A & $5.29 \mathrm{e}+005$ & $2.65 e+005$ \\
\hline NP-239 & $2.64 e+006$ & $4.43 e+005$ & A & $3.64 e+005$ & $1.82 e+005$ \\
\hline $\mathrm{Nb}-95$ & $1.41 \mathrm{e}+008$ & $1.70 e+007$ & A & $3.88 \mathrm{e}+004$ & $1.93 e+004$ \\
\hline PM-149 & $-6.40 e+005$ & $6.99 e+005$ & $\mathrm{AU}$ & $1.96 e+006$ & $9.78 \mathrm{e}+005$ \\
\hline Pr-144 & $1.09 e+009$ & $1.34 \mathrm{e}+008$ & A & $4.81 \mathrm{e}+007$ & $2.40 e+007$ \\
\hline RU-103 & $5.50 \mathrm{e}+007$ & $6.63 e+006$ & A & $9.60 e+004$ & $4.79 e+004$ \\
\hline RU-106 & $6.55 e+006$ & $8.06 e+005$ & A & $4.97 e+005$ & $2.48 e+005$ \\
\hline SB-124 & $-2.84 e+004$ & $2.62 e+004$ & $\mathrm{AU}$ & $6.30 \mathrm{e}+004$ & $3.16 \mathrm{e}+004$ \\
\hline SB-125 & $3.97 e+005$ & $7.71 e+004$ & A & $1.79 \mathrm{e}+005$ & $8.94 e+004$ \\
\hline SB-127 & $-6.62 e+004$ & $3.66 e+004$ & $\mathrm{AU}$ & $1.23 e+005$ & $6.12 \mathrm{e}+004$ \\
\hline Tc-99m & $4.11 \mathrm{e}+006$ & $8.23 e+005$ & A & $1.23 \mathrm{e}+005$ & $6.18 \mathrm{e}+004$ \\
\hline Te-127m & $-2.44 e+006$ & $8.20 e+006$ & $\mathrm{AU}$ & $3.71 e+007$ & $1.85 e+007$ \\
\hline
\end{tabular}

Page 36 of 49

\begin{tabular}{|r|lll|}
\hline Waste Flags: & \multicolumn{1}{l|}{ + Segregate as Radioactive } & * - Do Not Recycle \\
\hline Quality Flags: & A - Accepted & J - Estimated & R - Rejected \\
\hline Detection Flags: & (Blank) - Detected & U - Not Detected & N - Poor Statistics \\
\hline
\end{tabular}

UNM AGN-201_6-19 


\section{AB51165}

\begin{tabular}{|c|c|c|c|c|c|}
\hline Analyte & $\begin{array}{c}\text { Activity } \\
\text { (dpm) }\end{array}$ & $\begin{array}{c}\text { Unc } \\
(2.0 \sigma)\end{array}$ & $\begin{array}{l}\text { Lab } \\
\text { Flag }\end{array}$ & $\begin{array}{c}\text { MDA } \\
\text { (dpm) }\end{array}$ & $\begin{array}{c}\text { CL } \\
\text { (dpm) }\end{array}$ \\
\hline Te-129m & $3.98 e+007$ & $4.91 e+006$ & $\mathrm{AU}$ & $1.76 e+006$ & $8.82 e+005$ \\
\hline Te-131m & $5.29 \mathrm{e}+006$ & $6.19 e+005$ & $A U$ & $1.34 \mathrm{e}+005$ & $6.66 \mathrm{e}+004$ \\
\hline Te-132 & $3.34 e+006$ & $5.38 \mathrm{e}+005$ & A & $8.28 e+004$ & 4. $13 e+004$ \\
\hline$U-232$ & $1.83 e+008$ & $8.28 e+007$ & A & $1.21 \mathrm{e}+008$ & $6.06 e+007$ \\
\hline$U-234$ & $1.25 e+009$ & $3.13 e+008$ & A & $3.08 \mathrm{e}+008$ & $1.54 e+008$ \\
\hline U-237 & $-1.00 e+005$ & $1.13 e+005$ & $A U$ & $4.92 e+005$ & $2.46 e+005$ \\
\hline XE-131m & $3.22 e+008$ & $6.45 e+007$ & $\mathrm{AU}$ & $4.60 \mathrm{e}+006$ & $2.30 \mathrm{e}+006$ \\
\hline XE-133 & $1.32 \mathrm{e}+007$ & $2.67 e+006$ & A & $2.47 e+005$ & $1.24 \mathrm{e}+005$ \\
\hline$Y-88$ & $-4.46 e+003$ & $4.01 e+003$ & $\mathrm{AU}$ & $1.56 e+004$ & $7.74 e+003$ \\
\hline$Y-91$ & $1.02 \mathrm{e}+008$ & $1.37 e+007$ & A & $1.65 e+007$ & $8.22 e+006$ \\
\hline Y-91m & $2.28 \mathrm{e}+006$ & $3.60 \mathrm{e}+005$ & $\mathrm{AU}$ & $3.80 \mathrm{e}+005$ & $1.90 \mathrm{e}+005$ \\
\hline ZR-95 & $1.27 e+008$ & $1.52 e+007$ & A & $7.20 e+004$ & $3.59 e+004$ \\
\hline
\end{tabular}

\begin{tabular}{|r|lll|}
\hline Waste Flags: & + - Segregate as Radioactive & * - Do Not Recycle \\
\hline Quality Flags: & A - Accepted & J - Estimated & R - Rejected \\
\hline Detection Flags: & (Blank) - Detected & U - Not Detected & N - Poor Statistics \\
\hline
\end{tabular}

UNM AGN-201_6-19 
AB51166 - AGN Fine Rod

Live Time (s): 14400 Real Time (s): 14986

Detector: FAL07
Geometry: AGN-FCR-I

Library: AGN-201M

Background: 07_FAL_190514
Count Date: 5/16/2019 10:34:16AM Collection Date: 5/13/2019 12:00:00PM Quantity (each): $1.00 \mathrm{e}+000$

Analyzed By:
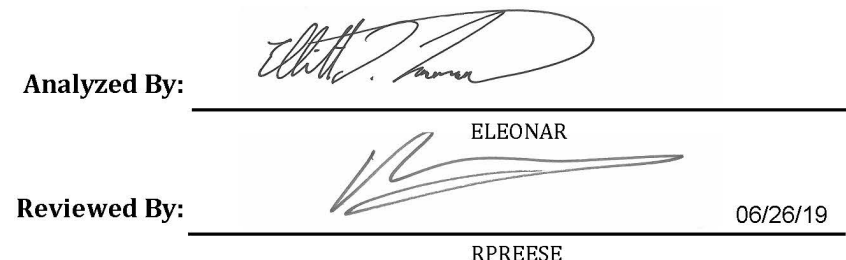

RPREESE

AB51166

\begin{tabular}{|c|c|c|c|c|c|}
\hline Analyte & $\begin{array}{c}\text { Activity } \\
\text { (dpm) }\end{array}$ & $\begin{array}{c}\text { Unc } \\
(2.0 \sigma)\end{array}$ & $\begin{array}{c}\text { Lab } \\
\text { Flag }\end{array}$ & $\begin{array}{c}\text { MDA } \\
\text { (dpm) }\end{array}$ & $\begin{array}{c}\text { CL } \\
\text { (dpm) }\end{array}$ \\
\hline U-238 & $8.65 e+006$ & $1.07 e+006$ & A & $1.25 e+006$ & $6.18 \mathrm{e}+005$ \\
\hline RA-226 & $1.97 e+008$ & $3.54 \mathrm{e}+007$ & $\mathrm{AU}$ & $4.13 e+005$ & $2.06 e+005$ \\
\hline PB-214 & $9.67 e+004$ & $4.08 e+004$ & A & $4.79 e+004$ & $2.39 e+004$ \\
\hline $\mathrm{Bl}-214$ & $-7.94 e+003$ & $6.90 \mathrm{e}+003$ & $\mathrm{AU}$ & $4.97 e+004$ & $2.48 e+004$ \\
\hline PB-210 & $-1.33 e+006$ & $1.19 e+006$ & $\mathrm{AU}$ & $1.60 e+006$ & $7.98 e+005$ \\
\hline AC-228 & $2.03 e+005$ & $3.70 \mathrm{e}+004$ & $\mathrm{AU}$ & $4.34 \mathrm{e}+004$ & $2.16 e+004$ \\
\hline RA-224 & $6.82 e+003$ & $6.93 e+003$ & A & $1.13 e+004$ & $5.58 \mathrm{e}+003$ \\
\hline PB-212 & $-2.21 e+005$ & $4.58 e+004$ & $\mathrm{AU}$ & $3.75 e+004$ & $1.87 e+004$ \\
\hline BI-212 & $-1.86 e+006$ & $2.51 e+005$ & $\mathrm{AU}$ & $5.23 e+005$ & $2.61 e+005$ \\
\hline TL-208 & $3.44 e+004$ & $1.91 e+004$ & $\mathrm{AU}$ & $2.48 e+004$ & $1.24 \mathrm{e}+004$ \\
\hline U-235 & $1.23 e+007$ & $2.22 e+006$ & A & $2.59 e+004$ & $1.30 \mathrm{e}+004$ \\
\hline TH-231 & $5.83 e+007$ & $1.17 e+007$ & A & $1.60 e+006$ & $7.98 \mathrm{e}+005$ \\
\hline PA-231 & $4.23 e+004$ & $1.87 e+005$ & $\mathrm{AU}$ & $9.84 e+005$ & $4.91 e+005$ \\
\hline $\mathrm{TH}-227$ & $4.46 e+004$ & $9.68 e+004$ & $\mathrm{AU}$ & $1.27 e+005$ & $6.30 e+004$ \\
\hline RA-223 & $3.84 e+006$ & $7.69 \mathrm{e}+005$ & $\mathrm{AU}$ & $7.86 e+004$ & $3.94 \mathrm{e}+004$ \\
\hline $\mathrm{RN}-219$ & $-1.54 e+005$ & $1.99 e+005$ & $\mathrm{AU}$ & $2.78 e+005$ & $1.39 e+005$ \\
\hline PB-211 & $-1.31 e+005$ & $3.90 \mathrm{e}+005$ & $\mathrm{AU}$ & $4.85 e+005$ & $2.42 e+005$ \\
\hline TL-207 & $-8.44 e+005$ & $2.97 e+006$ & $\mathrm{AU}$ & $3.76 e+006$ & $1.87 e+006$ \\
\hline NP-237 & $-3.95 e+008$ & $7.91 \mathrm{e}+007$ & $\mathrm{AU}$ & $5.48 e+006$ & $2.74 \mathrm{e}+006$ \\
\hline PA-233 & $-2.47 e+004$ & $3.38 e+004$ & $\mathrm{AU}$ & $4.39 e+004$ & $2.19 e+004$ \\
\hline TH-229 & $1.83 e+007$ & $3.66 e+006$ & $\mathrm{AU}$ & $2.89 e+005$ & $1.45 e+005$ \\
\hline BA-133 & $5.59 e+002$ & $2.31 e+004$ & $\mathrm{AU}$ & $2.88 e+004$ & $1.44 e+004$ \\
\hline $\mathrm{Ba}-140$ & $5.00 e+006$ & $6.18 e+005$ & A & $8.82 e+004$ & $4.41 e+004$ \\
\hline \multirow{3}{*}{ Page 38 of 49} & Wast & \multicolumn{3}{|c|}{ + - Segregate as Radioactive } & \multirow{3}{*}{$201 \_6-19$} \\
\hline & Quali & A - Accepted & $\mathbf{J}$ - Estimated & R - Rejected & \\
\hline & Detectio & (Blank) - Detected & U - Not Detected & $\mathrm{N}$ - Poor Statistics & \\
\hline
\end{tabular}


AB51166

\begin{tabular}{|c|c|c|c|c|c|}
\hline Analyte & $\begin{array}{c}\text { Activity } \\
\text { (dpm) }\end{array}$ & $\begin{array}{c}\text { Unc } \\
(2.0 \sigma)\end{array}$ & $\begin{array}{l}\text { Lab } \\
\text { Flag }\end{array}$ & $\begin{array}{c}\text { MDA } \\
(\mathrm{dpm})\end{array}$ & $\begin{array}{c}\text { CL } \\
\text { (dpm) }\end{array}$ \\
\hline CD-115 & $-1.25 e+004$ & $3.22 e+004$ & $\mathrm{AU}$ & $4.00 e+004$ & $2.00 e+004$ \\
\hline CE-141 & $1.17 \mathrm{e}+007$ & $2.35 \mathrm{e}+006$ & A & $3.85 \mathrm{e}+004$ & $1.93 e+004$ \\
\hline CE-144 & $9.44 e+006$ & $1.91 e+006$ & A & $1.85 e+005$ & $9.24 e+004$ \\
\hline CO-60 & $1.13 e+004$ & $1.23 e+004$ & A & $2.01 e+004$ & $1.00 e+004$ \\
\hline CS-137 & $4.50 e+006$ & $5.41 e+005$ & $A$ & $1.65 e+004$ & $8.22 e+003$ \\
\hline $\mathrm{Ce}-143$ & $5.71 e+003$ & $1.66 \mathrm{e}+004$ & $A U$ & $4.05 e+004$ & $2.02 \mathrm{e}+004$ \\
\hline $\mid-131$ & $1.20 \mathrm{e}+006$ & $1.78 e+005$ & A & $2.60 \mathrm{e}+004$ & $1.30 e+004$ \\
\hline I-132 & $5.24 e+005$ & $6.25 e+004$ & A & $2.33 e+004$ & $1.16 e+004$ \\
\hline $1-133$ & $2.38 e+005$ & $3.07 e+004$ & $A U$ & $2.62 e+004$ & $1.31 e+004$ \\
\hline In-115m & $-1.65 e+004$ & $4.25 e+004$ & $\mathrm{AU}$ & $5.27 e+004$ & $2.63 e+004$ \\
\hline La-140 & $5.95 e+006$ & $4.77 e+005$ & A & $1.48 \mathrm{e}+004$ & $7.32 \mathrm{e}+003$ \\
\hline MO-99 & $2.62 \mathrm{e}+005$ & $7.78 e+004$ & A & $1.15 \mathrm{e}+005$ & $5.75 e+004$ \\
\hline NB-95m & $1.67 e+005$ & $3.39 e+004$ & A & $5.91 e+004$ & $2.95 e+004$ \\
\hline ND-147 & $1.49 e+006$ & $1.91 e+005$ & A & $1.63 e+005$ & $8.16 \mathrm{e}+004$ \\
\hline NP-239 & $1.88 \mathrm{e}+005$ & $9.40 e+004$ & $\mathrm{AU}$ & $1.17 e+005$ & $5.86 e+004$ \\
\hline $\mathrm{Nb}-95$ & $1.76 e+007$ & $2.11 e+006$ & A & $1.75 e+004$ & $8.70 e+003$ \\
\hline PM-149 & $8.90 e+004$ & $1.95 e+005$ & $\mathrm{AU}$ & $5.54 e+005$ & $2.77 e+005$ \\
\hline Pr-144 & $1.17 e+008$ & $1.65 e+007$ & A & $1.37 e+007$ & $6.84 e+006$ \\
\hline RU-103 & $6.82 \mathrm{e}+006$ & $8.23 e+005$ & A & $3.02 \mathrm{e}+004$ & $1.51 e+004$ \\
\hline RU-106 & $7.64 e+005$ & $1.50 e+005$ & A & $1.91 e+005$ & $9.54 e+004$ \\
\hline SB-124 & $1.73 e+004$ & $1.51 e+004$ & $\mathrm{AU}$ & $1.99 e+004$ & $9.90 \mathrm{e}+003$ \\
\hline SB-125 & $-1.84 e+003$ & $3.62 e+004$ & $\mathrm{AU}$ & $6.36 e+004$ & $3.19 e+004$ \\
\hline SB-127 & $-6.40 e+003$ & $6.26 e+003$ & $\mathrm{AU}$ & $3.92 e+004$ & $1.96 \mathrm{e}+004$ \\
\hline Tc- $99 \mathrm{~m}$ & $4.35 e+005$ & $8.76 e+004$ & A & $2.77 e+004$ & $1.39 e+004$ \\
\hline Te-127m & $1.72 e+006$ & $2.27 e+006$ & $A U$ & $7.68 \mathrm{e}+006$ & $3.85 \mathrm{e}+006$ \\
\hline Te-129m & $5.12 \mathrm{e}+006$ & $7.22 e+005$ & A & $5.98 e+005$ & $2.98 \mathrm{e}+005$ \\
\hline Te-131m & $6.31 e+005$ & $7.69 e+004$ & $\mathrm{AU}$ & $3.89 e+004$ & $1.94 \mathrm{e}+004$ \\
\hline Te-132 & $3.62 \mathrm{e}+005$ & $5.98 \mathrm{e}+004$ & A & $2.23 e+004$ & $1.12 \mathrm{e}+004$ \\
\hline U-232 & $1.87 e+006$ & $4.23 e+006$ & $\mathrm{AU}$ & $1.92 e+007$ & $9.60 \mathrm{e}+006$ \\
\hline$U-234$ & $1.67 e+008$ & $5.62 e+007$ & A & $7.44 \mathrm{e}+007$ & $3.71 e+007$ \\
\hline U-237 & $-2.08 e+004$ & $3.10 e+004$ & $\mathrm{AU}$ & $1.03 e+005$ & $5.14 e+004$ \\
\hline$X E-131 m$ & $4.73 e+007$ & $9.49 e+006$ & $\mathrm{AU}$ & $1.15 e+006$ & $5.72 e+005$ \\
\hline
\end{tabular}

Page 39 of 49

\begin{tabular}{|r|lll|}
\hline Waste Flags: & + - Segregate as Radioactive & ${ }^{*}$ - Do Not Recycle \\
\hline Quality Flags: & A - Accepted & J - Estimated & R - Rejected \\
\hline Detection Flags: & (Blank) - Detected & U - Not Detected & N - Poor Statistics \\
\hline
\end{tabular}

UNM AGN-201_6-19 
AB51166

\begin{tabular}{|c|c|c|c|c|c|}
\hline Analyte & $\begin{array}{c}\text { Activity } \\
\text { (dpm) }\end{array}$ & $\begin{array}{c}\text { Unc } \\
(2.0 \sigma)\end{array}$ & $\begin{array}{l}\text { Lab } \\
\text { Flag }\end{array}$ & $\begin{array}{c}\text { MDA } \\
\text { (dpm) }\end{array}$ & $\begin{array}{c}\text { CL } \\
\text { (dpm) }\end{array}$ \\
\hline XE-133 & $2.04 e+006$ & $4.11 e+005$ & A & $5.58 e+004$ & $2.78 e+004$ \\
\hline$Y-88$ & $2.76 e+002$ & $1.17 e+003$ & $\mathrm{AU}$ & $5.49 \mathrm{e}+003$ & $2.68 \mathrm{e}+003$ \\
\hline$Y-91$ & $1.05 e+007$ & $2.76 e+006$ & A & $4.15 e+006$ & $2.06 e+006$ \\
\hline Y-91m & $3.11 e+005$ & $1.19 e+005$ & $\mathrm{AU}$ & $8.82 \mathrm{e}+004$ & $4.41 e+004$ \\
\hline ZR-95 & $1.58 e+007$ & $1.89 e+006$ & A & $3.04 e+004$ & $1.52 \mathrm{e}+004$ \\
\hline
\end{tabular}

Page 40 of 49

\begin{tabular}{|r|lll|}
\hline Waste Flags: & + - Segregate as Radioactive & * - Do Not Recycle \\
\hline Quality Flags: & A - Accepted & J - Estimated & R - Rejected \\
\hline Detection Flags: & (Blank) - Detected & U - Not Detected & N - Poor Statistics \\
\hline
\end{tabular}

UNM AGN-201_6-19 


\section{AB51167 - AGN Safety Rod 1}

Live Time (s): 14400 Real Time (s): 17878

Detector: FAL07
Geometry: AGN-SR

Library: AGN-201M

Background: 07_FAL_190515
Count Date: 5/15/2019 1:58:17PM Collection Date: 5/13/2019 12:00:00PM Quantity (each): $1.00 \mathrm{e}+000$

Analyzed By:

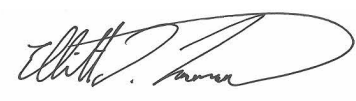

Reviewed By

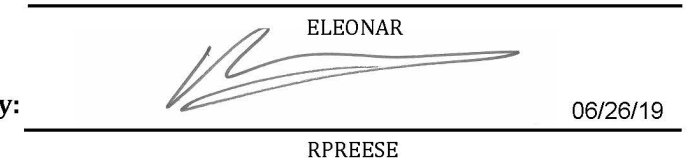

AB51167

\begin{tabular}{|c|c|c|c|c|c|}
\hline Analyte & $\begin{array}{c}\text { Activity } \\
\text { (dpm) }\end{array}$ & $\begin{array}{c}\text { Unc } \\
(2.0 \sigma)\end{array}$ & $\begin{array}{l}\text { Lab } \\
\text { Flag }\end{array}$ & $\begin{array}{c}\text { MDA } \\
\text { (dpm) }\end{array}$ & $\begin{array}{c}\text { CL } \\
\text { (dpm) }\end{array}$ \\
\hline U-238 & $5.57 e+007$ & $4.73 e+006$ & A & $3.32 e+006$ & $1.65 e+006$ \\
\hline RA-226 & $1.25 e+009$ & $2.25 e+008$ & $\mathrm{AU}$ & $1.66 e+006$ & $8.34 e+005$ \\
\hline PB-214 & $1.30 e+005$ & $1.33 e+005$ & $\mathrm{AU}$ & $1.63 e+005$ & $8.16 e+004$ \\
\hline $\mathrm{Bl}-214$ & $-1.97 e+005$ & $4.20 \mathrm{e}+004$ & $\mathrm{AU}$ & $1.58 e+005$ & $7.92 e+004$ \\
\hline PB-210 & $-5.74 e+006$ & $4.86 e+006$ & $\mathrm{AU}$ & $8.22 e+006$ & $4.12 e+006$ \\
\hline AC-228 & $6.00 e+005$ & $1.09 e+005$ & A & $1.49 e+005$ & $7.44 e+004$ \\
\hline RA-224 & $2.25 e+004$ & $9.52 e+003$ & A & $1.49 e+004$ & $7.38 \mathrm{e}+003$ \\
\hline PB-212 & $-2.01 e+006$ & $3.40 \mathrm{e}+005$ & $\mathrm{AU}$ & $1.39 e+005$ & $6.96 e+004$ \\
\hline Bl-212 & $-1.72 e+007$ & $2.10 \mathrm{e}+006$ & $\mathrm{AU}$ & $1.73 e+006$ & $8.70 e+005$ \\
\hline TL-208 & $-4.63 e+003$ & $6.08 e+004$ & $\mathrm{AU}$ & $8.04 e+004$ & $4.00 e+004$ \\
\hline U-235 & $7.84 e+007$ & $1.41 e+007$ & A & $1.04 \mathrm{e}+005$ & $5.21 e+004$ \\
\hline TH-231 & $4.59 e+008$ & $9.19 e+007$ & A & $6.54 e+006$ & $3.28 \mathrm{e}+006$ \\
\hline PA-231 & $-1.56 e+006$ & $9.13 e+005$ & $\mathrm{AU}$ & $3.52 e+006$ & $1.76 e+006$ \\
\hline TH-227 & $2.05 e+006$ & $4.87 e+005$ & $\mathrm{AU}$ & $4.73 e+005$ & $2.36 e+005$ \\
\hline $\mathrm{RA}-223$ & $2.87 e+007$ & $5.74 e+006$ & $\mathrm{AU}$ & $3.65 e+005$ & $1.82 e+005$ \\
\hline $\mathrm{RN}-219$ & $2.36 e+005$ & $6.20 e+005$ & $\mathrm{AU}$ & $9.30 e+005$ & $4.65 e+005$ \\
\hline PB-211 & $-1.73 e+005$ & $1.31 e+006$ & $\mathrm{AU}$ & $1.63 e+006$ & $8.10 e+005$ \\
\hline TL-207 & $3.54 \mathrm{e}+006$ & $9.34 e+006$ & $\mathrm{AU}$ & $1.19 e+007$ & $5.92 e+006$ \\
\hline NP-237 & $-4.47 e+009$ & $8.95 e+008$ & $\mathrm{AU}$ & $2.05 e+007$ & $1.03 e+007$ \\
\hline PA-233 & $-1.66 e+004$ & $8.70 e+004$ & $\mathrm{AU}$ & $1.54 \mathrm{e}+005$ & $7.68 e+004$ \\
\hline TH-229 & $1.90 e+008$ & $3.81 e+007$ & $\mathrm{AU}$ & $1.16 e+006$ & $5.80 e+005$ \\
\hline BA-133 & $6.40 e+004$ & $8.00 \mathrm{e}+004$ & $\mathrm{AU}$ & $9.90 e+004$ & $4.94 e+004$ \\
\hline Ba-140 & $3.98 \mathrm{e}+007$ & $4.80 e+006$ & A & $2.89 e+005$ & $1.45 e+005$ \\
\hline \multirow{3}{*}{ Page 41 of 49} & Wast & \multicolumn{3}{|c|}{ + - Segregate as Radioactive } & \multirow{3}{*}{$201 \_6-19$} \\
\hline & Quali & A - Accepted & $\mathbf{J}$ - Estimated & R - Rejected & \\
\hline & Detectio & (Blank) - Detected & U - Not Detected & N - Poor Statistics & \\
\hline
\end{tabular}


AB51167

\begin{tabular}{|c|c|c|c|c|c|}
\hline Analyte & $\begin{array}{l}\text { Activity } \\
\text { (dpm) }\end{array}$ & $\begin{array}{c}\text { Unc } \\
(2.0 \sigma)\end{array}$ & $\begin{array}{l}\text { Lab } \\
\text { Flag }\end{array}$ & $\begin{array}{c}\text { MDA } \\
(\mathrm{dpm})\end{array}$ & $\begin{array}{c}C L \\
(\mathrm{dpm})\end{array}$ \\
\hline CD-115 & $2.20 \mathrm{e}+004$ & $6.00 e+004$ & $\mathrm{AU}$ & $1.39 e+005$ & $6.96 e+004$ \\
\hline CE-141 & $9.70 \mathrm{e}+007$ & $1.94 \mathrm{e}+007$ & A & $1.63 e+005$ & $8.16 e+004$ \\
\hline CE-144 & $7.87 e+007$ & $1.58 \mathrm{e}+007$ & A & $8.34 \mathrm{e}+005$ & $4.17 e+005$ \\
\hline $\mathrm{CO}-60$ & $9.05 e+004$ & $3.59 \mathrm{e}+004$ & A & $5.75 e+004$ & $2.87 e+004$ \\
\hline CS-137 & $3.07 e+007$ & $3.69 \mathrm{e}+006$ & A & $4.88 \mathrm{e}+004$ & $2.44 e+004$ \\
\hline $\mathrm{Ce}-143$ & $-4.12 \mathrm{e}+004$ & $4.48 \mathrm{e}+004$ & $\mathrm{AU}$ & $1.45 \mathrm{e}+005$ & $7.26 \mathrm{e}+004$ \\
\hline $\mid-131$ & $8.96 e+006$ & $1.33 e+006$ & A & $8.28 e+004$ & $4.14 e+004$ \\
\hline |-132 & $4.69 \mathrm{e}+006$ & $5.49 \mathrm{e}+005$ & A & $8.52 \mathrm{e}+004$ & $4.25 e+004$ \\
\hline $\mid-133$ & $1.93 e+006$ & $2.35 e+005$ & A & $8.76 e+004$ & $4.37 e+004$ \\
\hline In-115m & $3.05 \mathrm{e}+004$ & $8.32 e+004$ & $\mathrm{AU}$ & $1.93 e+005$ & $9.66 \mathrm{e}+004$ \\
\hline La-140 & $4.77 e+007$ & $3.81 e+006$ & A & $3.63 e+004$ & $1.81 e+004$ \\
\hline MO-99 & $2.31 \mathrm{e}+006$ & $3.02 e+005$ & A & $2.77 e+005$ & $1.38 \mathrm{e}+005$ \\
\hline NB-95m & $1.39 \mathrm{e}+006$ & $2.36 \mathrm{e}+005$ & A & $2.11 e+005$ & $1.06 \mathrm{e}+005$ \\
\hline ND-147 & $1.19 \mathrm{e}+007$ & $1.45 e+006$ & A & $5.39 \mathrm{e}+005$ & $2.69 e+005$ \\
\hline NP-239 & $2.06 e+006$ & $3.56 \mathrm{e}+005$ & A & $3.70 e+005$ & $1.85 e+005$ \\
\hline $\mathrm{Nb}-95$ & $1.48 \mathrm{e}+008$ & $1.78 e+007$ & A & $3.94 e+004$ & $1.96 e+004$ \\
\hline PM-149 & $-4.77 e+005$ & $7.06 e+005$ & $\mathrm{AU}$ & $1.99 \mathrm{e}+006$ & $9.96 e+005$ \\
\hline Pr-144 & $1.15 e+009$ & $1.41 e+008$ & A & $4.88 e+007$ & $2.44 e+007$ \\
\hline RU-103 & $5.71 \mathrm{e}+007$ & $6.88 \mathrm{e}+006$ & A & $9.78 \mathrm{e}+004$ & $4.88 \mathrm{e}+004$ \\
\hline RU-106 & $6.63 e+006$ & $8.27 e+005$ & A & $5.27 e+005$ & $2.63 e+005$ \\
\hline SB-124 & $-1.94 e+004$ & $2.41 e+004$ & $A U$ & $6.42 \mathrm{e}+004$ & $3.21 \mathrm{e}+004$ \\
\hline SB-125 & $4.41 \mathrm{e}+005$ & $8.17 e+004$ & A & $1.73 e+005$ & $8.64 e+004$ \\
\hline SB-127 & $2.11 e+005$ & $9.72 e+004$ & $A U$ & $1.25 e+005$ & $6.24 \mathrm{e}+004$ \\
\hline Tc-99m & $3.53 e+006$ & $7.07 e+005$ & A & $1.24 e+005$ & $6.24 e+004$ \\
\hline Te-127m & $1.59 \mathrm{e}+006$ & $8.26 \mathrm{e}+006$ & $A U$ & $3.74 e+007$ & $1.87 e+007$ \\
\hline Te-129m & $4.21 \mathrm{e}+007$ & $5.18 \mathrm{e}+006$ & $\mathrm{AU}$ & $1.79 \mathrm{e}+006$ & $8.94 \mathrm{e}+005$ \\
\hline Te-131m & $4.58 \mathrm{e}+006$ & $5.37 e+005$ & $\mathrm{AU}$ & $1.30 \mathrm{e}+005$ & $6.48 \mathrm{e}+004$ \\
\hline Te-132 & $2.82 \mathrm{e}+006$ & $4.55 e+005$ & A & $7.80 e+004$ & $3.89 e+004$ \\
\hline U-232 & $1.44 e+008$ & $7.99 e+007$ & A & $1.22 \mathrm{e}+008$ & $6.12 \mathrm{e}+007$ \\
\hline U-234 & $1.21 \mathrm{e}+009$ & $3.17 e+008$ & A & $3.36 \mathrm{e}+008$ & $1.68 \mathrm{e}+008$ \\
\hline U-237 & $-1.36 e+004$ & $1.12 \mathrm{e}+005$ & $\mathrm{AU}$ & $4.96 e+005$ & $2.48 e+005$ \\
\hline XE-131m & $3.22 e+008$ & $6.45 e+007$ & $\mathrm{AU}$ & $4.64 \mathrm{e}+006$ & $2.32 e+006$ \\
\hline
\end{tabular}

Page 42 of 49

\begin{tabular}{|r|lll|}
\hline Waste Flags: & + - Segregate as Radioactive & ${ }^{*}$ - Do Not Recycle \\
\hline Quality Flags: & A - Accepted & J - Estimated & R - Rejected \\
\hline Detection Flags: & (Blank) - Detected & U - Not Detected & N - Poor Statistics \\
\hline
\end{tabular}

UNM AGN-201_6-19 


\section{AB51167}

\begin{tabular}{|c|c|c|c|c|c|}
\hline Analyte & $\begin{array}{l}\text { Activity } \\
\text { (dpm) }\end{array}$ & $\begin{array}{c}\text { Unc } \\
(2.0 \sigma)\end{array}$ & $\begin{array}{l}\text { Lab } \\
\text { Flag }\end{array}$ & $\begin{array}{c}\text { MDA } \\
(\mathrm{dpm})\end{array}$ & $\begin{array}{c}\text { CL } \\
\text { (dpm) }\end{array}$ \\
\hline XE-133 & $1.61 \mathrm{e}+007$ & $3.25 e+006$ & A & $2.30 e+005$ & $1.15 e+005$ \\
\hline$Y-88$ & $-4.37 e+003$ & $4.02 e+003$ & $\mathrm{AU}$ & $1.57 e+004$ & $7.74 \mathrm{e}+003$ \\
\hline$Y-91$ & $1.11 \mathrm{e}+008$ & $1.50 \mathrm{e}+007$ & A & $1.81 e+007$ & $9.00 e+006$ \\
\hline Y-91m & $2.43 e+006$ & $3.95 e+005$ & $\mathrm{AU}$ & $4.34 \mathrm{e}+005$ & $2.17 e+005$ \\
\hline ZR-95 & $1.32 e+008$ & $1.58 e+007$ & A & $7.32 e+004$ & $3.65 e+004$ \\
\hline
\end{tabular}

Page 43 of 49

\begin{tabular}{|r|lll|}
\hline Waste Flags: & + - Segregate as Radioactive & ${ }^{*}$ - Do Not Recycle \\
\hline Quality Flags: & A - Accepted & J - Estimated & R - Rejected \\
\hline Detection Flags: & (Blank) - Detected & U - Not Detected & N - Poor Statistics \\
\hline
\end{tabular}

UNM AGN-201_6-19 


\section{AB51168 - AGN Safety Rod 2}

Live Time (s): 14400 Real Time (s): 17898

Detector: FAL07
Geometry: AGN-SR

Library: AGN-201M

Background: 07_FAL_190515
Count Date: 5/15/2019 8:49:40AM Collection Date: 5/13/2019 12:00:00PM Quantity (each): $1.00 \mathrm{e}+000$

Analyzed By:

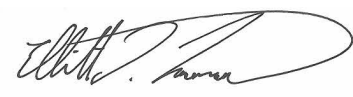

Reviewed By

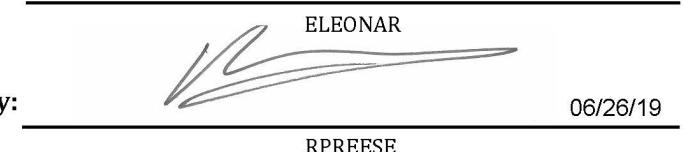

RPREESE

AB51168

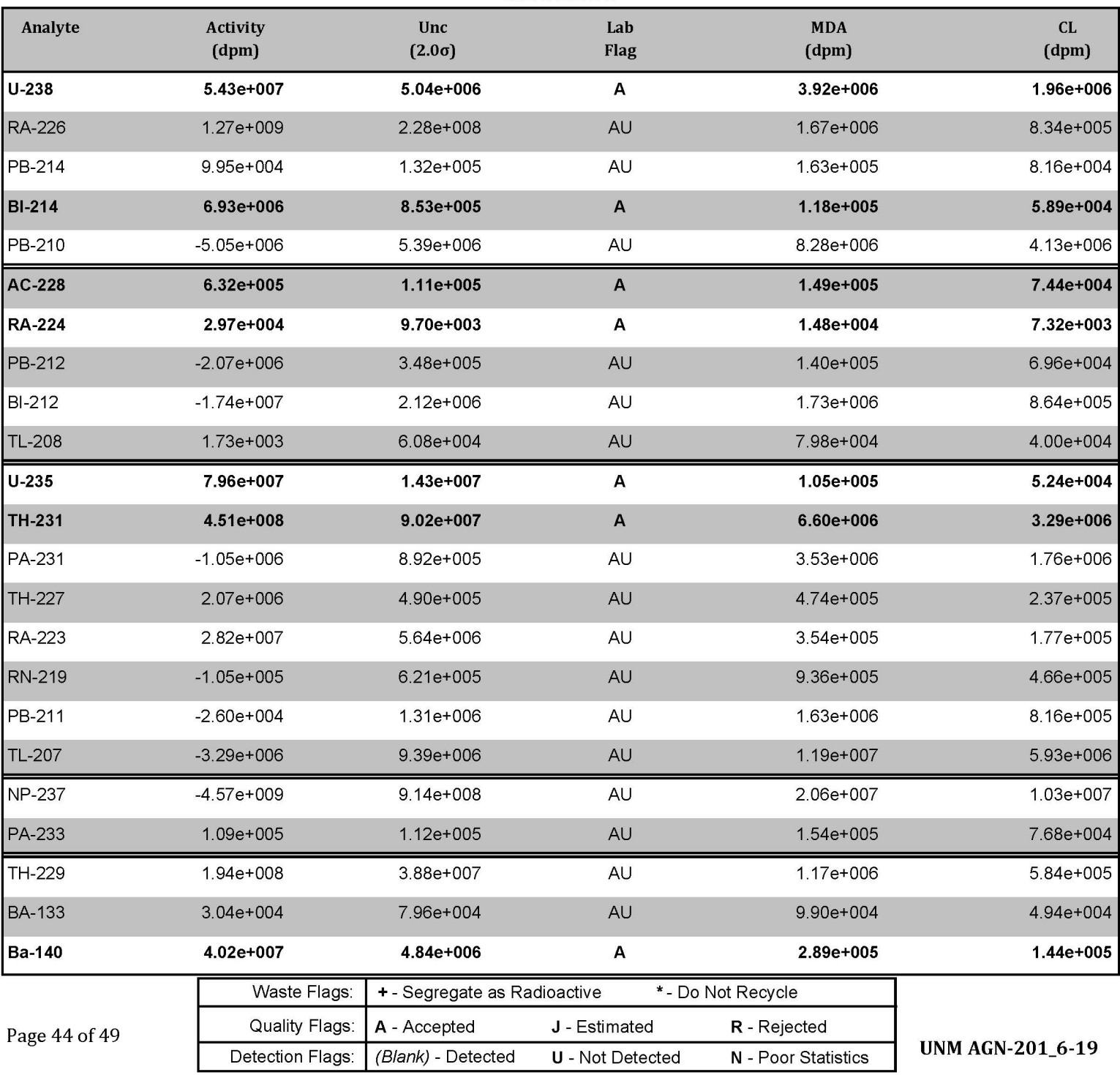




\section{AB51168}

\begin{tabular}{|c|c|c|c|c|c|}
\hline Analyte & $\begin{array}{c}\text { Activity } \\
\text { (dpm) }\end{array}$ & $\begin{array}{c}\text { Unc } \\
(2.0 \sigma)\end{array}$ & $\begin{array}{l}\text { Lab } \\
\text { Flag }\end{array}$ & $\begin{array}{c}\text { MDA } \\
(\mathrm{dpm})\end{array}$ & $\begin{array}{c}\text { CL } \\
(\mathrm{dpm})\end{array}$ \\
\hline CD-115 & $2.18 e+004$ & $6.00 e+004$ & $\mathrm{AU}$ & $1.39 e+005$ & $6.96 e+004$ \\
\hline CE-141 & $9.65 e+007$ & $1.93 e+007$ & A & $1.64 \mathrm{e}+005$ & $8.16 e+004$ \\
\hline CE-144 & $7.85 e+007$ & $1.58 \mathrm{e}+007$ & A & $8.40 \mathrm{e}+005$ & $4.19 \mathrm{e}+005$ \\
\hline $\mathrm{CO}-60$ & $7.61 \mathrm{e}+004$ & $3.26 e+004$ & A & $5.24 e+004$ & $2.62 \mathrm{e}+004$ \\
\hline CS-137 & $3.09 e+007$ & $3.69 \mathrm{e}+006$ & A & $4.88 e+004$ & $2.44 e+004$ \\
\hline Ce-143 & $-4.90 e+004$ & $4.51 e+004$ & $\mathrm{AU}$ & $1.45 \mathrm{e}+005$ & $7.26 \mathrm{e}+004$ \\
\hline $\mid-131$ & $9.21 \mathrm{e}+006$ & $1.36 e+006$ & A & $8.88 e+004$ & $4.43 e+004$ \\
\hline $\mid-132$ & $5.15 e+006$ & $6.03 e+005$ & A & $8.52 e+004$ & $4.25 e+004$ \\
\hline |-133 & $1.92 e+006$ & $2.34 e+005$ & A & $8.76 e+004$ & $4.36 \mathrm{e}+004$ \\
\hline In-115m & $3.03 e+004$ & $8.33 e+004$ & $\mathrm{AU}$ & $1.93 e+005$ & $9.66 \mathrm{e}+004$ \\
\hline La-140 & $4.79 e+007$ & $3.84 e+006$ & A & $3.65 e+004$ & $1.82 \mathrm{e}+004$ \\
\hline MO-99 & $2.49 e+006$ & $3.22 e+005$ & A & $3.01 e+005$ & $1.50 e+005$ \\
\hline NB-95m & $1.28 \mathrm{e}+006$ & $2.16 e+005$ & A & $2.12 e+005$ & $1.06 \mathrm{e}+005$ \\
\hline ND-147 & $1.18 \mathrm{e}+007$ & $1.44 e+006$ & A & $5.39 \mathrm{e}+005$ & $2.69 \mathrm{e}+005$ \\
\hline NP-239 & $2.50 \mathrm{e}+006$ & $4.23 e+005$ & A & $3.70 \mathrm{e}+005$ & $1.85 e+005$ \\
\hline $\mathrm{Nb}-95$ & $1.47 e+008$ & $1.77 e+007$ & A & $3.94 e+004$ & $1.96 e+004$ \\
\hline PM-149 & $-2.78 e+005$ & $7.04 e+005$ & $\mathrm{AU}$ & $1.99 \mathrm{e}+006$ & $9.96 e+005$ \\
\hline Pr-144 & $1.15 e+009$ & $1.41 e+008$ & A & $4.88 e+007$ & $2.44 e+007$ \\
\hline RU-103 & $5.68 \mathrm{e}+007$ & $6.84 e+006$ & A & $9.78 \mathrm{e}+004$ & $4.88 e+004$ \\
\hline RU-106 & $6.82 e+006$ & $8.54 e+005$ & A & $5.27 e+005$ & $2.63 e+005$ \\
\hline SB-124 & $1.02 e+004$ & $4.87 e+004$ & $A U$ & $6.42 e+004$ & $3.21 e+004$ \\
\hline SB-125 & $4.26 e+005$ & $8.04 e+004$ & A & $1.81 \mathrm{e}+005$ & $9.06 \mathrm{e}+004$ \\
\hline SB-127 & $2.16 \mathrm{e}+005$ & $9.76 e+004$ & $\mathrm{AU}$ & $1.25 e+005$ & $6.24 e+004$ \\
\hline Tc-99m & $3.76 e+006$ & $7.53 e+005$ & A & $1.25 e+005$ & $6.24 e+004$ \\
\hline Te-127m & $1.38 e+006$ & $8.29 \mathrm{e}+006$ & $\mathrm{AU}$ & $3.75 e+007$ & $1.87 e+007$ \\
\hline Te-129m & $4.20 \mathrm{e}+007$ & $5.16 e+006$ & $\mathrm{AU}$ & $1.79 \mathrm{e}+006$ & $8.94 \mathrm{e}+005$ \\
\hline Te-131m & $5.06 e+006$ & $5.93 e+005$ & $\mathrm{AU}$ & $1.33 e+005$ & $6.60 \mathrm{e}+004$ \\
\hline Te-132 & $2.96 e+006$ & $4.76 e+005$ & A & $5.97 e+004$ & $2.98 \mathrm{e}+004$ \\
\hline U-232 & $1.26 \mathrm{e}+008$ & $7.89 e+007$ & A & $1.22 \mathrm{e}+008$ & $6.12 \mathrm{e}+007$ \\
\hline U-234 & $1.43 e+009$ & $3.52 e+008$ & A & $3.38 \mathrm{e}+008$ & $1.69 \mathrm{e}+008$ \\
\hline U-237 & $-6.22 e+004$ & $1.13 e+005$ & $\mathrm{AU}$ & $4.97 e+005$ & $2.49 \mathrm{e}+005$ \\
\hline XE-131m & $3.22 e+008$ & $6.44 e+007$ & $\mathrm{AU}$ & $4.66 \mathrm{e}+006$ & $2.33 \mathrm{e}+006$ \\
\hline
\end{tabular}

Page 45 of 49

\begin{tabular}{|r|lll|}
\hline Waste Flags: & + - Segregate as Radioactive & ${ }^{*}$ - Do Not Recycle \\
\hline Quality Flags: & A - Accepted & J - Estimated & R - Rejected \\
\hline Detection Flags: & (Blank) - Detected & U - Not Detected & N - Poor Statistics \\
\hline
\end{tabular}

UNM AGN-201_6-19 


\section{AB51168}

\begin{tabular}{|c|c|c|c|c|c|}
\hline Analyte & $\begin{array}{c}\text { Activity } \\
\text { (dpm) }\end{array}$ & $\begin{array}{c}\text { Unc } \\
(2.0 \sigma)\end{array}$ & $\begin{array}{l}\text { Lab } \\
\text { Flag }\end{array}$ & $\begin{array}{c}\text { MDA } \\
(\mathrm{dpm})\end{array}$ & $\begin{array}{c}\text { CL } \\
\text { (dpm) }\end{array}$ \\
\hline XE-133 & $1.58 e+007$ & $3.19 e+006$ & A & $2.31 e+005$ & $1.15 e+005$ \\
\hline$Y-88$ & $1.13 e+002$ & $3.06 e+003$ & $\mathrm{AU}$ & $1.57 e+004$ & $7.80 \mathrm{e}+003$ \\
\hline$Y-91$ & $1.02 \mathrm{e}+008$ & $1.48 e+007$ & A & $1.90 e+007$ & $9.48 e+006$ \\
\hline Y-91m & $2.26 \mathrm{e}+006$ & $3.71 e+005$ & $A U$ & $4.12 \mathrm{e}+005$ & $2.06 \mathrm{e}+005$ \\
\hline ZR-95 & $1.31 e+008$ & $1.58 \mathrm{e}+007$ & A & $7.32 \mathrm{e}+004$ & $3.65 e+004$ \\
\hline
\end{tabular}

Page 46 of 49

\begin{tabular}{|r|lll|}
\hline Waste Flags: & + - Segregate as Radioactive & * - Do Not Recycle \\
\hline Quality Flags: & A - Accepted & J - Estimated & R - Rejected \\
\hline Detection Flags: & (Blank) - Detected & U - Not Detected & N - Poor Statistics \\
\hline
\end{tabular}

UNM AGN-201_6-19 
AB51171 - Blank

Live Time (s): 54000 Real Time (s): 54259

Detector: FAL07
Geometry: EMPTYSHLD

Library: AGN-201M

Background: 07_FAL_190515
Count Date: 5/15/2019 5:15:01PM Collection Date: 6/13/2019 12:00:00AM Quantity (each): $1.00 \mathrm{e}+000$

Analyzed By:

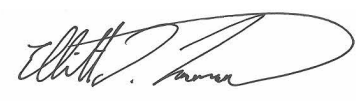

Reviewed By

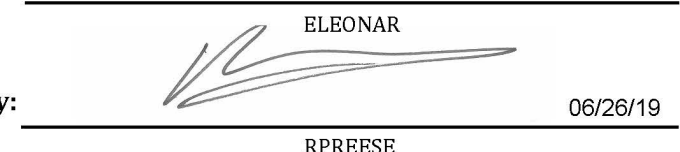

RPREESE

AB51171

\begin{tabular}{|c|c|c|c|c|c|}
\hline Analyte & $\begin{array}{c}\text { Activity } \\
\text { (dpm) }\end{array}$ & $\begin{array}{l}\text { Unc } \\
(2.0 \sigma)\end{array}$ & $\begin{array}{l}\text { Lab } \\
\text { Flag }\end{array}$ & $\begin{array}{c}\text { MDA } \\
\text { (dpm) }\end{array}$ & $\begin{array}{c}\text { CL } \\
\text { (dpm) }\end{array}$ \\
\hline U-238 & $7.76 e+001$ & $2.61 e+030$ & $\mathrm{AU}$ & $3.54 \mathrm{e}+001$ & $1.75 e+001$ \\
\hline RA-226 & $1.14 e+003$ & $4.68 e+030$ & AN & $5.79 \mathrm{e}+001$ & $2.89 e+001$ \\
\hline PB-214 & $3.89 e+001$ & $1.32 e+005$ & $\mathrm{AU}$ & $3.71 \mathrm{e}+000$ & $1.85 e+000$ \\
\hline Bl-214 & $4.74 \mathrm{e}+001$ & $8.53 e+005$ & AN & $1.91 \mathrm{e}+000$ & $9.54 e-001$ \\
\hline PB-210 & $-1.23 e+001$ & $2.86 e+001$ & $\mathrm{AU}$ & $3.67 e+001$ & $1.83 e+001$ \\
\hline TH-232 & $2.73 e+001$ & $3.70 e+004$ & AN & $1.22 \mathrm{e}+001$ & $6.06 e+000$ \\
\hline RA-228 & $2.94 \mathrm{e}+001$ & $3.70 \mathrm{e}+004$ & AN & $2.52 \mathrm{e}+000$ & $1.25 e+000$ \\
\hline AC-228 & $3.02 e+001$ & $1.11 e+005$ & AN & $1.55 e+000$ & $7.74 \mathrm{e}-001$ \\
\hline TH-228 & $3.64 e+001$ & $6.93 e+003$ & $\mathrm{AU}$ & $3.50 \mathrm{e}+001$ & $1.75 e+001$ \\
\hline RA-224 & $8.63 e+000$ & $2.01 e-001$ & A & $7.32 \mathrm{e}-002$ & $3.52 \mathrm{e}-002$ \\
\hline PB-212 & $2.99 e+001$ & $3.48 e+005$ & $\mathrm{AU}$ & $3.04 \mathrm{e}+000$ & $1.52 e+000$ \\
\hline BI-212 & $3.49 e+001$ & $2.12 \mathrm{e}+006$ & AN & $8.04 \mathrm{e}+000$ & $3.98 \mathrm{e}+000$ \\
\hline TL-208 & $1.11 \mathrm{e}+001$ & $6.08 e+004$ & $\mathrm{AU}$ & $1.01 e+000$ & $5.05 e-001$ \\
\hline U-235 & $5.07 e+001$ & $1.43 e+007$ & $\mathrm{AU}$ & $1.67 e+001$ & $8.34 \mathrm{e}+000$ \\
\hline TH-231 & $1.28 e+003$ & $8.41 e+030$ & $\mathrm{AU}$ & $2.60 \mathrm{e}+002$ & $1.30 e+002$ \\
\hline PA-231 & $0.00 \mathrm{e}+00$ & $0.00 e+00$ & $\mathrm{AU}$ & $0.00 \mathrm{e}+00$ & $0.00 e+00$ \\
\hline TH-227 & $0.00 \mathrm{e}+00$ & $0.00 e+00$ & $\mathrm{AU}$ & $0.00 e+00$ & $0.00 \mathrm{e}+00$ \\
\hline RA-223 & $1.23 e+002$ & $5.64 e+006$ & $\mathrm{AU}$ & $1.34 \mathrm{e}+001$ & $6.72 e+000$ \\
\hline RN-219 & $0.00 \mathrm{e}+00$ & $0.00 \mathrm{e}+00$ & $\mathrm{AU}$ & $0.00 e+00$ & $0.00 e+00$ \\
\hline PB-211 & $0.00 e+00$ & $0.00 e+00$ & $\mathrm{AU}$ & $0.00 e+00$ & $0.00 \mathrm{e}+00$ \\
\hline TL-207 & $0.00 \mathrm{e}+00$ & $0.00 e+00$ & $\mathrm{AU}$ & $0.00 \mathrm{e}+00$ & $0.00 \mathrm{e}+00$ \\
\hline AM-241 & $0.00 \mathrm{e}+00$ & $0.00 e+00$ & $\mathrm{AU}$ & $0.00 e+00$ & $0.00 \mathrm{e}+00$ \\
\hline PU-239 & $0.00 \mathrm{e}+00$ & $0.00 e+00$ & $\mathrm{AU}$ & $0.00 \mathrm{e}+00$ & $0.00 \mathrm{e}+00$ \\
\hline \multirow{3}{*}{ Page 47 of 49} & Was & \multicolumn{3}{|c|}{ +- Segregate as Radioactive $\quad{ }^{*}$ - Do Not Recycle } & \multirow{3}{*}{ 01_6-19 } \\
\hline & Qual & A - Accepted & $\mathbf{J}$ - Estimated & $\mathbf{R}$ - Rejected & \\
\hline & Detectic & (Blank) - Detected & U - Not Detected & N - Poor Statistics & \\
\hline
\end{tabular}


AB51171

\begin{tabular}{|c|c|c|c|c|c|}
\hline Analyte & $\begin{array}{c}\text { Activity } \\
\text { (dpm) }\end{array}$ & $\begin{array}{c}\text { Unc } \\
(2.0 \sigma)\end{array}$ & $\begin{array}{l}\text { Lab } \\
\text { Flag }\end{array}$ & $\begin{array}{c}\text { MDA } \\
(\mathrm{dpm})\end{array}$ & $\begin{array}{c}\text { CL } \\
\text { (dpm) }\end{array}$ \\
\hline NP-237 & $0.00 e+00$ & $0.00 e+00$ & $\mathrm{AU}$ & $0.00 e+00$ & $0.00 \mathrm{e}+00$ \\
\hline PA-233 & $0.00 \mathrm{e}+00$ & $0.00 e+00$ & $\mathrm{AU}$ & $0.00 e+00$ & $0.00 \mathrm{e}+00$ \\
\hline TH-229 & $0.00 e+00$ & $0.00 e+00$ & $\mathrm{AU}$ & $0.00 e+00$ & $0.00 e+00$ \\
\hline$A G-108 m$ & $0.00 e+00$ & $0.00 e+00$ & $\mathrm{AU}$ & $0.00 e+00$ & $0.00 \mathrm{e}+00$ \\
\hline AG-110m & $0.00 \mathrm{e}+00$ & $0.00 e+00$ & $\mathrm{AU}$ & $0.00 \mathrm{e}+00$ & $0.00 \mathrm{e}+00$ \\
\hline BA-133 & $0.00 \mathrm{e}+00$ & $0.00 e+00$ & $\mathrm{AU}$ & $0.00 \mathrm{e}+00$ & $0.00 \mathrm{e}+00$ \\
\hline BE-7 & $0.00 e+00$ & $0.00 e+00$ & $\mathrm{AU}$ & $0.00 e+00$ & $0.00 \mathrm{e}+00$ \\
\hline CD-115 & $0.00 e+00$ & $0.00 e+00$ & $\mathrm{AU}$ & $0.00 e+00$ & $0.00 e+00$ \\
\hline CE-139 & $0.00 e+00$ & $0.00 e+00$ & $\mathrm{AU}$ & $0.00 \mathrm{e}+00$ & $0.00 \mathrm{e}+00$ \\
\hline CE-141 & $6.03 e+001$ & $1.26 e+030$ & AN & $3.99 \mathrm{e}+000$ & $1.99 \mathrm{e}+000$ \\
\hline CE-144 & $4.69 e+001$ & $1.56 e+007$ & $\mathrm{AU}$ & $2.05 e+001$ & $1.02 e+001$ \\
\hline $\mathrm{CO}-56$ & $0.00 e+00$ & $0.00 e+00$ & $\mathrm{AU}$ & $0.00 e+00$ & $0.00 \mathrm{e}+00$ \\
\hline CO-57 & $0.00 e+00$ & $0.00 \mathrm{e}+00$ & $\mathrm{AU}$ & $0.00 e+00$ & $0.00 \mathrm{e}+00$ \\
\hline $\mathrm{CO}-58$ & $0.00 e+00$ & $0.00 \mathrm{e}+00$ & $\mathrm{AU}$ & $0.00 \mathrm{e}+00$ & $0.00 \mathrm{e}+00$ \\
\hline$C O-60$ & $6.54 \mathrm{e}-001$ & $0.00 e+00$ & $\mathrm{AU}$ & 4.14e-001 & $2.05 e-001$ \\
\hline CR-51 & $1.20 e+001$ & $0.00 e+00$ & AN & $1.36 e+001$ & $6.78 \mathrm{e}+000$ \\
\hline CS-134 & $0.00 e+00$ & $3.71 e+006$ & $\mathrm{AU}$ & $0.00 e+00$ & $0.00 \mathrm{e}+00$ \\
\hline CS-137 & $2.99 \mathrm{e}+001$ & $3.71 e+006$ & AN & $6.42 \mathrm{e}-001$ & $3.20 \mathrm{e}-001$ \\
\hline EU-152 & $0.00 e+00$ & $0.00 e+00$ & $\mathrm{AU}$ & $0.00 e+00$ & $0.00 \mathrm{e}+00$ \\
\hline EU-154 & $0.00 e+00$ & $0.00 e+00$ & $\mathrm{AU}$ & $0.00 e+00$ & $0.00 e+00$ \\
\hline EU-155 & $0.00 e+00$ & $0.00 \mathrm{e}+00$ & $A U$ & $0.00 e+00$ & $0.00 \mathrm{e}+00$ \\
\hline FE-59 & $0.00 e+00$ & $0.00 e+00$ & $\mathrm{AU}$ & $0.00 e+00$ & $0.00 e+00$ \\
\hline GD-153 & $0.00 e+00$ & $0.00 e+00$ & $\mathrm{AU}$ & $0.00 e+00$ & $0.00 \mathrm{e}+00$ \\
\hline HG-203 & $0.00 e+00$ & $0.00 e+00$ & $\mathrm{AU}$ & $0.00 e+00$ & $0.00 \mathrm{e}+00$ \\
\hline $\mid-131$ & $1.05 e+001$ & $1.78 e+005$ & $\mathrm{AU}$ & $1.49 \mathrm{e}+000$ & $7.44 \mathrm{e}-001$ \\
\hline$K-40$ & $6.14 \mathrm{e}+002$ & $5.37 e+000$ & A & $2.99 \mathrm{e}+000$ & $1.48 \mathrm{e}+000$ \\
\hline MN-52 & $5.80 \mathrm{e}-002$ & $2.21 \mathrm{e}-001$ & $A U$ & $2.97 e-001$ & $1.47 e-001$ \\
\hline MN-54 & $2.06 \mathrm{e}-001$ & $3.22 e+005$ & $\mathrm{AU}$ & $3.60 \mathrm{e}-001$ & $1.79 \mathrm{e}-001$ \\
\hline MO-99 & $0.00 e+00$ & $0.00 e+00$ & $\mathrm{AU}$ & $0.00 e+00$ & $0.00 e+00$ \\
\hline NA-22 & $0.00 e+00$ & $0.00 e+00$ & $\mathrm{AU}$ & $0.00 \mathrm{e}+00$ & $0.00 e+00$ \\
\hline $\mathrm{NA}-24$ & $8.44 \mathrm{e}-002$ & $3.70 \mathrm{e}-001$ & $\mathrm{AU}$ & $4.94 \mathrm{e}-001$ & 2. $45 \mathrm{e}-001$ \\
\hline ND-147 & $0.00 e+00$ & $0.00 e+00$ & $\mathrm{AU}$ & $0.00 e+00$ & $0.00 \mathrm{e}+00$ \\
\hline
\end{tabular}

Page 48 of 49

\begin{tabular}{|r|lll|}
\hline Waste Flags: & + - Segregate as Radioactive & * - Do Not Recycle \\
\hline Quality Flags: & A - Accepted & J - Estimated & R - Rejected \\
\hline Detection Flags: & (Blank $)$ - Detected & U - Not Detected & N - Poor Statistics \\
\hline
\end{tabular}

UNM AGN-201_6-19 
AB51171

\begin{tabular}{|c|c|c|c|c|c|}
\hline Analyte & $\begin{array}{c}\text { Activity } \\
\text { (dpm) }\end{array}$ & $\begin{array}{c}\text { Unc } \\
(2.0 \sigma)\end{array}$ & $\begin{array}{l}\text { Lab } \\
\text { Flag }\end{array}$ & $\begin{array}{c}\text { MDA } \\
(\mathrm{dpm})\end{array}$ & $\begin{array}{c}\text { CL } \\
\text { (dpm) }\end{array}$ \\
\hline NP-239 & $0.00 e+00$ & $0.00 e+00$ & $\mathrm{AU}$ & $0.00 e+00$ & $0.00 e+00$ \\
\hline RU-103 & $6.01 e+001$ & $8.47 e+030$ & AN & $1.27 e+000$ & $6.30 \mathrm{e}-001$ \\
\hline RU-106 & $0.00 e+00$ & $0.00 e+00$ & $\mathrm{AU}$ & $0.00 e+00$ & $0.00 \mathrm{e}+00$ \\
\hline SB-122 & $0.00 e+00$ & $0.00 e+00$ & $\mathrm{AU}$ & $0.00 e+00$ & $0.00 e+00$ \\
\hline SB-124 & $0.00 e+00$ & $0.00 e+00$ & $\mathrm{AU}$ & $0.00 e+00$ & $0.00 \mathrm{e}+00$ \\
\hline SB-125 & $0.00 \mathrm{e}+00$ & $0.00 e+00$ & $\mathrm{AU}$ & $0.00 \mathrm{e}+00$ & $0.00 \mathrm{e}+00$ \\
\hline SN-113 & $0.00 e+00$ & $0.00 e+00$ & $\mathrm{AU}$ & $0.00 e+00$ & $0.00 \mathrm{e}+00$ \\
\hline SR-85 & $0.00 e+00$ & $0.00 e+00$ & $\mathrm{AU}$ & $0.00 e+00$ & $0.00 e+00$ \\
\hline TA-182 & $0.00 e+00$ & $0.00 e+00$ & $A U$ & $0.00 \mathrm{e}+00$ & $0.00 \mathrm{e}+00$ \\
\hline TA-183 & $0.00 e+00$ & $0.00 e+00$ & $\mathrm{AU}$ & $0.00 e+00$ & $0.00 e+00$ \\
\hline TL-201 & $0.00 \mathrm{e}+00$ & $0.00 e+00$ & $\mathrm{AU}$ & $0.00 \mathrm{e}+00$ & $0.00 \mathrm{e}+00$ \\
\hline$Y-88$ & $7.01 \mathrm{e}-002$ & $1.09 \mathrm{e}-001$ & $\mathrm{AU}$ & $1.56 \mathrm{e}-001$ & $7.62 \mathrm{e}-002$ \\
\hline ZN-65 & $7.97 \mathrm{e}-001$ & $1.58 e+007$ & AN & $7.20 \mathrm{e}-001$ & $3.56 \mathrm{e}-001$ \\
\hline ZR-95 & $1.18 \mathrm{e}+002$ & $1.82 e+030$ & $\mathrm{AU}$ & $9.42 \mathrm{e}-001$ & $4.69 \mathrm{e}-001$ \\
\hline
\end{tabular}

Page 49 of 49

\begin{tabular}{|r|lll|}
\hline Waste Flags: & + - Segregate as Radioactive & * - Do Not Recycle \\
\hline Quality Flags: & A - Accepted & J - Estimated & R - Rejected \\
\hline Detection Flags: & (Blank) - Detected & U - Not Detected & N - Poor Statistics \\
\hline
\end{tabular}

UNM AGN-201_6-19 
